

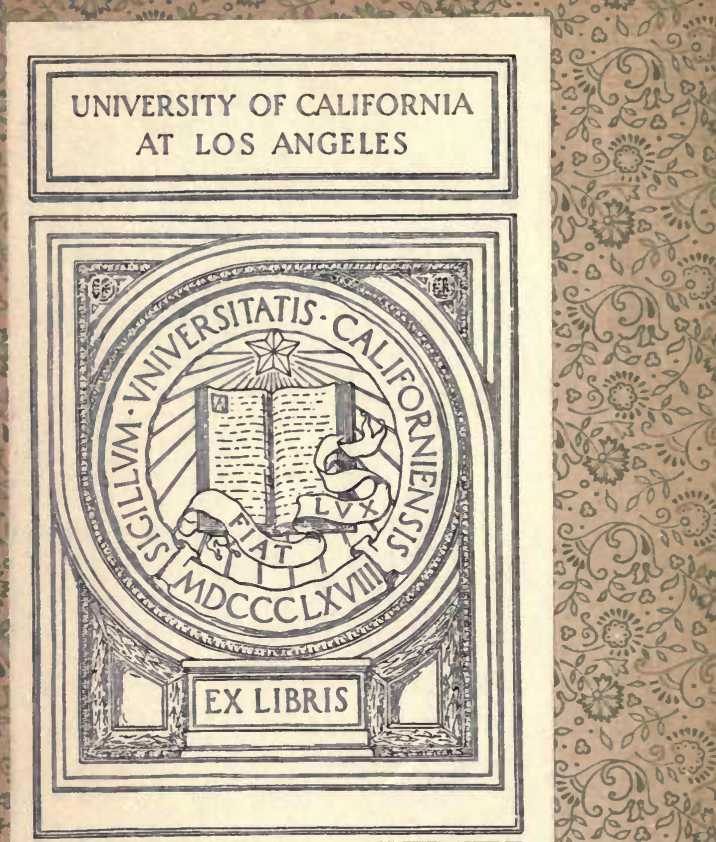

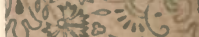
$\frac{10.0}{10.0}$ do - ev/5 d bis.

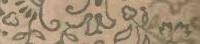
- of acos? . $05=0.8004$

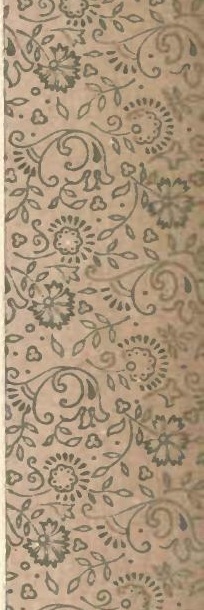

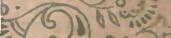

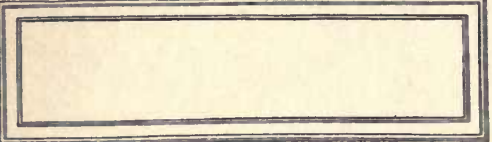

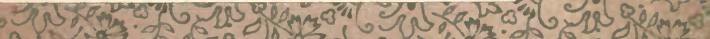

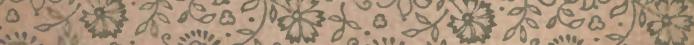

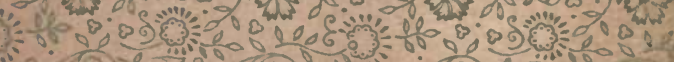

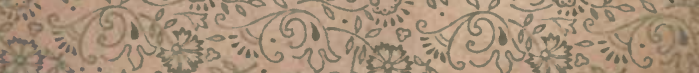

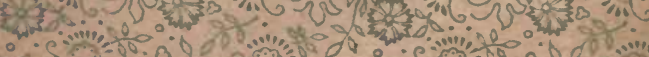

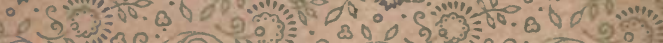

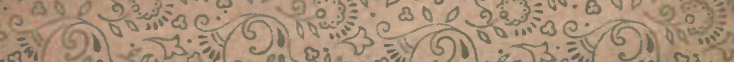




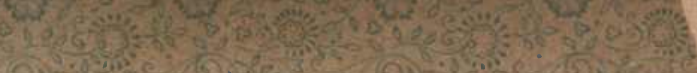

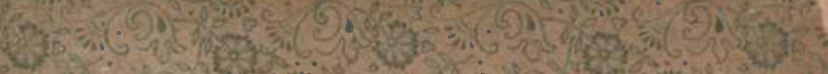

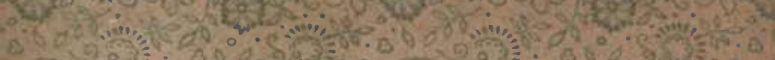
Con so'

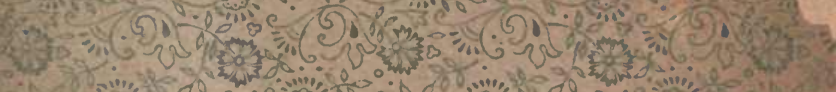

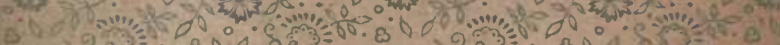

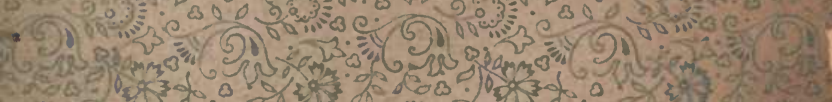

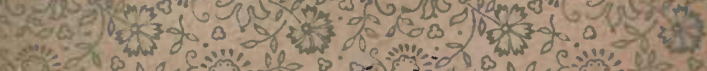

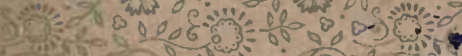

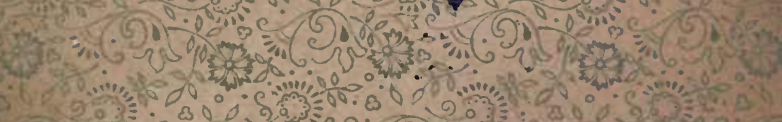

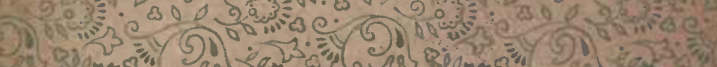

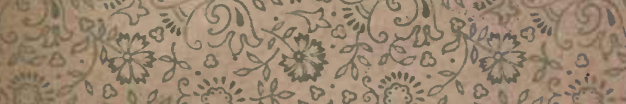

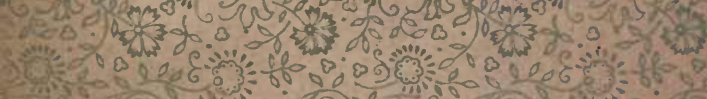
2.

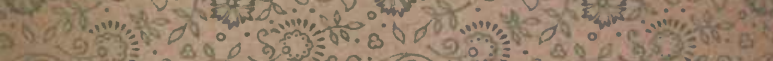

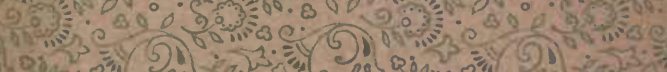

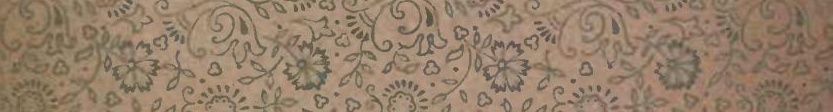

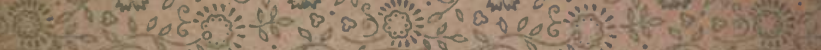
(1)

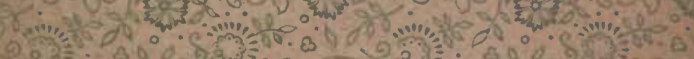

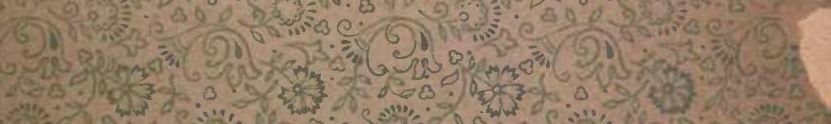

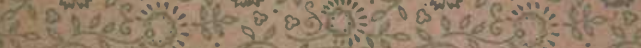

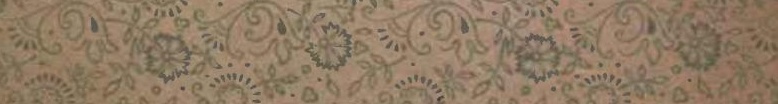

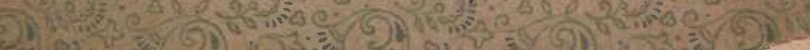


FREDERIC W. TAYLOR, 




\section{IN PREPARATION.}

\section{SYSTEMATIC POMOLOGY.}

\section{(American Horticultural Manual. Part II.)}

The plan of this work is to include only the varieties recommended at this time by societies and growers, including those of special value locally $\rightarrow$ so far as known-and those on the trial lists of the horticulturists of the Northwest and of the northern limits of successful fruit-growing.

For the benefit of amateurs and beginners the relative hardiness of varleties will be given witli their adaptationso far as known-to given soils, exposures, and altitudes. The names of fruits will be made to conform to the code of the American Horticultural Society, but the popular name and the synouyms will follow.

Fruit lists and the classification and description of varieties are used mainly for reference in time of need in selecting varieties for planting, aud for determining the correctness of their names when they come into bearing. The identification of unknown varieties is not s" easy, as widely differing varieties in value are often sinilar in form, shape, and color.

Yet as a guide such a select list of varieties will have great value in many ways.

In the preparation of this work the writer has the valuable assistance of Prof. N. E. Hansen, who has given several years to a study of fruits in various parts of the United States and over a large part of Europe and A sia.

AMEs, Iowa.

J. L. Bund. 


\section{AMERICAN}

\section{Horticultural Manual.}

\section{PART I.}

COMPRISING THE LEADING PRINCIPLES AND PRACTICES

CONNECTED WITH THE PIROPAGATION, CUL'TURE, AND IMPROVEMENT OF FRUITS, NUTS, ORNAMENTAL TREES, SHRUBS, AND

PLANTS IN THE UNITED

STATES AND CANADA.

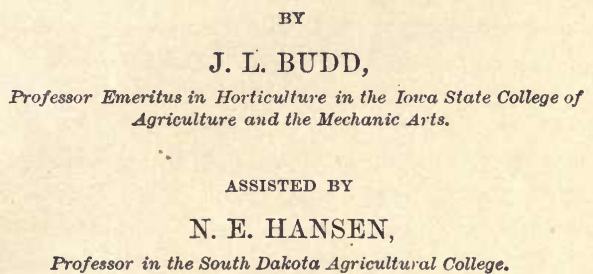

Professor in the South Dakota Agricultural College.

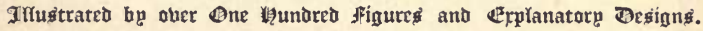

FIRSTEDITION. FIRST THOUSAND.

NEW YORK :

JOHN WILEY \& SONS.

LONDON: CHAPMAN \& HALL, LIMITED, 1902. 


\section{Copyright, 1902,}

BY

J. L. BUDD.

ROBERT DRUMMOND PRINTER, NEW YORK

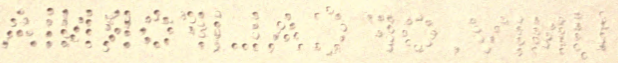




\section{SB93 \\ B85 a \\ $\checkmark .1$}

\section{PREFACE.}

THE meaning of Horticulture as given by Noah Webster is the "cultivation of a garden, or the art of cultivating 品 gardens." But nodern advancement has given the word a much broader signification. It now includes such important divisions as pomology, or fruit-growing, ornamental and shade trees and shrubs, flowers and their culture, modes and methods of propagation, landscape gardening, spraying for insects and fungi, garden and orchard irrigation, systematic pomology, or plant description and classification, and still other divisions and subdivisions in varied climes and on different soils.

Quite as important is the modern change in the requirements of the student or beginner in horticulture. In the days when gardening was a mere art the operator was told what to do and how to do it. At this time the student is required to know not only how to perform a given work, but to give the reasons for doing it in a certain way in order to reach given results.

In agricultural college work, at institutes, and at horticultural meetings the discussion of practical details is now associated with the underlying principles that of ten border on science.

Commercial horticulture in its many classes is also a 
modern development. This is specially true of the commercial growing of the orange, grape, strawberry, apple, tomato, melon, and indeed all fruits and nuts that can be widely distributed in fresh or preserved form.

Modern facilities for transportation have had much to do with this rapid development, together with the muchpublished information and literature that naturally grew up in connection with these extended systematic operations. Indeed the literature connected with growing fruits for market has advanced far more rapidly than that pertaining to home-making, home propagation, and the principles connected with the modes and methods used in the varied divisions of work. Hence in this volume the needs of the student, amateur, and beginner have been regarded in every section and every chapter.

To prevent duplication and to give a clearer presentation of the union of theory and practice, the work and the reasons therefor are given in connection, or reference is made to other explanatory sections.

The division of systematic pomology, or the description and classification of fruits and nuts, is quite distinct and separate as a study. In some respects chapters on this subject are used for reference in time of need as we use a dictionary, while the theory and practice of horticulture is a continued study in which about all classes are interested.

A number of years ago Daniel Webster said: "Horticulture is one pursuit of natural science in which all sexes and degrees of education and refinement unite. It attracts, delights all. It seems to be a common field where every degree of taste and refinement may unite and find opportunity for their gratification."

Hence the principles and practices of horticulture are outlined in Part I in a separate volume.

Sytematic pomology, giving a description of the fruits 
in cultivation largely planted in the varied parts of the United States and Canada, together with those of special promise in local parts, will follow as a completed volume as Part II. Part II will also be published as a separate volunie probably for the benefit of those most interested in varieties that succeed most perfectly on varied soils and in different sections and districts.

The figures used in Part I, when not original, are copied by permission from those used by Professor Goff, Professor Green, Professor Bailey, and others, as credited in each case, to whorn special thanks are due.

My able associate, Professor N. E. Hansen, has read the manuscript of Part I and assisted in various ways, and he has given much time and labor to the responsible and difficult work of describing and deciding the status of the many varieties in cultivation as given in Part II.

The discussions and statements in Part I have been carefully considered, and verified as far as possible by travel, correspondence, reading, and consultation, yet in some cases they will be questioned. But this will lead to investigation. It cannot be hoped that a volume of this character can be faultless in all respects. The details of modern horticulture are so varied that no one person can cover the whole range without omissions and mistakes of judgment.

$$
\text { J. L. BUDd. }
$$

Ames, Iow A, March 1, 1902. 



\section{CONTENTS.}

CHAPTER I.

SEEDS AND SEED-GROWTH.

1. Seedling Variations.......................... 1

2. Seed Variation of Cultivated Plants............... 2

3. Commercial Seeds............................ 2

4. Seed-saving................................ 3

5. Seed-stratification......................... 4

6. Soaking and Scalding Seeds..................... 5

7. Fall Planting of Seeds........................ 6

8. Seed-testing............................... 7

9. Depth of Planting Seeds...................... 8

10. Best Time to Plant Seeds....................... 9

11. Seeds in Shallow Boxes or "Flats"................ 10

12. Seeds in Hot-beds............................ 10

13. Shaded Beds for Seed-planting.................. 11

14. Retained Vitality of Seeds..................... 12

\section{CHAPTER II.}

\section{BEED-GERMINATION AND SEEDLING-GROWTH.}

15. Seed-germination $\ldots \ldots \ldots \ldots \ldots \ldots \ldots \ldots \ldots \ldots \ldots \ldots, 13$

16. Some of the Modes of Root-growth................. 14

17. How Seedling Ronts Grow .................... 15

18. The Office of Roots........................... 16

19. Root-protection............................. 16

20. Root-division ............................. 17

21. Roots as Modified by Variety of Top................ 18 
CHAPTER III.

STEM-AND TOP-GROWTH, APPENDAGES, AND CIRCULATION. BECTION

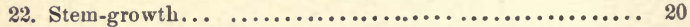

23. General Classes of Stems....................... 21

24. Heart-wood and Sap-wood...................... 22

25. Proper Height of Fruit-tree Stems................ 22

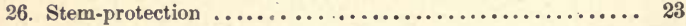

27. Proper Mode of Branching..................... 23

28. Leaf- and Fruit-buds........................... 24

29. Adventitious and Lateral Buds................... 27

30. The Leaf................................ 27

31. Sap and its Movements ...................... 28

\section{CHAPTER IV.}

\section{THE FLOWERS AND FRUITS.}

32. Parts of the Flower......................... 32

33. Inferior and Superior Flowers................. 33

34. Monœcious and Diœcious Flowers................ 34

35. Perfect and Imperfect Flowers .................. 35

36. Cross-pollination........................... 35

37. Nutrition of the Fruit Blossom.................. 35

38. Long-blossoming Period...................... 36

39. Possible Flower Production..................... 36

40. The Fruit and its Maturation................... 37

41. Air-drainage............................ 37

42. Fruit Soils.............................. 38

43. Fruits as Modified by Climate................... 38

CHAPTER V.

MODES AND PRINCIPLES OF PROPAGATION.

44. Some Preliminary Considerations................. 40

45. Root-grafting in Europe..................... 40

46. Some European Criticism..................... 41

47. Commercial Stocks......................... 42

48. Propagation by Seeds...................... 43

49. Propagation by Suckers..................... 43

50. Propagation by Root-cultings................... 44 
51. Rooting Sprouts by Mounding ................. 45

52. Summer Layering......................... 45

53. Spring Layering. ......................... 48

\section{CHAPTER VI.}

\section{PROPAGATION BY INARCHING AND FROM WOODY AND IMMATURE CUTTINGS.}

54. Propagating by Inarching.................... 50

55. Long-scion Inarching. . . . . . . . . . . . . . . . 52

56. Propagating by Ripe Wood Cuttings............... 53

57. When and How to Prepare Cuttings................ 53

58. Fall Planting of Cuttings .................. 55

59. Some Reasons for Fall Planting................. 55

60. Spring-planted Cuttings...................... 56

61. Cuttings Kept in the Cellar..................... 57

62. Immature-growth Cuttings .................... 57

63. Controlling Heat and Moisture.................... 58

64. Why Cuttings Need Bottom Heat................. 59

65. The Hot-bed............................. 59

66. Preparing and Setting Green Cuttings.............. 61

67. Need of Buds in Plant Division.................. 62

68. Division of Perennials, Tubers, and Root-stalks.......... 63

\section{CHAPTER VII.}

PROPAGATION BY BUDDING AND GRAFTING.

69. Propagation by Budding $\ldots \ldots \ldots \ldots \ldots \ldots \ldots \ldots \ldots \ldots \ldots$

70. Some of the Purposes of Budding................ 66

71. Some Native Stocks that Should be Used............. 67

72. Summer Budding.................................. 68

73. How to Cut and Insert Buds.................... 70

74. Budding the Same Season that Pits are Planted......... 71

75. After-care of Summer Buds..................... 71

76. June Budding............................. 72

77. Ring Budding $\ldots \ldots \ldots \ldots \ldots \ldots \ldots \ldots \ldots \ldots \ldots \ldots \ldots \ldots \ldots$

78. Grafting............................... 74

79. Limits of Grafting........................ 75

80. Cutting and Packing Scions.................. 75

81. Taking Up and Packing Stocks................... 76 
82. Short Roots and Isong Scions................... 76

83. Grafting-wax for varied Uses................... 77

84. Root-grafting the Apple........................ 78

85. Packing Away the Grafts....................... 79

86. Crown-grafting Pear, Plum, and Cherry............. 80

87. Trenching for Graft-planting.................. 82

88. Top-grafting.............................. 84

89. Top-working the Apple....................... 85

90. Top-working Old Trees ....................... 85

91. Top-grafting Cherry and Plum.................... 86

92. Top-working in the Cellar...................... 89

93. Scions to Save Girdled Trees................... 89

94. Bark-grafting.............................. 91

95. Soft-tissue Grafting........................ 91

\section{CHAPTER VIII.}

SOME LEADING PRINCIPLES OF FRUIT-GROWING AND DEVELOPMENT.

96. Selection of Soil and Subsoil $\ldots \ldots \ldots \ldots \ldots \ldots \ldots \ldots \ldots \ldots, 93$

97. Air-drainage ........................... 93

98. North and South Slopes...................... 94

99. Orchard Protection........................... 95

100. Retarding Fruit Blossoms $\ldots \ldots \ldots \ldots \ldots \ldots \ldots \ldots \ldots \ldots, 96$

101. Washing of Orchard Soils.................... 97

102. Variety Modification......................... 99

103. Crossing and Hybridizing....................... 100

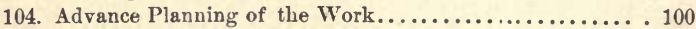

105. Nearly Allied Crossing......................... 101

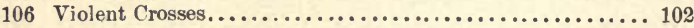

107. Gathering Pollen in Advance.................... 103

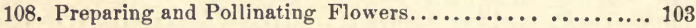

109. When and How to Apply Pollen................... 104

110. Speedy Testing of the Crosses and Hybrids............. 105

\section{CHAPTER IX.}

TRANSPLANTING FRUITS AND ORNAMENTALS.

111. Transplanting............................. 106

112. Width of Spaces Between Orchard Trees............. 106 
113. Distance Apart of Applc- and Pear-trees.............. 107

114. Double Planting of Orchards.................... 10

115. Distance Apart of Peach, Plum, and Cherry ........... 108

116. Planning and Staking the Orchard Site.............. 109

117. Fall or Spring Planting...................... 110

118. Young 'Trees Best for Planting.................... 110

119. Securing and Caring for Nursery 'l'rees............... 111

120. Proper Depth to Plant Trees .................... 112

121. Pruning Tops and Roots Before Planting or Heeling In .... 112

122. Alternating Varieties in the Rows................. 113

123. Planting and $W$ atering Trees..................... 114

124. Transplanting Evergreens...................... 114

\section{CHAPTER $\mathrm{X}$.}

\section{ORCHARD MANAGEMENT.}

125. Culture After Planting..................... 116

126. Shading Orchard Soils. . . . . . . . . . . . . . . . . . 116

127. Cover-crops and Blight......................... 118

128. Do Cover-crops Dry the Soil ?................... 119

129. Protection from Mice and Rabbits ................. 119

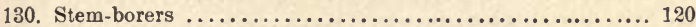

131. The Tent Caterpillar............................. 121

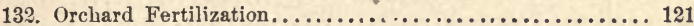

133. Low Hedges for Shelter-belts.................... 121

134. Marketing Summer Ripening Fruits................ 122

135. Picking and Handling Fall and Early Winter Apples...... 123

136. Picking and Handling Winter Apples.............. 124

137. Earth-covered Cave for Apple Storage................ 124

138. Tile-draining of Orchards.................... 125

139. Fruit-growing Neighborhoods.................. 126

\section{CHAPTER XI.}

PRUNING OF TREES AND ORNAMENTALS.

140. Need of Pruning.......................... 127

141. Pruning in Nursery ........................ 127

142. Proper Time for Pruning in Nursery and Young Orchard.. 128 143. Pruning Young Apple and Pear Orchards ............ 128 
144. Heading Back Old Apple- and Pear-trees.............. 130

145. Training Dwarf Apple- and Pear-trees.............. 131

146. Pruning for Cordon-training. . . . . . . . . . . . . 131

147. Pruning to Shape Trees ... . . . . . . . . . . . . . 133

148. Pruning the Cherry and Plum.................. 133

149. Pruning the Peach and Apricot................... 134

150. Pruning the Orange......................... 137

151. Pruning the Quince........................... 137

152. Pruning and Shaping Shrubs.................... 137

153. Pruning and Shaping Evergreens................. 139

154. Pruning Ornamental Hedges and Screens............. 139

\section{CHAPTER XII.}

SPRAYING FOR INSECTS AND FUNGI.

155. Evolution of Spraying....................... 141

156. Spraying for Codling-1noth................... 145

157. Curculio of the Apple, Pear, Plum, Cherry, and Peach.... 147

158. Spraying for the Bark and Leaf Aphis.............. 148

159. Leaf Aphis of Apple, Plun, Cherry, and Peach......... 150

160. Spraying for Scale Aphis...................... 150

161. Some Miscellaneons Insects..................... 152

162. Spraying for Fungous Diseases.................. 153

163. Apple and Pear Scab.......................... 154

164. Brown Rot of the Stone Fruits.................. 155

165. Fungi of the Grape and Small Fruits............... 156

\section{CHAPTER XIII.}

THE APPLE, PEAR, AND QUINCE.

166. Origin of the Cultivated Apples.................. 159

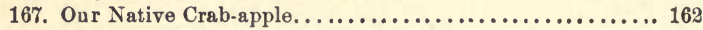

168. Dwarf Apple-trees ............................ 164

169. Propagation of the Apple....................... 164

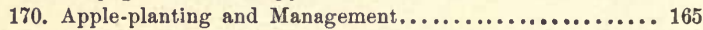

171. Varied Seasons and Behavior of Varieties.............. 165

172. History and Some of the Races of the Pear............ 167

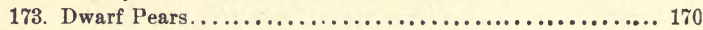

174. Propagation of the Pear........................ 171 
175. Soil and its Management for the Pear............... 171

176. The Fruit and its Care........................ 172

177. Origin and Races of the Quince.................. 173

178. Propagation and Management.................... 174

\section{CHAPTER XIV.}

THE CHERRY, PLUM, IRUNE, APRICOT, AND PEACH.

179. History and Classification of the Cherry............ 175

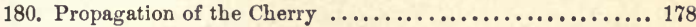

181. No Market Supply of the Cherry................. 178

182. History and Classification of the Plum............... 180

183. The Prune................................. 183

184. The Apricot................................. 184

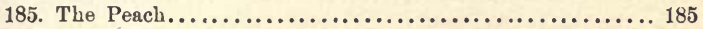

186. Propagation of Plum, Prune, Apricot, and Peach....... 186

187. The Nectarine............................. 187

188. Laying Down the Peach and Apricot............... 188

189. Orchard Management of the Stone Fruits............. 190

190. Thinning the Stone Fruits..................... 191

CHAPTER XV.

SOME SUBTROPICAL ORCHARD FRUITS.

191. The Orange................................ 193

192. Orange Propagation............................ 196

193. Top-working the Orange..................... 198

194. Orange Cultivation.......................... 198

195. Pruning the Orange $\ldots \ldots \ldots \ldots \ldots \ldots \ldots \ldots \ldots \ldots \ldots \ldots \ldots . \ldots \ldots$

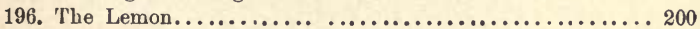

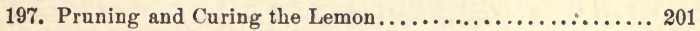

198. The Pomelo or Grape-fruit.................... 202

199. The Kumquat.............................. 203

200. The Lime................................ 203

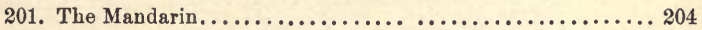

\section{CHAPTER XVI.}

SOME OTHER TROPICAL AND SUBTRGPICAL FRUITS.

202. The Olive ............................... 205

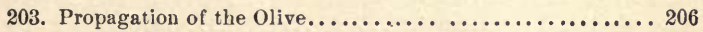


SECTION

204. Commercial Olive Products ...................... 206

205. The Fig.................................. 207

206. Possible Fig Improvement . . . . . . . . . . . . . . . . 208

207. Fig-growing at the North....................... 209

208. The Date-palm .............................. 210

209. Date Propagation and Management................. 212

210. Possible Improvement of the Date by Crossing.......... 213

211. The Banana.............................. 213

212. The Pineapple.............................. 214

213. Increased Use of the Pineapple.................. 216

214. The Luquat.............................. 217

215. Propagation of Loquat....................... 218

216. The Pomegranate .......................... 218

217. The Persimmon............................. 219

218. The Native Persimmon........................ 220

219. Persimnon Propagation and Management............ 222

220. The Guava.................................. 223

221. The Tomato................................. 224

222. The Melons................................. 225

\section{CHAPTER XVII.}

THE AMERICAN GRAPE.

223. Grape History and Development................. 228

224. Grape Propagation ......................... 230

225. Growing Vines from Single Buds................. 231

226. Grafting the Grape... ....................... 232

227. Some Modes of Grafting the Grape................. 232

228. Best Soil and Location for Vineyard................ 235

229. Varieties for Varied Sections................... 235

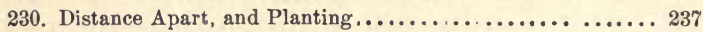

231. Varied Modes of Training...................... 239

232. Training for Laying Down at the North............... 239

233. Diagonal Training Plan....................... 243

234. The High Renewal System..................... 244

235. The Pacific Slope Systenı. ..................... 246

236. Other Systems of Pruning.................... 247

237. Cultivation and Manuring.................... 248

238. Need of Humus in Cultivated Soils.................. 249

239. Shading Vineyard Soils...................... 250 


\section{CHAPTER XVIII.}

SECTION

THE RASPBERRY AND BLACKBERRY.

240. The Raspberry : Origin of American Varieties...........

241. Cultivated Species............................ 251

242. The Blackcap Family........................ 252

243. Propagation and Transplanting.................. 252

244. The Purple Cane Varieties...................... 254

245. American Red Varieties........................ 255

246. Propagation and Transplanting.................... 255

247. Pruning the Raspberry........................ 256

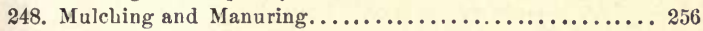

249. Winter Protection .......................... 257

250. Staking, and Distance A part.................... 258

251. The American Blackberries..................... 259

252. Propagation and Management................... 260

253. The Dewberry ............................. 261

\section{CHAPTER XIX.}

THE STRAWBERRY AND ITS CULTURE.

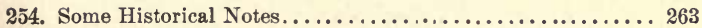

255. Staminate and Pistillate Varieties.................. 265

256. Setting Out and Care of Plants .................. 267

257. The Two-year System of Cropping................. 268

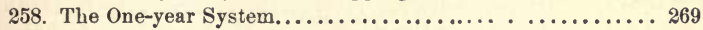

259. The Hill System of Growing................... 269

260. The Strawberry under Glass. ................ 270

261. Shelter for Small Fruits....................... 271

\section{CHAPTER XX.}

THE CURRANT AND GOOSEBERRY.

262. The Red and White Currants.................. 272

263. Currant Propagation......................... 273

264. Manuring and Mulching..................... 274

265. Pruning and Training........................... 274

266. The Black Currant............................ 275

267. The Golden Currant........................ 276 
268. The Gonseberry........................... 277

269. Its Propagation and Culture.................... 278

270. Pruning and Training......................... 279

271. Culture and Management....................... 279

\section{CHAPTER XXI.}

PROMISING WILD FRUITS WORTHY OF SOME ATTENTION.

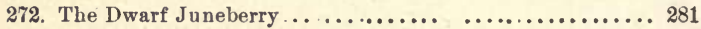

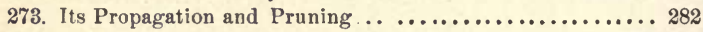

274. The Buffalo-berry ............................ 283

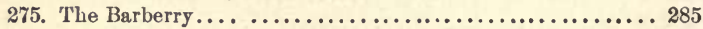

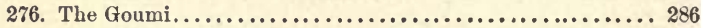

277. The Huckleberry.......................... 286

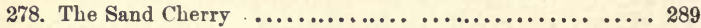

279. The Tree Cranberry......................... 290

280. The Cranberry............................. 290

\section{CHAPTER XXII.}

SOME LEADING NUT-TREES.

281. Advance in Nut-growing....................... 294

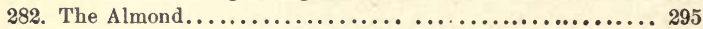

283. The English or Persian Walnut.................. 297

284. Walnut Propagation.... .................... 298

285. Possible Increase of Hardiness.................... 299

286. The Black Walnut.......................... 299

287. Its Propagation and Planting.................... 300

288. The Butternut............................. 300

289. The Hickory-nut............................ 301

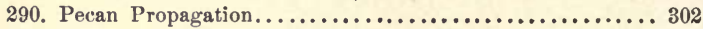

291. The Chestnut................................ 303

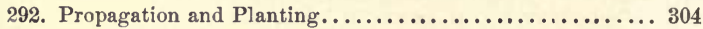

293. The Filbert................................. 306

294. The Hazel-nut............................ 306

295. Its Propagation and Pruning.................... 308

296. The Cocoanut............................. 308

297. Its Propagation and Varieties.................... 310

298. The Brazil-nut................................. 311 


\section{CHAPTER XXIII.}

SECTION

PLANNING AND PLANTING THE HOME GROUNDS.

299. American Rural and Suburban Homes . .................

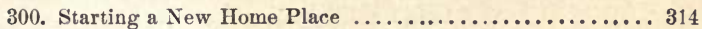

301. Grading and Enriching the Lawn................. 315

302. Where to Plant Trees and Shrubs................. 315

303. Planning and Planting more Extended Grounds......... 319

304. Improving Old Places......................... 321

305. Transplanting Trees and Shrubs.................. 324

306. The Need of Hardy Trees and Shrubs............... 325

\section{CHAPTER XXIV.}

SOME OF THE LEADING LAWN AND PARK TREES.

307. Adapting Trees to Soil and Climate.............. 327

308. Sugar or Rock Maple........................ 328

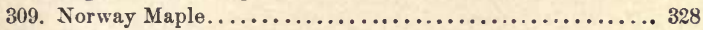

310. The Dwarf Oriental Maples...................... 328

311. The Box Elder............................. 329

312. The Silver Maple............................ 329

313. The Red Maple........................... 329

314. The Elms.................................. 329

315. The Hackberry............................ 330

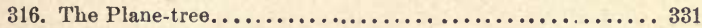

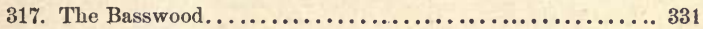

318. The Honey Locust......................... 332

319. The Birches................................ 332

320. The Oaks.................................. 334

321. The Oleasters................................. 335

322. Ornamental Species of Prunus.................... 336

323. The Mountain Ash Family..................... 337

324. The Apple Family........................... 338

$324 a$. Poplar and Willow Family .................... 339

325. The Magnolias............................. 340

326. The Larches.................................... 341

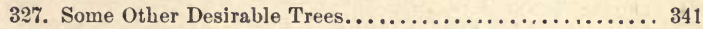

328. The Spruces. ............................ 343

329. The Firs............................... 345 
$330 a$. The Hemlock................................... 347

330b. The Arbor Vitæ.

\section{CHAPTER XXV.}

SOME OF THE ORNAMENTAL SHRUPS AND VINES.

331. Some of the Uses of Shrubs.................... 349

332. The Spiræas............................. 350

333. The Lilacs............................... 352

334. The Mock-oranges.......................... 352

335. The Barberries............................. 353

336. The Snowball Family........................ 355

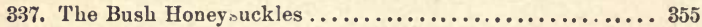

338. The Hardy Roses. . . . . . . . . . . . . . . . . . . 356

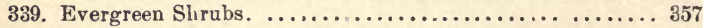

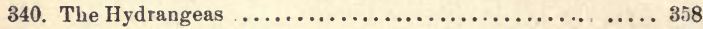

341. The Tamarix............................ $\quad \mathbf{3 5 8}$

342. The Buffalo-berry............................. 359

343. The Japan Quince.......................... 360

344. White Fringe.............................. 360

345. Purple Fringe............................. 360

346. Cut-leaved Sumach........................ 360

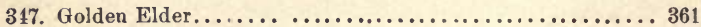

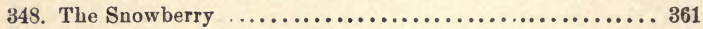

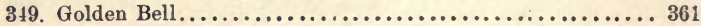

350. Pearl Bush............................... 362

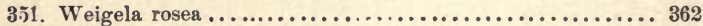

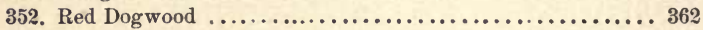

353. The Climbing Honeysuckles...................... 364

354. Climbing Bittersweet ......................... 364

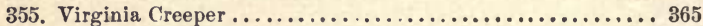

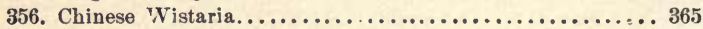

357. Jackman's Clematis.......................... 365

358. Actinidia arguta ..................................... 365

CHAPTER XXVI.

PERENNIALS AND BULBS.

359. Thr, Perennial Beds ....................... 366

360. The Herbaceous Pennia. ........................... 366 
361. Perennial Phlox............................. 367

362. The Double Hollyhock....................... 367

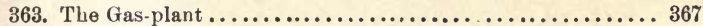

364. The Hardy Lilies. . . . . . . . . . . . . . . . . . . . . 367

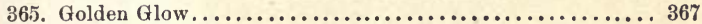

366. Japan Iris . . . . . . . . . . . . . . . . . . . . . . . 368

367. Oriental Poppy... ........................ 368

368. Japan Spiræa.............................. 368

369. Hardy Feverfew . . . . . . . . . . . . . . . . . . . 368

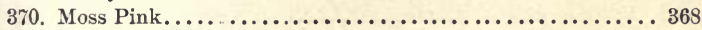

371. Plume Poppy............................ 368

372. Lily-of-the-valley ............................ 369

373. Care of the Perennial Beds...................... 369

374. The Tulip Bed............................. 369

375. Less Hardy Holland Bulbs...................... 370

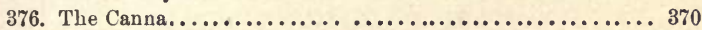

377. The Gladiolus............................. 371

378. The Dahlia ...................................... 371

379. Elephant's Ear.......................... 372

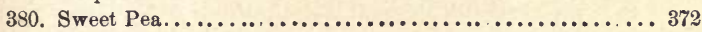

381. The Castor-bean................................... 372

\section{CHAPTER XXVII.}

THE VEGETABLE AND SMALL-FRUIT GARDEN.

382. Its Location, Shape, and Shelter.................. 374

:83. Rotation of Crops.......................... 375

384. Fall Plowing of Garden..................... 373

385. Garden Culture............................. 377

386. Procuring Good Seed ........................ 380

387. Plant Propagation and Transplanting................ 381

388. Garden-manuring . . . . . . . . . . . . . . . . . . 833

389. Preservation of Vegetables........................ 384

390. Garden Insects............................. 385

391. Spraying Garden Plants. . . . . . . . . . . . . . . . . . 386

392. Miscellaneous Garden Insects. . . . . . . . . . . . . . . 386

593. Some Neglected Garden Crops..................... 387

394. Asparagus .............................. 387

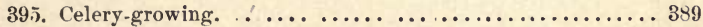

396. Egg.plant Culture......................... 391 


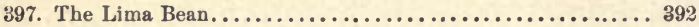

398 The Melons................................. 393

\section{CHAPTER XXVIII.}

IRRIGATION.

399. Irrigation in the Humid States.................. 394

400. Watering the Orchard Fruits.................... 395

401. Reservoirs with Puddled Bottoms................. 397

402. Artesian-well Irrigation........................ 398

403. Sub-irrigation.. . ......................... 399

404. Greenhouse Irrigation. . . . . . . . . . . . . . . . 400

405. Surface Culture Needed..................... 400

406. Remarkable Results of Irrigation ................ 401 


\section{HORTICULTURAL MANUAL.}

\section{CHAPTER I.}

\section{SEEDS AND SEED-GROWTH.}

SEEDS are embryo plants capable of growing into new individual plants more or less varied from the parent plant. As the first stage of plant-life it should have the first attention of the beginner in horticulture.

1. Seedling Variations.-Under natural conditions the seed reproduces the species very nearly. If we plant the pits of our native plums, the species will in the main be reproduced, yet no two of the seedlings will be alike in all respects. Not only will we have slight variations in leaf and habit of growth, but in the size, color, and season of the fruit. This variation has given us by selection such native plums as Wyant, Wolf, and Rollingstone, and some of our nost valuable grapes, gooseberries, raspberries, and other fruits.

The natural variation from the seed has also by selection given us some of our most desirable ornamental and shade trees and shrubs. As a well-known instance, the handsome cut-leaved weeping birch is a sport or variation of the Amur-birch species (Betula Amurtnsis). If propagated 
from seeds, the cut-leaved variety will reproduce the species, but the variety can only be preserved by propagating from the buds.

2. Seed Variation of Cultivated Plants.-The cultivated varieties of the fruits and ligneous plants are far more variable when grown from seed than those nearer to Nature. In many cases they are crosses or hybrids and for generations have been planted intermingled with other varieties. If we plant the seeds of the Grimes Golden or Jonathan apples, we get an exceedingly varied lot of seedlings in leaf, bud, habit of growth, and fruit. Some of them will produce no larger nor better fruit than the Siberian crabs, and perhaps no seedling will bear fruit approaching the parents in size or quality. When propagated by budding, grafting, or cuttings of the top or roots, these choice old varieties are reproduced indefinitely with very slight individual variations. While this is the rule with cultivated trees and plants, we find some partial or entire exceptions. As examples, some of the Russian fruits, such as the Duchess apple and the Spate Morello cherry, come near to reproduction from seed, and the same is true of some peaches.

Among garden vegetables we have many varieties that have been so fixed by selection, and growing in isolated position, that they reproduce the variety very nearly true from seed, indefinitely, if kept apart from other varieties of the same species.

3. Commercial Seeds.-It has been said with much show of truth that the Americans are not gatherers of the seeds of native ligneous trees and plants, while in Europe seed-growing and seed-gathering is a business in which the peasant and his children are helpers.

In the United States growers of vegetable- and some flower-seeds supply the home market largely, and to some extent coasignments are sent abroad. 
But our nurserymen ard tree-growers mainly rely on foreign nurseries for tree-stocks and seeds of the conifers, bulbs, and many of the leading flower-seeds.

Each year large consignments of evergreen seed are received from western Europe, while tons of the cones of such beautiful and hardy native species as Black Hills spruce, silver spruce, white spruce, Colorado fir, Black Hills pine, and red pine are allowed to go to waste.

In the line of tree-stocks it is much the same. French crab-apple seed and Mazzard and Mahaleb cherry stocks and pits are imported by the carload, while native seed is neglected to large extent. In the States west of the lakes the use of native seeds of the conifers and tree-stocks is most important for climatic reasons. The seeds of hardy home-grown apples, the pits of our select native plums, the pits of our wild red cherry, the seeds of our home-grown flowers, and the seeds of the Colorado and Black Hills conifers should be used at the West, and they would prove more valuable than the imported ones over a large part of the union. Indeed, in all parts of the union the use of home-grown seeds should be encouraged, especially in the way of conifers and fruit-tree stocks.

4. Seed-saving. - In selecting seeds for growing fruittree stocks it is desirable to secure those from primitive or nearly primitive types and species. The abnormal development of the edible portion of fruits is not favorable for the development of plump and perfect seeds. In many of the highly developed fruits of the apple, pear, cherry, plum, grape, pineapple, banana, and tomato we find no perfect seed, and the few capable of germination fail to develop strong, healthy seedlings. A well-known propagator has said that he would sooner pay twenty-five dollars for a bushel of Red Romanite apple-seed than to have the seed of Yellow Bellflower and Crimes Golden as a gift. Expe- 
rience has also shown that the pits of our highly-developed cherries and plums are either entirely abortive or of little value for stocks on account of feeble growth. On the other hand, the pits of the wild cherries of Europe or of our native wild red cherry develop vigorons, strong-growing stocks, and the same is true of the primitive plums of Europe and America.

Over all parts of Europe the seeds of the native primitive orchard fruits are alone used for stocks. In the States where safe from root-killing these European wild stocks are also prized on account of their uniform and vigorous growth. This has favored the use of French crab-seed, the seed of the small Perry pears of Europe, and the use of the primitive Mazzard and Mahaleb cherry stocks, as well as stocks of the Myrobalan and St. Julien plum. These imported primitive stocks are found to develop strong, uniform seedlings, while those from cider-press seed or from marketable fruits of any kind are weak, uneven, and relatively worthless. As the years go on, more attention will be given to gathering our native seeds for propagation where possible; and if imported, let it be from the parts of Europe corresponding in climate most nearly to the different parts of our Union.

For commercial use and transportation such carbonaceous seeds as apple, pear, quince, and the small fruits require careful drying and storing in a dry room. Freezing will not harm them if kept dry. The conifer seed can also be kept dry until time for planting. The subtropical flowerseeds and fruit-seeds not only require dry storage quarters, but freedom from severe freezing. If kept dry they may germinate, but their vitality will be low if frozen.

5. Seed-stratification.-The practice known as stratification by gardeners is simply mixing thoronghly the seeds with sand in a box and burying outside on dry ground, with 
the top about four inches under the earth, where it will freeze solidly if at the north, or be kept moist if at the south. It is practised with hard, bony seels that are injured or ruined by drying, such as pits of plum, cherry, honey locust, Kentucky coffee-tree, some of the shrubs, and seeds of the small fruits and roses. If well mixed when stratified, it is usual to sow the seed and sand together in the spring.

Such nuts as the hazel, filbert, chestnut, acorns, and hickory nuts, it is best to mix with sand and store in a cool cellar, protected by covering from rats and mice. But kept in this way the nuts will usually sprout early in the spring. For this reason we have practised planting when the ground has thawed out three inches deep in the spring. Such nuts as the black walnut, English walnut, and butternut are provided by Nature with a covering that holds moisture as it decays. It is best to cover these, as spread out in thin layers in a grove, with forest leaves for early spring planting. Seeds that require to be kept moist should be stratified very soon after gathering, and the pits of the stone fruits should be washed to free them from all traces of pulp, followed by partial drying before mixing with the sand. If not washed and partly or wholly dried, the adhering pulp often develops fungus growth that is destructive. If the stone fruits rot in boxes or piles and the pits are washed out and dried, they rarely can be made to germinate on account of fungus injury.

6. Soaking and Scalding Seeds.-Dry commercial seeds of the apple and pear are soaked at the North about twelve hours, just prior to a night of low temperature, during the latter part of winter. The water is then drained off, the seeds mixed with sand and placed outside in shallow boxes to freeze solidly. While frozen the boxes are placed on the north side of a building and covered with straw to 
hold the frost as long as possible. Early in spring they are planted without separating from the sand.

At the Sonth the dry seed is soaked for a longer period, with frequent changes of water to prevent fermentation, and they are kept moist until they are planted. But the writer's observation has favored the belief that this plan does not give as perfect a stand as the one of soaking and freezing practised at the North.

The dry small-fruit seed is soaked about the time of planting until most of the seeds change color with frequent changes of water. Some garden-seeds, such as onion and parsnip, are usually soaked before planting to hasten germination, giving less trouble in weeding. But all small seeds - and indeed all seeds-when soaked must be planted in moist earth. When the surface is dry, if the - sceds come in contact with dry earth they will dry up and usually fail to germinate.

Hard, bony seed, such as honey locust, black locust, Kentucky coffee-tree, and canna, when dry and hard will endure soaking in scalding-hot water without injury if not placed on the stove. When ready to plant they will swell perceptibly and change to a lighter color. The swelled seeds can be sifted out and the dark ones can be re-scalded. Seeds treated in this way must be planted at once in moist earth. In place of scalding, water is often introduced beneath the dry shell of canna and moonflower by filing or boring the hard covering.

7. Fall Planting of Seeds.-Planting some of the bonyshelled seeds in autumn answers well the purpose of stratification if properly managed. If planted at proper depth for germination, they are apt to be thrown out by winter and early spring frosts. They are also apt to be eaten by birds, mice, or other vermin, and in spring the soil is baked over them, giving most unfavorable conditions for 
germination. The writer's plan has been to plant at usual depth and then mounding a ridge of earth two or three inches deep over the line of each row. This defines the line of row, and in spring, with a pronged hoe, the mounding is raked off, leaving a mellow seed-bed. When small seeds, such as those of the grape, raspberry, blackberry, currant, gooseberry, strawberry, and Juneberry, are planted in the fall, the raking off in spring should about reach the seeds. In the relatively dry air of the prairie and arid States the line of row after raking should be covered with boards or mulch until the roots of the delicate seeds start, when the covering is removed.

8. Seed-testing.-Seed-testing indoors is not wholly satisfactory, as the conditions are more favorable than in the soil of the open field or garden. The best test for the amateur or commercial planter is probably in quite deep earthen dishes placed in the greenhouse or a warm livingroom or kitchen. But the test should be continued until the plantlet shows the true leaves and a system of roots for taking up nutriment from the soil. The simple sprouting of seeds is no satisfactory test of their vitality, as many seeds will sprout that are not capable of forming perfect plants. What is commercially called seed-testing is simply sprouting the samples. The number of seeds that sprout are counted. The experiment stations and seed-dealers have several kinds of apparatus for this use, in which the moisture and temperature are so controlled that a seed with low vitality will sprout feebly that never can develop true leaves or roots. As Bailey says: "The sprouting-test is almost wholly an attempt to arrive at a numerical estimate of the sample rather than an effort to determine the relative strength of germinating power." With home-sared seeds kept as outlined under the head of Seed-saving (4) tests of vitality are not needed. But with 
commercial seeds the dish test, carried on to perfect leafdevelopment, is often a time- and money-saving process.

9. Depth of Planting Seeds.-As a rule, the depth of planting depends on the size of seeds. But this is not invariable. Some quite large seeds, such as those of the bean, castor-oil bean, and some of the nuts, send out thick, clumsy seed-leaves, and if planted three inches deep, followed by slight soil-baking, they are unable to force their way upward. This quite numerous class, including the pumpkin and squash, should not be covered more than an inch deep, and in heavy soils still less. On the other hand, such plants as leave the seed-leaves or cotyledons in the soil, such as corn and the pea, will bear deep planting if the soil is not too compact to admit air freely. The closeobserving horticultural student will soon notice that some plants, such as bean, pumpkin, and the orchard-fruit seeds, when germinating lift up the seed-leaves bodily into the air, while in others the seed-leaves remain in the soil. If deeply planted, the clumsy leaves may fail to lift the compact covering, while in such as corn and peas the sced-leaves do not emerge, but growth takes place upward from a growing point or plumule (Fig. 1). All fruit-tree seeds should be planted early, and planted no deeper than is necessary to secure the needed moisture. Even where small-fruit seeds are planted on the surface and pressed down firmly with a board early in the spring, they usually start the root downward in time to escape injury by drying. But it is safer to press down such seeds and cover with a board or mulch to lessen evaporation while the roots are starting. When the first upward growth is observed the covering is removed.

In planting nuts it is best to follow Nature as closely as possible. Plant shallow-not more than an inch deep -and press the soil down firmly. In early spring plant- 
ing, when the surface soil is moist, we have planted black walnuts, butternuts, hickory-nuts, chestnuts, and oak acorns by merely crowding them down in mellow soil with
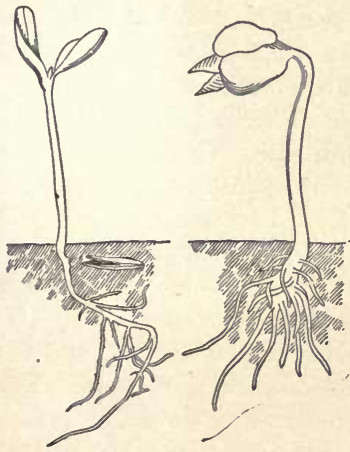

FIG. 1.
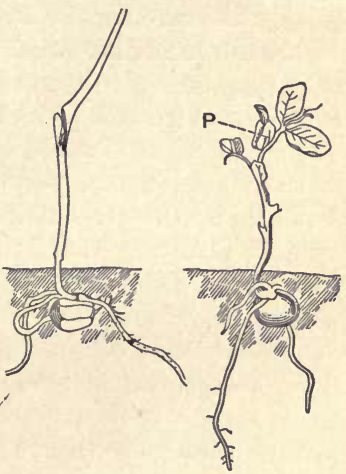

$\begin{array}{cccc}\text { Plantlet of } & \text { Plantlet of } & \text { Plantlet of } & \text { Plantlet of } \\ \text { Pumpin. } & \text { Bean. } & \text { Indiay Coln. } & \text { Pea. }\end{array}$ In the pumpkin and bean, the seed-leaves (cotyledons) are lifted above the surface of the soil in germination.

In the corn and pea, the cotyledons are not lifted above the surface of the soil in germination. (After Goff.)

the boot-heel, with a success never attained in.planting over one inch deep.

10. Best Time to Plant.-As previously stated, stratified seeds kept in open air or the cellar must be planted very early or they may sprout in the boxes. But aside from this the fruit-tree seeds germinate at a low temperature and succeed best when planted quite as early as seeds of such cold-blooded plants as the pea, lettuce, and radish. But the temperature of our northern summers-especially west of the lakes-permit the growing of many subtropical annuals, such as corn, bean, melon, cucumber, 
tomato, egg-plant, and subtropical flowers. If planted in the open air in any part of the Union, we must wait until the soil is warm enough to germinate the seeds quickly to secure healthy after-growth.

11. Seeds in Shallow Boxes, or "Flats."-What are known to propagators as "flats" are shallow boxes with sides four inches high and perforated bottoms. The size as to length and width is varied for different uses and convenience in handling. These are filled with fine rich soil favorable for the germination of delicate seeds unsafe for open-air planting. They are used by amateurs and professional growers for growing plants, such as tomato, eggplant, peppers, and small flower-seeds, both Northern and Southern. Very delicate seeds, such as those of the verbena, are planted in rows with slight covering, and the whole surface is then pressed down with a board. The pressed surface is then covered with sheets of porous carpet-paper cut to the size of the box. In watering, the paper is taken off for sprinkling gently, so that the surface will not be washed. When the plants begin to show, the paper is taken off. At home the box can be kept in a warm, well-lighted room, or in a gentle hot-bed. As soon as the plants develop perfect leaves they are potted in thumb-pots, which can also be kept in the "flats" with the open spaces filled with sand or earth, where they remain until outside conditions are favorable for planting. out.

12. Seeds in the Hot-bed.-Bottom heat, secured by manure in the heating stage, or by hot water or steam, is nuch used by professional gardeners, and to less extent by amateurs for starting subtropical plants, such as tomato, pepper, egg-plant, and subtropical flowers. After potting, the plants are set in flats and gradually hardened for outdoor planting. As the hot-bed and cold-frame are 
used also for cuttings, their structure will be given in the chapter devoted to growing plants from cuttings (65).

13. Shaded Beds for Seed-planting.--Some of our cultivated trees and plants, that under natural conditions $d$ rop their seeds in forest shade, seem to require the same protection when propagated in open exposure. This is specially true in interior climates, such as the prairie States, with such trees as the conifers and the birches. For shading the beds, lath frames for the top and sides are now generally used. Amateurs and smaller growers use beds four feet wide covered with lath frames four feet square, only eighteen inches above the bed, with sides lathed to exclude the birds. Larger growers erect a framework high enough to work under, covering the top and sides with lath, with three-quarter-inch spaces between them.

Fig. 2 shows the plan of making the lath screen, and

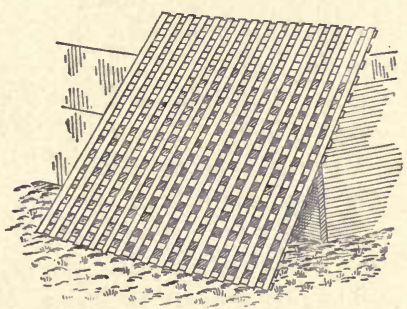

FIG. 2.-Lath Screen.

Fig. 3 gires the plan of lath-covered shed for sheltering seed-beds from the direct rays of the sun and to lessen evaporation. These are made large enough for a number of beds, highest in the centre, to run off surplus water from rains into the slightly sunken paths between the beds. The seed is sown in drills very shallow, and the 
surface is covered at once with evergreen leaves or othel light shading to lessen evaporation, which is mainly removed when the plants begin to appear. The after-care of the seedlings is given in the chapter on seedling-growth.

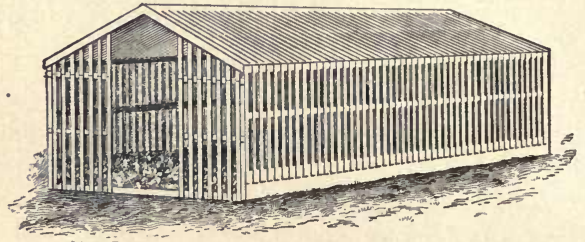

Fig. 3.-Lath-covered Shed for Seed-beds. (After Bailey.)

14. Retained Vitality of Seeds.-Varied opinions have been given as to the duration of vitality of seeds of the cultivated plants. This largely comes from the varied modes of drying and storing of seeds. As an instance, onion and other seeds are often sunk in water to clean, as the chaff rises to the surface. Such seed is only good for one year as a rule. But onion-seed properly handled is good for ten years or more. As a rule, the vitality of all seed is reduced by age. Some seeds with the best care rarely germinate when more than one year old, and the fruit-tree seeds kept dry for one year are much lowered in vitality. Tables are often compiled giving the extreme duration of seeds under proper conditions. But they are so unsafe, on account of varying conditions, that the certain rule is to plant seeds the season following their gathering. The only exceptions are possibly with melons, cucumbers, squashes, and some other plants noted for excessive vigor of growth. It is claimed in such cases that seed three or four years old gives less growth and more fruit than the new seed. 


\section{CHAPTER II.}

\section{SEED-GERMINATION AND SEEDLING-GROWTH.}

15. Seed-germination.-With an ordinary magnifyingglass the tiny plantlet is not difficult to discover compactly folded up within the seed. If we place seeds of pumpkin, bean, corn, or pea in boiling water until fully swelled, and then carefully dissect them, we will soon find the embryo plantlet which exists in all seeds grown by the horticulturist. What is known as sprouting or germination is merely the unfolding and growth of the embryotic plant. Some of the soil requisites and other favoring conditions for germination have been given in the preceding chapter. The mature seed contains starch or protoplasm in dormant condition. When placed in moist soil, with temperature suited to the variety or species, the protoplasm becomes active, as when the spring awakens activity of circulation and growth of dormant trees in spring.

The cells of the embryo begin to increase in number by division, and soon the tiny shoot, known popularly as the sprout and by botanists as the hypocotyl, starts downward. If the seed is not properly placed, this first growth will make a curve before the rounded point extends downward. In the forest we often see the acorn, lying on moist leaves, project the hypocotyl through the leaves to the moist earth, and later, when fastened to the soil, the up-growing 
shoot, known as the plumule, starts. All seeds start the root or hypocotyl downward prior to the starting of the plumule upward to be exposed to the air and sun.

Germination is said to be completed when the young plantlet forms perfect leaves and is capable of living without additional support from the stored nutriment in the seed.

16. Some of the Modes of Root-growth.-As the hypocotyl, or first seed-growth, extends downward into the soil, rootlets start from its sides and rounded point. From the point the main or tap-root extends downward, and from the sides extend the branch or feeding roots. The length of the hypocotyl varies in seeds of different plants and trees. The long list of plants that lift up bodily the halves of the seed or what remains of it, such as the bean, pumpkin, and most of the fruits, make a relatively long growth of the hypocotyl during the process of root-extension. This seems to be a wise provision for forming a foundation for the forcing process of lifting the bulky cotyledons to the surface with a force that often uplifts a hard-baked earth surface.

This class of seeds should be planted shallow. If as deeply planted as peas, they will not be able to force the cotyledons to the surface. At the West a heavy rain followed by dry days often forms a crust that makes it difficult for apple-seed to germinate if planted more than three fourths of an inch deep. If the soil is well firmed in planting, the whole of this numerous class will do best if not covered more than from one half to three fourths of an inch deep (Fig. 1).

On the other hand, all plants that do not lift up the sced-lcaves or cotyledons will bear deeper planting. The pea is an example. This forms the two cotyledons, but they remain in the soil and the slender shoot pushes up 
easily to the surface. In this class of plants the hypocotyl lengthens but little and does not lift up the cotyledons. Hence this class of plants, including those with one cotyledon, such as corn, can be planted five or six inches deep and yet reach the surface in favorable soils. But, as a rule, horticultural seeds should not be planted deeper than is required to secure the needed supply of moisture. As an example, it is often recommended to plant the sweetpea deep in trenches, gradually filling up to a depth of five or six inches. But experience shows that if planted one inch deep they will succeed much better when planted on heavy soils.

17. How Seedling-roots Grow.-The tree-seedling permitted to stand where the seed was planted extends the main or water-feeding roots downward, if the soil is favorable, to a depth of several feet. The writer has traced the tap-root of a Buckeye seedling one foot in height to a depth of five feet. In the deep gullies or washes in the loess soils of western Iowa we have seen roots of older trees that were two inches in diameter at a depth below the treecrown of twenty feet. But the depth reached depends on the nature of the subsoil and the depth of the water-level. The branch or surface-feeding roots also reach farther than is usually suspected. As a rule, if conditions permit, the surface nitrogen-feeding roots extend beyond the spread of branches. The deep extension of the seedlingroot that goes down where the seed is planted, and the speedy extension of surface-feeding roots, has led planters of groves and plantations of forest-trees in Europe and America to plant seeds where the trees are to stand.

In practice it has been found that seedlings not transplanted are much larger and thriftier when ten years old than the two- or three-year-old plants set out when the 
seeds were planted. If practicable, the budding and grafting of seedlings standing where the seed is planted would prove a great advantage. But in this case the roots that favor rapid and thrifty growth of the top are not as favorable for transplanting as those that have been transplanted.

18. The Office of the Roots.-The roots of trees and plants serve the purpose of holding the top erect and to supply water, with its dissolved elements, for sustaining growth of the tree or plant. The deep roots take up the water mainly and the surface-roots largely take up nitrates and other essentials of growth. The soil conditions have much to do with the vigorous growth of roots and the closely related tops. In Nature the extension of roots in the soil favor the admission of the oxygen of the air, and the leaves that accumulate give the needed supply of leafmould and nitrogen required for healthy growth. On the other hand; the clean culture of the orchard and small fruit-plantation without the application of barn-yard manure or other organic material, will soon so change the mechanical condition of the soil that air cannot enter to give life and growth to the protoplasm of newly formed and growing roots. The continued clean culture without the application of vegetable matter will soon take the humus from the soil and starre the roots and whole plantgrowth by lessening the supply of nitric acid and its combination with alkalies, such as nitrate of soda and other useful plant-nutrients.

19. Root-protection.-It may be said that Nature protects tree- and plant-roots by shading in summer and surface-protection in winter. Under clean culture the bare surface is heated abnormally between the rows of cultivated trees to such extent that surfuce-roots and roothairs cannot come near enough to the surface to reach the 
most plentiful supply of food-material, and in winter, at the North, the feeding-roots have no protection. Rootkilling is quite common in the States west of the lakes and not unusual in open winters as far east as the Atlantic States. In Iowa, Wisconsin, and other western States even the forest-trees in great number are root-killed at times, where pasturing or other agencies have removed the undergrowth and leaf and leaf-mold protection. Hence the growing of cover-crops is now being considered across the continent, especially north of the $42 d$ parallel. By "cover-crops" is meant early culture followed by the sowing of a crop of peas, beans, cowpeas, vetch, or other leguminous plant for soil-covering during late summer and autumn and for winter protection. This gives a near approach to forestry conditions and the needed supply of nitrogeu and surface-soil humms. Some of the advantages of this system of culture are summed up by Professor Bailey as follows: "(1) Cover-crops improve the physical condition of the land; (2) prevent hard soils from cementing or puddling; (3) hold the rains and snows until they have time to soak away into the land; (4) dry out the soil in spring, making earlier tillage possible; (5) sometimes serve as a winter protection from frost; (6) catch and hold some of the leaching nitrates, of which the roots of trees are in little need late in the season; $(7)$ add humus to the soil; (8) render plant-foods available; (9) appropriate nitrogen if it is a leguminous crop."

20. Root-division.-The common practice of growing trees and some shrubs and plants from root-cuttings well illustrates some of the varied peculiarities of root-structure. It may be said that all trees and plants which naturally sucker from the surface-roots, or which may be made to sucker by breaking with the plough, or cut with the spade, may be grown from root-cuttings. But this only 
applies to the surface-roots which are capable of developing adventitious buds naturally or when injured. The deeper water-feeding roots do not develop buds soon enough for use in propagation, but if they come to the air by soil-erosion or in other ways they soon change into surface-roots with an ample supply of starch for the development of buds and even upward growth. It is also easy to graft pieces of the surface-roots successfully, but in no case have we known the pieces of the deep roots to unite with a scion, as they are not well stored with starch.

21. Roots as Modified by Variety of Top.-The cultivated orchard fruits vary peculiarly in the manner of rootgrowth when grown on their own roots or grafted. With a given lot of apple-seedlings, if we graft enough for a nursery row of Soulard Crab and for another row of Ben Davis, we find on digging when two years old that the Soulard roots run down and are as difficult to dig as peartrees. But the Ben Davis row we find easy to dig, as it has a great supply of fibrous surface-roots, and the deep extending ones are small but numerous. Indeed, with the same seedlings we find that the roots of all the varieties will maintain their usual characteristics of growth when on own roots.

Every nurseryman is familiar with the fact that when one hundred varieties are root-grafted or budded on the same lot of seedling stocks, each variety when dug will show its characteristic roots. The Red Astrachan roots will be fibrous, branching out near the surface, with few deep roots; while the Duchess, Fameuse, and Hibernal will show few fibrous roots, but several pronged coarse ones, one of which, or more, runs deep into the subsoil. This is also true of the pear and other fruits. If the same pear-seedlings are grafted in part with Bartlett and a part 
with Onondaga scions the two varieties can be separated in digging by inspection of the roots alone.

The influence of the stock upon the top in root-grafted trees is not so apparent; but in top-grafting on varied stocks that are well established the effect on growth and fruitage is often very striking. 


\section{CHAPTER III.}

STEM- AND TOP-GROWTH, APPENDAGES, AND CIRCLLATION.

22. Stem-growth. - After the seed is established by starting rootlets the upward-growing shoot, or plumule, starts growth and soon forms perfect leaves. The root-

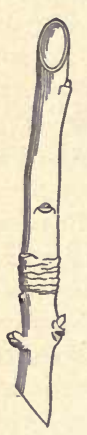

FIG. 4. Union of new

and older wood. (After Goff.) growth, after the first extension of the hypocotyl, is by cell-growth at the tips something like the extension of an icicle except that the ice lengthens by addition from the outside and the root by the cellgrowth within. The stem makes each year's growth by elongation usually at one time in the spring, something like the stories of a building. Each story of growth when young is shown by a slight enlargement, or by the leaf-scars as shown in Fig. 4. At the point between the one- and two-year old wood, called the node, most starch is stored at the base of the buds. Hence in making cuttings of the new wood of the grape and many trees and shrubs the node is included, as roots more readily start from this point. The part between the buds, known as the internode, after completion of its elongation, remains stationary. It increases in diameter, but never in length. 
The stem or branches below the one-year-old growth never increase in length. The space between the nodes on a grape-vine or tree depends on the rapidity of growth. In nursery trees the thriftiness of growth can be determined by the purchaser by observing the length of the internodes. With evergreens, small fruits, and in other cases, it is often a gain to secure more compact growth by pinching the points during the season of active growth. Pinching stops the development of the succeeding node and causes the development and growth of buds farther back on the plant.

23. General Classes of Stems.-Roots are annual, biennial, or perennial, depending on their length of life. In the same way the stem-growth is divided into two main classes or divisions, the herbaceous stems living only one year, and the woody plants living more than one year, and in some cases one hundred years or more. When of small growth woody plants are classed as shrubs. But it often happens that shrubs in one climate are trees in another, and herbaceous plants in one climate become woody-stemmed trees in another. As an instance, we have seen the castor-oil bean grown into a woody-stemmed tree in Cuba thirty or more feet in height and with a stem ten inches in diameter. As to mode of cell-growth, our cultivated plants are divided into two main classes or divisions, the "exogens" and the "endogens," meaning " outside growers" and "inside growers." Corn, asparagus, palms, ferns, and many tropical trees are inside growers or endogens. In this division the new cell-growth is mingled with the older tissue, and growth of the stem is by distension or pressing outward from the inside. This class of stems does not show the bark, wood, and pith of the outside growers. The exogenous division includes all our northern trees. 
24. Heartwood and Sapwood.-In the one-year-old seedling the stem is composed wholly of live or sap wood. But with increased age the older layers or rings of growth are buried by the newer ones. The newer layers with light color on the outside are called sapwood or alburnum. As the tree gets old the inner wood becomes drier, darker, and more solid. This interior darker wood is not alive. If kept from the air by the live wood and perfect bark it may remain sound for a century or more, but if the air is admitted by cutting or accident it will soon make a rotten spot in the stem. Such rotten spots often result in the interior States from sunscald of the stem on the south side. Premature darkening of the wood or "black heart" may also result from feeble growth from any canse after transplanting. But it more frequently comes in the prairie States from severe winter freezing. This winter injury often extends to near the cambium layer, and the tree may survive feebly at first, but soon the injury is covered by new growth. But in such cases the heartwood never assumes its proper color.

25. Proper Height of Fruit-tree Stems.-The advice in the past has been to trim up nursery trees when planted in orchard high enough to work under the branches. At this time in all parts of the Union-even in California and the South-the advice of experienced orchardists is in favor of stems of orchard trees not to exceed three feet in height. During the first year's growth in orchard the exposed stem four or five feet in height is apt to be so injured on the south side that growth is ehecked with consequent check to growth of roots. The increased growth on the north side of the stem, as well as branches and root, soon causes the tree to lean to the north with increased liability to stem injury. Even isolated shadeand park-trees in the prairie States, when the stems are 
sawed off, shov most growth on the north side. 'Trees of thirty species sawed off at Ames, Iowa, showed the heart to be well over to the south side. Even with a stem three feet in height the young orchard-tree is apt to lean to the north if the top is not inclined to the south when transplanted.

26. Stem-protection.-In California, in starting orchards of the citrus and other fruits, stem-protection, while the tree is getting some spread of top, is given by rived shakes or boards on the south side. In the prairie States the most approved plan of shading is with a lath screen attached together with wires as shown in Fig. 5.

But the writer's long experience is not favorable to long-continued stem-protection. When finally discontinued the bark is softened by the prolonged shading and not in proper condition for sudden exposure to wind and sun. The low stem and the inclination of the stem to the south in planting is all that is needed with hardy trees.

27. Proper Mode of Branching.-It is usually the case that nursery trees as received for planting are not in proper shape for the orchard. Some slight changes can be made at time of setting out, but the main pruning should be given after one ycar's growth. If a young tree has too high a top, is forked, or is too high and slim, it can be shaped the second year, taking care to cut so as to leave buds for forming an evenly shaped and balanced top. The peach will bear more pruning when set than other orchard fruits. It is common in peach-growing sections to cut the tops as closely as shown in Fig. 6. In the illustration the stem is too long, but this is changed by allowing buds to start lower down the next season. A main fault with nursery-grown apple-trees is usually that the top is too high and the stem too slim. The needed pruning to start a properly shaped top is shown at Fig. 7. 
The cherry and plum do not stand severe pruning after they attain some size. Hence it is important to start the top properly when transplanting.

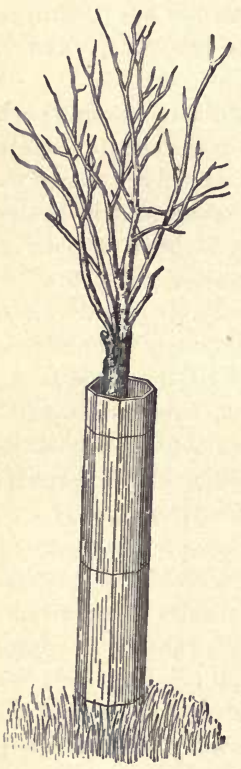

Fig 5. - Apple-tree encased in lath screen. (After Goff.)

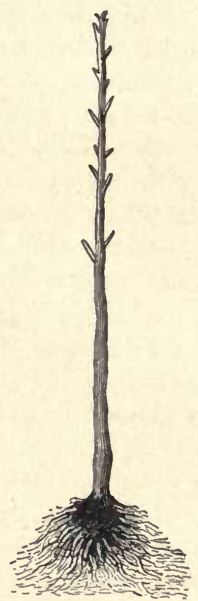

Fig. 6.- Young peach-tree as pruned for setting in the South. (After Bailey.)

28. Leaf- and Fruit-buds.-Buds that appear in the axil of the leaf are in some respects like seeds. Indeed scme buds, such as those of the tiger lily, drop to the earth and germinate like seeds. The grape and some other frnits and shrubs also grow from planted buds with a little wood 
attached, and it may be said that about all buds of woody -plants will grow when inserted uuder the bark of a variety of the same species. The great distinctive difference between the bud and the seed is that the leaf-bud reproduces the individual parent without change, while the seed

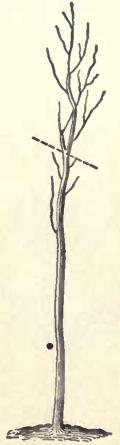

A

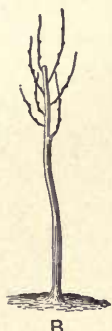

B

Fig. 7.-The dotted line in $A$ shows where the cut is made, and $B$ shows the same tree after starting growth.

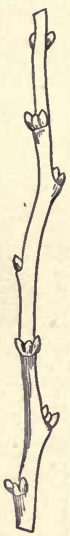

Fig. 8. - Pottawatamie plum. The centre bud in the group of three is a leaf-bud, and the two outer ones are fruit-buds. (After Goff.)

reproduces usually the species but not the variety. The fruit-buds of the peach, apricot and Chicasa, and some Japan plums, grow on each side of the leaf-bud as shown in Fig. 8. In the apple and pear the flower-buds are mostly formed on short spurs as shown in Fig. 9. The European plums also fruit on short spurs as shown in Fig. 10. 
After a little study even the amateur can distinguish in advance the difference between leaf- and flower-buds.

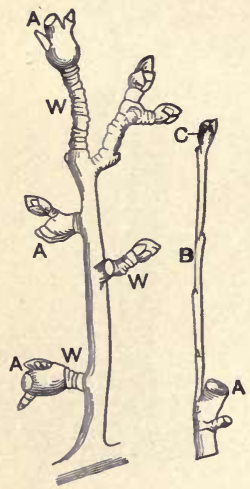

Fig. 9.-Fruit-spurs of the apple. $A, A$, points at which apples were detached the preceding year; $W$, $W$, wrinkles narking points at which fruit and leaves were detached in previous years.

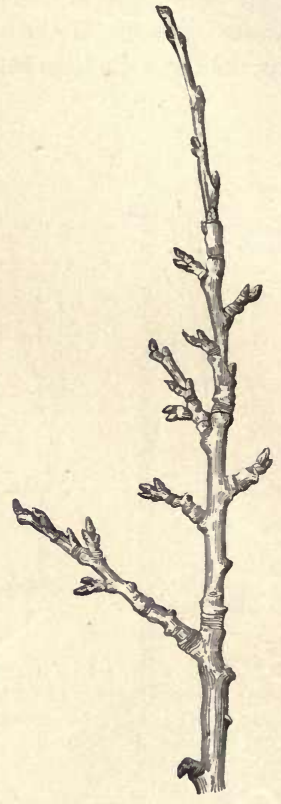

FIG. 10.-Fruit-spurs of European plums. (After Bailey.)

But some seasons the fruit-spurs of the apple, pear, and plum develop as leaf-buds. 
29. Adventitious and Lateral Buds. - Buds usually form only at the nodes of the stem and at the axil of the leaves, but some species develop buds under certain conditions at any point on the stem or root. These that may develop anywhere on stems, branches, and in some cases on the surface-roots, are called adventitious buds. The willows, some of the poplars, and elms are of this class, and among the fruits, plum, cherry, raspberry, and blackberry may develop such buds when cut back or wounded. This peculiarity is utilized by propagators in growing plants by root-cuttings and in some cases from the cuttings of the new or older wood.

Lateral buds of fruit-trees, and other trees and shrubs, form on the young growth and usually do not push into growth the same season. But if the points of growth are pinched or clipped they may be developed. Many of these lateral buds distant from the point of growth remain dormant and become overgrown the succeeding seasons. Such overgrown buds often push into growth after remaining dormant for several years. On the two-year-old wood of some fruit-trees, and of the cut-leaved birch, these dormant lateral buds are still quite prominent and can be utilized for grafting. In the propagation of the cut-leaved birch the two-year-old buds are used, as those on the new shoots are too small.

30. The Leaf--Most plants under culture develop true leaves or what Gray terms "Leaves as foliage." In horticulture the mode of connection of the leaf with the branch and root, and its relative thickness and texture, have more importance than its morphology and action as given by the botanist. Over a large part of the United States the texture and relative thickness and firmness of the leaf are far more important than in moister and cooler climates with less-continued clear air and sunshine. The 
framework of the leaf gives strength and the ribs bring in the ascending fluid and distribute it to every part by means of the veinlets. The lower part of the leaf has its air-chambers and breathing-pores, which vary in different varieties and species less in structure than the upper surface exposed to the sun. The upper surface exposed to the sun is protected by a more compact structure, which varies in different climates. If we examine under a microscope the leaves of the Oleander, Duchess apple, or Concord grape, we will find a greater part of the leaf's thickness to be made up of elongated cells placed endwise close together, so as to expose as little surface as possible that is not protected. In interior climates the structure of the leaves is quite a certain guide as to the ability of any variety to endure the summer sun and periods of dry, hot air.

The time of ripening of the leaf is also important as an indication of hardiness in cold climates. Such hardy fruit-trees as Duchess, Hibernal, and Yellow Transparent apple, for instance, prior to the advent of cold weather will show the leaf ripening, like those of the hard maple and the oak, by change of color and the other changes that precede natural dropping. - This perfect ripening of the leaf before cold weather is important also in the way of storage of the cell-structure with reserve starch and other food which ensures the perfection of the flowers and the holding of the fruit the succeeding season. On the other hand, the fruit-tree that has its leaves blackened by the first severe freeze rarely has the reserve food stored for safe wintering, or for the starting of new growth, flowers, and fruit the next spring.

31. Sap and its Movements.-The movement of water in cell-structure, transpiration in the leaf, and the downward current of assimilated food belongs to botany. But the work of the horticulturist soon shows the need of some 
knowledge relative to sup-movement. This is specially true of the descending movement of assimilated food. As an example, if a label wire is left on the stem of a young

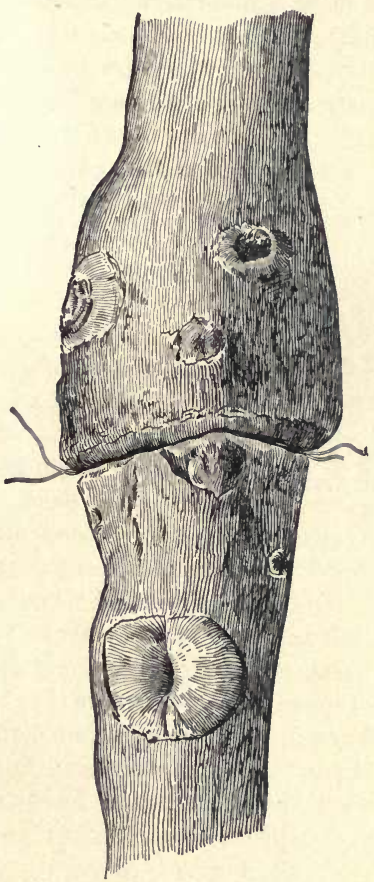

Fir. 11. - Stem of young tree girdled by wire. (After Bailey.) tree we find that it soon is sunk into the bark and wood, and the part above enlarges, while the stem below seems to grow smaller, as shown in Fig. 11. 
Aside from scientific theory this would clearly show that cell-forming material descends near the cambium layer. In the same line, if we remove a ring of bark in June from the stem of an apple-tree we obstruct the downward movement under the bark. Soon we begin to observe a process of healing over the wound by cell-formation on the cut surface above the ringing, and as the season

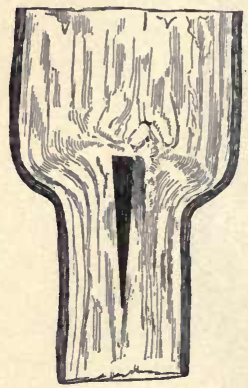
advances we notice that the ripened and mature condition of the wood above has changed leaf-buds into fruit-buds. Again in spring budding, those with most experience make the cross-cut of the T below, and shove the bud upward as the cross-cut above obstructs the movement of the assimilated food from the leaf.

In regard to sap-pressure we have also a good example in working Fig. 12. - An old cleft scions on uncongenial stocks. As graft, showing point of instances, the apricot on myrobalan
union of stock and scion.

stocks makes no real union of cells. The cells of the apricot rest on cells of the myrobalan. The growth seems to be thrifty and unimpeded, but the winds usually topple them over before they reach the bearing-stage. When blown orer it is found that there is no rupture of cells, but a clean separation of the two woods. Where the stock and scion are so nearly allied that the union of cells takes place, breaking down causes rupturing of the wood. Yet the wood of the stock and scion remain distinct. If orange is budded or grafted on lemon the shoot that starts from the stock balf an inch or less below the union will be lemon. But what are known as "graft hybrids" have come from sprouts from the point of union. 
But this is rare, perhaps for the reason that shoots rarely start from the exact point of union of stock and scion.

In Fig. 12 the stock has grown faster than the scion yet the union of the cells of stock and scion can be plainly seen. 


\section{CHAPTER IV.}

\section{THE FLOWERS AND FRUITS.}

IN the higher plants the flower is the expanded fruitbud and is the organ of reproduction. A few plants under culture like the horseradish multiply rapidly by root extension, and nearly all plants cin be propagated in other ways than from seed. Yet the flower in fruit- and nut-growing must precede the fruit.

32. Parts of the Flower.-A knowledge of the parts of the flower is needed by the modern strawberry- and grapegrower. It is also needed in crossing and in working with diœcious plants and trees. It is essential, too, in detecting varieties such as many of the plums that ripen the pistils before the pollen of that flower or tree is ready for their pollination.

The parts of flowers of different species vary materially. But the horticulturist who makes a brief study of the divided cherry-blossom in Fig. 13 will recognize the corresponding parts in the pea and most cultivated plants. The green part at the base marked $(C)$ is the calyx. This is usually green in fruits. But in the tulip and other flowers it is colored.

The prominent organ rising in the centre marked $(P)$ is the pistil with the ovary at the base. The flattened eniargement at the top is the stigma and the connecting slender part is the style. Some of the fruits have more 
than one pistil. 'The corolla marked "cor" is in the cherry and most flowers the colored part. In the cherry it has fire divisions called petals. The stamens are marked $(S)$. The enlarged part at the top is the anther containing the pollen. The slender part connecting the anther with the calyx is called the filament.

The young orchardist or gardener when able to identify

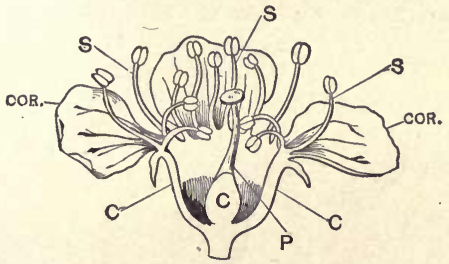

Fig. 13.-Divided cherry flower. (After Goff.)

and name the parts of the flower will usually give more attention to flower-structure and variation in some botanical treatise.

33. Inferior and Superior Flowers.-In horticulture the flowers of the orchard fruits are divided into two classes, known as inferior and superior.

The cherry and peach are superior in formation, as the fruit forms above the calyx, as shown in Fig. 13. In this case the fruit is developed by growth and alteration of the sides of the ovary and other parts of the pistil in the cherry, often leaving the calyx on the stem of the fruit. In the apple and pear the pistil and calyx grow together and the fruit is practically an enlargement of the whole flower, as shown in the divided flower of the apple at Fig. 14.

In this class of fruits the calyx is shown at the eye of the fruit, while in the cherry it shows at the lower end of the stem. 
The superior fruits, such as strawberry, raspberry, peach, plum, apricot, cherry, grape, and fig, are more exposed when in flower to frosts, dry air, and other weather changes, and the ovary of the fruit-bud is more liable to be injured in winter, than the inferior class protected by the base of the calyx.

It is also true, as a rule, that the fruits that form above the calyx are not as well fed as those below it, as the con-

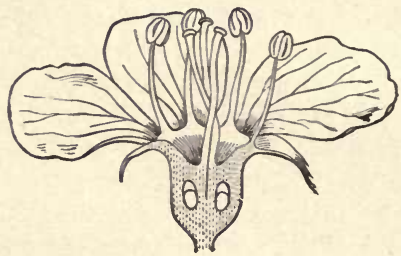

Fig. 14.-Divided flower of the apple.

nection with the leaves is not as direct. But in this varieties differ. As instances, some varieties of the cherries and plums develop perfect leaflets at the flowerclusters by the time the flowers are opening, while other varieties blossom in advance of the leaves. In the prairie States those that develop leaves and flowers together are more certain to bear regular crops.

34. Monœcious and Diœcious Flowers. - When the stamen-bearing and pistil-bearing flowers are on separate trees or plants they are classed as diœcious. Examples of this class are found in the date, box-elder, and buffaloberry. Where the staminate and pistillate flowers are separated, but on the same tree or plant, they are classed as monœcious, such as chestnut, oak, and walnut. Polygamous plants are those having both perfect flowers and those of one sex on the same or on different individuals, such as the red maple, hackberry, and elm. 
35. Perfect and Imperfect Flowers.-Where the stamens and pistils are found in the same flower it is called perfect or hermaphrodite, as in most of our orchard fruits and garden plants. But when only one sex of these essential organs is found in the same flower it is called imperfect. This with the fruits is often caused by cultivation or crossing, as in the strawberry, where some varieties have perfect and others imperfect flowers. Some of the hybrid grapes and other fruits are practically imperfect. Though they show imperfect stamens, they are not capable of selfpollination. In still other cases the stamens and pistils do not develop together. In some pears, cherries, and plums the pistils are erect and show receptive stigmas while the stamens are yet undereloped. In such eases cross pollination of varieties is essential to fruitage.

36. Cross-pollination. - Even when the flowers seem perfect in all respects they often in the cultivated fruits seem incapable of self-pollination. This is not confined to the individual flower or to the flowers of a single tree or a large block of trees. As a rule, large blocks of a single variety of the orchard fruits have not proven productive. As Bailey says: "We chiefly know that the most productive orchards are usually those of many varieties, and that some varieties sometimes refuse to fertilize them. selves." The concensus of opinion at this time of those with most experience and extended observation is that it is best to mingle varieties of the cultivated fruits and nuts in planting for profit or home use.

37. Nutrition of the Fruit-blossom.-Growers of the strawberry now unite mainly in the belief that the flowers of the pistillate varieties are capable of enduring unharmed frosts and adverse weather conditions that destroy the germs of perfect varieties. The reason given is that pollen-bearing is an exhausting process. As the pistillate 
sorts bear no pollen they are able to store more perfectly the cell-structure with the needed nutriment to resist frost and exposure.

This storing up of plant-food is important in orchard fruit-culture. The variety of the orchard fruits and small fruits that ripens its wood perfectly in autumn will best protect its fruit-buds in winter and its flowers in spring, and will best endure frosts and trying weather conditions. In top-working and ringing this same principle applies. These operations favor the more perfect ripening of all parts of the top, and experience has demonstrated that given varieties top-worked or ringed will bear fruit when the blossoms of root-grafted trees are ruined by frost. The altitude, air-drainage, and porosity of soil and subsoil also have much to do with the ripening of all parts of the tree, including the flowers.

38. Long Blossoming Period.-Varieties of our fruits differ materially in their blossoming habits. Some varieties expand all their flowers in a brief period. Others seem to have two sets of flowers. As an extreme example, some of the east European cherries when white with blossoms show many buds still unopened. If the first bloom is destroyed by frost the later ones are numerous enough for a full crop. If both mature fruit we have an early and late picking. Close observation will show that many of our fruits that do not ripen the crop evenly have a long period of blossoming.

39. Possible Flower Production.-To the true lover of horticulture there is a fascination in the work of systematic hand-pollination of a flower. As Lindley said many years ago: "What increases the charm of the game is that although the end of it may be doubtful, yet a good player can judge of the issue with tolerable confidence, and that 
skill and judgment have in this case all their customary value."

$\mathrm{Up}$ to the present time the great advance in this line has been with the roses and border flowers. The production of the orchard fruits by crossing is a slower process, but the outcome is quite as certain. As an example, the writer a few years ago crossed some flowers of the De Soto plum with pollen of a Japanese variety. Through an accident only four plants were saved. All of them bear fruit better in quality than any of our natives and one of them is as large as the Lombard and superior to it in quality.

40. The Fruit and its Maturation.-The botanist defines fruit as "The ripened pericarp and attachments." This would hardly answer for a description of Grimes Golden apple, Seckel pear, Ponderosa tomato, or other products of the gardener's art of developing delicious flesh at the expense of the seeds. Some of the conditions most favorable for perfect fruit development are of far more value to the grower than a discussion of the principles connected with fruit- and seed-growth.

Some of the essentials connected with the development of flowers and the starting and holding of the fruit have been outlined above. In practice it is found that some of the conditions favorable to perfect flowers are also favorable for the perfect maturation of the fruit.

41. Air-drainage.-In all parts of the Union most of the orchard fruits bear more regularly, and mature their fruits most perfectly, on land higher than the adjacent sections at least in one direction. In California the citrus fruits, and most others, thrive best on the mesa tracts with quite abrupt air-drainage to lower levels. In Georgia the profitable peach-orchards are on the high ridges and even mountains. In the prairie States it is the same with 
the commercial orchards of southwest Iowa, Missouri, and indeed westward to Arizona. On the prairies an elevition of only twenty feet above the general level is a signal advantage in orcharding. It not only gives comparative exemption from frosts in spring, but it usually gives better soil conditions as to porosity and drainage, and even comparative exemption from blight and fungus troubles.

With the small fruits lower positions are sometimes best on account of increased moisture. But in many cases the greatest success attained on the relatively low land comes from the fact that still lower levels are adjacent giving fair air-drainage.

42. Fruit Soils.-Perhaps there is not a settled area in the United States where certain varieties and species of the fruits may not be grown with reasonable care. Even in the arid States the conditions of soils are usually favorable where water for irrigation is obtainable. But commercial fruit-growing sooner or later springs up on soils not too compaet, and with jointed clay or other kinds of porous subsoil below. In California the orange reaches its highest perfection on the slopes where the mountain wash has given porosity to the subsoil. In the arid States, Arkansas, Missouri, and the States bordering on the Missouri the present commercial fruit centres are on land that will permit the descent of water in a wet time, and its rise by capillary movement in a dry time, if needed culture is given. It is the same with the fruit centres of Michigan, New York, and the selection of soil for the great peach-orchards in Georgia. At the great expositions of the past fifteen years the finest specimens of given varieties of fruits have come from the orchards with most favored soils and subsoils, combined with culture and cover-crops (19).

43. Fruits as Modified by Climate-Heat and light 
during the period of ripening affect the ripening and perfect flavor of fruits. When American fruits are shown in Europe at expositions their bright coloring and flavor are commented on by all visitors. Given varieties color more perfectly and are richer in flavor than when grown in the moister and cooler air of west Europe. In the same way, apples, pears, grapes, and other fruits show higher color, and are better in flavor grown west of the lakes than in the moister and cooler summer air of Michigan or New England. Even the size and shape of apples are modified and changed by either the air or soil of some of the Rocky Mountain districts. The largest specimens of given varieties have been shown from these regions at our expositions, and in some cases the specimens were longer than those grown farther east, and enlarged in all their parts. 


\section{CHAPTER V.}

\section{MODES AND PRINCIPLES OF PROPAGATION.}

44. Some Preliminary Considerations.-As stated in (1) and (2), plants or trees grown from seed of the cultivated varieties are too variable for practical uses. The perpetnation of given varieties has led to the invention of many methods of propagation. The methods nearest to Nature, such as growing from cuttings of root or top, from sprouts, or by layering, have not been questioned by practical and experienced growers.

Budding and grafting are old methods in Europe, but the process was confined until recent years to changing the tops of hardy stocks by inserting buds or scions if desirable varieties. Root-grafting and commercial stockbudding are modern methods that have led to much discussion among American planters of trees, and in Europe the adverse decisions have been still more pronounced.

45. Root-grafting in Europe-OVer a large part of Europe fruit-trees are found on their own roots. Sprouts and suckers of cherry, plum, prune, apple, pear, and other fruits are used for orchard-planting. In some noted centres of commercial prune- and cherry-growing the use of grafted trees seems quite unknown except in the way of changing the tops of hardy native stocks. In 1882 the writer gave the summer to a study of pructical orcharding 
over a large portion of west and east Europe. After the extended ohservations of four months the decision was reached that the sections where trees on their own roots were used in connection with top-working on hardy indigenous stocks, could show longer-lived, thriftier, and more fruitful orchards of given varieties than the sections near cities where modern budded and root grafted trees were used.

46. Some European Criticisms.-Since the writer's visit to Europe many adverse. opinions have been given by eminent horticulturists of Europe on modern root-grafting and stock-budding. As instances, F. W. Burbidge, a practical propagator and fruit-grower and the author of "The Propagation and Improvement of Cultivated Fruits" and other standard works on European horticulture, said, as early as 1888, editorially: "We doubt if there is a greater nuisance in the whole practice of gardening than the art of grafting. It is clever, it is very interesting, but it will be no great loss if it is abolished altogether. It is for the convenience of nurserymen that it is done in nine cases out of ten, and in nearly all cases it is not only needless but harmful. If we made the nurserymen give us things on their own roots they would find some quicker means of doing so."

In a later number of The Field he said in reply to criticism: "If in certain cases grafting as a convenience has to be resorted to, then let it be root-grafting, a system that eventually affords the scion a chance of rooting on its own account in a natural way."

The editor of the London Garden, in his comments on the subject, said: "Wo should not plant any grafted tree or shrub, so far as ornamental trees or shrubs are concerned. There may be reason for the universal grafting of fruit-trees, but we doubt it." As usual, in this noted 
discussion over all Europe the extremes were urged on both sides.

47. Commercial Stocks. - The real truth is that budding and grafting may give us as healthy and long-lived fruittrees as can be grown on own roots. To illustrate: If we bud or graft a favorite variety of the plum on a thrifty seedling of our native species it will prove equal or superior as a fruit-bearing tree to one on its own roots. The decision rests on the securing of stocks hardy and healthy in a given section of our own country or Europe. The pro and con discussion comes from the use of the same commercial stock over a vast region running through many degrees of latitude and longitude. As an instance, the Prunus Mahaleb or St. Lucie wild cherry grows freely on the mountains over west Europe. Its pits are gathered in vast quantity and used over Europe and America for stockgrowing. As a stock for low rich soils it has been a failure in Europe and America, but on high dry land it is a grand success wherever it does not root-kill in severe inland climates, and when its use is confined to the uncoloredjuiced cherries. The colored-juiced varieties make an imperfect union with its wood in Europe and America.

Investigation will show that grafting and budding as practised universally in this country is a process near to Nature and will give healthy and long-lived trees, but it is necessary to get nearer to Nature in the selection of seeds for stock-growing. At this time the use of the red wild cherry (Prunus Pennsylvanica) stocks in cherry propagation is being urged in the Northwest and in parts of Canada, and several are growing the stocks. In South Dakota, Professor Hansen and others are urging the use of Siberian crab stocks in apple propagation. The use of native plum stocks is almost general west of the Great Lakes. As the years go on the stock question will be ad- 
justed locally and there will be less demand for European seeds. That the subject of hardier stocks is important is shown by the fact that in the winter of 1898-99 tens of thousands of bearing fruit-trees were root-killed as far south as Missouri, with no trace of injury in the tops. As the years go on the commercial prejudice against the propagation of trees on their own roots will be a thing of the past.

Our grapes, small fruits, and nearly all our ornamental trees and shrubs are now on their own roots, and Nature has made it possible to grow all the orchard fruits of the north temperate zone from euttings of the surface roots.

48. Propagation by Seeds.-As what might be called the foundation of horticulture, the leading facts were given relative to the handling, care of, and planting of seeds in the first chapter. In this connection it is only necessary to state that seedling production is only practised in horticulture and forestry where exact reproduction is not required, such as garden seeds, flowers, nursery fruit stocks, forest- and shade-trees, and last but not least, in starting new varieties from crossed seeds or seeds from selected plants. But in this ease each individual plant found worthy of attention must be propagated later by division of the root or top.

49. Propagation by Suckers.-About all the orchard fruits of the temperate zone throw up suckers from the surface-roots, especially if wounded by the plow or spade. Popularly they are called sprouts, but these more properly are the shoots that come from the crown and not from the surface-roots.

Over Europe these suckers are taken up, sorted as to size, and the grades planted separately in nursery. After standing in nursery from one to three years, depending on size, and shaped by pruning, they are ready for orchard 
planting or planting by the roadside. Nearly or quite all of the roadside cherry-, plum-, and apple-trees of Germany and Russia are grown from suckers. A main difficulty in the United States is that our fruit-trees are not on their own roots as a rule, yet a larger proportion of our crowngrafted stone fruits have rooted from the scion than is usually suspected, where planted moderately deep on dry soil. This is specially true of the cherry crown-grafted on mazzard and set down to the top bud of the scion in nursery and still deeper in orchard. A comparison of the bud and leaf of the sprouts and branches of the tree will soon tell the story. The plum, also root-grafted and set deep in nursery and deeper in orchard, is soon on own roots.

The ornamental trees and shrubs that sprout from the crown, like the juneberry and flowering almond, will also form roots in nursery if taken off with care close to the crown of the parent. They will also take root if mounded for one year before taking up.

50. Propagation by Root-cuttings. - All fruits, ornamental trees, and shrubs that will sprout from the surfaceroots naturally or by wounding with plow or spade will grow from root-cuttings. Indeed, some trees not known to sucker, such as the hackberry, have been found to grow readily from properly kopt root-cuttings.

The cuttings are made four inches long late in autumn and packed away in boxes, mingled with sand, which are kept over winter in the cellar. In planting in early spring the advice is usually given to cut the roots shorter and plant horizontally in shallow trenches; but this applies to root-cuttings in cold frames, or with bottom heat. In planting in the open air long experience has shown the best results and most even stand from planting in a shallow trench with one sloping side, as shown in Fig. 15. 
In filling, the earth is pounded in tightly to firm the cuttings, covering about one inch over the upper end of the root-cutting. Flanted in this way the upper buds will push upward and the lower ones will form roots sooner on account of moisture four inches below the surface.

Root-cuttings will usually grow if planted wrong end up, but

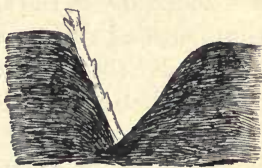

FIG. 15. - Root or other cuttings planted in trench. growth is retarded and not as certain as when in natural position. With a lit'le practice the one who places the cuttings can tell at a glance the top end by the fibres (17).

In the South, root-cuttings are usually planted as soon as made, but at the North it is best to start callusing and bud-development in the cellar. An outdoor dirt-covered cave is best for storage, as the temperature and moisture are better under control.

Many of the roses not easy to grow from ripe or green wood cuttings, such as Rosa rugosa and its hybrids, can be grown from root-cuttings.

Where tree-seeds are not easily obtainable, as with the hackberry, trees can usually be grown from root-cuttings.

The rose, lilac, juneberry, flowering almond, barberry, and other shrubs do not sucker, but throw out subterranean sprouts from the crown. Cuttings can be made from the subterranean sprouts, which can be treated the same as those made from surface-roots.

51. Rooting Sprouts by Mounding.-If the sprouts or side shoots of cultivated trees or shrubs are cut back quite low in early spring an additional number of sueculent sprouts will spring up. If these are earefully mounded the excitable young growth will soon root and can be 
detached the next spring. The Paradise apple stocks are usually propagated in this way, as shown in Fig. 16. Roses and many of the shrubs can be cut back in this way and propagated rapidly by mounding. But the mounding of the tender shoots must be gradual and with care, with fine earth that will not injure the tender growth. At the North the rooted plants must be separated in the fall and wintered in pit or cellar or by quite deep burying outside

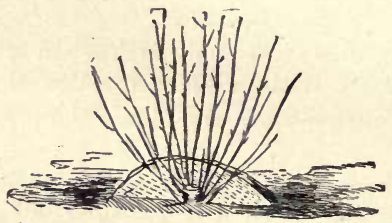

FIG. 16.-Mounding of paradise apple and shrubs to secure rooting of the shoots.

on dry ground. Even rooted shoots of plants as hardy as the gooseberry, mock orange, and bush honeysuckle are apt $f_{0}$ be injured or killed the first winter after mounding if not cared for as indicated. If mounded shoots do not form roots the first summer they will not fail to make roots the second or third year. But a large number of cultivated plants root the first season.

52. Summer Layering.-This is a method of division effected by bending down and covering shoots at about the completion of spring growth. Usually summer layering is confined to the shoots of the same season's growth. The old plan was to slit the shoot at the point of burial in the soil, as shown in Fig. $1 \%$

But a better method with young shoots liable to break is to twist the shoot at the point of burial. Severe twist- 
ing does not break the shoot and the cell injury starts the process of healing sooner than by slitting.

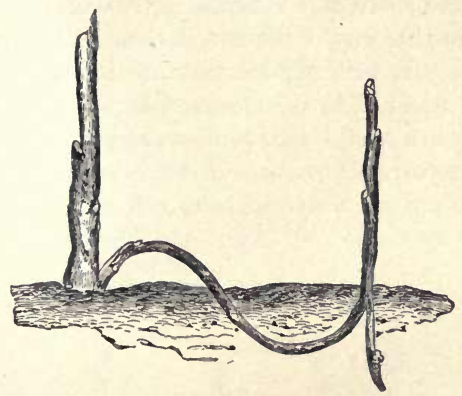

Fig. 17.-Layered branch split to favor root formation. (After Goff.)

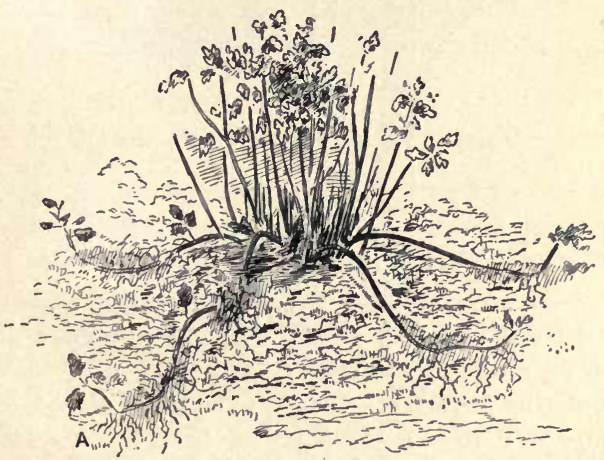

Fig. 18.-Summer layering of shrubs. (After Bailey.)

Summer layered shoots of a shrub are shown in Fig. 18. The figure does not show the pegging down. If not 
fastened down before covering with earth the spring of the branch and wind are apt to draw it gradually from its position before rooting. Very many trees and shruls can be layered in this way, but some of them, such as cherry, plum, and birch, will require two or three years. The layer being attached to the mother plant is able to retain life and growth while the covered and injured part is getting ready to emit roots. In the South the rose and other shrubs are often layered in the air in pots, as shown at Fig. 19.

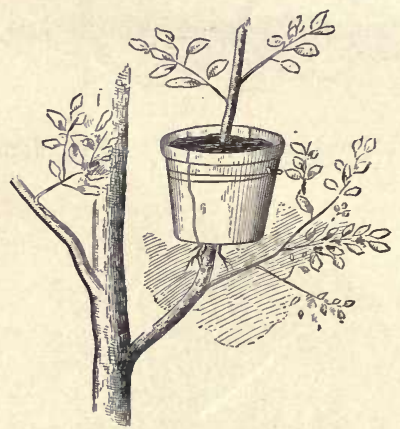

FIG. 19.-Layering in divided pots. (After Bailey.)

If young, excitable wood is used the twisted shoot will soon fill the pot with roots. The divided flower-pots shown are now manufactured.

53. Spring Layering.-In spring layering a whole cane of grape or limb of a shrub is laid down in a trench as shown in Fig. 20. After pegging down in the trench the limb or vine is left exposed to the air until the buds at the nodes start an upward growth of three or four inches. The shoots are then banked up gently and as growth 
advances the whole trench is filled. The rooting is from the base of the new shoots as noted in mounding (51). In the fall after the leaves drop, the layered shoots are eut apart half way between the sets of growth. In spring layering of single shoots and twigs the operation is usually delayed until the bark will peel. A ring of bark is then taken off at the point to be covered in pots or in the earth. This favors more rapid rooting, as the process of healing begins at once. But as a rule such plants as the grape, climbing honeysuckle, tecoma, and passiflora put down in

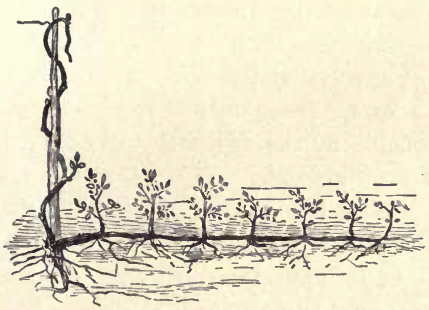

FI*. 20.-Spring layering of the grape.

spring will root without ringing or twisting. In spring layering of branches of the rose, spiræa Van Houtteii, and other shrubs, where the twigs were twisted before laying down, it is found in autumn that many have not rooted, but have formed a large callis. If such shoots are made into callused cuttings and buried over winter they will grow readily as cuttings the next spring. This is also true of twisted summer layers that fail to root.

In summer layering of the climbing roses and shrubs the ones that callus and fail to emit roots will also grow as cuttings if buried and planted the next spring. 


\section{CHAPTER VI.}

PROPAGATION BY INARCHING AND FROM WOODY AND IMMATURE CUTTINGS.

54. Propagating by Inarching.-This is a process of layering by uniting a limb or branch of one tree or shrub with that of another of the same species or a nearly allied one. This quite frequently happens in the primitive forests probably by the twisting together of the tops of young trees by animals. Fig. 21 shows an example of this kind, where two oaks are thus mited, forming one tree. In Europe it is common to unite the tops of two elms standing on opposite sides of a gateway, forming a common top over the centre of the opening. Inarehing is often useful on the home place. As instances we may have a very hardy wild rose or a strong plant of Rosa rugosa standing beside a desirable garden rose. If a branch of the tender variety is brought in contact with one of the rugosa, with the bark of each shaved off where they meet, the two will unite if the point of union is waxed or covered with waxed paper to exclude air. But indoors the two . cut surfaces will unite without waxing by merely binding them together with raffia or woolen yarn. After uniting, the top of the stock is cnt away and the desired top saved, as shown in Fig. 22, where two potted plants are inarched.

In amateur practice it is a good way to get our best varieties of the grape on wild stocks. In German school- 
yards the writer found low-branched cherry-trees with many wild-cherry stocks planted beneath. In June when new wood was rapidly forming the children were taught to inarch twigs of the cherry on the wild stocks beneath, where they stood until the next spring, when each student claimed his own tree to plant on the home grounds. It

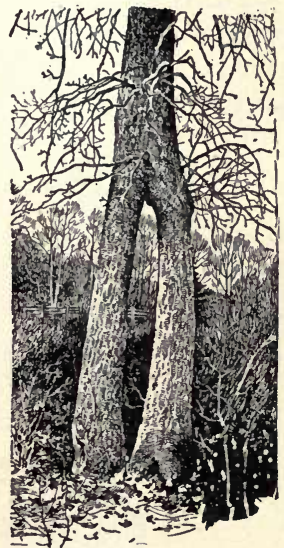

FIG. 21.-Natural inarching. (After Bailey.)

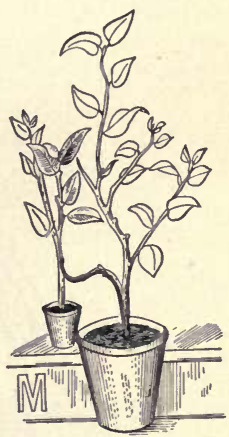

Fig. 22.-Inarching two potted plants.

is the most certain way yet found by the writer to graft young stocks of the shellbark hickory, chestnut, oak, and English walnut, where the seedlings are in pots. In France and other parts of west Europe the writer has observed some queer effects produced by inarching. In gardens every branch of fruit-trees was inarched on one of neighboring trees in such a way as to form fanciful designs and arbors beneath. Indeed, whole groups of trees had a common circulation of top and a common support from 
the roots. In Europe inarehing is also much used by amatenrs in filling in naked spaces, in peach-and neetarinetrees. Even on vines mammoth bunehes of grapes are formed by inarching bunches together, often of different colors of fruit. This, under glass, is done as soon as the berries are set.

55. Long Scion Inarching.-Like inarehing, this will only be practised on the home grounds. Fig. 23 gives

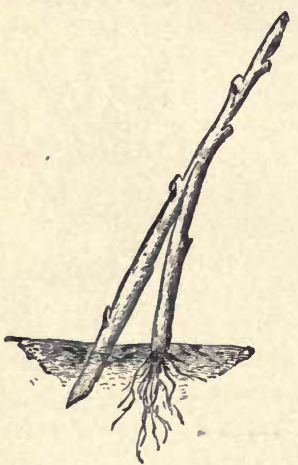

FTa. 23.-Long scion inarching.

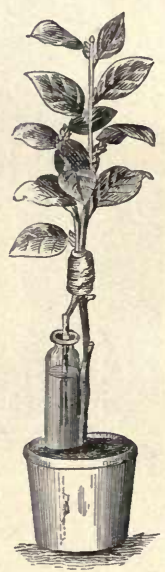

Fig. 24.-Long scion with lower end in water.

the method of doing the work. A scion eighteen to twenty inches long is used with one end stuck info the soil and near the top it is grafted on the stoek by inserting a wedge at the top of the stock into an upward cut two thirds of the way through the scivn. The long scion. with lower end in the soil, holds moisture while the nnion 
takes place. The writer has grafted the grape in this way when the scion rooted below while the union was taking place above. We have also found this a certain method of grafting the peach, cherry, and plum, if the work is done very early before sap-movement commences, using a dormant scion cut the winter previous to using.

With potted plants this method is adopted with some plants by placing the lower end of the long scion in water. In this case, as stock and scion are in leaf the union is made as in Fig. 24 and the top of the stock is not cut back until the union is complete. This plan is also adopted sometimes in the open air in top-grafting, in the dormant period.

56. Propagating by Ripe Wood-cuttings.-The successful growing of cuttings of woody trees and shrubs in the open ground is much varied by climatic conditions. In the moister air and warmer soil of the Southern States and in south Europe certain varieties of the apple, pear, plum, and cherry are readily propagated from cuttings of the one-year-old wood. In the island of Chiloe, near the west coast of Patagonia, orchards are started, we are told by Humboldt, by planting large bearing-limbs. The moist air and soil retain the life and moisture of the limbs until roots are developed for their support. In the drier air of the Northern States, especially west of the Great Lakes, the number of varieties and species that can be propagated in the open soil and air is much lessened.

57. When and How to Prepare Cuttings.-As the leaves of varieties and species reach in succession the ripening stage they are stripped and the cuttings made if wanted for immediate planting. But the leaves should be so mature that they are ready to part readily in stripping. If wanted for wintering in the cellar or solar hot-bed, or for spring planting, it is better to prepare the cuttings 
when fully ripened and the leaves have fallen. The recommendation to cut and plant as early as possible in the fall is given, as it has been found that many species will emit roots before winter sets in, as shown in Fig. 25 .

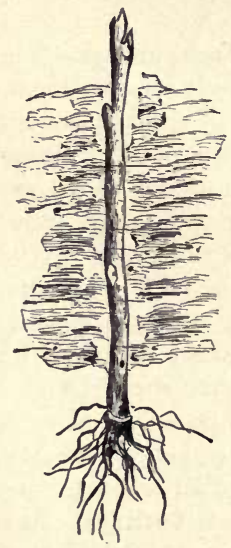

Fic. 25.-Cutting rooted in the fall.

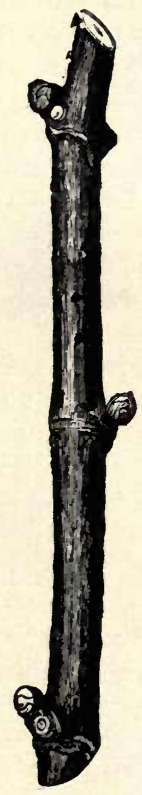

FiG. 26.-Properly cut grape-cutting.

It is usual to make all ripe wood-cuttings about eight inches long, cutting quite close to a bud at the lower end and half an inch or more from a bud at the top. Cuttings of the willow and some other species will emit roots at 
almost any point on the bark, but the rule is that most of our cultivated woody plants root with greatest certainty at the base of a bud. This is specially true of pithy plants like the elder, which are filled at the nodes with starchy cells. In preparing cuttings of the grape and other species with varying space between the nodes the length of cuttings cannot well be uniform. The usual grape-cutting has three eyes, as shown in Fig. 26. But the internodes are often longer, when only two buds are used.

58. Fall-planting of Cuttings.-The cuttings are kept moist until planted. In fall-planting of cuttings of hardy trees and shrubs it is found best to plant on a shouldered trench, as shown at Fig. 15. In filling in, when the earth is not too moist, the most successful propagators use a pounder, pressing the dirt tightly on the cuttings at the base, filling above with mellow earth.

Prior to severe freezing the line of the nursery rows is covered with coarse manure, half-rotted straw, or other litter not liable to blow off, to prevent heaving out by frost as spring approaches at the North, and to prevent baking and too rapid evaporation at the South. In early spring the mulching is removed, and as the buds begin to start the surface should be raked with a pronged hoe to prevent hardening and baking.

59. Some Reasons for Fall-planting.-With many of our shrubs and trees considerable time is essential to prepare cuttings for rooting. When planted in the fall the process of callusing and final rooting goes on at a lower temperature than leaves or bud-starting require. Some species, such as the currant and willow, will grow readily from cuttings planted in the spring, but even these will make far more growth the next season if planted in the fall. Long experience has shown that best results would follow if all woody cuttings could be planted in the fall. But in 
practice it is found that in a few cases the buried buds decay when set deep in fall-planting. The treatment of this class is given in succeeding section.

60. Spring-planted Cuttings. - If grape-cuttings are planted in the fall, at time of pruning of the vines, a good stand at the North is rarely secured on account of rotting of the buds in contact with the cold earth. In the South, and in all parts where very early spring-planting is possible, the cuttings are planted in the usual way. In such cases roots usually start in time to support the growth that starts from the top bud in May. But in such cases commercial growers usually mulch the cutting rows with spent tanbark, sawdust, or leaf-mould, to hold back the top buds while roots are forming. In the prairie States north of the $42 \mathrm{~d}$ parallel it is usual with vine-growers to callus the cuttings in what is known as the "solar hot-bed" prior to planting. This consists in bundling the euttings by tying with willow bands, taking care to make the lower ends even. It has been found best not to make large bundles. Fifty cuttings in one bundle will callus better than in larger packages. As made they are placed bottom end up in a pit about fourteen inches deep and as wide and long as needed. The bundles are set perpendicular, with earth packed tightly between. In case the bundles vary in length dirt is crowded under the short ones to give an even surface on top of the upturned cuttings. When all are in, cover with five inches of fine mellow earth and over all cover a foot or more of forest leaves or manure, with some sticks and pieces of boards to hold the covering in place. Quite early in the spring the leaves are taken off and the earth-covering raked. If dry weather follows water is needed with after-raking, the purpose being to faror the heating of the soil over the cuttings, giving farorable con- 
ditions for callusing and even starting roots while the tops of the cuttings in the colder soil below are dormant.

When the upturned euttings begin to show roots starting quite freely the time has come for planting, which is often as late as early June. As taken out, place the cuttings in water, and in planting take them from a pail of water in placing, and after placing cover at once, firming the soil at the base (50). In planting, the rootlets that have started are usually broken off, but the conditions are favorable for speedy emission of roots before the top starts.

Several other species not easy to root from cuttings are propagated in this way, such as Populus Bolleana, hackberry, mulberry, and plum. Instead of planting in trench some growers stick the cuttings in well-prepared ground.

61. Cuttings Kept in the Cellar.-A few valuable shrubs will not bear propagation in the ordinary ways. One of these is the Amur Tamarix. The successful practice has been to make the cuttings late in fall, tie in bundles with the bases evened, and set the bundles on a bed of sphagnum moss in the cellar. It is not difficult to keep the moss wet. During the winter the process of eallusing and rooting goes on and in early spring they are ready to set in nursery. In a warm and quite moist cellar the writer has prepared cuttings of Delaware grape, Rosa rugosa, and some cherries and plums, for nursery planting in this way. A dirt-covered cave or cellar not heated by a drying heating-plant are needed for this interesting system of propagation.

62. Immature-growth Cuttings. - In propagating by cuttings of growing shoots cut from growing branches of herbaceous plants, or the tip growth of woody plants, we are dealing with live, growing vegetation suddenly deprived of the moisture, circulation, and nutriment of the parent plant. The ripe wood-cutting has its supply 
of starch and plant-food in its cell-structure to aid in starting root and top. If months are required to furnish the needed conditions for growth its contact with moist earth retains its life. But the cutting made from the young and growing parts of the plant must have warm, moist, and more or less confined air where the rays of the sun and rate of evaporation can be controlled.

63. Controlling Heat and Moisture - Various plans have been devised to secure the needed conditions as to light, moisture, heat, and transpiration. In all of them nearly,

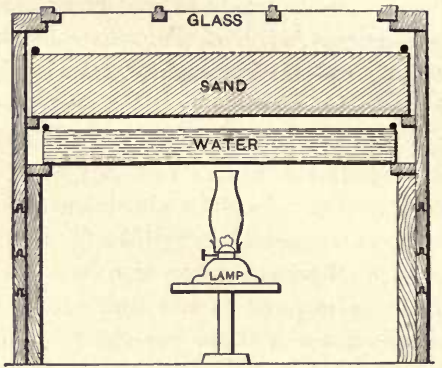

Frg. 27.-Simple propagating bed.

glass is the covering used, as it is cheap and best combines the essentials needed. Its fault is that it not only admits light and lessens transpiration and evaporation, but it admits the sun's rays that do not return. In other words, the radiant heat of the sun passes through glass and accumulates to such extent that a hot-bed or other structure of limited space under glass may burn and scorch every plant in two hours if the ventilation is neglected. Yet glass is the best covering known, and with a little timely care it answers the purpose well.

The bottom heat is given in various ways. One of the 
simplest forms of combining the confined air and bottom heat is shown at Fig. 2\%. The box is about iwo feet deep with glass over the top. The water over the lamp is in a sheet-iron tray supported as shown. The sand shown is held up by placing in a shallow wooden box. With a little practice and experience cuttings can be rooted in a small way in this frame with about as much certainty as in a greenhouse cutting-bench.

The principle is the same in the private house, conservatory or the great commercial greenhouse. But in these cases the heating of the houses in winter and the needed bottom heat of the cutting-bench are given by steam- or hot-water pipes.

64. Why Cuttings Need Bottom Heat.-In section (60) the reasons why grape and other cuttings are put in solar hot-bed in inverted position are given. If most heat is given at the base of the cutting it favors the emissson of roots, while the top buds are relatively dormant. In the same way if green cuttings are inserted in sand warmer than the air above, it favors the more rapid callusing and rooting of the base, while the parts in the air show less active cell formation. Even rooted plants in the open air during the growing segason are in most if not all countries favored with a warmer soil than the average temperature of the air. But as stated in (19), exposed soil in interior climates often gets much hotter than the air. In this case the branches and leaves will give off moisture faster than the roots can supply it. In the same way the soil of the cutting-bench may get too hot under artificial conditions as well as too cold.

65. The Hot-bed.-The use of the hot-bed for growing seeds of subtropical and other seeds is noted in prior section (12). At the home place, and in commercial gardens, the hot-bed is used mainly for growing tomato, egg-plant, pepper, flowers, and many other plants. Even where large 
areas are occupied by what are known as forcing pits, as shown by end section in Fig. 28, the hot-beds and coldframes are not dispensed with. But it is so cheap and simple in construction that it is found at the homes of amateurs across the continent and its use is on the increase. After the first crop, when the bottom heat has lessened, it

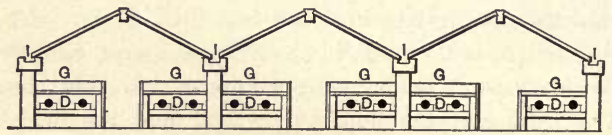

FIG. 28.-End view of forcing pits heated by hot-water pipes.

is useful for rooting cuttings of immature growth or those of dormant woody growth.

In making and filling the pit a few essentials must be kept in mind: (a) At the North the pit should be dug in the fall and filled with coarse manure to prevent freezing. In digging make it large enough for the frame to set on the filling so as to settle as the manure goes down. The commercial hot-bed sash are three feet wide and six feet long. For a bed with three sash the pit should be excavated nine feet and six inches long, six feet six inches wide, and thirty inches deep, for ordinary home use.

(b) When the time arrives for starting the heat the filling is taken out and about twenty inches of horse manure are put in. This should be well fined and placed in layers evenly so as to secure even settling when the frame is put on. If the filling is quite dry it is best to wet the layers as placed to give the needed moisture.

If forest leaves are obtainable it is best to mix them with the manure in filling. (c) The frame is made, as shown in Fig. 29, with the back six to eight inches higher than the front, to favor the reception of the sun's rays and to carry 
off rain. When the frame is set on the filling, and the first intense heat has subsided, fill in with six to seven inches of mellow, rich, well-fined earth. (d) Ventilation when the sun shines by moving sash is essential and watering must not be neglected. Fig. 29 shows the frame covered with lath for shading.

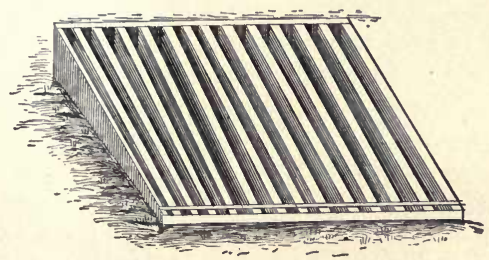

Fig. 29.-Hot-bed frame, covered with lath frame later in the season.

66. Preparing and Setting Green Cuttings.-Cuttings of most herbaceous house and greenhouse plants are made from the soft growing tips that will snap off when bent at the point where roots are to form. While a bud at the base is no disadvantage, and may be a gain, no attention is paid to this in practice. If too much leafage, a part is cut away. They are stuck deep enough in the bench sand to hold them erect.

Cuttings are also rooted of such shrubs as weigelia, roses, hardy hydrangea, and lilacs. With such plants the cutting is made with a bud at the base and a large part of the leafage is cut away. It is found best also to use the small side shoots that can be cut off so as to leave a little ring of half-ripened wood at the base. In proparing these slips a very sharp knife should be used and they should be prepared in shady quarters and stuck about as rapirlly as prepared. Fig. 30 shows a rose and hydrangea cutting 
with the leaves cut off or divided. If quite pure freshwater stream sand is used with needed bottom drainage, there is little danger of using too much water, as such sand will only retain a certain amount. As soon as roots have pushed an inch into the sand the cuttings should be potted in good soil.
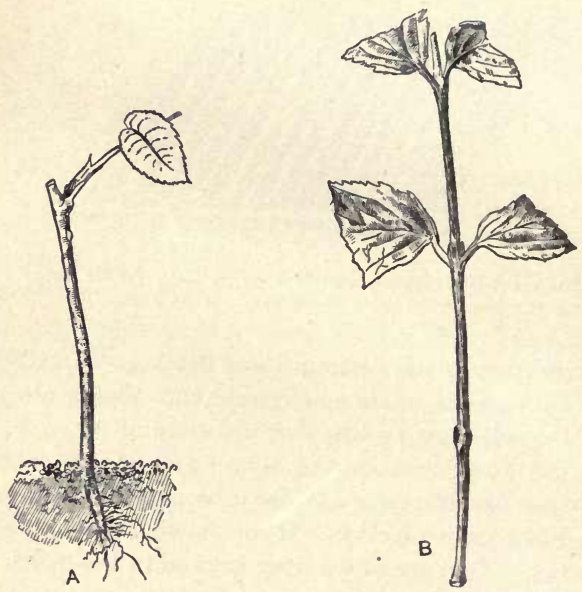

FIG. 30.-A, rose cutting; $B$, hardy hydrangea cutting.

67. Need of Buds in Plant Division.-The beginner in this interesting work will find some curious confirmation of the theory that leaf buds are essential to root and top growth. As an example, a leaf of some plants will root in the cutting-bench from the stem cut above the axillary bud. After rooting the leaf will increase in size and thickness and continue to live for years. A leaf of wax plant (Hoya carnosa) will throw out roots and at the end 
of six years it will be only a leaf enlarged and much thickened. It makes no further growth, as there is no bud from which a plant can extend upward. But if the leaf is cut so as to include the bud in the axil we soon have roots and plant growth.

Again, if we make a dahlia cutting without a bud at the base we can develop a flowering plant with supporting roots, but we find no tubers below. In this case we have buds for upward growth, but no bud below for tuber formation. Still again, if we root the stem of a gloxinia leaf it will continue to grow as a leaf like the Hoya carnosa, but it will develop at the lower end of the petiole a small tuber, which can be dried off, planted, and it will produce a perfect plant.

On the same principle, if the crown buds of the tubers of dahlia, peony, or rhubarb are broken or cut off we will have root enlargement and growth below the ground, but they will perish after a longer or shorter period, as they cannot develop buds for upward growth. On the other hand, we have tubers like the potato that have eyes or buds for growth at many points, and we have leaves, like the rex begonia, that when pegged down on moist sand of the cutting-bench will develop buds and make root and top growth at every point where wounded, as shown in Fig. 31.

68. Division of Perennials, Tubers, and Rootstalks.About all the perennial flowers and garden plants, such as perennial phlox, hemerocallis, funkia, fraxinella, and pie-plant, may be divided by separations, including a bud at the top of each section. In some cases even biennials may be perpetuated by division. As an instance, the double hollyhock flowers the second year from the seed and the year following, when the plants die. But if the fleshy roots are divided after the second year's flowering 
with a sharp knife, so as to leave a bud at top of each piece, a new lease of life is given. The writer has retained a

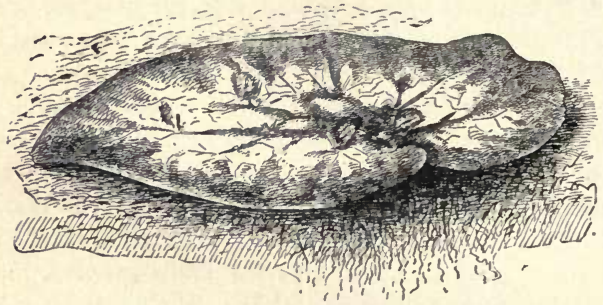

Fra. 31.-Rex Begonia leaf rooting in sand. (After Bailey.)

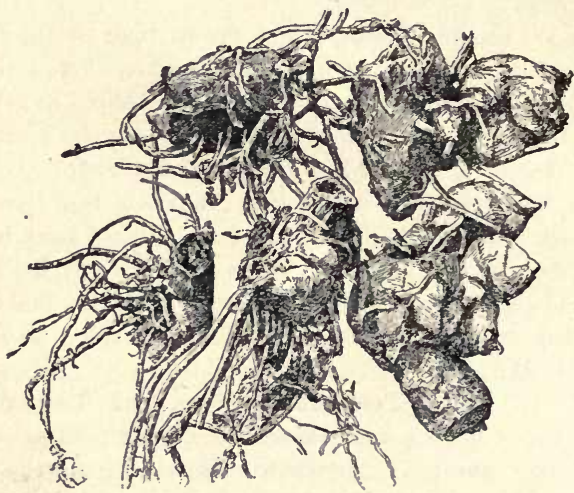

Fie. 32.-Divided canna stool. (After Bailey.)

favorite variety by division a number of years. Such tubers as the dahlia and peony are propagated by division, cutting so as to leave a bud at top of each section. This is true also of such rootstalk species as lily-of-the-valley 
and eamma by making as many divisions as there are buds, or rather separate crowns, as shown in Fig. 32.

Some of the scaly-bulbed lilies can also be divided and yet remain strong for flowering if separated in sections as indicated by the bulb, as shown in Fig. 33 .

As to the time most favorable for division, at the North the spring is the best period for separating hardy perennials, as it is the period of starting growth. But in mild climates the work is usually done in winter or very early spring.

But we have many kinds of bulbous or tuberous plants that make all their growth early in spring

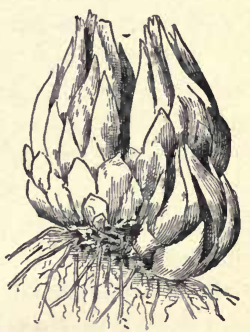

Fia. 33.-Lily bulb show. ing sections for division. and rest in summer, such as the narcissus, hyacinth, tulip, dicentra, and perennial poppy. In such cases the division follows the ripening of the foliage.

With tubers and rootstalks, such as the dahlia and canna, the season for division is in the dormant period in autumn, or prior to time of planting in the spring. 


\section{CHAPTER VII.}

PROPAGATION BY BUDDING AND GRAFTING.

69. Propagation by Budding.-In some cases the leafbud is so perfectly developed that it drops to the ground, where, if the conditions are favorable, it takes root and develops a perfect plant. At the North the tiger lily furnishes a good example, as the buds can be picked from the leaf-axils and will grow if planted like seeds. In favorable climates, or under glass, single eye or bud cuttings with a little wood attached are planted and develop perfect plants. The grape is propagated in this way, especially new varieties where it is desirable to ntilize every bud. But the fruits mainly, and the useful ligneous plants, are not so easy to propagate, as the buds must be planted under the bark of a nearly allied species or variety.

70. Some of the Purposes of Budding.-Aside from the perpetuation and multiplication of given varieties the purposes of budding are manifold. Not the least one in Europe is the working of highly developed fruit and flower varieties on hardy robust stocks. Another main object with commercial propagators is the more rapid propagation of new and scarce varieties, as every perfect bud may make a salable plant by budding on cheap commercial stocks. In section (45) some of the evils of using a given stock for varied climates and soils are stated. In this country the almost exclusive use of imported fruit stocks 
and stock seeds has led to much criticism of the system, especially in the use of west European apple, pear, and cherry stocks and fruit-stock seeds.

71. Some Native Stocks that Should be Used.--In all parts of Europe primitive wild fruit-tree species are found nearly allied to the cultivated varieties, and their seeds are utilized for stock-growing as found in different localities. In this country we are blessed with several species of native plum, which by selection have given us a number of valuable varieties for cultivation in orchards, and in addition all develop strong vigorous stocks from their pits. It has been urged by propagators that our native plum stocks do not, when budded, develop as strong and numerous a system of roots as the imported Myrobalan and St. Julien stocks. If our plum seedlings are budded in the rows where they grew from the pits this statement is true. But if taken up and later transplanted as we handle the imported stocks, the natives will give the strongest system of roots to the budded trees. With the cherry we are also provided witl a vigorous stock, safe from root-killing in all parts of the Union. The seedlings of our wild red cherry (Prunus Pennsylvanica) are peculiarly strong and vigorous, and all varieties of our cultivated cherries form a good union with its wood. The pits of this native species should be utilized for budding stocks, especially in the North, where the imported stocks often are killed in open winters. In the handling of this stock it seems to be necessary to success in budding to plant the pits very thickly, so the growth will be small the first season. They should be taken up and handled like small Mahaleb stocks for spring planting. If grown thinly on fairly rich grounds the seedlings are too large for profitable use in this way or any other.

Another essential is budding later in the season than is 
usual with the Mahalob. As to the apple we havo no nearly allied native species for nse as stocks, as practice has shown that the cultivated varieties do not make a good union with any species of our native apple. But in the Northwest, where common seedling stocks are liable to root-killing, the use of the Siberian cherry crab is promising, as the union by budding seems to be good, especially with the hardy northern varieties. The use of Siberian stocks for budding has solved the question of root-killing in the northern apple-growing regions of Russia. We also have at the North hardy prepotent varieties of the apple, such as Duchess, Hibernal, and Anis, the seeds of which develop strong, hardy seedlings which may be used for stocks. Farther south, as noted in section 4, vigorous hardy seedlings can be grown from small apples, such as Gilpin, Milam, and small seedling varieties, while the imperfect seeds of commercial apple culls sent to the cider-press should be avoided in stock-growing.

72. Summer-budding. - What is known as summerbudding is now employed on a mammoth scale in the larger nurseries in the propagation of fruit-trees, ornamental trees, roses, and many shrubs. The work at the North is done at the close of the spring season of growth with buds cut as used that are mature. The intention is to secure the union of the buds without growth the first season. If inserted too early on vigorous growing stocks, the buds are often overgrown, and there is danger of starting a soft growth that will perish the next winter. In waiting for the best time a brief dry period may tighten the bark. In this case the dirt is scraped aside and the buds are inserted lower down where the bark separates later in the season. At the West this very low budding is most satisfactory, as when set in orchards four or five inches deeper than they stood in nursery the point of 
union is buried. If the stock is not entirely hardy the low setting is a great gain.

A good rule for summer-budding at the North is to

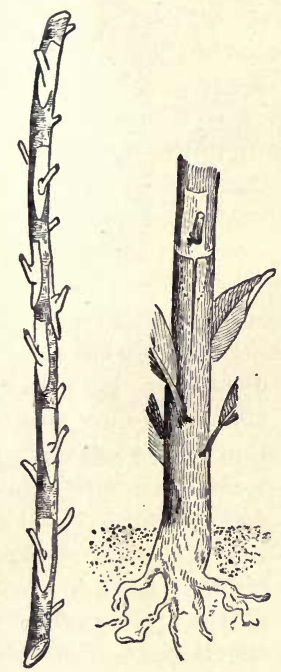

Fig. 34.

Fig. 35.

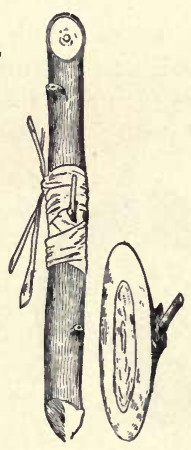

FIG. 36. Fig. 37.

Fig. 34.-Shoot containing Buds. The white spaces about the buds indicate the amount of bark to be cut off with the bud. The shoot is inverted for cutting the buds.

Fig. 35. - Bud partially inserted between the lips of the stock. Fig. 36. - Bud inserted and tied.

Fig. 37.-Bud cut off, ready for insertion. (All after Bailey.)

commence work when the terminal bud of the stocks begins to form. As this period is variable with the different species it lengthens the budding season. It is usual at the North to bud plum stocks in early July, and apple 
and pear as late as the last days of August and first days of September.

73. How to Cut and Insert Buds. - What is known as the $\mathrm{T}$ or shicld bud is used almost exclusively in the United States and Canada. The buds, as shown in Fig. $3 \%$, are cut from the new wood of the same season's growth. The shoots cut from the variety we wish to propagate are called "bud sticks." As cut the leaves are clipped off, leaving a short stub, as shown in Fig. 34, to handle the bud with when inserting. If taken in the fingers the tender cut surface is injured. In using, the bud sticks are kept wrapped in a moist cloth, whence they are taken one at a time as used. In making the $\mathrm{T}$ cut a smooth surface is selected on the north side of the stock. The downward slit is first made. In making the cross-cut slope the knife

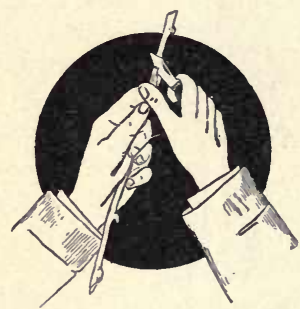

FIG. 38. - Cutting the bud with inverted scion. downward, as shown in Fig. 39. This slope aids in shoving the bud quickly under the bark. To prevent moisture getting in at the top cut the bud with the longest part above. Shove it down to place and cut off the upper part so as to join the slope of the stock. The mode of tying is shown at Fig. 36. The material used for tying is a palm fibre from Madagascar, known commercially as "Raffia." For use it is slightly moistened, but not made wet. If used wet it will loosen when dry. In cutting the buds from the bnd-stick, the novice usually cuts too shallow and splits the bark at each end. In cutting. invert the bud-stick as shown in Fig. 38. From start to finish keep the knife down, taking with the bark a thin shaving 
of wood. A large part of the snceess in budding depends on the ability of the operator to keep a smooth, sharpedged budding knife.

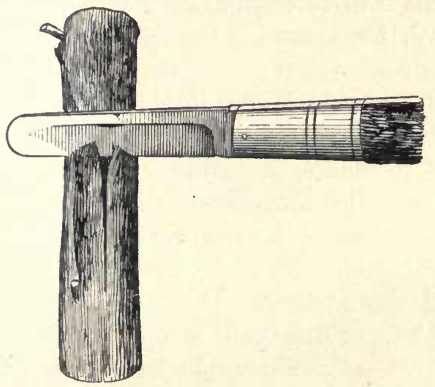

Fit. 39.- Downward slope in making the $\mathrm{T}$ cut.

74. Budding the Same Season the Pits are Planted.The pits of our native plums are often planted very early in spring quite thinly, given good cultivation, and are budded quite late the same season. These young, exeitable seedlings continue growth late and the bark can be raised two weeks after the usual season of plum-budding The stocks, rather small above the ground, can be budded an inch below the surface where the size is larger. The seedlings of wild red eherry (Prunus Pennsylvanica) ean in like manner be budded late the same season the pits are planted. It is the same with the peach, and in the South it is now the usual commercial method. But it is necessary, to secure good roots on seedling stocks budded without transplanting, to cut the tap-roots with a spade or to run a side-cut tree-digger under the rows.

75. After Care of Summer Buds.-A few days after the buds are inserted the growth of the stocks above and below 
the ligature begins to be observed. With a sharp knifo the raffia fibre is cut on the side opposite to the bud. With the stone fruits it is necessary to retie above the bud. If this is not done the bark below the cross-cnt will roll outward, often causing the death of the bud before spring.

In late fali at the North it is safest to bank up the

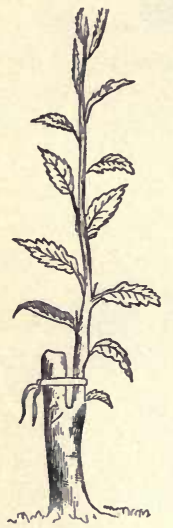

Fig. 40. - Stub left for tying the young shoot. stocks abore the bud with the plow for winter protection, finishing the irregularities with a hoe. Quite early in spring the banking is raked down and the top cut off so as to leave a ring of bark above the cross-cut. If cut too low the upper part of the bud is apt to be dried up and often the whole bud. Some propagators cut so as to leave a stub, as shown in Fig. 40 , to which the growing shoot is tied to keep it erect. Others cut four inches above the bud at first, and then, after the bud has made some growth, cut so as to leave a ring of bark as above stated. But long experience has shown that it is best to cut by sloping the cut upward from above the eross-cnt. On well-established stocks the growth from the bud is often so strong, especially with the plum, that staking is necessary to give an erect growth. The small stakes if cared for can be used several years in succession.

76. June Budding.-What is known as June budding at the South gives salable trees of the peach and other trees the first season from three to five feet in height. The budding is done about the middle to the last of June on stocks grown from the pits planted in very early spring. 
The buds are inserted somewhat higher than usual and the bract leaves are left on the stock below the bud-insertion. As soon as the bud is inserted a part of the top is cut back. In eight or ten days the tying is cut and the top cut back, but a stub is left, as shown in Fig. 40, to which the growing shoot is tied. In this Southern method the bud-sticks are eut as wanted, as in August-budding at the North, where growth is not wanted until the next spring.

At the North, spring-budding is done on established stocks one or two years old, using dormant bud-sticks cut the previous autumn or winter. They are kept dormant until the bark peels well by covering with sawdust over ice. The buds are inserted somewhat higher than usual, leaving the bract leaves on below. In cutting the bud is left longer than usual above. After shoving to place the extra length is cut off at the cross-cut of the T. The top is cut back in part when the budding is done, and when the tying is cut still more is taken off, leaving quite a long stub with leaves, on to which the growing shoot is tied. Trees three to four feet high well branched are grown in this way the season the buds are put in. In top-working trees set the preceding year in orchard, this plan gives growth the same season.

Where the citrus fruits are grown, bearing seedling trees are budded in this way by cutting back the tops early the previous season, developing new shoots in which the buds are inserted. In the propagation of species on which the young shoots are very small, the buds are cut from two-year-old wood in spring-budding. This is done usually with the cut-leaved birch, leaving a long spur clothed with leaves at first, to which the growing shoot from the bud is tied to keep it erect.

77. Ring-budding.-'This old European mode of bud- 
ding is coming into use in this country in changing the top of mulberry, fig, walnut, chestnut, and oak. A ring

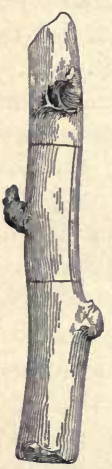

Fig. 41. of bark two inches Jong is peeled from the stock and thrown away. A similar ring is peeled from the variety wanted and fitted in the opening. To get a fit, it is usual to cut the ring to be fitted from a shoot a little larger than the stock and then paring with a sharp knife. The top is not cut back the same season. When cut back in the dormant period the cut surface is waxed. The buds on the inserted ring make vigorous growth the next season. Fig. 41 shows the ring when replaced on the stock. While uniting it is safest to bind moist elay over the whole surface of the ring. In this way the Ring-budding. writer has known the chestnut to be budded on white oak and the lilac on green ash.

78. Grafting.-There is no essential difference in principle between budding and grafting. In both cases the bud of the variety we wish to propagate is united to the stock from which it develops growth. But in grafting we usually use more than one bud attached to the wood on which they grew. A main difference in favor of grafting is that it can be used on a greater number of species in the dormant period, while budding is confined to the season when the bark will peel. Many modes of grafting are used by amateurs, especially in Europe, but aside from those described in this chapter they have no practical value except with the curious in special cases.

A number of machines and appliances have been invented and patented for grafting, but in practice, so far as known to the writer, the hand work gives the safest and surest results. As in budding all methods of grafting are 
used to perpetuate varieties which cannot be profitably grown from cuttings of new wood or roots, or by division.

79. Limits of Grafting.-As in budding, the possible limits are not yet known. As a rule, close botanic affinity must exist between stock and scion, such as apple upon apple, pear upon pear, and plum upon plum, etc. But this rule is not wholly adhered to in practice. As an instance, in order to secure a dwarfed growth and earlier bearing, certain varieties of the pear are worked on quince roots. Also to secure a dwarfed habit and earlier bearing, certain varieties of the plum are worked on sand cherry (Prunus pumila) stocks. As to the need of both budding and grafting, it happons that budding will succeed often on stocks not wholly congenial where grafting fails to secure a good union. As an instance, the uncolored juiced varieties of the cherry seem to unite well with the wood of Mahaleb-cherry stocks. On the other hand, grafting seems to give a poor union and usually the scions fail to grow. Again, the cultivated apples secm to make a good union with stocks of the cherry crab (Pyrus baccatu) by budding, while the root grafts usually fail to grow, and when they start growth the union is far from perfect.

80. Cutting and Packing Scions.-The new wood of the preceding year's growth is usually used in grafting. In mild climate the new wood or scions are cut as used, or at least before starting of the buds. But at the North, especially west of the lakes, scions are cut late in autumn, tied up in bundles with the bases evened, and packed away in rather dry moss or forest leaves. Packed away in a box with dry leaves and kept in the cellar they may show a slight shrivelling of the bark when used in late winter. But in practice the relatively dry scion is more certain to make a good union and growth than those kept so moist that they show a eallusing process at their base. If kept 
too wet the young wood will absorb water enough to change the cell starch to sugar water to some extent. In spring top-working in the orchard scions that seem a little dry will unite and grow, while those that show a callus at the base will fail. If designed for top-working in the spring, or for spring-budding, it is best toward spring to bury them in the sawdust on top of the ice in an ice-house.

81. Taking Up and Packing the Stocks.-If grown at home the apple, plum, cherry, and other stocks should stand in nursery as late in autumn as possible, and after taking up they should be heeled in on dry ground outside, with some straw over the tops to still more perfectly ripen the roots. As cold weather comes on at the North they are stored in the cellar without cutting back the tops, as perfectly ripened roots are essential to the most perfect success in root- or crown-grafting in the graft-room. In storing the stocks they are ranked up in a corner of the cellar with earth or sand between the layers of roots. If the seedlings or stocks are ordered, explicit instructions should be given as to the taking up and handling. If taken up too early and the tops cut back for shipment the faulty handling can be detected at once, after some experience, by inspection of the roots. Imported stocks are usually well ripened, as the growers know by experience that imperfectly ripened stocks will not stand the long transportation and that they will arrive in poor condition.

82. Short Roots and Long Scions.-Much has been said and written during recent years in regard to piece roots and whole roots in apple-root grafting. As noted (47) many of the commercial stocks used are not hardy in some parts of the Union. In mild climates the use of the whoie root, or at least the upper part of the seedling root, will give stronger growth the first year the root-grafts are set in nursery. But experience has shown that when a given 
variety is grown from a cutting, or a cutting grafted on a very short piece of root to favor starting growth, the trees are as thrifty and long lived as when grown by budding or grafting on a whole root. Where tender ronts are liable to root-killing, as in the prairie States, there is a great gain in using a scion eight inches long on a piece of root two or three inches long. Such root-grafts set in nursery down to the top bud usually root from the scion in the nurzery rows, and if they fail to do so they will root when set four or five inehes decper in orchard. With the apple ordinary seedling-roots give on an average two to three sections for grafting. But with the pear, cherry, and plum, only the upper part of the scealling is used and the scion is inserted at the erown.

83. Grafting-wax for Varied Uses.-The most useful grafting-wax for varied uses is known as "French mastic" or Lefort's liquid grafting-wax. For a long period the composition of this wax was a trade seeret in Europe and America. It is made by melting one pound of white resin slowly. When hot add one ounce of beef-tallow. When melted take away from the fire and add slowly, with constant stirring, one tablespoonful of turpentine and five ounces of alcohol. During recent years we have used wood alcohol, which seems to answer the purpose well where alcohol is not readily obtainable in the prohibition States.

The liquid wax is used for all indoor grafting and can be used for top-grafting in the open air if a strip of white cotton cloth is wrapped over it while yet soft to prevent melting or cracking. In indoor and outdoor grafting it works best by keeping it soft by the flame of a small kerosene lamp under the dish. The dish is set over an opening in the top of a small iron box with a door in the side for setting in and earing for the small lamp. The finger 
does the work of crowding the wax into the cavities best and does away with the danger of getting the wax too hot.

In the Sonth, a favorite grafting-wax for ontdoor use is made from resin, pitch, tallow, and red ochre. The proportions are three pounds white resin, one and one-half pounds of pitch, and eight ounces of tallow. The tallow is melted separately and poured into the hot resin and pitch slowly with constant stirring. While yet hot, add the ochre slowly by stirring. This mixture is worked by the hands before using like the old-fashioned graftingwax. It also needs the warming stove under to keep it soft enough for use.

The wax used for the winding thread in root-grafting is made by melting six parts white resin, two parts beeswax, and one part of tallow, with enongh wood alcohol to make the mixture about like syrup when in a warm room.

The use of linseed oil in making grafting-wax is now abandoned, mainly on account of its modern adulterations or processes of manufacture.

84. Root-grafting the Apple.-The now common plan of root-grafting the apple is by the method known as tongue- or whip-grafting. It is easier and simpler than other methods, and no waxing seems needed. If corresponding sloping cuts are made on root and scion, and the inner bark of the two are united and wound, the union will take place with common care. But this plan is troublesome, as it is difficult to hold the parts together while winding with the waxed thread. Hence as a matter of convenience a small. tongue is cut on the sloping surfaces. When shoved together the tongue holds the parts quite firmly until wound. Fig. 42 shows the sloping cuts with tongue and as joined together ready for tying. The essentials are a smooth cut with a sharp, thin-bladed knife, the union of the inner bark on at least one side of 
scion and root, and firm tying to hold the parts together tightly.

The tying is done with waxed thread that will stick without tying when the winding is completed. The common plan of waxing the thread is to immerse the balls of cotton yarn (No. 18 or 20) in hot wax (83) until well saturated. But this plan gives trouble. The wax is unevenly distributed and the end is frequently lost. A better plan is to run the thread through melted wax by winding it on an improvised reel. To take off the surplus wax the thread as it leaves the wax passes through a piece of folded

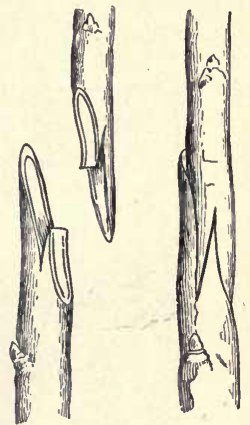
sheep skin with the wool on that Fig. 42.-Whip-grafting returns the surplus to the dish. the apple.

This gives evenly waxed thread and saves much time in graft-winding.

85. Packing Away the Grafts.-While grafting and winding keep the grafts as finished under a damp cloth. In packing set the box on end as shown in Fig. 43. A layer of sandy earth is followed by a layer of grafts until the box is full. In filling, the grafts are kept pressed down tightly. This plan is followed with all root- and crown-grafts.

The storing of the packed boxes of grafts in a common cellar subjects them to changing conditions of air as to heat and moisture and often develops what is known as the graft-box fungus. The best quarters for storing the grafts is in a dirt-covered cave. During winter and early spring the cave is kept eold by opening early in the evening and keeping it closed during the day. If the air at 
times is several degrees below freezing the earth-packed grafts will not be harmed. To avoid disease, and to keep the grafts dormant until planting-time, the care must be kept as cool as possible. The writer has had graft-boxes frozen up solidly for a period of over one month and

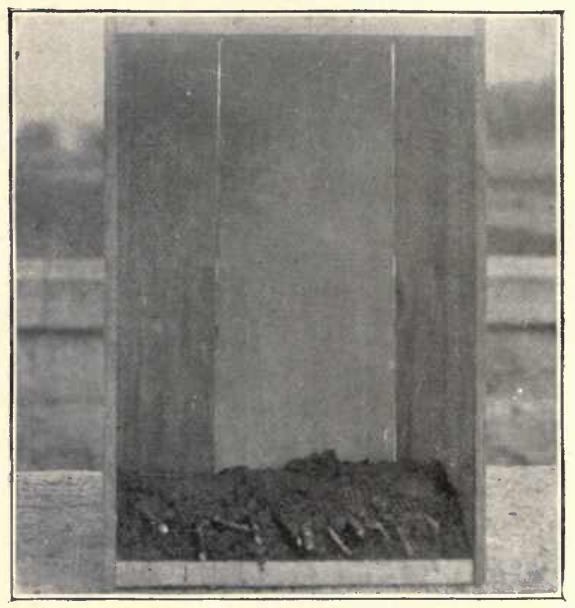

Fig. 43.-Box set on end for packing root.grafts.

secured a better stand in nursery than we have ever known with grafts kept in a warm cellar.

86. Crown-grafting Pear, Plum, and Cherry.-These fruits are not as certain to unite as the apple in grafting unless additional care is taken. The common plan of indoor grafting is by wedge and side-miting, as shown in Fig. 44. This plan gires uniting cell-surface on both sides of the scion. The grafts are inserted in the crown 
and only one graft is made from each seedling. They are tied and waxed, as shown in the figure, with the liquid grafting-wax (83). In making the wedge it is desirable to cut both sides the same thickness. If the slope is made thickest on the onter edge the pressnre at the bark and

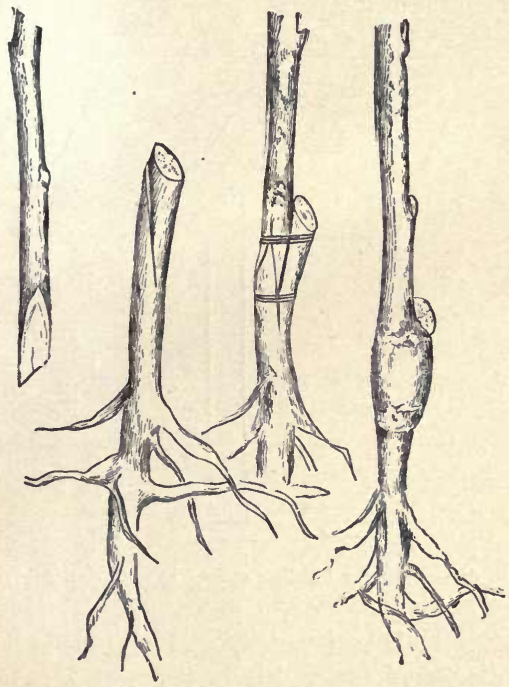

Fig. 44. - Side-grafting plum, cherry, and pear.

cambium layer is not favorable to the union. In making a true side cut in the crown of the stock it must be held in some way firmly. A barrel-stave fastened at the back side of the cutting-bench with a wire passing down to a foot-rest, as shown in Fig. 45, answers the purpose well, but at the poir.t where the stave rests in the stock it must be padded to prevent injury when pressed down firmly. 
As the grafts are waxed they are rolled in sand to prevent sticking together. In sections where root-killing occurs the use of a long scion set down to the top bud in nursery is desirable where stocks are not entirely hardy. As the scion is inserted at the crown, and the saving of the fibrous part of the root is desirable, the use of the long

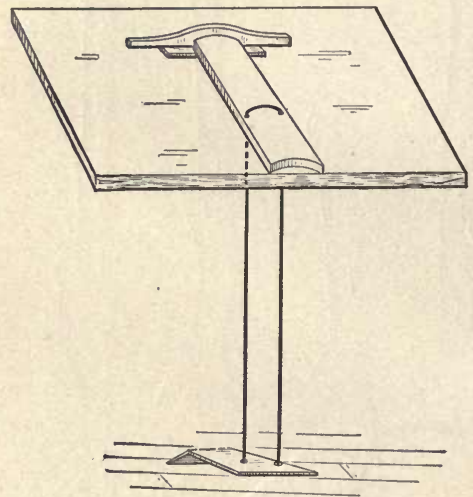

FIG. 45.-Plan for holding stocks in side root-grafting.

scion gives a graft twelve or more inches in length. These long grafts need a deeper box in packing. However well cherry and plnm grafts are made an even stand in nursery is unusual if the packed boxes are not stored in a cool cave (85). If the buds start prior to planting they usually fail to grow.

87. Trenching for Graft-planting.-The long grafts of the pear and stone fruits are difficult to plant firmly at proper depth without trenching with a nursery subsoil plongh made for this use. Fig. 46 shows the construc- 


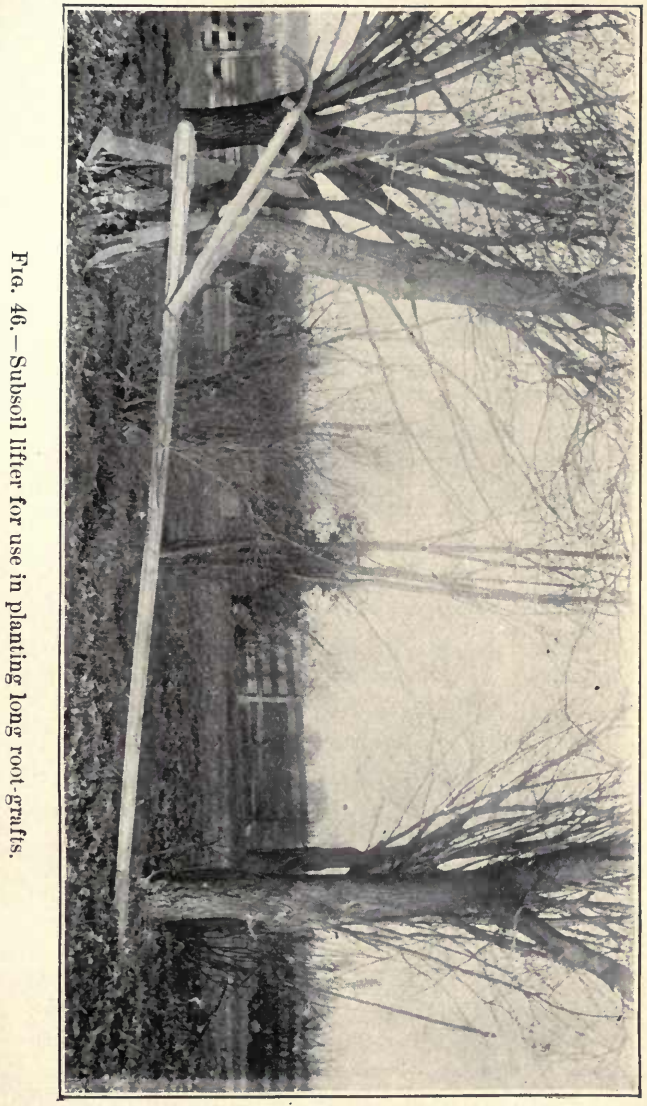


tion of this useful nursery implement. 'The shovel-plow in front spreads the earth and the subsoil lifter passing through the base of the pole lifts and fines the earth to a deptin of fourteen inches. With only two lorses this depth is reached by running twice in each row. The grafts are set with a narrow spade which is thrust down in the mellow earth, the handle leaned forward, and the graft is set in back of the blade, when another movement of the spade presses it in firmly. 'The setting is rapid and the conditions for growth are far better than ean be secured by other methods. Shorter grafts are set without the use of the spade. A boy spaces apple-root grafts and the man following presses them down in the soft soil and levels up the surface.

The trenching also is useful in holding the moisture. The summer rains run the water to the trenehes where the growing plants need it.

88. Top-grafting.- - In all climates grafting in the top is often an advantage. Usually the gain comes from working a highly developed variety of fruit, rather delicate and tender in tree, on robust, deeply rooted stocks nearer to Nature. Over Europe and a large part of Asia native wild stocks have been largely used, noted for their ability to endure every extreme of given climates. At the Pomological Institute at Proskau in North Silesia the writer asked the venerable and experienced Dr. Stoll to name the most satisfactory stock for top-working in that section. His reply was that no one variety was suitable for the varied soils and altitudes of even that vicinity. He then proceeded to name the best stock for top-working on sandy soils, retentive elays, porous soils and subsoils, and eren for lands naturally swampy and boggy. As yet we liave not been able to make these fine distinctions in the adaptation of fruit varieties and stocks to raried soils and atmos- 
pheric conditions, but we are rapidly gaining ground in this desirable direction.

89. Top-working the Apple.-In the more favored parts of the Union top-grafting as yet has been confined mainly to changing the tops of scedlings and undesirable varieties. In the citrus-growing districts in like manner the work has been mainly confined to changing the tops of seedlings and unprofitable varieties. In the prairie States some progress has been made in selecting stocks noted for their hardiness and inherent vitality, such as the Virginia crab, Gros Pomier, Hibernal, and some of the robust Russian varieties. Some advance has also been made in following the European method of setting the stocks in orchard and top-working them the snceeeding spring. This working of young trees permits the insertion of scions in the top and side branches, giving forks of the hardy variety used for working, as shown in Fig. $4 \%$. In top-working young trees it is

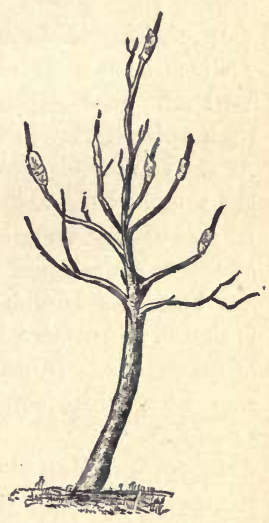

FIG. 47. - Top - grafting the apple. best to use the side-cut method as in crown-grafting plum and cherry (86). If the waxing is done with the liquid plastic covered by winding with white cotton strips, it answers the purpose of tying. Yet as growth goes on the covering loosens without injury to the graft or stock.

90. Top-working 0ld Trees.-In the South and the States east of the lakes top-working old trees and undesirable varieties is so common that travelling professional grafters follow the work each spring. In the prairie States 
this rough cutting-back was also tried by the travelling grafters. But the dry and hot interior air developed ferment in the stock, blight, and other troubles that soon put a stop to the rough practice. At the present time the top is eut back less severely, or the grafting of one side at a time is practised. Even at the east experienced orchardists now graft more at the extremities, as shown in Fig. 48.

In grafting these larger limbs the scions are inserted by what is known as cleft-grafting, as shown in Fig. 49. With the tool shown at Fig. 50, the eleft is cut rather than split if the tool is made thin, smooth, and sharp. At the top of the tool is a wedge which is driven down in the centre of the cleft while the scions are being inserted. In making the wedge on the scions the cuts should be flat, so the pressure when the wedge is taken out will not crush the bark and cambium layer. In applying the wax (83) it should be crowded into the cleft tightly before the wedge is taken out. In interior climates it is best to cover the wax with white cotton cloth to prevent its melting or cracking.

In top-grafting old seedlings or undesirable varieties of the pear the same plan is adopted. But in mild, relatively moist climates the plan adopted often with seedling orange-trecs in California is to cut back one-half the top the first season and to permit vigorous sprouts to grow.

The next spring the other half is ent back and the sprouts of the preceding year on the other half are springbudded (76). The succeeding spring the other half of the tree is budded in the same way. This is really a profitable plan for all top-working of large trees.

91. Top-grafting Cherry and Plum. - Comparatively little has been done as yet in top-working the stone fruits. But Western experience with the cherry leads to the belief 
PROPAGATION BY BUDDING AND GRAFTING.

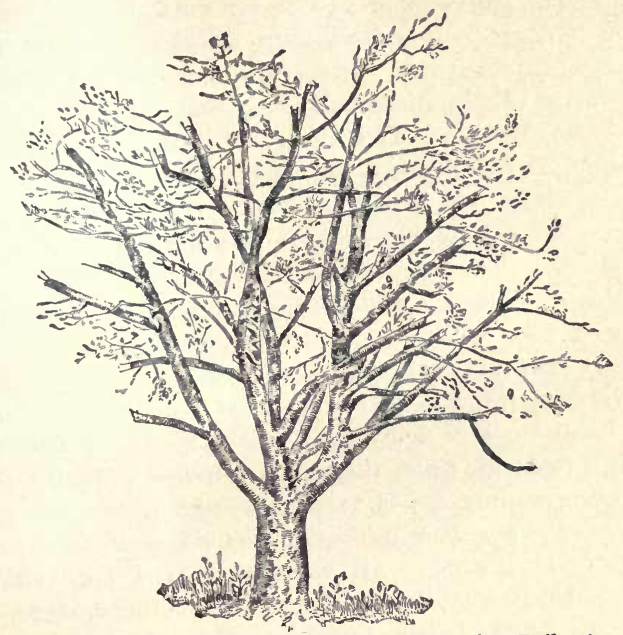

Fig. 48.-Old apple-tree top-grafted. (After Bailey.)

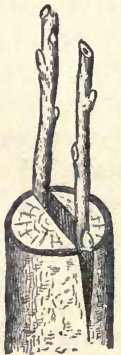

FIc. 49.
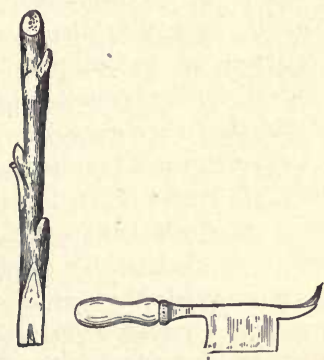

FiG. 50.

Cleft-grafting the apple. 
that it will pay commercially to top-work the cherry and plum on vigorous deep-rooting stocks. In Dupage County, Illinois, over forty years ago James Wakeman top-worked Early Richmond on stocks now known as American Morello. The history of this variety is not known. It is worthless for fruit where better varieties can be grown, but it has remarkable vigor and hardiness and has been scattered by means of sprouts over the whole Northwest. The large commercial orchards top-worked on this stock have borne heavily and regularly and have outlived two or three generations of Early Richmond nursery-grown trees on mahaleb roots.

The same favorable experience has followed the use of this hardy stock in many parts of the West. At first the trees sprout lut, when they come into heary bearing the sprouting mainly ceases to give trouble. The wild red cherry (Prunus Pennsylvanica) has also been used successfully as a stock. All varieties worked on it have proven hardier, lived longer, and have borne more regularly and profusely than the same varieties root-grafted or budded.

With the plum the benefits of top-working have been less apparent, except in the way of top-grafting select native varieties on native plum seedlings. Where the Japan and all foreign varieties have been top-grafted on native stocks they hare come into bearing very young, but the top soon outgrows the stock and breaks off with the heavy load of fruit. This does not seem to arise from weakness of the stock, but from the hardening of the outer bark below the grafts. By slitting and peeling off the bands of outer cuticle the season after the grafting is done we have secured an even growth of scion and stock, both with the cherry and plum. Contrary to usual belief the top-working of cherry and plum is as easy and certain as 
grafting the apple or pear if the work is done very early with dormant gcions and where the stocks are perfectly dormant. The side-cut method is employed on relatively small stocks, but on older stocks the cleft-and-wedge plan gives as good results.

92. Top-working in the Cellar.-If spronts or seedlings of any of the orchard fruits are taken up late in autumn and stored in cellar with proper root-covering they can be top-grafted during winter indoors and set in orchard the next spring. In this system a single scion is inserted in the stock at proper height to form the top. After grafting the only care needed is root-protection and care in handling to prevent breaking off the scion. When set in orchard or nursery shoots will start below the scion. These are left until the scion has made some growth, when they are rubbed off. This method is useful to amateurs, but is rarely practised in nurseries except with some shrubs, and the grafting of the gooseberry on Ribes aureum stocks.

93. Scions to Save Girdled Trees.-Young orchard trees are often girdled in winter by mice, rabbits, and sometimes by sheep. If sawed off below the injury they usually fail to grow from the stub, as buds are slow in development at that point and the sap pressure, as the heat comes on, brings about ferment and low vitality of the stub and roots. Such trees can be saved by cleft-grafting of the stub. A scion is inserted on both sides of the stub to favor the healing of the wound. If both grow the weakest one is cut back after making growth enough to help in covering the wound on that side with cell-growth. The well-established stub will give rapid growth from the strong buds of the scion and in one season develop a tree with side branches. Trees saved in this way will come into bearing about as soon as those not girdled, set at the same time. 
This plan is better to save young orchard trees than

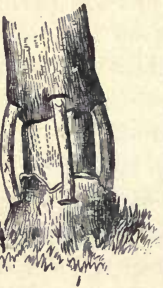
inserting scions to bridge over the stem injury. But where quite large trees are disbarked in any way in the dormant season it is best to spring in scions as shown by Fig. 51. When the bark begins to peel in spring, seions somewhat longer than the space to be bridged are cut to a wedge at each end as for cleft-grafting, and by bending Fig. 51. - Saving the scion the wedge ends are slipped girdled trees. between the bark and wood through openings cut above and below the injury. The parts are

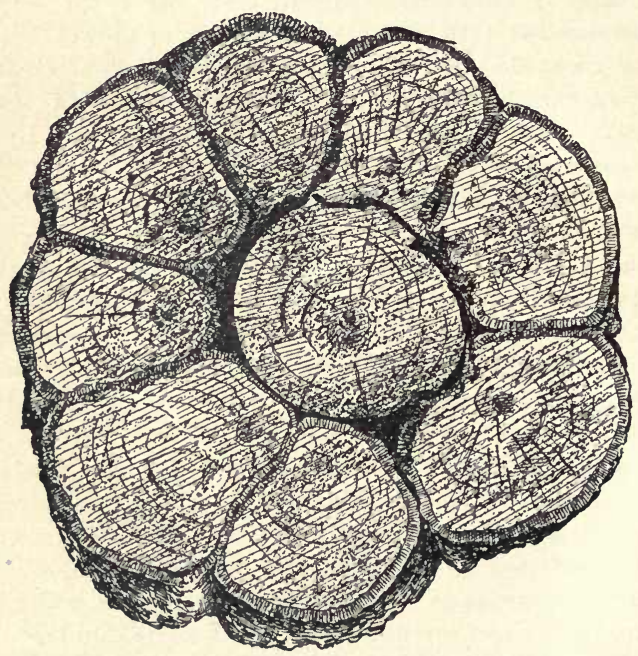

FiG. 52.-Sawed-off section of a bridged tree. 
waxed and then the whole is covered with burlap or old cloth. After a few years such a bridged stem gives an odd appearance, as is shown by Fig. 5\%, as given in the Rural New Yorker by Mr. Leroy Whitford.

94. Bark-grafting.- This grafting is done after the bark begins to peel in early spring when the leaves begin to start. The stock is eut back as in eleftgrafting, but no cleft is made. The bark is slit downward in two or three places as shown in Fig. 53. The scion is cut at lower end into a thin wedge with a notch on top that rests on the top of the stub when the wedge is shoved down to place.

The scions do not need tying in our climate, if, after waxing, the surface is covered by winding with a cotton strip. If tied under the wax the string is liable to do injury as the size of the stock and FIG. 53.--Scions inscion increases. As growth is secured. the same season this is a eertain method

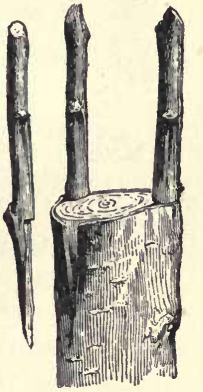
serted under the bark. of working small and large stocks of several species. Where limbs have been broken on fruit and ornamental trees the writer has inserted bark grafts that soon repaired the injury.

95. Soft-tissue Grafting.-Wedge- and cleft-grafting are used in many instructive ways with tubers that have lost their erown-buds, and in grafting one species of eactus on another, and in grafting very many greenhouse- and house-plants. It is often curious, if not profitable, to see two varieties of herbaceous plants upon the same roots. It is easy to graft the finest flowering species of cactus on common stocks, as shown in Fig. 54, where the parts are held together with a pin, but we have found it best to 
cover the wounded parts with waxed paper. Peonia tubers that have lost the crown-buds can be grafted in the same way; also the dahlia tubers, the fleshy roots of the hollyhock, ipomoa, and other fleshy roots. It is also quite possible to unite two fruits of the same species when in a growing condition and both connected with the parent tree. One-half of each is cut away and the two halves left are neatly Fig. 54. joined and covered with a sack of oiled Cleft - grafting paper. Under glass it is easy to unite the
of cactus. fruits of tomatoes, cucumbers, and squashes in this way. Such work only has value in the way of illustrating the principles of grafting 


\section{CHAPTER VIII.}

SOME LEADING PRINCIPLES OF FRUIT-GROWING AND DEVELOPMENT.

96. Selection of Soil and Subsoil.-Where possible the location of the home grounds, orchard, and nursery should be determined largely by the character of the soil and subsoil. Orchard trees, small fruits, ornamental trees, and shrubs thrive best and live longest on fairly rich soils with porous subsoil to a depth of at least twenty feet. In all parts of the Union we find decided variations in soil and subsoil in the same vicinity or even on the same farm. The porous subsoil permits the ascent of moisture from below in a dry time and favors the descent of surplus water in a wet period. It also favors a deeper root system less affected by the heat of summer and the cold of winter. This does not mean that fruits of some varieties and species cannot be grown for home use on almost any soil or subsoil with the help in some places of tile-draining, irrigation, fertilizing, or other aids. But fruit-growing, or fruit-tree growing for profit, gives best results with least expenditure on soils and subsoils well fitted by nature for conserving soil-moisture.

97. Air-drainage.-During recent years the word " Airdrainage" as applied to home and orchard sites has come into general use. Even in California the "mesa" or hillslope lands are now in demand for growing the citrus and 
most other orchard fruits. As the years go on it is found that the hill orchards in Michigan, Georgia, Missouri, Iowa, and indeed about all the States, are most productive, the trees most perfect, and the fruit commands best prices in market. The superior adaptation of orchard fruits to such sites do not all arise from free air-circulation and the descent of frosts, fogs, and vapors to lower levels. The mechanical condition and color of the soil have usually something to do with it and relative exemption from frost is not the least advantage in the blossoming period. In the prairie States a ridge only ten feet above the general level usually escapes ruinous frosts when the blossoms on the general level are killed. During still nights, when frosts at this season are most to be feared, an elevation of only ten feet on the prairies will show a temperature several degrees higher than the level where the cold air settles.

98. North and South Slopes.-In our relatively sunny and hot sections where dent corn ripens, and melons can be perfected in the open air, the direction of the slope is more important than in cooler and more humid climates. The temperate-zone orchard fruits will not endure without injury such heated soil and air as the grape or melon, hence the talk about cover-crops to cool the soil and north slopes to avoid the direct rays of the sun. In the dentcorn belts of the prairie States in the early days, the north slopes of ridges and drift moraines had thrifty thickets of wild plum, crab-apple, gooseberry, wild currant, and other ligncous growth never found on the south slopes. In like manner we now find our thriftiest and best bearing orchards of apple, pear, plum, and cherry on the north slopes. This is specially true of the bluff areas near our streams where the north slopes are more decided.

Yet to a large extent this is a subject for local study. 
In very many cases in mild climates not remote from the sea or large water areas those who wish to grow highcolored and early fruits will select a south or southeast slope and a warm soil. Very much depends on the locality and the species grown. The grape, peach, and citrus fruits love the heat and no practical grower will plant them in preference on a decided north slope, and the same is true of sub-tropieal flowers and such fruits as the tomato, melon, egg-plant, and all sub-tropical fruits.

98, Orchard Protection.- This also is a question for local study. Over large sections of the country a tree shelter on the south is desirable, as the violent winds come from that quarter at the period when orchard fruits are maturing. But on the Atlantic and Pacific coasts windbreaks are often desirable, as a protection from ocean winds and storms. In Minnesota and the extreme northwest part of the plains east of the Rocky Mountains, the consensus of opinion of fruit-growers is in favor of proteetion on the north and west. But in south Minnesota, Iowa, Kansas, Nebraska, and parts of Missouri, a southerly tree protection is favored to protect in part from the hot winds from the southwest, and the storms from the Gulf that often cause the premature dropping of the fruit. Over this region protection on the north is a disadvantage, as it checks the free air-circulation needed in summer, and favors starting sap-circulation in winter, leading to sunscald of the stems on the sonth side and in the forks. Close shelter also increases the liability to damaging frosts during the blossoming period and increases the liability to fire blight. But in all parts where large orchards are planted in rows running from north to south all the protection needed is given by the extended fruit-plantation itself. The north and south circulation between the rows is needed in summer and winter. 
Over the comparatively level surface of the whole Mississippi valley the small frnits, such as strawberry, raspberry, and blackberry, are materially benefited by tree-shelter on the south and west to lessen eraporation from the drying winds prevalent during the summer from these points. With such protection less trouble is experienced from fungus attacks of leaf and bark and more even and perfect development of the fruit is secured.

100. Retarding the Blossoming Period.-The belief is quite general that quite heavy mulehing of the roots of orchard trees when the ground is deeply frozen will retard the blossoming period. Repeated trials at the experiment stations and by private orchardists have demonstrated the fact that this belief has no foundation.

The flowers and leafage are started in spring by the temperature of the air. If we draw a branch of the grape or other climber through a hole into a greenhouse or warm room it will soon develop blossoms and leaves when its roots are encased in frozen earth and the temperature is that of winter outside. For this reason the retention of frost in the soil will not retard the period of flowering a single hour. This is true also of shrubs, vines, and all ligneous plants with tops exposed to the air. But strawberry-plants, grapes, climbing roses, and, indeed, any growth laid down and covered with earth or litter, will be retarded in blossoming several days.

The principle involved is that the bursting-time of Howers and leares depends on local stores of nutriment stored in the cell-structure, and to some extent it is independent of root action. But the roots nsually are not frozen at the season of blossoming even when encased in frozen ground. Moisture really ascends to the top when the air-temperature is warm enough to start top-growth; that is, enongh moisture to expand the flowers and start 
leafage. But it often happens where a heary mulching is covered over the deeply frozen earth in which the feedingroots are held that the full supply of water and plant-food is not earried to the top in time for healthy growth. In rare eases we have known the imperfectly supplied leaves and starting shoots to be injured by sun and wind and the vitality of the trees and bushes permanently lowered. Indeed, in one case reported by G. P. Peffer, of Wisconsin, bearing apple-trees were killed in this way.

101. Washing of Orchard Soils. - As each year the selection of hill and slope land for orchard sites is becoming more general, the washing and gullying of such soils under cultivation becomes an important subject for consideration. If the slope is quite decided the finer particles of soil are soon carried to lower levels and the storms and showers run off too quickly for penetration to the treeroots. In such older States as Virginia, Massachusetts, and New York, the hill soils under culture in many cases are already ruined by the washing process. In south France tens of thousands of acres once covered with orange-, grape-, and other fruit-plantations were ruined by washing to such extent that the lands were abandoned for many years. At this time they are mainly restored by levelling, fertilizing, and a system of planting by running the rows and cultivating at right angles with the slope of the hills. In that region the rows and culture often run around the circular hills. Hence the common name of " zone-planting."

With the rows planted at right angles to the slope and the culture between the rows given in the same direction, a ridge is soon formed in the line of the rows that helps to hold the water. If the slope is quite steep the space between the trees in the row is planted with small fruits, and in south France usually with filberts to strengthen 
the bank by root-growth. By this plan the rows may be cireular and varied in direction, but it does not seriously interfere with culture or the gathering of the fruit.

Where the plan has been tried in Kansas, Missonri, and other States, it has been found that it not only conserves

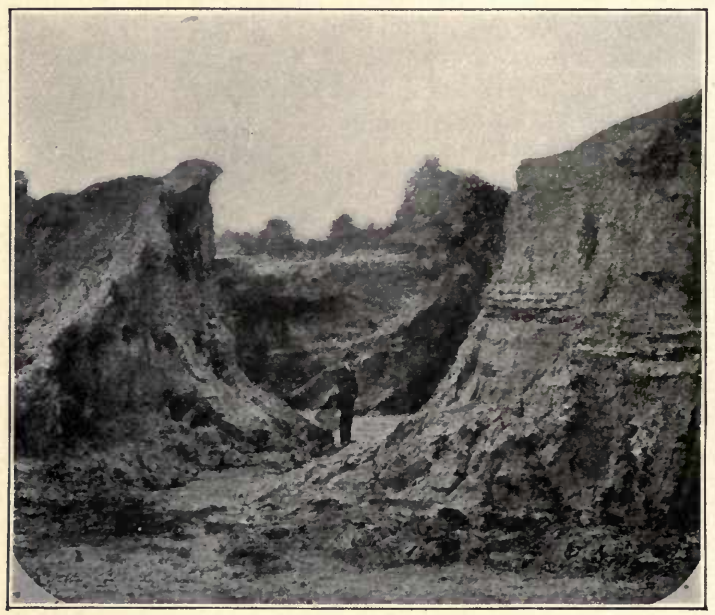

FIG. 55.-A gully in best orchard soils.

moisture by giving time for rains and melted snow to settle downward, but mainly stops the washiug and gullying. As a rule, the best orchard soils are most subjeet to deep gullying. On the loess soils of west Iowa, Tennessee, Georgia, Missouri, and other States, old cultivated fields are now eroded and gullied, as shown in Fig. 55, as given in "The Soils of Tennessee." The upper slope shown was the surface of a field ten years ago. After a gully 
was sitarted each heavy rain deepened it on account of the natural porosity of the soil and subsoil. On the start the water that centred in the gully might easily have been divided and scattered. Or had a zone system of culture been given, with fruit-trees or other crops, the whole surface would have been retained. The figure only shows one gully, but the visitor to the old plantation hill lands of Georgia will find a succession of such deep gullies on many fields once productive.

102. Variety Modifications.-A common popular belief is that a given variety of the cultirated fruits does not yary in tree or fruit. But the close observer will find in every orchard-row planted with a given nursery variety that no two individual trees are exactly alike in tree and fruit. In every row of orchard or small fruits can be found one tree or plant that year after year is better in tree and fruit than the others. Those who have not made a study of the subject may conclude that the evident variation comes from the stock on which the tree or bush was grafted or budded, the soil at that point, or other natural cause. But when we propagate this superior tree or plant we find a duplication to great extent of this individual variation. The truth is that our cultivated fruits vary in individual trees of a variety as much, or more, than a row of elms or maples.

Some of our propagators and fruit-growers are now cutting scions and buds from selected individual trees and shrubs, and we have reason to believe that it will do much to advance horticulture. In some cases the variation of an individual tree is sufficient to class it as a distinct variety. As an instance, in a row of Fameuse apple, the writer observed one tree that bore year after year distinctly striped fruit. In other respects it was in quality 
and texture of flesh a true Fameuse. This is now known as the Striped Fameuse.

103. Crossing and Hybridizing.-The florists have not neglected the interesting and profitable work of crossing and hybridizing. Indeed, by crossing and selection a large part of our beautiful flowers and flowering shrubs have been developed. But aside from the noble work of Luther Burbank, of California, little has yet been done in this country in improving the orchard fruits by crossing. This does not come from the difficulty of performing the work, but mainly from the fact that it requires longer time to test the value of the seedlings produced.

In Nature the bees and other insects perform the work of crossing, but not in a methodic way. In artificial pollination we are able to select the parents that promise the most useful and desirable combination of hardiness on one side and best fruits on the other.

104. Advance Planning of the Work.-Professor Bailey says in his book on "Plant Breeding": "It is necessary, on account of the indefiniteness of the term 'variety, to remember that only varieties true to seed, or races and sub-species, can bequeath their characteristics with any degree of certainty; inconstant species often designated as varieties are not considered in the theory of hybridization."

The development by crossing and selection of our native grapes, strawberries, blackberries, raspberries, and gooseberries has been quite rapid and satisfactory, but much remains yet to be done. The possibilities are shown by one test with the gooseberry. The blossoms of the wild species of Manitoba were pollinated with the pollen of Champion and Industry; over one hundred seedlings resulted, all of which were more vigorous than the wild species, with larger, thicker leaves, and some of them bear 
fruit as large as the Champion. Other indigenous fruits are as yet neglected, such as the sand-cherry (Prunus pumila), the dwarf Juneberry, and possibly the huckleberry.

In the mild and relatively equable parts of the earth the orange, lemon, eitron, banana, date, fig, guava, loquat, persimmon, and even pineapple, have been developed so far by eulture and selection. So far as known no attempt has been made to improve any of them by crossing or hybridizing. Judging by advances made with other fruits it would prove valuable work to cross the Japan persimmons with our native species, the St. Johns River oranges with the hardy, rather dwarf types of north Japan, the common figs of the South with the best varieties from Smyrna, the common mission date palm of Arizona with the best grown in Algeria. Still other lines of profitable crossing will oceur to the mind, especially in Cuba, Porto Rico, and Mexico.

105. Nearly Allied Crossing.-In erossing the orehard fruits the work has not proven as uncertain in results as most persons suspect. The remarkable results achieved by Luther Burbank, of California, have by many been attributed to the favorable climate of the west coast. But a visit to Santa Rosa, in conneetion with a record of the results attained during the past fifteen years, will show that all the new creations of special value have come from nearly allied erosses that have been duplieated in a small way east of the mountains. As an instance, some of his best results with plums have eome from crosses of our native plums with the Japan varieties. Ameriea, Gold, Juicy, and other fine varieties, we are told, came from pits of the Robinson pollinated with Japan varieties. In like manner the crosses of Japan pollen on our native varieties have given most promising results in all the States where 
it has been tried. As an instance, the writer crossed the blossoms of the De Soto with Japan pollen. By accident all the plants were lost but four. One of these now called Ames is as large as Lombard, sutured and better in quality than either parent. The other three trees produce fruit superior in quality to the De Soto or any of our native varieties, especially for culinary use, and all of them retain the hardiness of the Americana species. In all other cases the hybrids of the Japan varieties with our natives have given results as striking as those realized on the west coast. The little done as yet in crossing nearly allied varieties of the apple, pear, and cherry gives equal promise of quick and valuable results.

106. Violent Crosses.-All experience favors the belief that such violent crosses as wheat with rye, raspberry with blackberry, peach with plum, or our native wild erab with the cultivated apples, will not give results of value. Without doubt some of these violent crosses can be made, but the writer's experience has been that the seeds were either abortive or only capable of making a weak growth. It has been claimed that hybrids have been developed by crossing the blossoms of our wild crab (Pyrus coronaria) with pollen of the common apples. On the college grounds at Ames on several occasions such crosses have been made with great care by only pollinating the first blossoms that opened on the Soulard and wild crab. That a cross was secured is evidenced by the fact that the sliape, color, and cavity were changed in the crossed apples. Where the Soulard was crossed with Roman Stem pollen even the fleshy protuberance at the base of the stem of the latter variety was reproduced in the Soulard crab. But not a single perfect seed was found in over one hundred specimens.

In some cases the near relation of two species can only 
be determined by trial. As an instance, the blossoms of Pyrus Toringo - which is a mere bush with fruit not much larger than a pea-were crossed with pollen of Oldeuburg apple. The resulting hybrids were upright and tree-like in habit, with much enlarged leaves, and unexpectedly the fruit yielded enlarged and perfect seed. The size of the fruit was not larger than a small Siberian crab. In this case repeated crossings may give winter apples of real value and of fair size for market.

107. Gathering Pollen in Advance.-Some American authors advise the nse of pollen gathered as needed. In practice this is not easily possible, as the pollen is scattered about as soon as the anthers burst. A more certain plan is to stick a number of small branches loaded with newly opened flowers in moist sand in a warm room. As the anthers become about mature they are clipped off and dropped on white paper. In a dry room the ripening process will soon be completed and the liberated pollen dried. With this dry pollen thus roughly gathered, mixed with the dried anthers and pistils, the most perfect success has been often secured. Even with pollen thus gathered and sent in a letter from Oregon, the success in using has been satisfactory.

108. Preparing and Pollinating Flowers.-When fruittree flowers are fully expanded, or even one half of them have opened, it is not easy to prevent self-pollination. It is far safest to begin the work when the first flowers are nearly expanded. The petals are clippped off with small scissors, followed by carefully clipping off the anthers. At once, after emasculation, the flower or flowers left in a cluster are covered with a paper or muslin bag. The writer's experience favors the use of muslin bags, as thev can most rapidly be gathered and pinned to hold the bag in place and to exclude insects. In ease high winds and 
rains occur the thin muslin sacks are not torn or displaced, as often happens with the paper sacks, and they are not so much swayed by the winds, which with the paper often injure the delicate pistils and ovary. The novice who knows the parts of the flower can do this simple work as well as the expert, and those who do not know the parts will make no mistake if a minute's study is given to Fig. 10, showing an enlarged flower of the cherry. The floral part, marked $\left(c o r^{*}\right)$, is clipped off before opening fully and the stamens around the centre, marked $(S)$, are clipped off, taking care that the anthers do not lodge in the emasculated flower. With the fruit blossoms that grow in clusters, all should be clipped except one or two of the strongest. In Nature it is not common for more than one fruit to set in a cluster. With monœeious and diœeious flowers (34) and pistillate flowers (35) we have no stamens to take from the flowers supplied alone with pistils. But they should be covered before fully opening to exclude foreign pollen.

109. When and How to Apply Pollen.-When partly developed flowers are emasculated the stigmas are not ready for the pollen in less than three days, as a rule, even when the weather is clear and warm. If cloudy and cool they may not be ready in less than five or six days. The nsual mistake is applying pollen too soon. When ready the stigmas exude a sticky nectar that holds the pollen when applied. With the dry pollen gathered in advance a small camel's-hair brush, slightly moistened, gives the best results in covering the stigma with pollen dust. At once, after pollination, the bag is replaced and the label is attached, giving date and record of the pollen used. This will indicate the flowers not receptive to which pollen is to be applied the next day. In all work keep a brusl for each bottle of pollen used. 
In from six to ten days the sacks can be taken off, as the ovaries will then indicate success or failure. Those with enlarged ovaries are covered with mosquito bar, which may remain until the fruit is perfectly developed as a protection from birds and insects and to distinguish the pollinated fruits.

110. Speedy Testing of the Crosses and Hybrids.-The small lots of seeds developed by crossing are usually kept in flower-pots mixed with sand (5). When the seedlings produced are one year old the tops can be cut off just above the crown late in autumn and used the next spring for top-working on young bearing-trees of the same species (88). By ringing (40) the branch after it has made two years' growth we can usually secure fruit for testing the third year. The seedling crosses cut back will start from the stub the next spring and can be used to determine the relative thrift and hardiness of the new variety on its own roots. 


\section{CHAPTER IX.}

\section{TRANSPLANTING FRUITS AND ORNAMENTALS.}

111. Transplanting.-When trees or shrubs are transplanted from the nursery or forest to the orchard or lawn, the feeding-roots and rootlets are largely left in the soil and those retained are more or less mutilated or bruised at the ends in digging. When moved to the new position they stand in isolated exposure, subjected to wind and sun during the quite long period prior to growth of new rootlets capable of sustaining the rapid evaporation of the first feeble growth of top.

If the handling, planting, and soil conditions are not favorable, the transplanted tree or shrub may not be able to start growth in the way required for healthy aftergrowth if they do not wither and die. Hence the need of methodic care and management in this important work.

The distance apart of orchard trees and small fruits, best size of trees to plant, when and where to plant, are topics for consideration in connection with the transportation, handling, and planting of orchard fruits, lawn trees, and shrubs.

112. Width of Spaces between Orehard Trees.-The different orchard fruits require different distances between the trees, depending on their size of top and spread of roots. It is also true that the different species and varieties attain varying size in different climates and 
different soils and subsoils. In southern Georgia, for instance, the writer has seen peach-trees with stems fifteen inches in diameter and a spread of branches of thirty feet. In the same way the apple, pear, cherry, and plum vary exceedingly in size of tree and spread of root in different climates. The established distances apart can best be given by separating the different species into small groups.

113. Distance Apart of Apple- and Pear-trees. - In such apple-growing belts as some portions of New York, Pennsylvania, Missouri, and Arkansas, the apple and pear attain very large size with great spread of root. In such sections forty feet each way is close enough for planting. Where experience has shown that the trees attain less size in thirty years, thirty-three feet apart each way is preferred by experienced planters. In the prairie States from thirty to forty fect apart is preferred on the loess soils of southwest Iowa, while on the northern limit of apple- and pear-growing much closer planting is permissible, as the varieties grown are much smaller in size when fully developed. Perhaps the best plan on the northern limits is to plant in rows running north and south sixteen feet apart, with a space of thirty feet between the rows. This plan gives air-circulation, and the thick north and south planting gives needed protection of the stems and forks from sun-scald. Where the climate permits the growing of pyramid apple-trees on Doucin stocks the usual distance apart is fifteen feet each way, and dwarf trees on Paradise stocks are planted only eight feet apart each way. Dwarf pears on quince roots are usually planted twelve feet apart each way. The sand and snow pears are smaller in tree than the European varieties and are usually planted only twenty feet apart each way.

114. Double Planting of Orchards. - The wide spacesthirty to forty feet-between the small trees of apple or 
pear have tempted many to plant peaches, dwarf pears, or plums and cherries between the trees both ways, with the intention of taking them out when the permanent trees needed the whole space. But this is not satisfactory, as the double planting interferes with proper culture, the use of cover-crops, spraying, and all needed orchard care, and too often robs the permanent trees before the interspaces are cleared. A far better plan is to plant only one way with early bearing varieties of apple or dwarf pear, leaving open spaces north and south for air-circulation, culture, cover-crops, and spraying. At the north where the open spaces are narrowed the strawberry can be profitably grown in newly planted orchards. The partial protection from wind-sweep will benefit the plants, and the strawberry rows, with the winter covering of straw raked between the rows, make a good cover-crop in summer and a fair protection of the surface-roots in winter. After picking the second crop the turning under of the rows and the mulching adds needed humus to the soil and benefits the succeeding crop of strawberries as well as the orchard trees.

115. Distance Apart of Peach, Plum, and Cherry.-In peach-growing centres where the trees are properly pruned the usual distance apart is only fifteen feet each way. But farther north, where less cutting back and pruning is done, twenty feet apart is the usual distance. Where orchards of the duke and heart cherries are planted for profit in rows running north and south, twenty feet apart, with thirty-foot spaces between the rows, gives ample room. The Morello varicties are usually planted twenty feet apart both ways in relatively mild climates. In the prairie States the preferred plan is that of planting the Morello varieties and the native plums only twelve feet apart in rows running north and south, with spaces between the 
rows of not less than twenty feet. This plan gives the needed circulation between the rows and shades the stems and main limbs from the noonday sun in summer and to a great extent in winter. The spacing of other orchard fruits and the small fruits are given in connection with their discussion on future pages.

\section{Planning and Staking the Orchard Site.-A little} advance work in the way of setting a small stake where each tree is to stand will save much time and give straight rows in all directions. Prepare at a leisure time as many small stakes as there are trees to plant. 'T'he small stakes or pins can be split from sections of inch-board about fifteen inches long. Also secure, by purchase or borrowing, a surveyor's steel tape four rods long. With this chain set stakes that can be seen four rods apart across the orchard in a straight line by sighting. These sight-stakes can be set for all the rows at the same time. By stretching the steel tape from one stake to another the small stakes where the trees are to be set are stuck at proper distances apart as indicated by figures on the tape. To make quick work it is best to tie red yarn on the tape at the figures, giving equal spacing. When all the small stakes representing the trees are stuck, what is known as the "planting-board," as represented by Fig. 56, comes into use. The centre notch in the board is placed around

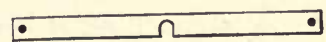

FIG. 56.-Planting-board. the little stake and wooden pins are stuck through the holes at the ends. These pins remain in place as the board is taken forward until the work is completed. The board should not be less than nine fect long and the central notch should be exactly equidistant from the holes in the ends. When the holes are dug the stakes are taken up, but the pins remain as a guide in replacing the board 
on the same side of the tree or stake. If reversed on alternate rows it will make a crook in the rows.

117. Fall- or Spring-planting.-In all parts where severe freezing occurs in winter it is a gain to dig the holes in the fall. The dirt thrown out is fined and mellowed by frost and the sides and bottom of the holes are softened and moistened by frosts, rains, and melted snow. With the holes dug in autumn an opportune time can be selected in spring for planting the trees. If the holes are dug in autumn it is necessary to stick the pins (116) quite firmly to prevent displacing during winter.

Even in the South the digging of the holes in autumn is quite as profitable with a view to fining the soil by exposure. If dug in the spring when wet most of the southern soils will bake and become lumpy and compacter. In the Eastern and Southern States, and on the Pacific coast, the holes are dug and the trees often planted late in fall or in midwinter. The moist soil and relatively cool air of mild climates in winter are favorable for the starting of rootlets, and the evaporation from the top is not sufficient to injure them. But in the interior east of the Rocky Mountains to the lakes, the dry winds of winter and early spring often draw more moisture from the tops than the unestablished roots can supply. In the West the planting is usually deferred (119) until the heeled-in trees have started buds and some root-growth. If planted when trees can first be dug the dry spring winds often damage the tops before the season of growth.

118. Young Trees Best for Planting.-In all parts the use of what T. T. Lyon, of Michigan, called "maiden trees" for orchard planting is now advocated by experienced planters. In the peach-growing districts Junebudded trees attaining a height of only three or four feet are now preferred to large ones. At the North and in 
California one-year-old budded cherry-and plum-trees are now preferred to older trees. Two-year-old apple- and pear-trees are now valued and taken in preference to the four-year-olds planted a few years ago by experieneed planters. These thrifty young trees are more excitable, have a better root system in proportion to the top, can be shaped as wanted, are easier to handle and plant, and in practice are found to eome into full bearing as soon as older trees planted at the same time.

119. Securing and Caring for Nursery Trees.-If a local nursery is near it is usually best to visit it and seeure the varieties doing best in the vieinity. If they must be shipped in, take the same care in selecting varieties. In both cases it is better to have the trees dug early and heeled in near the orehard with tops to the soutl, as shown in Fig. $5 \%$ When the buds begin to start growth, it will

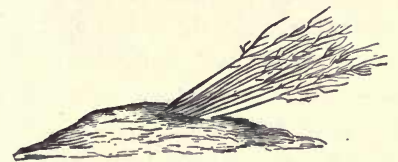

Fig. 57.-Heeling in, with tops to the south.

be found that the rootlets have begun to grow and the cut and broken roots that have been properly pruned with a sharp knife are beginning to eallus. They are now ready to plant. 'Trees handled in this way, and planted when the buds and rootlets are pushing, will start into rapid growth at once. But the trees planted early, that stand isolated in the dry spring winds until the time comes for starting growth, are often too much dried to start desirable growth, especially in the prairie States.

In planting the heeled-in trees care must be taken not to expose the roots. The best suceess is attained by taking 
the trees to the field with the roots in a large tub of water and planting with wet roots to which the dirt will readily adhere.

120. Proper Depth to Plant Trees.-The proper depth to plant fruit trees is variable, dependent upon climatic conditions. Where there is no liability to root-killing it is not desirable to plant trees and shrubs more than four inches deeper than they stood in nursery. But in the interior States and parts of Canada the winters are often Stle hijury or death of tender roots pianted at ordinary depth. Duing the winter of 1898-99 tens of thousands - of tralkible bearing fruit trees west of the lakes were rootkilled withgit a terminal bud of the top being injured.

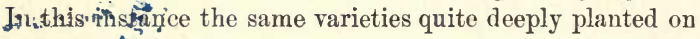
diry soil were not injured and the same was true of varieties With surface protected by cover-crops, weeds, leaves, and in parts of the States by snow. In such localities experience has demonstrated that young trees can be planted one foot deeper than they stood in nursery. But this deep planting only is practised with trees budded or grafted on tender stocks where the conditions are favorable for root-killing.

\section{Pruning Tops and Roots Before Transplanting or} Heeling In.-The young nursery tree usually needs some pruning of the top prior to planting with a view to giving proper height of stem and shape of top. It is now generally believed by experienced planters that a fruit-tree stem should not exceed three feet in height. Even in California the low-stemmed citrus and other fruit trees are preferred. If not high enough to work under, still shorter stems are desirable in the northern prairie States. The most desirable shape of top as to spacing of the limbs is shown at Fig. 58, at $(A)$ as received from the nursery, and 
at $(B)$ one year later in orchard when cut back and properly pruned. Prior to heeling in or setting out, the ends of bruised or broken roots should also be pruned with 8. sharp knife to favor rapid and more perfect healing.
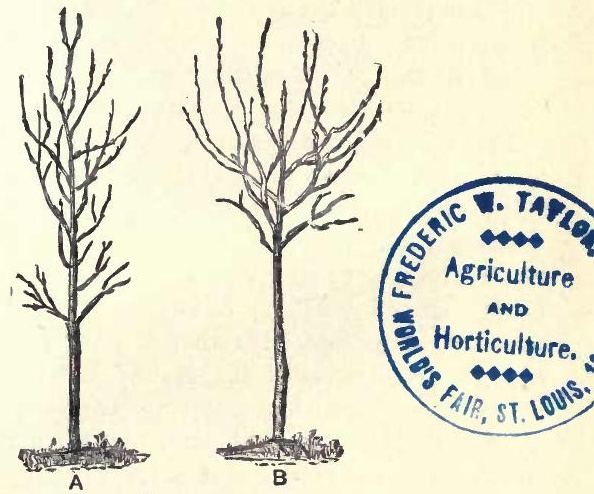

FIG. 58. $-A$, Tree as received from nursery; $B$, same tree after one ycar shaping in orchard.

122. Alternating Varieties in the Rows.-It is now generally conceded that nearly all varieties of the orchard fruits give increased crops of more perfect fruit when alternated in the rows with a view to securing cross pollination. The general record has been that orchards planted with mixed varieties are far more productive than blocks planted with a single variety. Indeed, many varieties of the cultivated fruits are not capable of selfpollination. While we have much yet to learn relative to this subject, enough is positively known to reach the decision that it pays to alternate all varieties of the orchard and small fruits in planting, except possibly the perfectflowered strawberries, and this is not certain with all 
varieties, as we have secured better erops and more perfect berries from the perfect-flowered Charles Dowuing when altermated with a good staminated variety. Darwin's great work on "Cross- and Self-fertilization in the Vegetable Kingdom" was at first received with many doubts ky fruit-growers, but during recent years his axiom, that "Nature abhors self-fertilization," has been quite fully verified by scientists and practical horticulturists.

123. Planting and Watering Trees.-If the soil is well firmed over the wet roots (117) and the soil is moist but not wet, it is rarely necessary to pour in water when transplanting. Even in the arid States this should not be practised, as firming very wet soil over the roots causes hardening and baking. It is poor policy, for the same reason, to transplant trees when the soil is wet and sticky. If heeled in wait until the ground is friable and works well. In orchard, with after-culture, watering is rarely needed except in the arid States, where it is applied to the whole surface, as during a rain. On the lawn, with evergreens and shrubs, watering may be needed. But such watering should be systematized. Dig away the surface earth around the crown and pour in water until the soil is well soaked. When settled away return the soil to prevent baking. Slight and frequent watering over a baked surface does more harm than good."

In planting, many experienced orchardists lean the trees to the south at an angle of about twenty degrees. When trees are set in this way in the prairie States they become upright in two or three years without making a crook in the stem, while trees set erect are liable to lean to the north (26). In climates where trees set erect are not liable to lean to the north, the inclination to the sonth in settirig is not required.

124. Transplanting Evergreens.-Evergreens taken up 
in the near vicinity and the roots kept moist should be planted at once. But experience has shown that it is safest to take them up and transplant when the buds begin to swell. At this time the rootlets will start quickly to sustain the rapid evaporation from the foliage. Plant when the soil works well and compact it firmiy on the roots spread in natural position. The spruees and firs have many fibrous roots to which earth adheres in transplanting. Hence they need no cutting back of the top except in the way of shaping. But the pines show few fibrous roots not left in the soil when digging. Yet Nature has provided for safe planting, as the branches are provided with latent buds from which growth starts from cut-back branches. If pines are more than one foot in height they are more certain to grow if the tops are cut back quite severely.

Evergreens boxed and shipped in from a distant point when opened usually show dried mud encased over the roots. Before planting it is best to dip the roots in thin mud to soften that which is dried and plant with the roots wet. If planted in only fairly moist soil with the dry mud over the roots, and dry days follow, the death of the trees from drying is quite certain.

It sometimes happens at the North that evergreens and fruit trees are received in a frozen condition. In such cases it is best to place the boxes or bundles in a cellar without opening. If the roots are tightly packed in moss or other packing, it often happens that such exposure is harmless if the frost is drawn out slowly in the cellar.

The handling, planting, and care of other ornamental plants and trees and small fruits will be given in connection with descriptive notes on varieties and species. 


\section{CHAPTER X.}

\section{ORCHARD MANAGEMENT.}

125. Culture After Planting. $-\Lambda$ s soon as orchard trees are planted the ground should be cultivated to conserve moisture. Even if no weerls start keep the surface earth mellow by frequent stirring. It is the best possible mulch for newly planted trees. In the arid States watering may be needed of the whole surface, but as soon as the top begins to dry the stirring should be continued, and in the rain-belt it should follow each rain to prevent soil-baking and hardening. It is specially desirable to get as much growth as possible in the growing season of the first year. If we secure growth of top we will also secure growth of feeding-roots and the extension of water-feeding roots downward. If the plough is used at first turn the furrows toward the trees and follow with small-toothed cultivator to pulverize the soil and level the surface. The wellpulverized soil the first season is more important than after the trees become well established and deeply rooted. In orchard culture the use of the rotary-disk harrow is to be recommended, but only to break up the surface for the after nse of a Thomas harrow or even a good steel-tooth harrow. The disk without the after use of the harrow leaves ridges and increases rather than retards evaporation.

126. Shading of Orchard Soils.-During recent years the continued culture of orchards has been advocated in 
California and in all fruit-growing centres. But a change in belief is now apparent in all sections. In section (19) the subject of shading of orchard soils and the use of cover-crops are discussed. In this connection the combined system of enlture and soil-shading will be noted. The orchard culture should begin early in the season. Early culture helps in saving the spring moisture and to start growth actively. The entire growth of the season of fruit trees is made early in the season. Hardy northern trees finish growth by the first of July and in the prairie States earlier. All cover- and catch-crops should be turned under in the spring as soon as the soil is in fair working condition. Some advise running the plough four or five inches deep, but a far better rule is to plough only deep enough to permit turning a flat furrow with levelling after culture.

The early culture answers the purpose of advancing growth and starting the fruit crop, and the after covercrop is an advantage in shading the soil, permitting the nitrogen-feeding root-hairs to come near to the surface as an aid to fruit ripening and the perfect maturing of the cell-structure of the tree.

While the orchard is young and the supply of plantfood and humus yet ample, buckwheat answers well the conditions for keeping the soil shaded and relatively cool and moist. It covers the ground much earlier than any of the legumes, and is easier to turn under in the spring. If one half of a young orchard is sown annually to buckwheat about the first of July and the other half is cultivated, the owner will discover in a shert time a surprising comparative thrift and vigor of growth on the bnckwheat portion and also an increase of yield and increased size and smoothness of fruit. As the orchard attains greater age hairy vetch has proven best for a cover-crop in the 
Western States and cow-peas in the South. In south California the common field-pea makes a surprising growth in late fall and early winter in orange orchards and so far is a favorite cover-crop to supply the soil with needed humus and nitrogen.

127. Cover-crops and Blight.-Beyond all doubt what is known as fire-blight of the apple, pear, and quince is caused by bacterial growth in the cell-structure of the leaf, blossom, and outer wood. Yet long-continued observation has demonstrated that the color of the soil, elevation, exposure, and soil-covering have much to do with its occurrence and spread in a given climate. Other things being equal, it is found that soil-shading during the heated term by a cover-crop of buckwheat, retch, rape, cow-peas, or soy-beans, will show less blight with given varieties than the orchard with bare soil during July and August.

It is also true in the prairie States that a given variety of the apple, such as Yellow Transparent, will be free from blight on light-colored ridge soil without shelter from winds, while on a lower level with darker soil and sheltered from winds it will be blackened with the disease. In the same line it is also true that in cooler moister climates like that of west Europe, from whence most of our fruits were derived, fire-blight is not known.

In these cases, and others now well known, we have reason to believe that abnormal heat of soil and air have much to do with the growth and development of this bacterial disease. Professor M. Fremy, of France, is a recognized scientist and a close observer. He says that fire-blight of the apple and pear only occurs in France when the trees are trained on south walls where subjected to abnormal heat. His opinion founded on chemical investigation was decided that ferment of the pectose preceded 
the introduction and growth of the bacterial spores. $\mathrm{He}$ says: "Pectose is accompanied in the vegetable tissues in which it is found by a ferment pectose, sometimes soluble and at others insoluble, which possesses the property of transforming pectose and pectin into pectic and metapeetic acid successively: Pectic fermentation plays an important part in the conversion of ripe fruits into an over-ripe, half-rotten, or sleepy state. It also assists in the formation of vegetable jellies. In fact the transformation of the natural juices of fruits into jellies is a result of the metamorphosis of pectin contained in these juices into the pectosic and pectic acids. Pectic fermentation is effected at about $95^{\circ}$ Fahr." It may be that with further investigation it will be discovered that a ferment precedes the attack of bacteria. If this proves true it would not disturb the fact that blight can be extended by inoculation.

128. Do Cover-crops Dry the Soil?-It is urged by those who yet favor continued orchard culture to conserve moisture that cover-crops rob the fruit trees of needed moisture at the time when fruit needs it most for perfect maturation. The first and even second leguminous covercrop sown in a bearing orchard will result in diminished supply of soil moisture as compared with the plan of continued culture. But this only favors the perfect ripening of relatively young trees. But the inrning under of two or three leguminous crops soon gives a supply of humus and nitrogen that so changes the meehanical texture of the soil that it will hold moisture through the season far better than the cultivated ones that each year become more destitute of needed humus and nitrogen.

129. Protection from Mice and Rabbits. - In the United States and Canada field-mice are found in all parts that are liable to girdle the stems of young orchard trees. A 
certain preventive is to throw a small monnd of earth around the lower part of the stem late in autumn. For some reason not known to the writer the mice never ascend the mound, but run their trails under the snow around it. If the mounding has been neglected damage may later be largely prevented by tramping the snow firmly around the lower part of the stem. If there is no snow, and mice are numerous, binding the stems with woven mosquito-bar wire will prevent damage. The wire will also protect from rabbits. But washing the stems with unpalatable solutions is the usual method of protecting trees from rabbits. The best wash yet tested is made by adding to one gallon of stale urine one quart of fresh lime, and one pint of pine tar stirred in when hot. Then stir in flowers of sulphur until it makes a wash that can be applied with a stiff brush or old broom. The writer has not known even the Jackrabbit, or the European rabbits, to touch a stem covered with this wash, that sticks well to the stem over winter usually. But during rainy winters it sometimes happens that a second wash is necessary where rabbits are numerous.

130. Stem-borers.-The crown borer often fatally injures young apple- and quince-trees. But it is easily managed by washing the stems about the first, middle, and last of June with a strong solution of soap and water. Before applying the wash search for the castings of the borers around the lower part of the stem. If any are found they can be crushed in their burrows without cutting the bark with a flexible wire that will follow the burrow. If the larva is reached the evidence will be given on the point of the wire. With this treatrnent the writer with forty years' experience has never sustained much injury by borers, while neighbors who trusted to cutting ont the larva have lost hundreds of trees. 
131. The Tent Caterpillar.-On young apple-trees the ring or cylinder of eggs covered with waterproof varnish can easily be detected, detached, and burned during the leafless period of winter. If any escape it is far better to twist ont the nests with a forked stick than to burn them out, as often practised with kerosene, which always injures the bark and leaves.

The rodents and insects noticed at this time the orchardist comes first in contact with in orchard management. A few of the leading insects encountered later will be discussed in the chapter on spraying. But we now have special books on spraying copiously indexed that can be used at the nick of time when exact information is needed to guide the work of insect extermination or control.

132. Orchard Fertilization.-In the Eastern and Southern States, and on the west coast, the commercial fertilizers have been used freely in orchards with continued culture. The result has been that the expression "Fertilizer sick" has come into use. The evident trouble in such cases is lack of humus in the soil and a changed mechanical condition of the soil. What is needed is a mingling of the humus and nitrogen of cover-crops, and a judicious application of potash and phosphoric acid. Even on the rich prairie lands of the West the soil is deficient in potash. After an orchard has borne repeated crops, and the spread of tops does not favor the sowing of catch-crops, the free use of barn-yard manure is advisable at least once in four years. The summary that will apply to all soils and all parts of the Union is that the orchard must have humus in the soil from cover-crops or manure, with an ample supply of nitrogen, potash, and phosphoric acid.

133. Low Hedge for Shelter-belt.-Stock should in all 
cases be excluded from the orchard. The low hedge is more attractive than the fence, and near towns is not so easy to climb. Another good reason for its use is that a low wind-break lessens evaporation by breaking the continuity of wind-sweep at the surface of the earth. A hedge eight feet in height of the Amur barberry at the north, or Osage or Cherokee rose at the south, does not affect the needed circulation of air, yet it will materially lessen surface wind-sweep and thus lessen evaporation. In different parts of Europe the low shelter-belts are used by seed-growers, nurserymen, and fruit-growers. An example of their value is shown in Manitoba, where many miles of shrubby Artemesia and other hedges have been planted to protect wheat-fields. Where the surface soil and even the seed wheat was blown away prior to their use little trouble is experienced at this time.

\section{Marketing Summer-ripening Fruit. - Properly} managed, there is profit in most localities in growing summer-ripening apples and pears. In picking the stems should be retained, as it farors their keeping, and they should be marketed in crates holding not more than half a bushel. They should also be picked when so nearly ripe that they will ripen fully in transit. In this form the summer fruits give less loss to the dealer and increase consumption, as most buyers will not ask for a division of a crate. In the prairie States the only neatly packed summer and early fall fruits seen in the markets are packed in Colorado, Utah, and other distant States, while home-grown apples and pears are marketed in bulk at local points or go to waste. In marketing strawberries, cherries, plums, peaches, tomatoes, and currants the same care is needed in retaining the stems and also in picking when ripe and packing as neatly in erates, as is done in a few fruit centres, notably in California. Professor Bailey 
says truly: "If one makes a study of the markets he will soon come to feel that the paekage and the packing eut a most important figure in fruit sales."

\section{Picking and Handling Fall and Early Winter} Apples.-Many of the fall and early winter apples will bear pieking when the seeds are first browned and before they are fully colored. The Fameuse, Wealthy, Alexander, Jonathan, Grimes Golden, and many of the Russian varieties will complete their coloring and ripen with unimpaired flavor if picked much earlier than is usual. Such early pieked fruit should be barrelled when dry and stored ranked up on their sides under a hay- or straweovered shed with free air-circulation until wanted for sale in early winter. If the cold becomes severe enough to endanger freezing, the barrels can be protected by a straw covering. Some methodic growers known to the writer keep Fameuse, Wolf River, Lubsk Queen, and other handsome fall apples worth twenty cents per bushel into winter, with profit in the way stated by waiting until the last of November before removal from the shed to the cellar. The straw- or hay-covered shed has done good service at the west, as it does not heat up in the sunshine like an enclosed building of wood or even brick. But I have had even better success in storing fall apple barrels on their side in a dirt-covered eave. 'This was closed during the day and opened on two sides during the night. In this way the cooler air of the night was stored for use during the day. The autumn pears ean also be picked when the seeds first turn brown. If picked when the stem parts quite readily from the spur and properly stored such varieties as the Kieffer and Mongolian snow will develop dessert quality never attained when ripened on the tree. For distant shipment most fall varieties of the pear picked when hard will ripen up in the covered crates or baskets 
in a cool, dry room. But it pays best to mature them before reaching the market.

136. Picking and Handling Winter Apples.-In different sections the season for picking a given variety varies exceedingly. As instances, the Rhode Island Greening and Northern Spy will ripen on the trees in Iowa or Kansas if left until the usual time of picking in western New York. In the dent-corn sections of the west and southwest winter apples are picked when the seeds are brown and the stem parts from the spur without rupture of the bark. Over the west and southwest winter apples must be picked three weeks earlier than in the Atlantic States. Yet picking at proper time is more imperative in the southwest than in New York, as even the Ben Davis will get mellow on the trees if left until freezing weather is feared. In picking, varieties of the season of Jonathan and Fulton are picked first, and the tougher late apples, such as Willow and Stark, last of all.

The essentials to good keeping are picking when the stem parts quite easily from the spur, picking when dry, handling as carefully as eggs, and getting them as soon as possible into a relatively dry, cool place. The old idea of "going through the sweat" before placing in the cellar has no foundation. Apples or other fruits will sweat at any time if when cool they are exposed to a current of warmer air loaded with moisture.

137. Earth-covered Cave for Apple Storage.-Earthcovered caves are used often by nurserymen to store grapevines and fruit trees and for storing grafts of the orchard fruits (85). The few who have tried it on a large scale also find it a desirable place for storing winter apples. For apple storage it should have ample ventilation. When the apples are put in from the orchard in the fall the days are usually warm and the nights cool. During 
the night keep doors and ventilators open, and during the day keep all elosed, putting in each day's picking early in the morning. Even in winter the eave is opened at night for a longer or shorter period, depending on the temperature, to let in cold air, which is held during the day by keeping every aperture closed. Those who have had experience with the cave method prefer it to all others except ammonia cold storage. But it must be kept in mind that when the cellar air is near freezing in winter, if it is opened at midday, when the air outside is much warmer and loaded with moist air, it will rush in and precipitate its moisture.

138. Tile-draining of 0rchards. - It often happens that ridge land with good air-drainage has too stiff a soil and subsoil for best success in orcharding. If the soil seems too wet, or alternately too wet or too dry, tile-drainage will prove a great gain. The tiles should not be less than four inches in diameter and laid in the centre between the rows after the trees are set or even after they come into bearing. The tiles should be laid not less than $3 \frac{1}{2}$ feet deep. The tiling of such land soon changes the whole character of the soil and even mode of growth of the roots. Literally the air is let into the soil, the water-level changed in a wet time, and the surface-feeding roots will run deeper and be less subject to injury by the heat of summer and the cold of winter. In a dry time also a change will be observed. The surface soil will be mellowed, fined, and relatively much cooler than the same grade of land not tiled. As to the often-repeated query: "Will the apple-roots choke the tile?" the writer's experience would answer, “No." Tiling laid down twenty-five years ago between apple-orchard rows is yet in good condition and working as well as ever. But willows, poplars, and most forest trees will clog tile. 
139. Fruit-growing Neighborhoods. - The amateur or commercial fruit-grower who finds that any one of the orchard or small fruits succeeds unusually well in his vicinity should encourage his neighbors to increase their plantings. Union is strength in fruit-growing to an unusual extent. The locality that becomes noted for the methodic growing and shipping of any given fruit, nut, or other horticultural product has advantages in shipping, selection of market, and in the way of procuring the neatest, best, and cheapest shipping crates, baskets, barrels, etc.

The neighborhood also can combine in the saving of what would prove waste products in a single orchard by drying, canning, cider, vinegar, and in other ways. 'The best-selling fruits in any market are from neighborhood combines where the gathering, sorting, and packing are systematized.

Another special gain in neighborhood fruit eentres is in the educational way. Spraying soon becomes systematized, and the same is true of alternating varieties to secure cross-fertilization, home propagation from the selected trees of given varieties, irrigation of small fruits, orchards, and gardens, and indeed in all lines pertaining to profitable fruit-growing on their soil and in their climate. 


\section{CHAPTER XI.}

\section{PRUNING OF TREES AND ORNAMENTALS.}

140. Need of Pruning.-Lindley said many years ago: "If well directed, pruning is one of the most useful, and if ill directed it is among the most mischievous, that can take place on a plant." It is too common to wait until undesirable habits of growth are apparent and then set a time for a general thinning out and shaping of trees and shrubs. The effect of this severe pruning is to secure a heavy growth of new wood in moist climates, and in dry interior climates it often starts blight, sap-stagnation, and sun-scald on the south side. The general rule for all pruning is simple: it should begin as trees or shrubs are received and heeled in (119) and be continued lightly each year until they reach, in the case of apple-trees, the " heading-back period" (144).

Always keep in mind the aphorism of Professor Bailey: "Trees which are alternately neglected and heavily pruned are kept in a condition which is apt to be fatal to the best productiveness."

141. Pruning in Nursery. - After setting grafts in nursery, if more than one bud starts from the scion rub off the surplus as soon as observed. As growth advances, clip the lower side branches, but in no case rnb off the leafbracts or small elusters of leaves with which the stem is clothed. Budded trees on strong stocks may be permitted to form a head the first season where low-stemmed trees 
are desired. In this case keep the side limbs clipped on the stem, but keep in mind that the stem leaves give stocky growth and the large stem a top-heavy growth. The second year the top is formed on root-grafted trees, using care to secure a central ascending stem with radiating branches (27) without forking. The second season also the leaves should be left on the stem to give the reqnired stockiness. The needed sprouting at the crown and cutting away the branchlets that appear on the stem, together with shaping the top, are the main essentials of pruning in nursery.

142. Proper Time for Pruning in Nursery and Young Orchard.-Where light pruning is done in nursery or young orchard the best time is when the leaves are about two thirds grown. This begins the period of active cellgrowth and favors the rapid healing of the wound. While it is true that pruning in the season of growth is theoretically a check on circulation and subsequent growth, yet on young, excitable trees under cultivation the light pruning at one time amounts to little in ehecking growth and is far more than offset by the rapid and smooth healing of the wounds. But the best time for pruning varies as applied for varied purposes.

The dormant season is essential for cutting back growing wood severely, removing large limbs, or where stunted trees are cut back to secure vigorous new growth, and where stunted branches are ent back to secure active growth and larger leafage. Summer pruning checks growth and tends to lower vitality. Yet it often is practised to hasten the fruit-bearing period of orchard trees and to give more bearing wood on shrubs that blossom on the preceding year's growth.

143. Pruning Young Apple and Pear Orchards.-Only a few years ago the advice given in the fruit books of 
Europe and America was to thin ont the tops of bearing fruit trees to let in the sun. Charles Downing was an innovator when he wrote in 1869: "Every fruit tree grown in the open orchard or garden as a common standard should be allowed to take its natural form, the whole effort of the pruner going no further than to take out all weak and crowding branches, those that are filling uselessly the interior of the tree where their leaves cannot be fully exposed to the light and sun, or those which interfere with the growth of others." At the present time our advanced horticultural writers say that the necessity for much pruning depends largely upon climatic peculiarities. As an instance, Professor Card says: "The Eastern grower finds it necessary to thin his trees and admit light and air to produce fruit of high color and good flavor. The Western man, however, finds that under his conditions of intense sunlight and low humidity, fruit will develop color regardless of such conditions. The Eastern grower, if he neglects this, may find his fruit suffering from attacks of fungous diseases; but in general fungi are less troublesome in the drier climate of the plain, so this reason loses its force."

Sometimes reasons for varied systems of pruning are found on two sides of a mountain range. As a marked instance, Professor J. A. Balmer, of the State of Washington, gives positive reasons why summer pruning, pinching, and even root-pruning of orchard trees are required west of the Cascade range to check exuberant growth. On the other hand, east of the range winter pruning is advised, as the trees are inclined to premature bearing and consequent stunted growth, which is corrected by the severe winter pruning or cutting back, which favors vigorous growth of young shoots.

In the prairie States fruit trees make quite rapid growth, 
and as stated by Professor Card fruit will eolor and develop in the interior of thick-topped trees, and it often happens that orchard fruits of all kinds exposed to the sun are scalded on the exposed side by sun heat. Young trees properly shaped when started in orchard are mainly grown on the let-alone principle, except in the way of eutting out dead twigs and such weak interior growth as eannot have exposure of leaves to the air and sun. The thick-top principle of fruit-growing is sustained by the fact that where the new growth of young orchard trees is cut back in autumn for three or four years in succession the top becomes very thick on the outside. Yet these trees bear finely eolored fruit beneath the thick exterior and better average crops than thimner-topped trees of the same varieties. But in quite moist regions of the East and South where moss grows on north-exposed house-roofs, or Spanish moss hangs down from tree branches, the old plan of thinning out to let in the sun will always be practised.

144. Heading Back 0ld Apple- and Pear-trees.-With the thick-topped plan of the prairie States and the arid regions, or the more open-topped plan of the moister belts, the bearing wood as the trees get old becomes far remored from the center of the tree. The time has now come for severe eutting back of the top, as is practised with old peach-trees. With the apple and pear in the dent-corn belt this severe heading back is an epoch in the life of the tree, and the shock is too severe if the cutting is all done at cne time. The safest plan is to cut one half the tree at a time, deferring the work on the other half to the next year, when the growth of new shoots is a relief from the injury liable to occur from sap-pressure. If two years are taken for the severe heading back of old orehard trees in connection with culture and manuring, new growth starts vigorously from the cut-back stubs and the 
water-sprouts that start in the irterior, and the trees may be said to be rejuvenated. During the period of eutting back little fruit will be gathered, but the bearing stage is soon renewed with increased size and perfection of fruit and the longevity and profit of the trees are much increased.

145. Training Dwarf Apple- and Pear-trees. - The use of dwarf apple- and pear-trees is becoming more general in nearly all parts of the States. Apple on Paradise roots and pear on.quince are now popular for amateur use, and even market, in sections where the roots are not liable to be injured by winter. In the prairie States apple-trees budded on Pyrus Toringo and plum on sand-cherry (71) stocks are coming into use, but as yet we have no dwarfing stock hardy enough for the pear.

The dwarf apple- or pear-tree as received from the nursery is usually given a rounded top secured by nursery pruning. Such trees are formed by heading back the one-year-old shoot about one foot from the ground and forming a rounded head by after-pruning. But if an approach to this form is kept up in orchard, continued attention must be given to pinching and heading back. Even the dwarf pear without the annual shortening of the new growth will soon reach undue proportions for a dwarf, even if it does not root from the scion when planted quite deeply.

146. Pruning for Cordon-training.-As the years go on apple-, pear-, cherry-, and plum-trees, trained as shown in Fig. 59, will become as common in this country as in Europe. It is known as simple cordon-training, and with dwarf apples and pears, and small growing varieties of the plum and Morello cherries, it is about as simple and easy as growing grapes on a wired trellis. At first those unacquainted with the system will say that it is an 
unnatural plan to adopt with trees. But the same may be said of the grape naturally running to the top of tall trees. With the tops all trained to the south, or indeed in any direction, along a road or walk, with the top of one tree meeting the stem of the next one, they form an unbroken growth, giving a handsome effect when loaded with fruit. In starting, the young trees are planted about ten feet apart and grow vertically at first and at proper height are bent for horizontal training along the wire.

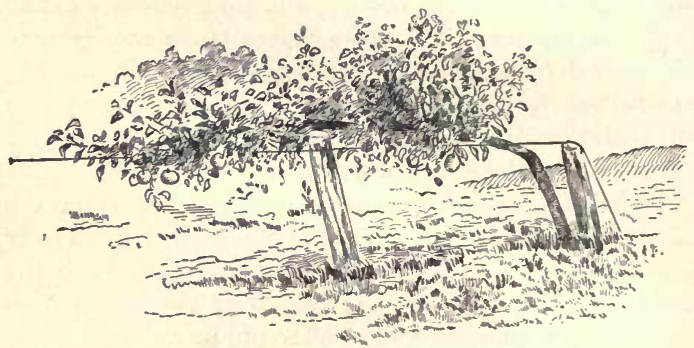

Fig. 59.-Cordon-training to the south. (After Bailey.)

The few attempts made in this country by foreign setters have given special satisfaction and pleasure. The stems and branches are covered with a garland of leaves and growth is so checked by the recumbent position of the bearing wood that early fruiting is secured. The exposed blossoms of the stone fruits are also less liable to injury by the weather extremes of spring.

The increased size and beauty of apples and cherries in interior climates when grown so near the ground is a surprise to all foreign visitors.

The annual pruning is in the way of cutting back two thirds of the new growth. The increase in length of the 
laterals is corrected by the occasional starting of new shoots from near the base, as with the grape.

147. Pruning to Shape Trees.-In the interior States young orchard trees are inclined to make most growth on the north side of the stem and top. This is corrected by summer eutting back on the north side. This checks growth and lessens growth of roots on the north side. If continued lightly on projecting points of growth for two or three years we can secure the most growth on the south side.

This applies to all isolated trees in the prairie States (26) and to a less extent in all parts of the country where the air is more humid. Even the evergreens and some shrubs in interior climates go out from the line of symmetry by greater length of shoots on the north side. In such cases the balance can be sustained by pinching the points of growth of leading shoots on the north side.

148. Pruning the Cherry and Plum. - The Morello varieties of the cherry form rather open, round-headed tops that need comparatively, little pruning if a welldefined stem and top are established when first set in orchard. As a rule, in all parts of the country where they thrive they will bear well without pruning except in the cutting out of dead twigs as they are noticed without regard to season. If at any time quite large limbs are cut the wounds do not heal over as readily as the apple or pear and usually form rotten spots, starting the exudation of gum. But the young growth can be shortened without injury where it is desirable to thicken up the top in interior climates, where it is often an advantage.

The duke and sweet cherries are upright in habit, and many commercial growers head back the top of young trees in orchard. In two or three years the natural habit is changed from the spire-shape to that of a round-topped 
apple-tree form. 'This plan better shades the stem and large branches, and shades the fruit more perfectly from the sun. The after-pruning consists mainly in taking out dead wood as it appears.

Some of the best native plums on rich soil make so much growth during the early stages of bearing that much of the bearing wood is exposed to the snn and the fruit is spoiled by scalding. This open habit is corrected by cutting back the new growth two or three years in suc. cession. When the heavy-bearing stage is reached, the long growths no longer appear and the only pruning required is taking ont the dead wood.

Some of the Japan and European varieties are also thickened in the tops by cutting back half of the new growth in the dormant period for two or three years in succession, when the trees are coming into bearing, to protect the fruit and broaden the tops for shading the stems and main branches. But it is now conceded by growers that cutting back the tops does not increase bearing or size of fruit. Its only value as indicated above is to shelter the fruit and better shade the stem and branches of some varieties.

149. Pruring the Peach and Apricot.-In peach- and prune-growing centres from California east to the Atlantic the commercial pruning is often excessive, literally cutting wagon-loads of brush to the acre. This severe thinning and cutting of side limbs is followed by excessive growth of new wood which forces summer cutting back to check excessive growth of new wood. Beyond all doubt this is an exhaustive and useless procedure where lighter annual pruning is possible under methodic management. The peach bears upon wood of the preceding year's growth mainly. Hence the growers who follow the directions of Charles Downing will secure the most perfect conditions 
for continued growth of firm bearing wood. He says: "Let us take a healthy tree in the orchard or garden in its first blossoming year. It is usually about six to eight feet high, its well-shaped head branching out about three feet from the ground. It has never yet been trimmed, except to regulate any deformity in its shape, and this is so much the better.

" At the end of February, or as early in the spring as may be, we commence pruning. This consists only of shortening-in, i.c., cutting off half the last year's growth over the whole outside of the head of the tree, and also upon the inner branches. As the usual average growth is from one to two fect, we shall necessarily take off from six to twelve inches. It need not be done with precise measurement; indeed, the strongest shoots should be shortened back most, in order to bring up the others, and any long or projecting limbs that destroy the balance of the head should be cut back to a uniform length. This brings the tree into a well-rounded shape. By reducing the young wood one half, we at the same moment reduce the coming crop one half in number. The remaining half, receiving all the sustenance of the tree, are of double the size. The young shoots, which start out abundantly from every part of the tree, keep it well supplied with bearing wood for the next year, while the-greater luxuriance and size of the foliage, as a necessary consequence, produces larger and higher-flavored fruit."

Where peach-trees are not subject to injury of top, as in southern Georgia at 'Tifton, or in California, the Downing plan, with such modifications as the age of the tree suggests, is still followed by methodic growers, with the added work of cutting out dead wood and all wood that has lost its usefulness. But in sections where the new wood is occasionally injured by winter, pruning is done on the 
principle of retaining a large majority of the buds found alive regardless of the form of the tree. With more favorable years the defects in form can be righted in large part. Pruning every year to regulate the supply of healthy bearing wood is the correct plan, and in reality it involves no more work than neglect for a few years, followed by the severe cutting back so often practised.

The apricot bears on the wood of the previous year's growth and on spurs of the newer wood. In the apricotgrowing centres of California under irrigation, the first two years, and the first half of the third year, are given to the development by pruning of a vigorous upright tree with good form and strong limbs, so arranged as to get the main crop of fruit near the centre of the tree. After fruitgathering while yet the foliage is perfect, the after-pruning consists mainly in cutting back half of the new growth over the whole top. This, with water at the roots, starts new growth on which fruit-buds develop for the next year's fruiting. The late summer pruning is continued until the time comes when the old wood must be cut out on the renewal plan for the formation of a new top.

East of the mountains the tendency of all the varieties tested under culture is to make long open growth when young. Hence the young trees need cutting back in the dormant period to thicken the top and increase the number of well-grown bearing spurs and shoots. After reaching bearing size summer cutting back of one lalf the new growth after fruiting tends to check the naturally rampant growth and seems to favor the holding and ripening of the fruit. But this cutting back is only needed in the early stages of bearing. As the trees get older the extension of growth will be less and the main pruning will be in the way of entting out dead wood and when the trees get old the shortening of the whole top (144). Old 
apricot-trees will bear this eutting back as well as the apple, if a few limbs are taken out each year until a new top is formed, as is done in California.

150. Pruning the Orange.-This semi-tropical fruit is included mainly to sustain the principle now so generally favored of growing thick tops in hot, relatively dry climates. Professor Wickson, of California, says: "The best form of tree is a low-headed compact growth. When young the stem must be protected by wrapping with paper or something of the kind until the leaves do that service. The lower branches will bear the first fruit, and as the tree attains age they will stop growing and can be removed. Thus the head of the trees is raised gradually and space is given for the drooping of the higher branches."

Visitors to California, Florida, and Cuba will be surprised by the thick foliage, under shelter of which perfect oranges develop, just as perfect fruits of all the orehard varieties in the arid States and prairie States east of the Rocky Mountains develop under the shelter of the outer thick foliage of headed-back trees.

151. Pruning the Quince.-The blossoms and fruit of the quince appear on new shoots of the same season's growth like the hickory, butternut, walnut, and some roses. That is, when growth commences in the spring no flowers appear; but after the terminal shoots have grown several inches the flowers appear at the top of the season's growth. Hence in pruning the quince, any attempt at cutting back will take away all the fruit-bearing wood of that season. Thus the pruning of this class of trees and shrubs, known as "co-terminal," is confined to removing dead wood and the interior growth no longer bearing perfect leaves or fruit.

152. Pruning and Shaping Shrubs.-All our ornamental shrubs of the lawn and park may be divided into three general classes as to habits of flowering and pruning: 
(1) Those that flower on the same season's growth, such as the rose, harly hydrangea, privet, mock-orange, and tamarix, should be cut back more or less severely in the dormant season. This cutting back of the new growth, and in some cases still lower, increases the number of new shoots on which the flowers appear. In the North and Northwest, where the best bybrid roses and such shrubs as Spircea callosa are not hardy in open exposure, the winter covering is easier when severely cut back to prepare for blooming the next summer. In milder climates where the natural shape can be retained the needed supply of bearing wood can be kept up by merely cutting back the growth that reaches out beyond the line of symmetry and shortening some of the inside growth.

(2) Many of our best shrubs bear flowers on the points or top of new growth that starts from wood of the preceding year's growth, like the grape and quince; others develop flowers on the preceding year's growth. With these classes it is evident that cutting back the top will remove the bearing wood, especially when cut below the new wood. Hence such shrubs are headed in as soon as the flowers fade. This light cutting back of points of growth starts an additional growth of new shoots to flower the next spring. Some well-known shrubs of this class are flowering almond, snowball, weigelia, exochorda, forsythia, Prunus triloba, lilac, tamarix, and some spiræas.

(3) A few well-known species, such as barberry, caragana, white fringe, bush honeysuckle, and kalmia, do not need pruning except when they get some age, when the pruning consists in cutting out some of the old wood, as in pruning the currant and gooseberry.

As a rule, in about all shrub pruning the operator must observe from actual inspection whether the flowers grow on the ends of terminal or lateral shoots of that season's 
growth, or on the ends or sides of the preeeding year's growth.

153. Pruning and Shaping Evergreens.-The varieties and species with upright habit of growth and upright leader, such as the spruce and fir, should have a low, quite broad base and symmetric form of top. In transplanting on the lawn from the nursery the most perfectly developed side should be turned to the south. This side, which in nursery has had the most light and air, usually needs, when planting, some shortening of the points of growth. The after eare will be in the way of pinching too vigorous points of growth as observed, and if the leader is broken off by sleet or stock, provide another upright point by turning up a side shoot and tying it to the stub. With a little continued care in merely pinching terminal buds the required form can soon be established. The species that do not form leaders, such as the hemlock, only need attention in the way of equalizing growth by pinching projecting points of extension, especially on the north side.

154. Pruning Ornamental Hedges and Screens.-The lawn hedge on the border or beside a walk must show uniformity of outline and thickness of base. The only durable forms are those with broad base and an approach to conical form, as shown in Figs. 60 and 61 . The orna-

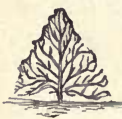

FIG. 60.

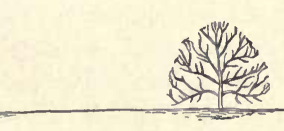

FIG. 61.

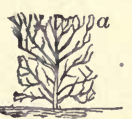

Fig. 62.

Figures 60 and 61 give correct form of hedge. Figure 62 will not give favorable results.

mental hedge with perpendicnlar sides is a failure in a few years. Even in California, where privet hedges were usually trained as shown in Fig. 62 a few years ago are 
now disfigured by dead patches. With plants of the habit of growth of privet, if needed strength of root is secured, they must be planted twenty inches apart, and as a start for securing a low base the plants must be cut off when planted to stubs only six inches in height. The first growth must be largely lateral as a foundation to build on. Each year thereafter the top can be raised, with sheared sides, until the required height is reached.

With such evergreens as white spruce and hemlock this severe cutting back at first cannot be practised. But by using plants not more than ten inches in height the lateral growth for a base can soon be secured by pinching or slight clipping of the up-growing points.

The main pruning should be done in the dormant period, but the lighter summer clipping of deciduous plants and the pinching or light clipping of the conifers, must also be kept up while the hedge is forming and after its final height and width have been reached.

In planting for ornamental screens plants can be used with a natural thick base, such as lilac, caragana, and Amur barberry. With slight pruning at top and sides these can be kept in neat form, while heavy pruning would take off most of the flowering and fruiting wood. 


\section{- chapter Xit.}

\section{SPRAYING FOR INSECTS AND FUNGI.}

- 155. Evolution of Spraying.-In the sense in which the word spraying is now used we may say that it is an operation of our day. In commercial fruit-growing centres of California, and indeed of all parts of the Union, spraying for the destruction of insects and lessening injury of plant, tissue by fungi has become almost as necessary as tillagepruning, and other leading essentials of fruit management. In Europe, France took the lead in this important work. But it was not until the appearance of the downy mildew upon the grape in $18 \% 8$ that any real advance was made in the way of methodic spraying. Indeed, it was not started until 1882, when Paul Oliver used the solution of water, sulphuric acid, sulphate of iron, and sulphate of copper for fungous diseases of the pear.

In 188\% the writer on a visit to France found spraying with sulphate of copper on the grounds of Sir Henry Vilmorin, south of Paris, and in 1883. Millardet wrote: "Recent observation makes me hope that perhaps the most satisfactory results may be obtained by the use of certain mineral solutions, such, for example, as the sulphate of iron or of copper." But it is singular that the practical use of the discovery was not made until spraying with milk, lime, and sulphate of copper was given along roadways and in exposed places to prevent the stealing of the 
grapes. The writer in 1882 was surprised to see vines with leaves and fruit covered with a light-blue coloring matter. It was soon found that the vines thus " poisoned" -as the people were led to believe-were the only ones that retained their foliage in the infected districts in 1882.

It was not until 1885 that Millardet gave the formula for making what is now known as Bordeaux mixture, but it was at first applied with a broom. So far as known to the writer the first perfected spraying machines used in Europe were made in the United States.

In the United States the first spraying, or rather sprinkling done with a broom, was in 1860, when the currant and gooseberry worm made its first appearance. A solution of hellebore in water was then used. In $187 \%$ the Colorado potato-beetle had extended over Iowa, and the first remedy used was spraying with Paris green, which was only partially successful on account of its varied purity. The sudden demand for the article led to adulteration to a remarkable extent. In $18 \% 7$ an agent of Hemanway \& Co., of London, visited Ames, Iowa, with a view to securing a trial at the Agricultural College of a waste product of their analine dye-works as an insecticide. In February, 18\%8, three kegs of the waste under the name of "London purple" reached Ames and were tested in the summer of $18 \% 8$ by the writer. At Ames the potato-beetle was then at its height of development and destruction. In the fall of $18 \% 8$ the writer gave in the Iowa Agricultural College Quarterly the following statement: "Jast winter the coilege received for trial a quantity of a material called by the manufacturers London purple, and designed to be used for the Colorado potatobeetle (the potato-bug of common parlance). Upon trial it was found very valuable, killing the old as well as the young insects with great certainty. The virtue of London 
purple lies in the arsenic it contains, just as in the case of the Paris green. There are, however, several advantages possessed by the new poison over the old, among which are: (1) its extreme fineness, permitting it to be mixed with water; (2) its adhesiveness: when once applied it adheres tenaciously to the leaves; this is due no doubt to its finely divided condition; (3) its purple color enables one always to detect its presence on leaves even when it exists in very small quantity; this will not only guard against accidents, but at the same time be of considerable account in enabling one to always know when it is necessary to make another application; (4) its cheapness as compared with Paris green."

At that time Hon. John N. Dixon, of Oskaloosa, Iowa, was a trustee of the Iowa Agricultural College and was the owner of one of the largest apple orchards in the State at that time. The canker-worm visited this orchard in 187\%. In 1878 he reported as follows in the Iowa Horticultural Report: "My success with these chaps has been so encouraging that I am very willing to talk about it. I mix a pound of arsenic in one hundred and fifty gallons of water, heated in a sort of sorghum-pan concern got up for the purpose. I dissolve the arsenic by boiling in much stronger proportion than this, but I am careful to add water when the liquid is put in the barrels for use, so as to make the proportion as above stated. The pump I use for throwing the water over the trees cost, in Chicago, sixteen dollars. I load the barrels of water in a wagon and drive on the windward side of the row to be sprinkled. I find I can thoroughly poison the foliage by showering from the one side. I first tried the Paris green, but found it expensive and liable to burn the leaves; it is also a dangerous stuff to use. The arsenic water makes a delicate coating of arsenic over the leaves, but the rains soon 
wash it all off; long before the fruit reaches maturity the last vestige is gone. I showered three thousand trees, when the most advanced worms were about full size; one application killed every one of them, and I have not seen a worm in the orchard since. I tried a solution of concentrated lye; the worms were soon on the ground, but they were soon on full diet in the trees again. The arsenic dodge they can't stand; in thirty-six hours every one turns black, and their bodies break like a pipe-stem."

It so happens that the season most farorable for killing the canker-worm is the most favorable for spraying for the codling-moth. Helice in spraying for canker-worm he met with the first great success in destroying the codlingmoth. He marketed carloads of apples in Minneapolis in 1878 entirely free from worms or worm-holes. John Smith, an extensive orchardist at Des Moines, and A. R. Whitney, of Franklin Grove, Illinois, made the same discovery in fighting the canker-worm, and Mr. J. S. Woodward, of Lockport, New York, also made the discovery in regard to the destruction of the codling-moth when spraying for canker-worm.

The florists were far in advance of orchardists in the use of insecticides, such as whale-oil soap, potash, pyrethrum, kerosene, buhach, tobacco infusions, and hot water for insect destruction. The use of kerosene emulsion and pure kerosene and raw petroleum in orchards is not new, especially the emulsion for the sucking and scale insects. It was first used by the florists, and for fighting the currant worm in 1868 and $18 \%$, but its commercial use began with orange-growers in Florida and California as late as 1882. But it was not until 1886 that the formula for scale as now used was generally recommended. Kerosene and raw petroleum were used on house-plants and greenhouseplants, and on the wounds made by cutting off plum 
knots, by the writer as early as 1876 , and at the Exposition in Philadelphia it was recommended for scale insects by European florists. On the plum-knot wounds it was used freely, but on oleander and other plants infested with scale it was used on the cloth with which the scale was wiped off.

The present use of kerosene and petroleum for scale and other insects by spraying trees in the dormant period dates only from the advent east of the Rocky Mountains of the San José scale. At this time (1901) the final effect of drenching trees with kerosene or petroleum prior to leaf expansion is not fully known. Apple and other trees well drenched by spraying two years in succession show clean bark and general thrift not found on unsprayed trees.

Since 1885 the appearance of the apple scab, grape rot, anthracnose, and other fungi in large commercial plantations has led to hundreds of trials at the experiment statious and by private growers of various fungicides. At this time nearly all the experiment stations send out each year spraying calendars giving reliable information up to date. Those interested in a more minute statement of the recent evolution of spraying are referred to Lodeman's reliable book on "Spraying."

156. Spraying for Codling-moth-Arsenite of Lime Solutions.-John N. Dixon in $187 \%$ and 1878 used a weak solution of white arsenic (155). With increased experience he wrote in 1881: "I consider the arsenic solution as complete a remedy for the codling-moth as for the cankerworm. When the apples are from the size of a bird-shot to that of a pea, if the orchard is carefully sprinkled with arsenic water at the rate of one pound of white arsenic to two hundred gallons of water it will not leave a cankerworm, codling-moth, tent-caterpillar, or buculatrix in the orchard. In view of this perfect and inexpensive remedy, 
we do not now consider these insects as any serious obstacle in the way of successful apple-growing, and we cannot see any reason why the remedy might not be successfully used on garden insects and on the grasshopper, cotton-worm, army-worm, Hessian-fly, and chinch-bug. One man with a driver and team can sprinkle twenty acres in a day for protection against any of these insects." *

But some entomologists yet prefer the Paris green, London purple, or other forms of the arsenites. The reasons given are that they are safer and less liable to burn the foliage than pure arsenic. But the writer can see little force in this argument, as John N. Dixon and others have found that one pound of white arsenic to four hundred gallons of water will do the work with the cankerworm, codling-moth, strawberry-worm, and tent-caterpillar, and this will not harm the tenderest foliage.

Until recently entomologists have not farored the use of pure arsenic, but the Paris green and London purple are so variable in quality as sold by druggists, and white arsenic is relatively so pure, that definite proportions can easily be secured. So a change in opinion is now evident in several States. At this time the spraying calendars give such statements as that of Professor Summers, who says: " As white arsenic, as found in the market, is little liable to adulteration, this insecticide is less liable to vary in strength than Paris green. The cost of materials is also somewhat less, and when an arsenite is to be used in such large amounts that the trouble of preparing is not an important item we strongly recommend the use of this compound." But lime or sal soda is now used in solution with the arsenic. This changes the color of the stock

* Premium essay by Hon. J. N. Dixon, published in Iowa Hortisultural Report, 1882. 
mixture, making it safer to store for further use, and it is claimed that it is less liable to burn the foliage. The approved formula now used is to boil in the open air one pound of white arsenic and four pounds of sal soda with one gallon of water until dissolved. This kept in a jug labelled "Poison" constitutes the "stock mixture." When wanted for use add the milk of three pounds of fresh lime, strained to remove sediment, to forty gallons of water. Into the lime solution pour one pint of the stock mixture and mix thoroughly by stirring. This is the formula used in spraying for codling-moth, canker-worm, and all insects that eat foliage or fruits.

In spraying with Paris green the formula used is one pound of Paris green and one pound of fresh lime in two hundred gallons of water.

Even where the slaked lime water is strained this mixture is apt to clog the sprayer and its strength is not as uniform as in the use of the arsenic and soda, and the same is true at this time of London purple.

157. Curculio of the Apple, Pear, Plum, Apricot, Cherry, and Peach.-The species of the curculio that penetrate the fruit of the apple, pear, plum, apricot, cherry, and peach are not identical, but their methods of working and treatment are nearly the same. The apple and pear curculio does not often do much damage at the North, but in some of the Central States it is very destructive in the way of knotting and distorting the fruit. The plum curculio also frequently feeds on the apple and its work is about identieal with that of the apple curculio.

The plum curculio or "Little Turk" is the most serious pest of the plum orchard, and it also works on the cherry. The plum, prune, apricot, and peach usually drop the fruit that is perforated by the grub when the pit is reacher. But the cherry does not drop, but comes to the front 
in the hands of the user under the name of "wormy cherries."

A common habit of all the curculios is, when alarmed, to draw up as if dead and drop to the ground. Advantage is taken of this habit in the way of jarring the tree, causing the dropping of the insects on sheets spread beneath during the first stages of fruit development. In the larger fruit sections an inverted umbrella-like frame covered with cotton cloth, divided in the centre so as to pass the stem, is rolled on low wheels under the trees for the reception of the curculios. The morning and evening are found to be the most favorable periods for this work. In some of the largest commercial stone-fruit orehards of New York, Ohio, and Georgia this plan keeps the curenlio in check with less trouble and expense, it is claimed, than can be done by spraying.

But spraying is relied on by other growers of the cherry, plum, and peach. The trees are sprayed, just as the buds begin to expand, with arsenite of lime solution (156). This reaches some of the adult insects under bark scales, and many are on hand to feed on the first opening leaf and fruit buds. The second spraying with the same mixture should be given soon after the blossoms have fallen. If rains follow a third spraying may be required.

In spraying with the arsenite of lime for codling-moth and curculio we are also waging a successful warfare on the canker-worm, tent-caterpillar, bud-moth, and about all leaf- or bud-eating insects.

\section{Spraying for the Bark and Leaf Aphis.}

Kerosene Emulsion.-The scale insects, plant-lice, and the true bugs (Heteroptera) that suck their food from the leaves or young growth of plants and trees cannot be controlled by spraying with the arsenites or other poisons used for the bud- and leaf-eating insects. The leading remedies 
for this numerous family are whale-oil soap, kerosene emulsion, and infusions of and powdered tobacco. But the standard solution tliat can be used profitably on all types of the sucking insects is kerosene emulsion. Kerosene has been used for many years in a pure state by carefully applying it to the insects or wiping them from the leaves and stems with a cloth moistened with kerosene. The next move was to mix it witl water for spraying. But not until soap or oil was added to the solution could a perfect mixture of the oil and water be effected. It is said that dealers in kerosene, when it commanded a higher price than at present, first made the discovery that oil and soft water would mix when a solution of soap was added. The use of the kerosene emulsion was quite common, when the writer visited west and east Europe in 1882, for the destruction of the several species of aphis in greenhouses, and at Proskau in north Silesia it was used for the bark and leaf lice of the orchard fruits. In this country the first one to use it known to the writer was Professor Cook, then professor of entomology at the Agricultural College of Michigan. During a visit to the Michigan station in 1878 the writer was shown the beneficial effects of spraying for sucking insects with a mixture of kerosene and soapy water.

The usual formula for making kerosene emulsion is to shave one half pound of ivory soap or whale-oil soap in one gallon of soft water and boil until dissolved. The kettle is removed from the stove and while boiling lot two gallons of kerosene are added that has been previously warmed in the sun or in a warm room. The mixture is then agitated by active stirring for ten minutes. If not very hot the mixing is often effected by forcing it through the sprayer back to the ressel until it is creamy in color and will flow evenly down the sides of the pail or tub. 
This stock mixture is diluted for use with from eight to fourteen parts of additional water. The apple- and pear-leaves when mature will bear an admixture to the stock of twelve or thirteen parts of water. But the stone fruits require a weaker solution of fourteen parts of water. In the dormant period spraying for aphis, to reach the eggs, only enough water is used to make it possible to use the solution in the sprayer.

159. Leaf Aphis of Apple, Plum, Cherry, and Peach.These are not identical species, but their habits are about the same. With the apple the winged lice lay their eggs around the buds of the new growth, which hatch into green lice as the buds begin to expand in the spring. It is about the same with the leaf and young-twig aphis of the plum, cherry, and peach, as the eggs are exposed at the base of the buds prior to the starting of growth in the spring.

The remedy is spraying in the dormant period with kerosene emulsion (158) made very strong, followed by spraying with the ordinary emulsion when the young lice appear. Still later the nearly mature insects can be reached that have escaped the first spraying by turning the nozzle upward to reach the under side of the leaves on the new growth.

The same solution can be used in spraying for leaf lice in the greenhouse, garden, and nursery, but cases may occur, as with the cabbage aphis, where hot water or pyrethrum is to be preferred.

160. Spraying for Scale Aphis.-This is a common trouble with the apple orchards in about all parts of the Union. During the summer little can be done, as the insect is well housed under its scale. In the spring the scales cover a number of light-colored eggs that usually at the North hatch in May. When exposed the young insects may be seen in great numbers on the younger growth. 
Before growth starts in the spring the eggs can be largely destroyed by spraying with kerosene emulsion made very strong. The kerosene and soap solution penetrates the scale and destroys a large proportion of the eggs. When the young insects appear in May the spraying is repeated with the emulsion of ordinary strength. This plan of spraying also destroys the woolly aphis and the scurvy scale-louse. It is not yet certain that the spraying in the dormant period with raw petroleum of good quality or a good grade of petroleum will harm the trees. The kill or cure methods of warring with the San José scale has seemed to demonstrate that petroleum and kerosene are not as harmful to the bark and buds of trees as had been suspected, and this agrees with the writer's experience on a smaller scale. But we have had more favorable experience on dormant trees in killing scale insects with kerosene and soap emulsion made with larger proportion of kerosene than usual than with the modern pumps using a mixture of kerosene and water, and far better than with whale-oil soap.

With proper care the scale-lice of the deciduous fruits can be controlled largely by spraying in the dormant season. But the different scale insects of the citrus fruits are not so easy to manage, as the persistent foliage prevents the use of kerosene or petroleum strong enough to penetrate the scales without injury to the leaves. Some of the least harmful species are kept in check by spraying when the insects are exposed with kerosene emulsion, whale-oil soap, or the resin solutions. But where the San José scale joins forces with other species the tent system with fumes of hydrocyanic-acid gas is the only certain method. In California parties with proper outfit make a business of clearing orchards of scale insects by this method. Nursery stock is now also fumigated with this 
gas in tight boxes or houses since the advent of the San José scale east of the Rocky Mountains.

161. Some Miscellaneous Insects.-The amateur and beginner in fruit-growing and home-making should keep in mind the-fact that about all our injurious insects may be divided into two general classes. (1) Those that have jaws for eating, such as the strawberry-worm, cankerworm, curculio, caterpillars, and beetles can be destroyed by spraying with poisons. (2) The scale insects, plant lice, true bugs, mosquitoes, and all insects with mouths fitted for sucking their food from the inner tissue of leaf, bud, or young wood must be destroyed by some application such as kerosene applied on their bodies or by some deadly gas. Kerosene in emulsion of soap has become a leading remedy, as it is about the only spray that will penetrate the scale, and it paralyzes the young insects as soon as it touches them.

In some cases it is not advisable to use poisons to destroy the gnawing insects. As an instance, the cabbageworm cannot be attacked by poisons when the worm is most active. So gardeners use very hot water to destroy the worms and others use a repellent that the butterflies will avoid, such as water that has stood on coal tar until well scented. As the worms are slimy, others dust the worms with wheat flour that kills them by closing their pores. Hellebore powder is also used, as it kills the worms and is said to lose its strength when exposed to the air.

The currant and gooseberry worm is destroyed by large growers by spraying with weak arsenite of lime when the leaves are beginning to expand and when the leaves are about fully grown. But the amateur is apt to wait until the fruit is half grown. In this case hellebore in powder, or mixed with water, can be used as above stated. If the 
arsenic solution is used early it is safe, and it destroys about all other leaf-eating insects of these fruits.

'The strawberry worm is checked in its work by spraying with a very weak solution of arsenic and lime if the work is done when the first scattering holes appear in the leaves. If neglected until the fruit is half grown it will not answer to spray with poison, but its work may be prevented the next season by mowing, and when dry, burning over the patch, which usually requires a sprinkling of straw. The strawberry-leaf roller is difficult to reach with poisons before the crop ripens. But spraying in August will kill the second brood and their career for the next season will be stopped. In applying the different classes of remedies the use of a standard work on spraying will prove an aid to the close-observing cultivators; such a work includes insects that only become numerous in localities over the Union.

The flat-headed and round-headed borers of fruit trees (130) have been treated in times past with sprays and washes to keep the insects from the trees, but all have been failures in whole or in part. The sure treatment is to crush them in their burrows with a flexible wire as stated and use the soap wash as a repellent.

162. Spraying for Fungous Diseases-The Bordeaux Mixture.-It is an interesting fact pertaining to the now general use of the sulphate of copper for controlling the fungous diseases of cultivated plants that its value for such use was discovered by chance (155). In south France near the city of Bordeaux, grape-vines near the highway suffered loss by stealing of the ripe fruit. The practice soon became quite general of sprinkling the foliage near the highway with a solution of milk of lime and sulphate of copper. This colored the leaves and gave rise to the belief that the fruit was poisoned. It was soon noticed 
that the vines thus treated were relatively free from mildew. Since that time the use of what became known as the Bordeaux mixture has rapidly extended to all parts of the earth occupied by civilized man, and is used for controlling nearly all fungous diseases of the orchard, vineyard, small fruits, flowers, and garden crops. The most approved formula for making the Bordeaux mixture at this time is to dissolve four pounds of copper sulphate in two gallons of hot water in a wooden pail with constant stirring. When dissolved pour the solution into the barrel or tank to be used, adding five gallons of hot water. Then slake four pounds of fresh lump lime thoroughly and strain the milk through a brass strainer-with not less than thirty meshes to an inch-and while hot pour it into the tank with hot water enough to make a total of fifty gallons.

In using, the solution must be kept stirred to prevent clogging the sprayer and to secure an even distribution. Some successful users throw away what is left and clean the tank and pipes and make a fresh supply at each successive spraying. But others-including the professional sprayers-keep on hand a stock solution of the sulphate and slaked and strained lime in separate barrels.

For the stock solution one pound of sulphate is dissolved in one gallon of hot water. In this proportion a barrel of the solution will keep through the season if well covered, and the same is true of the milk of lime in a separate barrel. In use the lime and sulphate are mixed in the proportions wanted for varied uses as noted in succeeding sections.

163. Apple and Pear Scab.-Excepting perhaps the codling-moth the scab is now the most destructive and widely spread drawback to apple culture and to a less extent of the pear. It is now so general in commercial 
apple-growing centres that every dealer and grocer in the Union is compelled to handle scabby Baldwin and most other leading commercial varieties. The fungus is first seen on the leaves in the form of smoky-brown patches. But it soon extends, changing the color and healthy expression of the foliage. The spores live over winter on the fallen leaves and on the branchlets of the trees. Hence it is advisable to plow under or to rake up and burn the leaves. In spraying it is usually advised to use the standard Bordeaux mixture (162) for the first as well as the after treatment. But the best results have come from spraying before the trees start growth with a inuch stronger mixture. Our practice has been to use six pounds of the sulphate to the milk of four pounds of lime, with water to make a total of fifty gallons.

After the blossoms have fallen the standard mixture may be used. In dry seasons the two treatments are sufficient with most varieties. But in neighborhoods where the scab is prevalent it is better to spray not less than four times, with intervals between of from ten, to fifteen days.

The spraying for scab will also answer to keep down the bitter rot, powdery mildew, and to some extent the apple rust.

164. Brown Rot of the Stone Fruits.-In the dry air of the prairie States the brown rot or fruit rot of the stone fruits is mainly confined to the foreign plums and the peach. It rarely attacks the native varieties of the plum, and the writer has never observed it on the Morello cherries. But in the moister air of the States east of the lakes it is a prevalent and serious trouble of the plum, prune, apricot, peach, and often the cherry. But fortunately it can be largely controlled by the methodic use of the Bordeaux mixture. The first spraying is done 
before the buds start, using one pound of the copper sulphate dissolved in fifteen gallons of water without adding milk of lime. When the buds are swelling use the ordinary Bordeaux mixture. When the leaves are fully expanded it is best to use a weaker mixture on all the stone fruits to prevent burning of the leaves. Two pounds of sulphate, two pounds of lime, with fifty gallons of water, has given best results.

To prevent the show of lime on the fruit of the plum and peach, the last treatment is given with a solution of ammoniacal carbonate of copper (165).

The treatment for the rot is equally effective in controlling the leaf spot or blight which, east of the lakes, often causes the premature dropping of the leaves of the foreign plums, and winter injury to the trees.

The same treatment also is mainly a preventive of what is known as "plum pocket." This is a disease to which some of the native plums are subject, which causes the fruits to assume the form of enlarged hollow bladders or pockets. But in addition the pockets shonld be picked and burned and also the swellings found on the leaves and twigs. In the rot of the stone fruits it is also a material aid to pick off and burn the dried fruits that hang on the trees after the leaves have fallen.

The black knot of the plum and sour cherry is also controlled by spraying as practised for destroying the rot of the stone fruits, with the addition of shaving off the knots as they appear and applying kerosene to the cut surfaces.

165. Fungi of the Grape and Small Fruits.-The different forms of rot of the grape, especially in the South, such as black rot, brown rot, and ripe or bitter rot, are controlled by a similar system of spraying. The usual plan has been to begin the spraying after the diseases begin to 
appear. But recent experience favors the first spraying with the double strength Bordeaux mixture before growth starts in the spring and continue with the ordinary strength at intervals of two weeks until the fruit is two thirds grown. During the seasons when the black rot is specially common the later applications, to prevent coloring of the fruit, are made with ammoniacal carbonate of copper, which is made by dissolving one ounce of carbonate of copper in one pint of strong ammonia. When used it is diluted with from eight to ten gallons of water. This solution is used in place of the Bordeaux mixture on ornamental plants and in all cases where the standard mixture is liable to color fruits. The powdery mildew of the grape is a surface-feeding fungus and easier to manage than the rots. If it occurs in connection with the rots the ordinary spraying will destroy it. But at the North and in the West it often occurs as a single disease. In such cases the flowers of sulphur is often used in a dry state by dusting, or by spraying with sulphured water. If it occurs when the fruit is well advanced the carbonate of copper dissolved in ammonia is used.

As with the raspberry the anthracnose or bird's-eye rot of the grape is the most difficult disease to treat successfully. This is an old discase of the grape in the wineproducing districts of Europe. The European treatment has proven successful where tried in this country, but it must be methodically practised. In the dormant season the canes, vineyard-stakes, and wires are washed with a solution of water, iron sulphate, and sulphuric acid. The formula is one hundred parts of water, with as much iron sulphate as the water will dissolve. To this mixture one part of sulphuric acid is added. It is applied with swabs or brushes with quite long handles and it blackens everything it touches. It needs care, as it is caustic if it gets 
on hands or clothes. In the growing season the usual sprayings for the rots are also favorable for keeping down the ravages of the anthracnose.

The strawberry-leaf blight and mildew can be controlled by spraying with Bordeaux mixture as soon as growth starts in the spring and repeating it when the blossoms are about to expand. If the diseases are well established it is best to mow and lightly burn over the plantation after picking-time. But some mow and rake the litter from the ground before burning, as they believe the burning an injury to the plants, which it is in a dry time. But when the ground is moist we have noted no injury, even where a light straw covering was given to assist in burning.

The anthracnose of the raspberry is most easily attacked by spraying with very strong solution of copper sulphate before the leaves expand in spring, followed with the Bordeaux mixture every two weeks until midsummer.

But the writer's long experience favors the destruction of plantations attacked by anthracnose or red rust and to plant on fresh ground, if possible, where the plants are sheltered from the direct sweep of the westerly winds. 


\section{CHAPTER XIII.}

THE APPLE, PEAR, AND QUINCE.

166. Origin of the Cultivated Apples.-From prehistoric times the apple has been a leading cultivated fruit of the temperate zones. Poets and writers have sounded its praises, and it is mingled with the mythology of about all parts of Europe and Asia. The common statement and belief as to its origin agrees with that of Professor Bailey, who says: "The apple has come from two original stems. All the common apples are modifications of Pyrus malus, a low, round-headed tree with thick and fuzzy irregularly dentate short-stemmed leaves and fairly compact clusters of woolly-stemmed flowers. The crab-apples are derived from Pyrus baccata, commonly known as the Siberian crab. Hybrids between these species have given the race of large-fruited crab-apples of which the transcendent is an example. This race is known to botanists as Pyrus prunifolia."

This statement may need some revision and change. In east Europe the cultivated apples seem to be quite as ancient as in west Europe. The writer in connection with the late Charles Gibb investigated this question quite closely in 1882. Of the apples of that region Mr. Gibb wrote on his return: "The Volga is a very old applegrowing region. I am told that old poems written about the time when Ruric was upon the throne at Kiev-about 
850 - alluded to this. The maiden, whose neek was like a swan and whose lips were like cherries, had cheeks like a Volga apple. The high color of the apples of this dry region is very striking. A wild, rugged race of apples has been grown here for many centuries by seedling production, until we have a number of seedlings much alike in tree and fruit and hence it is that the name Anis is but a family name with many varieties."

The Marquis Pauluci in the province of Kazan, on the $5 \%$ th parallel of north latitude, was able to prove to the writer from documents in the family possession that apples similar to or identical with some varieties on his grounds were grown in that vieinity eight hundred years ago. Beyond doubt the apples of the great east plain of Europe and north central Asia were developed by culture, selection, and natural crossing from the indigenous wild applies yet common in the forests.

Dr. Henfrey speaks from personal observation in his geographical distribution of plants of the wild apple-trees of east Europe towering up to the height of other forest species, and Loudon, who was exceedingly careful in dividing true species, had no hesitation in placing the native apples of east Europe as a distinct species under the name of Pyrus Astrachanica. Central Asia also has the same high-colored type of cultivated apples peculiar to the Volga region. Dr. Albert Regel, who spent nine years in Turkestan and north central Asia, speaks of " Fierytinted harvest apples" and "Large round apples of beautiful carmine color and with bloom like a peach or plum." $\mathrm{He}$ also speaks of a winter variety in northwestern Badakshan as "A roundish-pointed apple of beautiful color, firm flesh, and delightful flavor.” Dr. Regel also states that high-colored varieties with rich bloom seem to have been anciently cultivated as indicated by the old 
records in the eity of Bokhara. Such facts indieate that Henfrey was right in assuming two natural centres of plant distribution on the eastern continent, one in west Europe and the other in east Europe and north central Asia.

The fact can be sustained that most of the apples of west Europe and the United States and Canada are mongrels. They may in a broad sense all belong to one species, but they are a mingling of races. The elose observer can find in France, Germany, and over west Europe dozens of varieties introduced from east Europe and many dozens of varieties that show in leaf, bud, and color and bloom of fruit traces of European and Asiatic erossing with the typical west European Pyrus malus. In the United States it is a suggestive fact that what are ealled the iron-clad varieties in the North and Northwest all show the birth-marks of direct introduction or descent from the type or race which Loudon elassed as Pyrus Astrachanica. Even such standard varieties as Ben Davis, Gano, Baldwin, and Westfield seeknofurther show in leaf, tree, and fruit an admixture with the anciently cultivated varieties of east Europe and central $\Lambda$ sia.

In the same way it is not wholly correct to say that our Siberian crabs are all derived from the Pyrus baccata of Siberia. In 1882 we found in far east Europe varieties of crab-apple with fruit growing in elusters quite as large as the hyslop or transcendent, with large leaves as fuzzy on the under side as the wild Pyrus malus of west Europe. The well-known Virginia crab belongs to this race, and we have reason to believe that several of our large crabs that fruit in elusters are crosses of this race with the Siberian crab. It is not as easy to secure crosses between the Pyrus baccata and the common apple as is usually supposed. 'Thomas Andrew Knight, of England, carried on 
experiments. in this line for many years. His object was not to secure additional hardiness, but to infuse more character and sprightliness into the common varieties. The outcome was in no case a union of the two species. The seedlings all divided into two classes. Those that bore in clusters were crabs and those that had the required size and fruited on spurs were common apples, in no case of desirable quality. The only varieties yet retained are the Siberian Harvey and the Foxley. These are very small, nearly round, and grow in clusters like the crabs.

A study of this subje $t$ from the Kew Gardens at London to the Volga bluffs in Rnssia will lead to the belief that at least some of our large crabs are crosses of the crabs of east Europe with what we call the Virginia crab and varieties of this type.

167. Our Native Crab apple.-The most valuable native species of the United States is Pyrus coronaria. As found in the prairie States it differs some in habit of tree and flower and fruit, and Professor Bailey has given it as a distinct species under the name of Pyrus Ioensis. This race as found in the early days of prairie settlement in the hazel-thicket borders of native timber belts varied in habit of growth, leaf, and size of fruit fully as much as our native plums. Some of the selected varieties attain fair apple size under cultivation. On the college grounds at Ames, Iowa, can be seen a tree loaded every year with fruit. overtwo and one half inches in diameter and of nearly the shape of a medium-sized Rhode Island greening. This variety is known as the Flnke crab. Mr. B. A. Mathews, of Knoxville, Iowa, grows for market a variety fully as large as the Fluke. In fact, in about every neighborhood of the prairie States-especially in Iowa-can be found isolated trees and sometimes several trees together of these large-fruited varieties. Professor Bailey expresses the be- 
lief that these varieties, with leaves approaching in size and structure those of the common apples, are hybrids with the latter class. But this cannot be true, as in the early . days (1856) on the writer's farm in Benton County, Iowa, several trees on a thicket border bore bright yellow crabs larger in size than any Soulard we have since grown, but not quite as large as the Fluke. At that early date there was not a bearing apple-tree in that vicinity, and the trees bearing the large yellow apples dated back to the years when the buffalo ranged over Iowa prairie.

These select varieties attain quite large size under cultivation. On the college farm at Ames may be seen two trecs of Soulard that are larger in stem and have greater spread of top than any Duchess apple-tree of their age in this region. But the quality of fruit of these large-fruited varieties is not as varied as has been claimed. All of them have the smell and flavor of the wild crabs of our thickets.

As to improvement in size and quality by crossing with cultivated varieties our long experience is given in section (106). In all cases we were able to secure crossed fruits, as was evidenced by change of form, but without a single exception the fruits were destitute of perfect seeds. All attempts to bud or graft it with scions of our cultivated apple have resulted in poor union of the woods, soon broken off by storms. The Bethlehemite for a time seemed an exception. Top-worked on the native crab this variety soon came into bearing and at first the fruit was of the usual size and flavor. But the size in four years became smaller and the flavor was decidedly disagreeable, resulting, as afterwards ascertained, from poor union of the wood of the two species.

By culture and selection it is now evident we can increase the size of our best varieties, but the peculiar perfume and a stringency of flesh will be apt to be retained in 
large part for many years. Yet in the quite-distant future we may develop from this hardy species a race of apples that will become favorites for many purposes and possibly for dessert use. At this time Mr. B. A. Mathews, of Knoxville, Iowa, grows the Mathews crab for market, and reports that he sells it for one dollar per bushel when orchard varieties are selling for from fifty to seventy-five cents. But the use made of them by purchasers is to mix with common apples for culinary use to impart a quince flavor.

168. Dwarf Apple-trees. - In the growing of handsome and good summer and fall apples in private gardens dwarfing on paradise or other dwarf stocks is often an advantage, as they can be grown along drives or even walks. Section (145) gives hints on shaping and the selection of stocks for different parts of the country. Such varieties as Longficld, Anisovka, Red Astrachan, Jersey sweet, Porter, Baldwin, Dyer, Benoni, and sweet Bough form fine rounded tops without much attention to pruning. If not wanted along roads or paths they can be given a small plot of ground where they can be planted about as closely together as the grape and closer than sour cherries and the plums. They come into bearing as soon as the grape and when six years old usually bear a bushel each season. At the West we have known the Longfield on Pyrus toringo stocks to bear one bushel of fruit four years after planting in garden. The needed pruning is given in section (145).

169. Propagation of the Apple.-Within recent years the growing of apple-seedlings has become a business carried on by specialists. In the prairie States for many years they have been grown as a leading crop for sale to propagators in all parts of the Union. This extended business has grown out of the fact that the strongest roots and most numerous nitrogen-feerling fibres are found on 
seedlings grown on the virgin soils of the prairies. As this class of land has become scarcer in Illinois and Iowa, the business has mainly receded westward, and now the. main supply is grown in Kansas and Nebraska. Where grown on older land, the best grade of seedlings is developed on newly broken sod-land, or following a rotation of clover or other legumes. When grown on old land with a short supply of humus the seedlings do not attain the needed size for root-grafting when one year old, and the cell-structure of the roots does not develop as perfectly as when grown on new land.

The seed used commercially is largely washed from the pomace thrown out from the cider-presses in apple-growing centres. As the apples used includes the bruised specimens and windfalls of the large-sized commercial varieties that develop weak seeds (4) this plan of saving seed cannot be commended for reasons given in section (71). The handling of the seedlings for winter-grafting is given in section (81) and propagation by budding and grafting are given in the same chapter.

170. Apple-planting and Management.-The planting and management of the orchard fruits have many common modes, methods, and principles in all climates. In Chapters VIII, IX, and $\mathrm{X}$ the leading essentials and principles of orchard management are given, and spraying is discussed in Chapter XII. The Tablo of Contents on the first pages refers to the varied sections. As examples: Selection of soil and slope, 96 and $9 \%$; orchard shelter, 99 ; washing of hill soils, 101; spacing and transplanting, 113; alternating varieties in the rows, 122; cnlture, 125; cover-crops, 12\%; pruning, 143; and spraying (Chapter XII).

171. Varied Season and Behavior of Varieties.-As grown on varied soils, altitudes, and with varied heat and 
length of summer, varieties vary exceedingly in season of ripening, coloring, and distinetive form and markings. As to season, many varieties that keep through winter east of the lakes beeome fail apples when grown on the darker and richer soils and in the drier and hotter summer air of the prairie States in the same latitude. The drier and hotter air also gives richer coloring to all varieties, as shown at the expositions in eompetition with the same varieties grown in cooler, moister elimates.

Varieties that prove good keepers on their northern limits of growth also become late-summer or fall varieties when grown in the Southern States. This is specially true in the Mississippi valley. Many hardy varieties that keep well, if picked at proper time (136) on the 45th parallel, beeome late-summer varieties even in southern Iowa.

Many varieties of the apple also have proven loeal in their adaptation to a given soil and climate. The Esopus Spitzenburg, as an instance, was originated at Esopus on the Hudson, where it has been grown eommercially for fifty years and the fruit exported to Europe on a large scale. It is still the favorite variety at Esopus, but is only double-starred by the American Pornologieal Society in four of the pomological districts of the Union, three of which are west of the Rocky Mountains. The Belmont heads the list near Cleveland, Ohio, and fails at Cineinnati. The Baldwin is a leading eommercial variety, yet it is only double-starred in one pomological distriet east of the Rocky Mountains, running from the Atlantic west to Miehigan.

The Ben Davis reaches its highest development in the dry, hot summer air of the southwest prairie States and in some of the arid States. But at present, on account of its hardiness, heavy bearing, and size and beanty, it is the 
one cosmopolitan winter variety grown more or less across the continent. A close study of the American pomological list will show that most varieties are relatively local in exact adaptation to soil and climate. In many cases varieties that fail to prove profitable in a given locality are materially benefited by top-working (89) on stocks adapted to the soil and elimate. In Europe this plan is understood and practised to an extent not yet reached in this country. Different stocks are used often in one vicinity, on account of the varied soils, exposures, and elevations. Professor Bailey says: “It must follow that the promiscuous and wholesale dissemination of a few varieties over the country must eventually cease and that local and special sorts must constantly tend to drive out the cosmopolitan and general varieties. In this country it is only in the strawberry that the peculiarities of adaptation of varieties to soils have begun to be well understood; and this is rather because the subject is forced upon the attention by the short generations and constantly shifting plantations of the plant than from any investigational motive." Section (139) discusses the desirability of fruit-growing centres. In apple-growing for market, there is special gain in extended plantings in sections specially adapted to the development of some of the leading commercial varieties, as it leads to systematic orchard management and the handling and sale of the crop to the best advantage. It aiso gives an opportunity for saving apples that would go to waste by drying, canning, and cider- and vinegar-making.

\section{The Pear.}

172. History and Some of the Races.-High-grade pears for dessert use may be said to be a modern development 
in west Europe and the United States. Pears were cultivated in the early days of the Roman Empire, but Pliny says of them: "All pears whatever are but heavy meat unless they are well boiled or baked." The real development of the pear for dessert use began in the seventeenth century. Belgium has the credit for the first remarkable advances of which Van Mons was the noted leader in the early part of the nineteenth century. The pears of west Europe were introduced into this country at an early day and at this time a large part of our best dessert and culinary varieties have been developed from the seed of the best European varieties and of the sand pear of China.

All modern writers make the statement that the modern dessert and culinary varieties have come from these two sources together with their American-born secdlings. They also include the Russian varieties introduced by the writer as a race of the Pyrus communis of west Europe. In reaching this conclusion a third distinet race or species that seems to have been anciently developed in central Asia has been overlooked. Dr. A. Regel, after living in Sungaria and Turkestan nine years, wrote: "The pear is more extensively cultivated in the Amu-Daria River district than in other parts of central Asia. The firm-fleshed pears of Suidum are famed for their rich aroma, and the large yellow pears of Sharsause are equally popular. The pears mainly grown in Darwas are a large green variety and a smaller sugary-sweet variety. In Shugnan there is a yellow pear which, on some trees in the garden of the Shah, develops singular forms like birds, and another variety with rarely rich juicy flesh and which attains considerable size." He speaks of varietics of large size and good quality that seemed to have been anciently cultivaterl. As Dr. Regel was educated in Germany, he was aequainterl with the pears originated by Van Mons and urged that the 
ancient pears of Oriental origin were superior to any he had tested in Germany.

These ancient good pears of central Asia seem to have been extended east of the Ural range, as the late Charles Gibb of Abbottsford, Canada, a month prior to his death in Cairo, Egypt, spent a few days in Mongolia. He wrote from thence to the writer, stating that he was surprised to find pears of large size and excellent melting, juicy quality grown on very large and old trees. All of the varieties had snow-white flesh, and it was claimed that they very nearly came true from seed. He enclosed a few seeds from which we have grown trees now in bearing. They differ some in season and size of fruit, but all have tender, melting, white flesh as good in quality as the Mongolian snow. The variety we have named Gibb bore quite a full crop last year in Ames, and at this writing it is laden with young fruit, when the tree has a diameter of stem of only two inches, four years after the planting of a oneyear-old tree. It is of the size of Bartlett, pyriform in shape, and nearly equal to the Bartlett in quality.

Without doubt this snow-pear race of north central Asia has had much to do with the development of the Russian pears, extensively grown on the bluffs of the Volga in Russia, by crossing with the indigenous species. Several of the Russian pears now growing in the Western States have the close-textured, shining, sharply serrated leaves of the Oriental snow-pears and also their white flesh. But not one of them yet tested is as good in quality for dessert use as the snow-pears of Mongolia. The largest tree of any kind seen by the writer on the Volga, from the $5 \%$ th parallel south to the Caspian Sea, was a pear-tree of this Oriental type on the bluffs of the Volga on the 56th parallel of north latitude.

What is known to botanists as snow-pear (Pyrus nivalis), 
as grown in Enrope for perry making, is a small tree with small, roundish fruit, becoming sweet when over-ripe. But the Peli or snow-pear we have growing from Mongolia, makes a large tree, and the smallest fruit we have seen is pyriform and as large as Flemish beauty. The pears with silvery leaves and white-colored flesh of central Asia also attain very large size of tree and some of them bear whitefleshed fruits of large size. As the orchard fruits of north central Asia, the valley of the Amur, Mongolia, and Manchuria become better known, the fact will be recognized that they are distinct races and possibly distinet species, and also that they were the most anciently cultivated good fruits. Henry Lansdell, D.D., in his " Russian Asia" says on page $3 \% 5$ of volume I, that good fruit; seem to grow wild in the Province of Zarafshan, of cherry, plum, apples, pears, and apricots that seem to have escaped from cultivation as planted by birds and animals or from deserted plantations that have run wild.

173. Dwarf Pears.-When dwarfed by budding on the Angers quince, given varieties of the pear bear earlier and the small trees can be admitted on smaller grounds, as with the dwarf apple, and it is easier to thin the fruit and attend to spraying, pruning, and other needed care. But amateurs are apt to neglect the heading back needed to keep the trees in dwarf form. If not headed back in the top they soon reach the size of some of the Oriental varieties. The needed heading back soon gives a broad spreading top, heuce they shonld be planted not less than one rod apart. The buds are usually set low enough to permit covering the point of union from four to six inches. Some varieties unite well with the wood of the quince, while others make a poor union or fail altogether. Hence with some popular varieties, double working is practised. That is, the growth of varieties that make a good union 
are again budded or grafted with Seckel, Bartlett, and other sorts that fail on the quince.

The main commercial variety worked on the quince for marketing is Duchess d'Angoulême. The first part of the name is now dropped. This large, irregularly shaped pear is shipped to the West in barrels and half barrels and is mainly used for culinary purposes. Other commercial sorts are Louise Bonne, Anjou, Clairgeau, and Manning's Elizabeth.

174. Propagation of the Pear.-Nearly all the pearseedlings used in this country for propagation are imported or grown from imported seed. In either case the seed used is mainly saved in the perry-producing sections of west Europe. The variety used for perry in France, Germany, Italy, and Austria is almost exclusively the snow-pear (Pyrus nivalis). The fruit is small and near to Nature. Hence it has plump seeds that produce vigorous stocks. Where the snow-pear is not used for perry-making, the writer found small austere varieties used of the Pyrus communis type that gave equally plump seed. Pear-seedlings have been quite extensively grown on the virgin soils of the West, where they reach in one season a size suitable for budding or grafting. The plan of crown-grafting (86) and deep-setting in orchard is mainly practised in the West and budding (72) in the Eastern States. The pear seems to have a wider range than most fruits in the way of uniting with stocks not nearly allied botanically. Some varieties make a fairly good union with the quince, some with the apple, and others with the thorn, Juneberry, and even the bearberry (Pyrus arbutifolia).

175. Soil and Management.-In all parts of the world visited by the writer, Downing's statement, that "the best soil for this fruit-tree is a strong loam of moderate depth with a dry subsoil," holds good. Even in Belgium, 
which is claimed to be the most congenial home of our best pears, the famous old trees of our day are on such soil, and in addition they have good air-drainage (97) to lower levels. Also in east and west Europe the wild pears that reach the size and height.of their neighboring foresttrees are on relatively high land with dry porous subsoil. Yet we have some varieties, such as Besi de la Motte, Mongolian snow, and Gibb, that do well on ordinary drift soils of the West and on all soils where the apple thrives. In high, airy positions, with light-colored soil, the fireblight $(12 \%)$ is also less damaging than on lower levels in protected situations, and the same is true of all bacterial diseases.

The spacing, culture, spraying, and general management are discussed in the chapters on orchard management and spraying.

176. The Fruit and its Care.-To an extent not equalled by any orchard fruit of the temperate zones, the pear is grown mainly by specialists for marketing. In its commercial growing the most favorable soils and climates are selected and the management is under the care of skilled growers. Near the Atlantic sea-coast and in the great inland-lake region the pear is largely grown for market, while over a large part of the Union its cultivation is on a limited scale, mostly by amateurs who are willing to grow varieties that have proven adapted to their locality.

The fruit of most varieties needs careful hand-picking while yet hard, and to be ripened under cover. If spread upon shelres, or on.the floor of a dry, cool room, and not exposed to air-draughts, the fruit will slowly complete the ripening process with an added tenderness and melting quality not reached in open-air ripening on the tree. This is true of the summer pears, but to a still greater extent of the autumn and winter varieties. 
The winter pears for culinary use also need care to prevent shrivelling. They are usually barrelled or boxed and, kept in storage not too dry, such as would be suitable for storing the russet apples.

\section{The Quince.}

177. Origin and Races.-The quince is an ancient fruit that has been changed in size and quality less than any one of our orchard fruits by modern selection, crossing, and eulture. Regel says that the quince has been widely planted as far north as Tashkend and Koran in Asia, and De Candolle in his " Origin of Cultivated Plants" says it is found "wild in the woods in the north of Persia," which indicates its native origin in the far East. But it is also found wild in the Crimea and in the north of Greece. The varieties we grow are from west Europe, Japan, and China. It is more than probable that the varieties from as far north as Tashkend in Asia would extend its culture considerably to the north in the prairie States. Ten years ago it was difficult, if not impossible, to investigate, select, or send out seeds, scions, or trees from Bokhara, Tashkend, or other fruit-growing sections of north central Asia. But the recent control of this region by the Russian government and the extension of railroads across the great north plain to the west boundary of China, makes such work now possible, hence the historic notes given in these sections on hardy orchard fruits and their origin.

Downing says: "The quince is a well-known hardy, decidnous tree of small size, crooked branches, and spreading bushy head." This is true as to its being common and hardy in New York and westward to Michigan. But in the great prairie region west of the lakes, few of our young people ever saw a quince-tree and most of them never saw 
or tasted the fruit, unless obtained from a grocery, where it is sometimes found for sale as shipped in as are the citrus fruits. Commercially, the fruit is mainly grown east of the lakes, in some of the southeast States, and in Utah.

178. Propagation and Management.-The quince is easily propagated by cuttings of the new wood planted in the fall (58) and also from cuttings of the surface roots $(50)$. It is also propagated by mound-layering (51), and by root-grafting and budding of best varieties on the freegrowing Angers quince. It is also often propagated by root-grafting on apple-roots. In this case the grafts are set down to the top bud of the scion to favor rooting above the point of union. The pruning of the quince is peculiar (151) and should be mainly in the way of thinning out the inner branches. If the growth is shortened the best bearing wood is taken away.

It may be said that the fruit of the quince will never have the widespread consumption and uses of such orchard fruits as the apple, plum, cherry, peach, and orange. Its commercial status has not changed materially in modern times. It is not and never can be a dessert fruit, but it has been esteemed for the making of sweet preserves and marmalade for centuries. In time the marmalade may become commercial. If so, the growing of the quince will be more general in sections adapted to its culture. 


\section{CHAPTER XIV.}

THE CHERRY, PLUM, PRUNE, APRICOT, AND PEACH.

\section{The Cherry.}

179. History and Classification.-This refreshing and wholesome fruit is by no means a modern development. In the fourteenth century we are told by Marco Polo and others, that good cherries were grown in the kingdom of Timur the Great in Asia. Koch in his "Dendrologie" speaks of wild and cultivated cherries-both sweet and sour - over the parts of Asia Minor he visited, and Dr. E. Regel, who lived in Turkestan nine years, says: "Stately trees of the sweet cherry stand near Karatag in the Hisser district. The original district for cultivation of the sour cherries in central Asia embraces all of west Turkestan from Tashkend and Kokham to the upper Amudaria and Afghanistan. Well-flavored, clear, red kinds are found in Baldshuan. In Shugnan the cherry juice is used as a cooling drink, but cherry brandy is unknown." At the great commercial fair at Nishni Novgorod in 1883 the writer and Mr. Charles Gibb were told by Asiatic merchants and traders that tall-growing sweet cherries and nearly sweet cherries of the Vladimir type were grown up to the 56th parallel of north latitude and eastward to the Ural Mountains, where water was obtainable. Botanically it is true that all cultivated cherries have originated, as stated by De Candolle, from two species which are yet fuund wild: 
"(1) Prunus avium is tall, with no suckers from the roots, leaves downy on the under side, and the fruit sweet. (2) Prunus cerasus, shorter in growtl, with suckers from the roots, leaves glabrous, and fruit more or less sour or bitter."

But in the centuries of evolution in Asia and east Europe, as well as west Europe, varieties originating from the two original species have been crossed and recrossed until any attempt to classify them botanically must prove unsatisfactory. On this subject Dr. Hooker says: "As with most plants which have been long cultivated it is a matter of difficulty, if not an impossibility, to identify the parent stock of the numerous cultivated varieties of the cherry." Robert Hogg, the celebrated English pomologist, gave many years of study to a horticultural classification of the European varieties, and in his "Fruit Manual," he gives eight classes which are divided into eight races, as follows:

\section{Class I. Geans.}

Branches rigid and spreading, forming round-headed trees. Leaves long, waved on the margin, thin and flaccid, and feebly supported on the foot-stalks. Flowers large and opening loosely, with thin, flimsy obovate or roundish ovate petals. Fruit heart-shaped, or nearly zo. Juice sweet.

Race 1. Black Geans.-Fruit obtuse, heart-shaped; flesh tender and melting; dark; juice uncolored. Black Eagle and early purple gean are examples of this class.

Race 2. Red Geans. - Flesh pale; juice uncolored. Such as Downer's Late and Early Amber.

Race 3. Black Hearts. - Fruit heart-shaped; flesh half firm; dark; juice colored. Examples are Black Heart and Black Tartarian. 
THE CHERRY, PLUM, PRUNE, APRICOT, AND PEACH. $17 \%$

Race 4. Red Hearts or Bigarreaus._-Flesh pale; juice uncolored. Examples, Governor Wood and Elton.

\section{Class II. Griottes.}

Branches spreading at upright, or more or less long, slender, and drooping; leaves fiat, dark green, glabrous beneath and borne stiffly on the leaf-stalks, large and broad in Class I and narrow in Class II; flowers in pedunculate umbels, cup-shaped, with firm and crumpled orbicular petals; fruit round or oblate and sometimes in the Morello heart-shaped; juice subacid or acid.

Race 1. Black Dukes.-Branches upright, occasionally spreading; leaves large and broad; flesh dark; juice colored. Examples, Empress Eugenia and May Duke.

Race 2. Red Dukes.-Flesh pale; juice uncolored. Examples, Belle de Choise, Carnation, and Late Duke.

Race 3. Black Morellos.-Branches long, slender, and drooping; leaves small and narrow; flesh dark; juice colored. Examples, Double Natte, Cerise de Ostheim, and English Morello.

Race 4. Red Morello or Kentish.-Flesh pale; juice uncolored. Examples, Early Richmond, Early Red, Late Kentish, and Montmorency.

With this system in our vest-pockets, the writer and Mr. Charles Gibb in 1882 were able to classify all cherries in their season of fruitage in going eastward from France through Germany, Anstria, Poland, and Russia to the Volga. The names of the sour and sometimes the duke varieties were often misleading, but the Bunt Amarelle was plainly a Red Duke, as was also the Lutovka and the Black Amarelles, and the Weichsels with colored juice were plainly Morellos and those with uncolored juice and red color were as plainly Red Morellos or Kentish. It is true that such east European varieties as Brusseler Braune and 
Vladimer with colored skin and juice differ in tree habit and texture of fruit from the English Morello, yet they do not differ as much as the apples or oranges that are classed together, and the same is true of all the Red Morellos of all parts of Europe with red skin and uncolored flesh and juice. After separating into two groups the main after differences in the Morellos is in hardiness of tree as grown in various parts of the Union and difference in quality for varied uses.

180. Propagation of the Cherry. - The selection of stocks and propagation by budding and grafting are given in Chapter VII and the transplanting, spacing, and after care in Chapters IX and $\mathrm{X}$. The most important consideration in prairie propagation of the cherrry is that of selection of a hardy stock on which to bud or graft the hardiest known varieties. This is specially true north of the $42 \mathrm{~d}$ parallel. As stated on prior page all varieties of the cherry take well by budding on our native bird-cherry (Prunus Pennsylvanica) (\%1). At the experimental farm at Ottawa, Canada, during recent years, about the only cherry-trees that escaped root-killing were those on bird cherry-roots, and the same has been true in the prairie States. As Professor Bailey says, the bird cherry is quite a sprouter in its native localities. But when budded with the cultivated cherry we have seen but few sprouts on trees set twelve years in orchard. The draw on food-supply of the larger top and crops of larger fruit varieties seem to leave no reserve supply of nutriment for throwing up sprouts. But this only applies to the sections of our broad country where root-killing is frequent in open winters. Where the mazzard and mahaleb stocks are hardy they will continue to be the commercial stocks.

181. No Market Supply of the Cherry.-As we now have varieties of good quality for dessert use or canning in 
about all parts of the Union it is a peculiar fact that our markets are not supplied except at a few local points, and in a small way in crates put up on the west coast for dessert use at prices beyond the reach of the masses. As Professor Bailey says: "The cherry is not cultivated as a leading industry east of the Rocky Mountains except in western New York, where the sour varieties are grown for canning. The sweet cherry is confined mostly to dooryard and fence-corner plantings. Sour kinds are found in orchard blocks in New York, New Jersey, Pennsylvania, Ohio, Michigan, Indiana, Illinois, Kansas, and Nebraska."

It is true that relatively small orchards are found in all these States. Yet it is also true that such orchards are far apart as a rule and the cherry is rarely found in market for family use, as is the case with all other orchard fruits. There is no reason for this, except that as yet the commercial planting of the cherry is neglected, especially west of the Great Lakes. Even in the small city of Ames, Iowa, fifty varieties of fine cherries were picked from healthy trees for exhibit at the Trans-Mississippi and International Exposition at Omaha. Yet the local demand for family canning is so poorly supplied that cherries are engaged a year in advance by many families. But this was true of the blackberry supply five years ago, while at this time every grocery in the Northwest has its blackberry supply following that of the strawberry.

On hardy roots the identical varieties of the cherry used for roadside trees in Germany, north Silesia, Switzerland, and south Russia will mainly thrive as well in this country, and the writer repeats the desire of Charles Downing, who said nearly forty years ago: "We wish we could induce the planting of avenues of this fine-growing fruit tree in our country neighborhoods, as is the beautiful custom in 
Germany, affording ornament and a grateful shade and refreshment to the traveller at the same moment."

\section{The Plum.}

182. Its History and Classification.-The plum is also one of the anciently cultivated fruits of central Asia. Regel says in the Gartenflora, published in Berlin: "The common plum of the district of Tashkend and of the more elevated settlements of the southern territory is the beautiful Bokharan variety. It is particularly abundant in Karaegin, and may be found also in the middle district of the Paendsh valley."

Henry Lansdell, D.D., also spent much time investigating the fruits of central Asia. He reports finding an apricot-tree five feet and three inches in diameter of stem, and plums that were red, yellow, and black, "particularly well flavored," on October 11th.

De Candolle says: "It is very doubtful if Prunus domestica is indigenous in Europe. Authors who have seen the species in the east do not hesitate to say that it is 'subspontaneous." "

Some of the Asiatic plums seem to have been first introduced in Europe and planted on the Volga bluffs, as their culture there we were told goes back to the early history of that region. But varieties of the Prunus domestica type have been so long cultivated in west Europe that the race has changed in leaf, bud, and fruit materially from that found at this time in central Asia, which we know more nearly resembles the Chinese and Japanese plums (Prunus triflora). Several of the Russian plums we met with on the Volga had the triple bud, leaf, and pasty flesh of the Japan varieties, and we met with plums at the great fair at Nishni Novgorod, in 1882, that exhibited all the characteristies of the triftora and domestica 
species. Hence it can easily be believed that central $\Lambda$ sia had two species or races of the plum or that one original species differentiated as it spread east and west from one centre. But the writer personally believes from varied evidences that central Asia had, in prehistoric times, two species. Not the least reason for the belief is that we have found it easy to cross the Japan varieties with our native plum (105), but we have not been able to cross the Americana varieties with any variety tried of the doniestica race.

The domestica varieties of west Europe and their American seedlings are mainly grown commercially on the west coast. It is estimated by Stubenranch that the acreage of the plum and prune reaches a total of 55,000 acres, of which seven-eighths is in prunes in California. The domestica varieties are also grown quite extensively in the Eastern States and in Michigan. In fact, in the Sonthern States, the arid States, and the prairie States, certain varieties are starred or double-starred locally by the American Pomological Society. In the northern part of the prairie States the advent of the Russian plums has extended the culture of the domestica race farther north without loss in size or quality.

The Japan plums (Prunus triflora) have only been introduced within recent years, but their culture has been extended very rapidly in the lake region, in the South, and indeed in all the States where they have proven hardy. These Oriental varieties come into bearing earlier than the European sorts and, as a rule, mature their fruit earlier in the season. Usually they are rounder in form and the colors run to red and yellow. They sell well in market, but for dessert use at home and culinary purposes they are not equal to the best European or Russian varieties, as they lack in sprightliness and richness of flavor. 
Selected varieties of the native species of the North (Prunus Americana) and of the Chickasaw races of the South, have rapidly come to the front for general culture in the prairie States and to a large extent over the Southern and Eastern States.

In estimating the quality of our best native plums under culture, we need some new rules for judging. They have a juiciness and sprightliness peculiar to the race, and an invalid can eat, when fully ripe, several of them with satisfaction and without affecting a weak stomach, as do all the foreign varieties. Professor Goff also says truly: "The choicest varieties, peeled and served fresh, are equal to the finest peaches." Served on the table in this way they can be eaten freely by those who are obliged to use ripe foreign plums and prunes with care and in less quantity.

For culinary use, if peeled and the pits rejected, such varieties as Wyant, Hart's De Soto, Surprise, and Brittlewood are superior in some respects to the domestica or Japan varieties for daily use. At first the decision of all educated palates will be in favor of the sweeter and richer foreign frnits. But the pleasant fruit-acid of the native soon wins favor, and it can be eaten as freely as the strawberry or grape without the after effects of the free use of the foreign sorts.

Another class of American plums is beginning to attract attention. As noted in section (105) the Americana varieties cross readily with those of Japan and produce a desirable union of the good points of each. The pasty flesh of the Japans is given more juice and character in the hybrids and the thick skin of the natives, with more or less acridity, is changed in texture and materially thinned, yet not enough to prevent safe transportation. To an extent not usual in hybridizing, about all the 
hybrids yet produced have crisp, tender, juicy flesh with a perceptible flavor of the Japan varieties. 'The prepotency of the native species seems in every case to determine tlite hardiness of the hybrids produced, while the Japan species modifies and improves the fruit.

The Chicasa or angustifolia and hortulana species of the South have given us by selection and crossing some valnable varieties, such as Forest Rose, Maquoketa, and Golden Beauty, and some fine crosses with the Americana and triflora species.

183. The Prune.-Commercially, all the domestica varieties of the plum that can be cured without removing the stone, and that will keep well after drying, are classed as prunes in the dried form. But the popular classification in prune-drying districts of Europe and America is to include in the prune list only the varieties of the long oval form, swollen on one side, and drawn out toward the stem with distinct and often deep suture and firm flesh, such as German prune, Italian prune, Ungarish prune, and Prune de Agen. In France, parts of Germany and Austria, and in California, prune-growing and drying are carried on to an extent realized by few. It is said that from 1895 to 1900 the total of dried prunes prodiced in California reached an annual average of eighty-fire million pounds. The industry is still on the increase in sections favorable for drying. As the years go on the prune-producing areas will be mainly in districts favorable for drying in the open air, as is the case with the raisin-grapes. Partial cooking and drying in evaporation has been practised in Europe and California, but it is more expensive and the product does not equal that produced by drying in such a climate as that of Arizona, or Fresno, California. The light-colored, pitted prunes, sold as prunelles, are bleached with sulphur fumes so far as known to the 
writer. The process is an injury to the quality, and experience warrants the belief that they are not as healthful as properly dried commercial prunes with natural eolor.

184. Apricot.-The apricot seems elosely related to the plum, as it buds and grafts readily and makes a good union of wood on stocks of some of the plum species, especially the Americana. But it also unites well with the wood of the peach and the domestica plums, but it fails to unite with the wood of the myrobalan stocks. In California it is propagated mainly on apricot and peach-seedlings by budding seedlings of the same season's growth (74).

It is one of the most beautiful of the stone fruits, with handsome heart-shaped shining leaves and large white or pinkish-white blossoms. The tree runs into variations as to hardiness. Some good varieties, such as the Shense and the best Russian varieties, are, as hardy as most of the domestica plums, but all varieties have the fault of blossoming very early. Hence it can only be grown profitably where there is little danger from spring frosts.

In its ancient home in central Asia, it has run into many varieties, varying, we are told, in season of blossoming and ripening of the fruit. Edward Regel gare it much study in the far East, and says: "The earliest apricots of Tashkend ripen in May, and toward the upper Amudaria, however, the apricots hang on the trees until August. The beautiful and delicately flavored varieties of Badachshan before being dried are stoned and then pressed into a long shape like dates."

It is more than probable that later blossoming hardy varieties ean be secured from north Turkestan and Bokhara. Henry Lansdell, D.D., in his interesting work on central Asia says that at Samarkand he measured the stem of an apricot-tree, loaded with large and beautiful 
THE CHERRY, PLUM, PRUNE, APRICOT, AND PEACH. 185

fruit, that was five feet and three inches in circumference of trunk.

Samarkand is about on the 40th parallel, at an elevdtion of about two thousand feet above the sea. But it is in a river valley, near the centre of the broad continent, where the surnmers are hotter and drier than in Iowa and the winters will average much colder and drier. As this region is now accessible, the apricots of central Asia should be tested, especially the varieties latest to bloom in spring.

185. The Peach.-To an extent not realized with any of the stone fruits, the peach is now a commercial fruit in every village, eity, and mining and lumber camp of the Union. Yet the immense supply comes mainly from a few peach-growing centres. Prominent among these are the Michigan fruit-belt, the Long Island and Chesapeake peninsular belt, the ridge lands of part of Georgia and Alabama, and the Pacific coast. Yet the peach is grown across the continent by home-growers and locally in a commercial way. As stated of other stone fruits we may, in the near future, secure hardier varieties of equal size and quality of fruit from the original home of the species in central Asia and northwestern China. Our commercial varieties are derived from the original introductions from southern Persia, and they do not differ materially in hardiness of tree or fruit buds. But equally good varieties we now know are found far north of Persia in central Asia. Albert Regel says: "In Darvas the peach forms tops thirty feet high, with broad spread of branches. The rough-skinned giant peaches of the garden of Kalaichumb are of unsurpassed lusciousness and aroma and most inviting bloom. They attain the size of an average apple. The number of rough-skinned varieties is considerable. The yellow peaches are especially sweet."

As the points here named are the original home of such 
hardy trees and shrubs as the Eleagnus angustifolia and Lonicera tartarica, with hot dry summers and cold winters, it suggests a possibility of extending the American peachbelt farther north. In support of this belief the writer obtained a few peach pits in 1883 from south Bokhara, from which have come such varieties as Bokhara No. 3 and No. 10, which have proven fully thirty per cent hardier than any of the old varieties.

186. Propagation of Plum, Prune, Apricot, and Peach. -These fruits are so nearly allied that they can be all budded or grafted on the same stock. And commereially the peach is often worked on Chicasa-plum stocks and the plum on peach. The apricot is sometimes grown on apricot-seedling stocks, but far more generally on clomestica plum-seedlings.

Commereially, the domestica and Japan plums are mainly budded on myrobalan stocks imported or home grown. The apricot is nsually budded on its own seedlings or on seedlings of the domestica plums, and it also makes a good union with Americana stocks.

In the prairie States, for reasons given in section (47), Americana stocks are largely used in propagating all plums, prunes, and apricots. In budding on this stock the buds are often inserted the same season the pits are planted (74).

The summer budding (\%2) and winter grafting (86) of the plum, prune, and apricot are given in Chapter VII.

The peach is usually budded on peach-seedlings at the North. The stratified pits (5) are planted early in spring, given good culture, and budded in August. The tops are cut back the next spring (75) to start growth, which makes a well-branched tree for orehard-planting the first season.

In California and the South the long seasons permit the early planting of the pits and budding in June. The leaf- 
THE CHERRY, PLUM, PRUNE, APRICOT, AND PEACH. 187

bracts are left below the point of insertion and the top is only cut back partially until the bud is well started. 'These buds start late, yet they make sufficient growth to " please nearly all planters the same season the pits are planted. The same plan is taken with the apricot in California as in summer budding; with growth the next season, the trees attain an unhandy size for orchardplanting.

In the prairie States the plum, prune, and apricot are crown-grafted (86) more generally than in other parts. By using a long scion and setting in nursery down to the top bud of the scion, and later setting in orchard four inches deeper, roots are secured from the scion, giving practically trees on their own roots. These varieties, and also the cherry, are often grown from root-cuttings (50) in the West and North.

187. The Nectarine.-This fine fruit was once supposed to be a good species, as it seems to have been an anciently cultivated fruit. At the great commercial fair at Nishni Novgorod we saw tons of the fruit in fresh and dried form brought in by merchants from central Asia, and we were told that this had been a commercial product since the Fair was started, four hundred years ago. Regel says of the nectarines of central Asia: "The smooth-skimned nectarines of this region, among which are the smaller yellow varieties, and very large red-cheeked ones, are of unusually fine flavor and melting flesh; but they are equalled by the nectarines of Samarcand. There are also small, sweet, yellow kinds which stand half-way between the rough-coated and smooth-coated peaches. These grow in the exposed region of Vaendsh."

It is now known that nectarines can be developed from the peach by bud variation and peaches have been produced in the same way from the nectarine. 
The nectarine is grown on the west coast for drying and canning, and in peach centres and most neighborhoods of the South it is grown in a small way. But it is nowhere a commercial product, except in east Europe and central Asia. In all respects it is propagated and managed the same as the peach.

188. Laying down Peach and Apricot.-In the cold North, even in the trying climate of Minnesota, the peach is grown by laying down for winter protection. In north Iowa many have secured good crops by dividing the roots in planting so as to spread at right angles to the direction the trees are to be laid down. By digging down on the

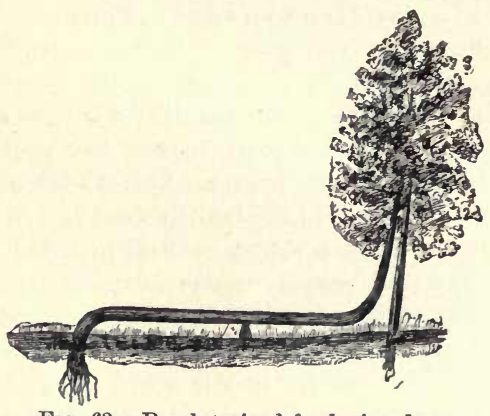

FIG. 63.-Peach trained for laying down.

side the tree is to be bent over, the stem is crowded over when young, and when it gets larger the previous crowding and bending and breaking of the roots farors the continuance of the operation.

But a better plan is shown in Fig. 63. The trees are encouraged to make an upright growth the first year. A strong one-year-old tree should be about six feet high 
when planted, and by pinehing the lower limbs it may be made to grow two feet more in height when ready for lay-, ing down in the fall. Late in autumn trim off all the side limbs and dig away the earth on the side it is to be turned over. By pressing at the erown and gently erowding the tree downwarl, the cane ean be laid flat on the ground and pinned fast. Then cover with straw, with dirt enough on top to hold it in place. The next spring the cane is left prostrate, but the point is turned upward and tied o a stake. The next fall the top attached to the stake is cut loose and turned to the right or left. The spring of the prostrate stem will permit a child to bend the top to the ground at this stage of growth. Later, as the stem attains greater size, it will need more strength, but if always turned in the same direction the top ean be turned over after the tree has produced several erops. The prostrate stem aud the crown must be covered as well as the tops. Before covering the top, eut back fully one-half of the new growth and take out also the weak inner shoots and the unripe twigs. For this plan of growing, select such varieties as Bokhara No. 3 or No. 10, that will ripen up the wood well in autumn. Farther south, where the wood i3 relatively unharmed in winter, but where the fruit-buds or blossoms are liable to be killed by frosts, spraying with milk of lime towards spring has proven an advantage, as the white color is less affected by heat-rays and the blossoming period is slightly retarded. But in north Silesia the writer observed a far better plan for retarding the blossoming period. In frosty localities amateur growers adopted the eordon system of training (146) of the cherry, plum, apricot, and peach, and after pruning in the fall the tops were eovered with gunny sacking whitened with lime. The light-colored cloth prevented the swelling of the fruit-buds during warm spells in winter 
and very much retarded the opening of the flowers in spring.

189. Orchard Management. - The stone fruits are superior (33) and more liable to injury of blossoms by late frosts than the apple or pear. Hence the most profitable and regular bearing orchards of cherry, plum, prune, aprieot, and peach are found where proximity to water lessens liability to damaging frosts in the blossoming period, or on relatively high land with good air-drainage (9\%). But it often happens that relatively low land has still lower levels of large extent in the near vicinity and may prove as free from frost as decided ridges.

Budded trees on strong stocks usually are large enough for orchard-planting when one year old. But crowngrafted trees should remain in nursery until two years old. The distance apart and plan of planting are discussed in sections (115) and (11\%), and the alternating of varieties in the row to secure proper pollination in section (122).

Pruning (147 and 148) varies much in different climates and with different varieties. The native plums usually require but little pruning, and that in the way of shortening rampant-growing shoots prior to the trees coming into bearing. When fruiting heavily the main essential in pruning is the cutting out of dead wood in the interior as it appears. The select native varieties are rapidly taking a place in the leading markets, but their habit of overbearing requires thinning if the best prices are to be realized. In California, and on rich soils in the South and East, the domestica varieties make too rapid growth when young. To secure the needed thickness of top to prevent the sunburning of the wood and fruit they are headed back (148), causing a subdivision of the growing wood. As the trees get older less pruning is done, confining it mainly to the removal of dead wood and shortening the young shoots 
making greatest length, to prevent unequal growth and to lessen the amount of bearing wood.

The domestica plums and the apricot seem to bear excessive cutting back of the top. In California and the South the low stem is now the rule, and when first set out the stems are protected by burlap or whitewashing. But on very rich lands a kind of renewal system is adopied with the tops. As an instance, in the San Joaquin valley on the west coast the tops of young plum-trees and even apricots are not cut back. The long shoots formed are thinned to some extent and encouraged to bend over. These when loaded with fruit rest their points on the ground. When these long canes droop too low they are cut back to the main stem and others take their place for the succeeding crop. But trees worked in this way are not as long lived as those on higher land pruned in a sensible way. The pruning of the peach and apricot in the commercial centres is often excessive (149), but amateurs in the Middle States usually go to the other extreme by mainly leaving Nature to have her own way.

With few exceptions, growing out of soil conditions and climate, Downing's instructions as given in (149) will apply well to-day in amateur peach- and apricot-growing, but not in commercial centres, as the shortening of all new growth gives more trouble and expense after the trees are in bearing than the rougher plan of thinning by cutting out superfluous branches.

Where winter-killing of the new wood is liable to occur, the pruning is deferred until the buds start in spring, and the thinning is confined in the unfavorable seasons to the injured wood, being careful not to injure the live buds.

190. Thinning the Fruit.-As a general rule amateurs and home-growers of the domestica plums and peaches never think of thinning the fruit, even in seasous when 
the trees are carrying double loads. The commercial growers also are more apt to neglect fruit-thinning than any other part of the work. Yet no work of the orchard pays in dollars and cents better than fruit-thinning, especially of the foreign plums and the peach. The thinning should be deferred until after the usual drop of the fruit in June, when it is as large as marbles. The peach and domestica plums should be thinned so that no two will touch each other when of full size, and experienced growers thin so closely that those left are from four to six inches apart, depending on the strength and leafage of the branch. Some of the gains of thinning are that it favors annual bearing, the fruit is less liable to the attack of rot, and if methodically packed the fruit sells at a much higher price. 


\section{CHAPTER XV.}

\section{SOME SUBTROPICAL ORCHARD FRUITS.}

191. The Orange.-This is one of the most ancient fruits and one that has been most modified by culture, selection, and natural crossing. De Candolle says : "Thanks to the discoveries of travellers in British India, they are able to distinguish the wild and therefore true and natural species." Those who have tasted the fairlooking ripe fruit of the bitter-orange seedlings, yet quite common from New Orleans sonth to the gulf, will have a feeble conception of the wild, bitter oranges from which the luscious, sweet varieties are supposed to have been developed during the ages in southern China. As a commercial fruit, found over the civilized world in every grocery, and even mining and lumber camps, it is a product of recent years. It first became commercial in parts of Europe and Asia. West Europe was first supplied commercially from the Azores. In 1878, C. P. Johnson says that 410,101 boxes of St. Michael oranges were received in Great Britain, which at that time were all produced in the Azores. Great quantities of the orange, less esteemed as to quality, were received in west Europe from Sicily, Portugal, and Spain. At that time the supply of the United States was mainly from Jamaica and the Bahamas, with a partial supply from Florida. Later orange-growing on a large scale was developed in Florida, 
mainly near the St. Johns Rirer, that gave us the cheapest and best oranges known at that time to history.

The orange to reach its highest perfection must, like Indian-corn, have warm nights as well as days. Hence the great supply from that source from 1880 to 1894 mainly shut out competition during late fall and early winter over a large part of the Union east of the Rocky Mountains. But the great freeze of 1894-95 cut off this supply suddenly, as most of the bearing trees were killed down to the latitude of Tampa. The very conditions of air that favor the development of the best quality of the orange, and favor early ripening, brought about the great destruction of trees in 1894-95. 'The writer was in Florida at the time of the February freeze which caught the trees with young foliage and tender shoots in a condition of growth. Peach-, mulberry-, and even black wild cherrytrees were killed at the same time, and wistaria vines of many years' growth that are hardy far north where the foliage is dormant in winter. The writer has experienced a greater degree of cold in the Salt River valley in Arizona that failed to injure the wood of orange-trees, except at the points of growth, and to cause the leaves to drop, as the trees in winter are in a relatively dormant and ripened condition.

At present extensive orange-planting in Florida is confined to the parts sonth of the latitute of Tampa. Without doubt the denudation of the timber-belt of pine, sixty miles wide in sonthern Georgia, by the lumbermen, turpentine and rosin operators, and fire, has had much to do with the destruction of orange-trees in central Florida since 1886. Orange-growing on the higher table-lands of Cuba at this time is making rapid advances with many favoring conditions. During the winter of 1894-95, the writer left the frozen orange orchards of Flordia to investigate orange- 
growing in west Cuba. Isolated trees and very small groves were found everywhere and without systematic cult- , ure or care, and without irrigation or soil fertilizing, the trees were thrifty, healthy, and loaded with fruit of high quality. In the near future it is probable that early ripening oranges of high quality will be grown on the rich soils of Cuba that can be furnished at prices within the reach of the laboring classes. The early maturing of the oranges of south Florida and Cuba will not interfere to any great extent with the profits of orange-growing on the west coast, as the navel variety, and most others grown, should not be shipped before midwinter to secure best prices, as the cool nights much retard the ripening period.

In California, orange-growing has made rapid advances within the past twenty years. The great commercial orchards on the mesa lands of south California have no equal in extent or methodic culture and care on this continent, and few if any equals on the Mediterranean. Indeed, orange-growing on the foot-hills and mesa ridges, with air-drainage (97) to lower levels, has extended north in California to Placer County and to a less extent to the north part of the Sacramento valley. The enormous extent of the business in recent years can be gathered from the statement of Leonard Coates, who says that in 1897-98 and 1898-99, the orange crop of the west coast reached an annual shipment of four million boxes, filling 14,000 cars.

It is not probable that this vast interest will decline for the reason stated above, that the cool nights favor late ripening. The use of this luscious and healthful fruit is on the increase. Cuba, Porto Rico, and south Florida will control the early market, but California will control the market from midwinter to July and will adapt shipments to this period. 
192. Orange Propagation. - The writer has had no experience in propagation except in the way of propagating the Otaheite variety as a house plant. But the results obtained by varied plans of propagation have been studied in the orange-growing centres of Europe, California, Florida, and Cuba, and the decisions of experts and growers have been compared.

As with other orchard fruits the best results have been obtained in growing uniform, vigorous, and healthy trees by using stocks for budding grown from seeds of fruits near to Nature. In California, strong, vigorous stocks have come from seeds of the primitive oranges of Tahiti, and also from the sour oranges yet found around the old missions. In north California, hardy dwarf stocks have been used grown from the varieties imported by General Chabot from north Japan. And also the relatively hardy and primitive Citrus trifoliata has been used quite extensively. The rough lemon also seems to give additional hardiness and inherent vitality to varieties worked upon it.

Since the freeze of 1894-95 in Florida and the Gulf States, the main stocks used have been the rough lemon and Citrus trifoliata. But farther south the sour-orange seedlings are mainly used. Those who have had a long experience in propagating the northern orchard fruits are surprised to find the citrus fruits so tenacious of life and easy to propagate in so many ways. Aside from liability to fatal injury by severe cold, we have no northern fruit tree so tenacious of life. Even where the top is wholly killed by fire or freezing and the roots show no sign of life or growth for a year or more, vigorous sprouts will finally appear. It is even said that trunks of quite old orangetrees that have lain as ballast in the holds of vessels for a month or more have grown into fine trees when planted 
as pollards. By cutting back the tops quite severely, large trees are planted successfully with roots cut so short that northern men are certain they will fail to grow. It also layers as easily as the grape, and often shoots resting on the ground will take root. When on own roots it is also propagated from root-cuttings $(50)$. Summer layering (52) is also practised successfully, and this is a principal method of propagation by the natives of Cuba.

Where the Otaheite orange is used for stocks it is mainly propagated by mounding (51). It also grows well from cuttings of the young wood with a heel of the two-year-old wood planted in the dormant period. But in propagating by mounding, layering, or enttings, it must be remembered that the orange must have water. If neglected in a dry time they will fail. Skilful propagators even insert buds in the top of a long cutting which is planted with the bud just above the surface in boxes of earth kept well watered. In this case the buds remain nearly dormant until the cuttings take root. But all these methods are confined to home-growers.

The commercial method is to grow seedlings in beds in well-prepared and rich soil. From the beds they are transplanted to nursery rows and budded when the bark peels well, as we manage the stone fruits at the North. The transplanting of the seedlings from the bed requires care, as the stocks have a full supply of leaves for rapid evaporation. $\Lambda$ moist soil and cloudy weather are requisite for success in planting.

Some growers familiar with northern methods plant the seeds in well-prepared rich soil in the nursery rows early and bud the same season, as practised at the North with the peach and plum (74). This plan gives trees large enough for orchard planting in less time than the common plan, but the root system is not so good if the tap-roots 
are not ent, as noted in section (\%4). In budding, the old plan was to shove the bud upward, as practised sometimes in spring-budding at the North (76). But those who practise the usual plan of shield-budding have quite as good success and the bud can be inserted lower down.

193. Top-working the Orange.-In orange-growing centres in this country the first plantings of the gulf region and west coast were mainly seedlings, and seedlings are yet set in orchard with view to top-working. In topworking old seedling orchards the usual plan is to cut back one half of the top at one time and insert buds in the young shoots that start from the stubs. This is repeated the next season on the other half. The top-working of young seedlings set in orchard for stocks is done by budding on the side limbs and at top the season after setting, as practised in top-working young apple-trees (89). Grafting is not often practised with the orange, for the evident reason that the leaves, even if cut back in part, are apt to dry the scion before it has time to unite with the stock. But under glass it is nearly as easy to graft as to bud the citrus fruits.

194. Cultivation.-During the early period of American orange-growing in a commereial way the advice was given to keep up clean cultivation through the season and to rely mainly on commercial fertilizers. The natural ontcome of this system has been the same as when practised with the deciduous fruits (125). With increased experience it was found that humus as well as fertilizers must be giren to the soil. Growers now recognize the need of adding barn-yard manure, straw, or other refuse, or to grow leguminous cover-crops (126), to give the needed fresh humus and nitrogen to the soil.

The orange is a gross feeder that throws out widespreading roots with an unusual supply of root-hairs and 
feeding-fibres. It must have water and a regular supply of vegetable humus to give the needed green color to the foliage and to carry a full crop of fruit to maturity. Experience has shown also that continued culture and the use of commercial fertilizers soon change the mechanical condition of the soil, and that a given supply of water is sooner evaporated than on soils well supplied with vegetable matter.

In the fine orange orchards of Redlands, Riverside, Colton, and other orange centres of south California, many growers are now cultivating and watering in the usual way during the season of growth, but follow it with a covercrop of the field-pea, cow-pea, or other legume to shade the ground during the period of fruit maturation and to add humus and nitrogen to the soil when plowed under the next spring. In the winter of $1897-98$ the writer travelled many miles to observe the effect of this treatment on the color of the foliage and the perfection of the fruit. In all cases the orchards given the cover-crop treatment in connection with fifty pounds of potash and twenty-five pounds of phosphoric acid to the acre annually, were indicated afar off by the dark green of the foliage alone.

On the foot-hill slopes of the Salt River valley in Arizona the observed benefit of this system was still more apparent, as the cover-crop seemed to bring about a ripening of the wood prior to danger from frost that prevented much damage to leaves or points of growth when cultivated orchards were defoliated.

195. Pruning the Orange.-The most approved plan of pruning in European and American orange-growing centres is to form a low head and compact top when the tree is young and up to the first stages of bearing. In sransplanting the tree is trimmed to a straight shoot, as practised with the peach in Georgia, and tying to a stake. 
All shoots that start above the bud are allowed to grow at first. This gives shade and favors the growth of the lower part of the stem. As a rule, the young tree is also shaded at first by stakes stuck on the south side. With a thick top the lower branches always give the first fruit. But as the top spreads the lower branches cease to bear or to increase in length and are gradnally cut away so as to give a well-defined stem two to three feet in height. The after pruning is mainly in the way of taking out dead or sickly inner wood to let in the air and to favor getting into the tree.

The best time for pruning is when growth starts in the spring. At this time the vital forces are most active and the wounds heal over soonest. The greatest need of pruning is in the nursery, where care is needed to bring the tree into shape, as with the deciduous fruits (150).

196. The Lemon.-This is closely related to the orange, as is indicated in horticultural practice in the choice of stocks. The lemon is often budced on the orange and the orange on the lemon on an extensive commercial scale. In the great lemon-growing centres on the Mediterranean the rough lemon is the favorite stock for the orange.

Lemon and orange hybrids are also frequently produced, but they have no commercial status, as they do not answer the purposes for which either oranges or lemons are grown. The lemons of the old California missions were of large size, the juice was low in acidity, and the rinds were more or less bitter. It was not until varieties were brought from the Mediterranean lemon-growing centres with fruit of proper size, percentage of acids, thinness of skin, and freedom from bitter rinds, that growers were able to compete successfully with those shipped from Sicily, Sardinia, and Spain. During the past fifteen years the output from the west coast of lemons has been a surprise 
to the Mediterranean growers, as over 1200 car-loads annually have recently reached the markets east of the mountain ranges.

The lemon is not as hardy as the orange. Its fruit, foliage, and wood will be seriously injured by a freeze that the orange will endure without serious injury. But this is not surprising, as the varieties from Sicily and extreme south France are the outgrowth of ages of selection in the soft mild climate of the great inland sea, where frost is unknown and where soil and air are never dry on the 10th parallel of latitude.

It is not probable that it would require a long period for a skilled expert, such as Burbank, of Santa Rosa, California, to develop, by crossing and selection, varieties of the lemon such as the market now requires from the varieties of the mountains of north India at a height of four thousand feet. If this ean be accomplished, we might secure varieties hardier than the orange, with a more compact form, that would be less troublesome to keep in shape by perpetual pruning.

197. Propagation, Pruning, and Curing. - In south Florida the lemon is budded almost exclusively on seedlings of the sour orange, and the same is true in California, as common experience has shown that on this stock the lemon-trees have a better habit of growth, the fruit averages less in size, and the tree seems to be some healthier and hardier. Where the Citrus trifoliata has been used, it has seemed to increase hardiness and the growth is less riotous than when on sour-orange or roughlemon roots.

The pruning of this rampant-growing tree seems as yet to be an unsettled problem, and growers differ materially as to methods. Many growers annually shorten the long leaders and rampant points of growth in the partially 
dormant season. Later in the season a large part of the shoots that start as an effect of the winter cutting back are cut out. Others are content with more moderate shortening and pinching points of growth, which results in an equal quantity of sizable fruit, but a less symmetric and compact form of tree. Upon the whole, it is a troublesome tree to manage, but to the methodic grower in a nearly frostless region it is one of the most profitable of the orehard fruits.

The fruit is gathered, when it attains proper size for shipping, when wholly green and not more than.half grown. The crop for summer use is mainly gathered in the winter and stored in what is known as a curing-house, built in such way as to be dark and free from sudden changes in temperature, yet with such an admission of air as will carry off the evaporation from the fresh green fruit. In these houses the lemons slowly mature and while taking on the golden color the rind is tonghened, which favors long keeping. The proper curing requires the same methodic care and skill as does the pruning and management of the tree.

198. The Pomelo or Grape-fruit.-This species (Citrus decumana) is quite closely allied to the orange, and it is the most ornamental tree of the genus when laden with its large golden fruit. Its flowers are large, white, and very fragrant. Its fruit runs into a great number of varieties of all shapes, such as oblate, oval, pyriform, and flattened, and the quality varies quite as much. In Cuba we found the fruit quite as popular as the orange, and even more so with the well-to-do classes, as it has an acid mingled with a slight bitter taste that is peculiarly refreshing in hot climates. It is prepared by taking out the bitter membranes and sprinkling the tender pulp with sugar. What is known as the pomelo commercially are round, often six 
to seven inches in diameter, weigh from eight to ten pounds, and the fruits grow singly. The type called grape-fruit is not larger than an overgrown orange and it grows in clusters. This is shipped North more generally than the large pomelos.

The commercial varieties are usually propagated by budding on the rough-lemon stocks and on the sour orange. The trees are not as hardy as the orange, but in nearly frostless regions it is a clean, healtliy tree, not liable to disease or troubled with scale or other insects. In south Florida the culture of the best varieties is being rapidly extended, and the same is true in Cuba and Porto Rico.

199. The Kumquat.-This is a dwarf species of the citrus family. As grown on Citrus trifoliata in Florida it makes a small, handsome bush. It is a heavy bearer of golden yellow fruit not often more than one inch in diameter. The rind is sweet, and unlike most fruits it is eaten entire, only rejecting the seeds. It is used also for marmalades and preserves. It is found at every home place on the gulf coast and in California, but so far as known it is not grown anywhere in a commercial way. At the North it is often found in sitting-rooms in large pots worked on the trifolicata, loaded with fruit. It is by no means a delicate shrub, as it will thrive in a living-room where a geranium can be grown. In frosty climates it seems much hardier than the orange.

200. The Lime.-The sour lime (Citrus medica, variety acida) is much grown in a home way, as its acid fruits are used to the almost total exclusion of the lemon in frostless climes for cooling drinks and for all culinary uses. It is also shipped in quantity from south Florida and the West Indies to New York, Boston, and other Atlantic cities, but rarely reaches the Western States. Budded on Citrus trifoliata it has proven about as hardy as the orange, and 
some of the East Indian varieties have proven hardier in Florida. This fruit will grow on poorer, thinner soil than any of the other citrus fruits.

201. The Mandarin (Citrus nobilis). - This peculiar member of the citrus family seems to be a distinct species. It is a large shrub or small tree with dense foliage and small lanceolate leaves. The fruit is small, bright yellow, with quite thin skin that peels off freely and easily. It is known to the trade as "kid-glove orange." It is grown and shipped in a small way for the fancy markets on the Atlantic coast, in south Florida and the West Indies. Budded on Citrus trifoliata some varieties are as hardy as the navel orange. 


\section{CHAPTER XVI.}

SOME OTHER TROPICAL AND SUBTROPICAL FRUITS.

202. The 0live.-Naturally the olive is a dry-climate fruit; that is, it needs a dry air as well as a relatively dry soil. Dr. Henry Lansdell says in his "Russian Central Asia:" "In the Zarafshan province there are whole forests of olive-trees." Dr. Albert Regel says in Gartenflora, of Berlin: "In the dry climate of eastern Bokhara, olives are gathered from the wild growth of the foothills and brought to market for dessert and confection. The olive-tree is cultivated largely in Tashkend and in the Kokan country." We have much evidence favoring the truth of the statement that in the dry air of the far East the insects and fungi attacking the olive in the moister climates of the Mediterranean and California are not known.

In California hundreds of thousands of olive-trees have been planted where, from the configuration of the country, too much moist air reached them from the coast. Experience has finally established the fact that it only reaches a profitable perfection of fruit in a dry atmosphere and on a quite rich dry soil, yet it will grow and bear crops in a greater variety of soils and air than almost any subtropical fruit tree. As the years go on it will be demonstrated that the highest quality of olives for oil and pickling will be reached in hot interior valleys of California, and in such 
warm interior valleys as those of the Salt and Gila rivers in Arizona. The best system of management will be that of early eulture during the season of growth, followed by a cover-crop (127) and irrigation at the time of sowing the cow-peas or vetch. While the olive will grow on thin land and will endure drought well, the fruit will suffer. It needs some water during the period of fruit development naturally or by irrigation, and it needs the humus and nitrogen following the use of a leguminous cover-crop.

203. Propagation of the Olive.-The most experienced growers prefer trees for planting propagated by the slower way of growing seedlings and budding them as we grow hardy deciduons trees. Such trees, as might be expected, are more robust, long lived, and productive than those grown from "tips" under glass, which is the commercial plan. The seeds are slow to germinate. But this amounts to little, as growers who will plant no trees from "tip" cuttings (62) stratify the seeds (5) months in advance of planting and keep stratified seeds on hand for use when wanted for planting.

204. Commercial Olive Products.-The ancient use of the olive fruit was mainly for oil-producing. The oil in Canaan, Syria, and central Asia was considered an essential to health in the dry, hot Oriental climate and was regarded as a symbol of peace and good-will. In the land of the East it was the substitute for butter and animal fats and an emblem not only of peace but of domestic plenty and prosperity. But the use of pure olive oil in our day has been lessened in all conntries, except central Asia, by the immense production of sunflower oil in Russia, which is mainly sold for pure olive oil, and about all the oil of commerce is now either adulterated with cotton-seed oil or sunflower oil, and in many cases the "sweet olive oil" and the " Lucca oil" have not a trace of olive oil in the mixture. 
Under such circumstances little olive oil is produced in California or in the United States. The main crop as yet grown in California is used for pickling when green for shipment to the States east of the mountains. Ripe-pickled olives are also prepared in large quantity for use on the west coast. In this form they are a healthy and nutritious food, as well as a luxury. Tourists who will not toueh the green-piekled olives nse the ripe ones freely. But as yet the ripe ones are rarely obtainable in the Eastern States, as they are not put up in shape for distant shipment, except in expensive bottles for those who ean afford to use them. The olive-pickling and oil-producing for market are speeial proeesses that require practical instruction not easily given on the printed page.

205. The Fig.-This ancient fruit, now found in about all subtropical climates, also seems to have originated in eentral Asia, and to this day a large part of the commercial dried figs found in every eivilized market come from Syria, Turkey in Asia, and Algeria, mainly. In Asia Minor, Turkestan, Persia, and in fact over a large part of Asia, it is a staple food-plant of the people and has been for centuries. Yet the varieties grown in the Gulf States, and mainly as yet in California, were introduced from Spain or south Europe or are seedlings from this race known to botanists as Ficus carica, variety Hortensis. These varieties are grown as home fruits, but they have never attained a commercial status in a fresh state or dried, except for loeal use and shipment at a price less than is obtained for the Oriental varieties.

At present the White $\Lambda$ driatic variety is eapable of selfpollination and has proven most profitable for drying on account of its eolor and quality. The California black is also widely planted ard his proven hardy and produetive. It is a popular table fig and excellent when dried, but the 
popular demand does not favor a dark-colored variety. Yet this Hortensis class includes the finest dessert and preserving varieties grown in this country.

What is known to scientists as Ficus carica Smyrniana has been, and still is, the leading commercial type of figs known to commerce over the civilized world. The typical white varieties of this elass come largely from Smyrna on the Mediterranean. The locality of this region is peculiar, giving it a soft, moist, and very mild climate. The southerly winds are tempered by the great inland sea and the northerly winds are tempered by the Black Sea and mountain ranges. In this soft, warm climate a race of the fig has been developed in time that will not develop perfect fruit without pollination by the Capri or wild fig. The pollinating process has long been called "caprification." The fig-wasp of that climate breeds on the wild fig. Branches of the wild fig in flower are placed in the tops of the fig-bushes and the insects puncture the receptacle and in the act pollinate the fruit. The researches of Dr. Eisen, of California, and others have fully established the fact that the old idea of caprification only means a process of pollination. In Fresno, California, the Smyrna figs have been hand-pollinated, thus proving conclusively that full crops can be secured without the aid of the fig-wasp. But hand pollination is too expensive for commercial work, and the fig-wasp has been introduced for trial in the orchards of Smyrna figs that have been planted. The growing of this class of figs is yet experimental. If pollination can be secured a new industry will soon be started, resulting in home-grown dried figs, dried and packed more systematically than ever has been done on the Mediterranean.

206. Possible Fig Improvement.-It is not probable that there is to be found a better class of figs on earth for drying than those from Smyrna. But the uncertainty of 
pollination by insects leads to the query: Are there not varieties that do not require pollen from the wild fig for pollination in central Asia that are as large and good in. quality as the White Smyrna? While attending the great commerical fair at Nishni Novgorod in 1882, this subject was discussed with my associate, Mr. Charles Gibb. Mr. Gibb had previously spent one season in Asiatic Turkey, and had become interested in the fig question. At the great fair we found tons of dried figs from Smyrna, Turkestan, Persia, and Syria. After careful testing our decision was that white varieties from west Turkestan were superior to those from Smyrna. Upon inquiry we found that the fig-wasp was not known in that region, and they had known no need of its services. If perfect varieties of size and quality can be secured from Turkestan the trees would prove much hardier than those from Smyrna and give less trouble in every way.

The query also arises whether the seeds of the White Smyrna pollinated by the White Adriatic might not give varieties profitable for drying. This is possible and is worthy of trial.

207. Fig-growing at the North.-Fig-growing at the North is interesting if not profitable. Of course the trees are not hardy enough to stand the winters without protection. A chief interest comes from its wonderful tenacity of life. On its borderland of growth, if it freezes down in winter it starts again from any unfrozen part and often bears fruit the next season. In the prairie States it is often grown by laying down and covering quite deeply in winter. When raised in the spring close observation will show the forming fruit. It will also start fruit in the cellar when taken in for winter protection. As a curiosity it is grown often by taking it up in the fall and burying the roots in a corner of the cellar. When replanted in the 
spring it again takes up growth and fruitage in a way that no Northern tree can equal. If desirable, the culture of the fig without winter protection can be extended farther north by importing the varieties grown on the $40 \mathrm{th}$ parallel in Turkestan. Dr. Albert Regel says: "The culture of the fig begins at the foot of western Karatan and the culture of the best varieties crosses the Hindoo Kush in a southern direction. But in Darvas the hardy figs form high shrubs, with a stem thicker than one's arm, which require no protection. The fruit is small and is used fresh. The drying and pressing of figs commercially is practised in more western districts of Turkestan." At the fair at Nishni Novgorod, figs of fair size and good quality were shown grown as far north as Bokhara in central Asia. These varieties probably could be grown up to the 40 th parallel in the prairie States.

It should be added that the fig grows readily from hardwood cuttings like the grape.

208. The Date Palm.-This is truly a child of the desert, and its delicions fruit only seems to reach perfection in climates with desert-like conditions as to heat and aridity of air. The tree is grown in California, on our gulf coast, and in Cuba. In these relatively moist climates it is a handsome palm, but its fruit rarely reaches perfection.

In the dry, hot valleys of the Salt and Gila rivers in Arizona, the old mission trees seem perfect, and the writer has picked, from bunches weighing forty pounds, as large and delicious fruit as has been tested in central Asia. In Sonora, Mexico, east of the coast range of mountains, the date is also a success in the way of bearing annual crops of good fruit. In these sections the planting of date-trees is rapidly on the increase.

The old trees, bearing at from eight to twelve years old 
over four hundred pounds of large fine fruit in this dry interior region, are all, so far as known to the writer, seedlings. Some of these seedlings, however, we know from testing bear larger and better fruit than the varieties imported by the United States Department of Agriculture from Algeria in 1891 and 1892, and planted at Phoenix, Arizona. Better results are expected from those secured in Algeria in 1899 by a special agent of the United States Department of Agriculture.

The Algerian dates and those from Arabia thrive as well as the old seedlings, and have borne fruit freely when only eight years old. The best varieties are now known, and the planting of date orchards with suckers of the best varieties, with proper alternation of the staminate and pistillate plants, has now started.

The present consumption of dates from the hot desert climates of Asia and Africa is light when compared with other commercial tropical fruits. Many who know the methods of preparing, drying, and pressing into boxes for shipping in the far East will not touch the fruit, and those who are less fastidious eat the pasty, dried dates sparingly. As picked fresh from the trees it is one of the most delicious and wholesome fruits of the tropics. The writer's experience fully agrees with that of Mr. W. G. Palgrave, who says in his "Central and Eastern Arabia:" "Those who, like most Europeans, only know the date from the dried specimens in shop windows, can hardly imagine how delicious it is when eaten fresh. Nor is it, when eaten fresh, heating - a defect inherent to the preserved fruit everywhere; nor does its richness bring satiety. In short, it is an article of food alike pleasant and healthy."

If grown commercially and put up neatly in dried or canned form in southeast California and Arizona, it would 
soon become a popular fruit in all the States where it cannot be grown.

209. Propagation and After Care.-The seeds germinate readily when planted, even under the most unfavorable conditions. We have known them to germinate in the streets of Ames, Iowa, where seeds were dropped that grew to a height of five or six inches, with continual travel around and over them. But they do not come true from seed, and up to the present no way is known to distinguish the pistillate from the staminate trees until they blossom. But with further experience-as with the Buffalo-berryit is probable that some close observer will reveal the sex difference when the plants are young. The usual plan is to bank up earth about the crown of the variety to be propagated and above the base of the suckers, keeping the earth moist by daily watering. Usually the suckers are severed partly from the crown before mounding, which favors the emission of roots and makes it easier to separate the plants when rooted. With the aid of glass covering to lessen evaporation and the liberal use of water, the suckers can be rooted in pots by severing them with a sharp chisel close to the crown of the parent and using them as green cuttings (62). When grown in pots it is far easier to transplant them in orchard where they are exposed to a dry air and hot sun. But in transplanting, the Arab saying that "the date should have its head in the fire and its roots in the water," should be kept in mind. In orchard planting it is usual to plant about one male tree to twenty-five pistillate ones, and to pollinate, the great clusters of flowers of male blossoms are tied to the leaf-stems above the eluster when expanded. But where the two sexes are growing near each other the clusters seem to be pollinated most likely by insects. 
210. Possible Improvement by Crossing.-When the fact is kept in mind that the date-palms commercially grown in Egypt, Algiers, and $\Lambda$ frica have come fróm selection and natural crossing in half-barbarous parts of the earth, it naturally suggests the possibility of improvement by crossing. The florists have done some work along this line in some eases with not nearly allied species. Burbidge states that Mr. M. Denis Hyeres secured an interesting hybrid between Chamerops humilis and the date-palm. In this case the leaves were like those of datepalm and also the fruits were similar, but the seed was too large in proportion to the flesh.

A close observer in Arizona will find that the union of the desirable traits of tree and fruit of two of the best seedling varieties will prove an advantage. It may also prove that the best varieties imported from Egypt or Algiers are bearers of larger and better fruit, and larger bunches, than any of the old seedlings, but they may not prove so hardy or perfect in tree. In such cases the crossing will most likely prove an advantage. The trees being diøcious the erossing will be a simple matter.

211. The Banana. - This valuable fruit of tropical climates is grown in eonsiderable quantity in southern Florida, as it will grow nearer the sea and on lower land than the citrus fruits. It is also grown for ornament and a home fruit in extreme southern Louisiana and in extreme south California. But the main supply of the United States comes from Central America, the West Indies, and Mexico. It is also grown in greenhouses quite commonly in all the States as an ornamental plant, from which welldeveloped bunches of fruit are often seeured. It is a far more interesting plant under gass than when growing almost spontaneously around the settlers' cabins in Cuba. Its immense undivided dark-green leaves are attractive, 
and it is very interesting to watch from day to day the giant flower-bud unfold as it elongates by the expansion of the covering bracts under which the flowers appear. As the separate tiers of bracts drop, the circle of ovaries develop into young bananas. All this goes on as naturally under glass as in its natal clime. If the large bunch of fruit ripens or aborts, the great stalk with its leaf-appendages dies like our raspberries after fruiting, while new shoots are coming forward from the base to bear the next year's crop.

The fruit has no perfect seeds and the varieties are propagated from the suckers that spring up from the base of the stools.

212. The Pineapple.-This delicious tropical fruit is native to Brazil, Mexico, and probably some of the West India islands. But doubts of this fact have arisen on account of the wide distribution of the plant to India, China, Africa, and other tropical climates early in the sixteenth century. But this was made possible by the easy and safe transportation of the plant by means of the fruit. The partially ripe fruit will bear distant shipping, and the fact became known to the early voyagers that the leafy crowns of the fruit will grow when cut off and planted in warm climates. The suckers, also planted in earth, can be safely carried on long voyages, which is not true of many economic plants. It seems a common belief at the North that the pineapple grows on trees. Hence the surprise of tourists when they find it growing on a low plant, not as tall as eight-rowed corn, on a stalk from one to four feet high, like a humble cabbage in some respects. But unlike the cabbage the stem rises from the centre of a rosette of sword-shaped stiff leaves with rough edges. The stalk that bears dies as with the banana and raspberry, and like the latter new suckers spring up for the next year's bearing. 
But the suckers must be thinned to one or two if marketable size is attained. With needed care to regulate the number of bearing suckers, and good cultivation and some fertilizing of the soil, crops can be secured from the one planting for many years. During a visit to Cuba in 1896 the writer gave much attention to their system of managing pineapple plantations. In some cases we found old plantations that had not been renewed in twenty years, but in no case were they equal in size or quantity of fruit to the younger plantations. The more systematic growers start new plantations to take the place of the old ones about once in six years, as it is found that old plants give too much trouble in thinning the sprouts from the buds in the axils of the lower leaves and the rattoons or rooted buds below the crown, and the fruit on the old plants becomes too small. In Florida the plantation is renewed at the close of from six to eight years, but the best crops often are harvested from the second and third years of bearing. In Cuba the pineapple for market is planted on upland suitable for tobacco-growing, in rows about four feet apart, with the plants three feet apart in the rows. Suckers are usually used for planting, as they are stronger and will come into bearing in one year. If crowns or rattoons are used they are grown in uursery until strong before planting.

The cultivation is only one way, and the usual plan is to hill up the line of the rows as the fruit approaches maturity, as we manage the sweet potato. This favors the better rooting of suckers, but does not seem to benefit the fruitage, as those who practised level culture secured as good or better crops. All growers practise very shallow culture, as the nitrogen-feeding roots run very close to the surface. So far as observerl in western Cuba the cost of growing an acre of pineapples will not much exceed that 
of growing an acre of corn, if the level-surface plan is adopted, with the exception of the added cost of planting the suckers. The soil is well supplied with phosphate pebbles and does not seem to need fertilizing except the adding lightly of vegetable matter of some kind on old lands, to give fresh humus to the soil when a new plantation is started.

In Florida it is claimed that the lath covering nsed to protect the plants in winter are a gain in summer in screening the foliage and fruit from the hot sun. But in Cuba the plantations are in open exposure with heated cultivated soil between the rows, yet we nerer saw healthier foliage nor tasted richer flavored fruit in any country yet visited.

In Florida in 1894 over four million pineapples were marketed. But the freeze of 1894-95 killed the plants, except at the extreme south and on keys. This resulted in the starting of new plantations south of the latitude of Tampa, under the shelter of lath-covered sheds, with lath spaced 'about the same as the frames used for evergreen seedlings in the West (13). Under the sheds the plants are set out much thicker than in Cuba, using, it is said, from eight to fifteen thousand plants to the acre, as varied by variety and the different opinions of the planters. The plants begin to bear in about eighteen months after setting out if strong suckers are planted, and with systematic care the plantations prove profitable for eight years or more. Those grown under sheds ripen a large part of the crop in winter, when larger prices are secured. But on Florida keys, where sheds are not used, the fruit does not ripen until April, and continues well into summer.

213. Increased Use of the Pineapple.-The pineapple may be said to be a new commercial fruit. Europe procures the main supply from the Azores at prices out of the 
reach of the masses, and so immature that they are only used in limited quantity. In California the supply comes from the Sandwich Islands in a nearly ripened condition and find a ready market at moderate prices. In the States east of the Rocky Mountains those reaching the markets come from the West India islands and Florida by sailingvessels mostly, and in imperfectly ripened condition, and the same is true in the Western States to a still greater extent.

As Lindley said many years ago: "The pineapple is acknowledged to be one of the most delicious fruits in existence." But this was said of the ripe fruit when the yellow pulp is too tender for slicing and can be eaten with a spoon. In this condition it is not only nutritions but healthful to a remarkable degree. Its free use cures dyspepsia, and is the best known remedy for throat diseases and other troubles of the system. In this perfect and healthful state it cannot reach distant markets, like the orange and banana, but as a canned fruit it would soon find an almost unlimited sale if put up in glass jars properly boxed for shipment. Marmalades in glass will also retain the remarkable flavor of this queen of fruits, if the fully ripe fruit is used. In these suggestions the ease of growing the fruit in Cuba is considered, if we secure proper trade relations, and an actual test of canned pineapple and marmalade made by American ladies residing in Havana. As grown in Florida, if shipped by rail the almost perfectly ripe fruit can be delivered North as safely as the south Georgia peaches.

214. The Loquat.-This is a combined ornamental and fruit-bearing shrub or small tree native to Japan and China. It has long, wide, evergreen leaves decidedly ornamental, and terminal panicles of white and very fragrant flowers that continue in succession from August 
until Decemper as grown on the sonth coast, in Arizona, and California. The fruits ripen from February to May, and bear transportation as well as the orange. It is creamy yellow in color, like a small apple, round or pyriform in shape, and grows in clusters almost like grapes. It is from one to one and one half inches in diameter, with quite large seeds, and with juicy, refreshing flesh mildly subacid. For pies, jellies, marmalade, and dessert it is preferred by most persons to the cherry.

215. Propagation.-In its relationship this fruit seems uncertain. It buds readily on the angers quince, pear, and we have budded it on Pyrus arbutifolia, or bearberry, of the North. It also grows readily from stratified seed kept moist, but freezing is not required. But where select varieties are wanted for fruit-bearing, such as the Giant, it is best to bud on angers quince stocks. At the North it is often propagated for growing in greenhouses and as a house plant. In pots it fruits well in an ordinary livingroom.,

216. The Pomegranate.-This ancient fruit grows wild in Persia and over central Asia, and some cultivated varieties grow as far north as Samarcand, where the winters are quite severe. In Bible history it was one of the fruits of the promised land, and it entered into the myths and religious ceremonies of the ancient Romans and Greeks. In ancient times its seeds were used for a cooling drink of special value in fevers and for general use in hot weather as is practised at this time. The varieties grown in south Florida and California were introduced from south China and south Spain, and are not much hardier than the orange. If desirable, much hardier varieties of equal size and beauty of fruit can be introduced from central Asia, as Regel says it is grown in Kulja on the 44th parallel of north latitude. In Persia also very large 
varieties are grown that are almost seedless and of excellent quality. We saw and tested some of these varieties five inches in diameter during the summer of 1882 in the far East.

It is much grown in the Gulf States, Arizona, and California, but the fruit is not commercial, as it is rarely seen in market except where locally grown. But it is superior to the lemon for summer drinks, and the less acid varieties with colored pulp have an agreeable, refreshing flavor, and are recommended by physicians as a tonic. Indeed, it seems a medicinal tree, as the astringent rind is used in medicine and the bark of the root is used as a vermifuge and in dysentery. It is quite easily propagated from hardwood cuttings planted early in the open ground and it layers about as readily as the grape. At the North, double red and yellow varieties are prized for ornamental use in plant-houses and in living-rooms. Where it bears as freely as in the dry climate of Arizona, this hand some fruit might be made commercial if the people were educated to its use as they have been with the lemon.

217. The Persimmon.-What is known as persimmon or date plum may be said to be a new fruit in west Europe and the United States. For this reason probably De Candolle in his "Origin of Cultivated Fruits" does not mention it, yet he gives quite large space to many fruits vastly inferior in size, value, and quality, to the varieties of the persimmon (Diospyros kaki) grown in China and Japan and to less extent in south central Asia and the mild climates of the United States. It is said that the Japanese regard the best varieties as the most desirable in size, quality, and beauty of the fruits grown in that climate. In the south of France it is now grown as a profitable home and market fruit, and in England, as grown under glass, Burbridge says: "The fruit is delicious, with a flavor like apricots." 
In the Southern States, P. J. Berckmans says of the best varieties: "The fruit of all the varieties is very attractive as to size and color. The latter is usually of a bright orange-red or vermillion shade, which is more or less intensified according to variety. The flesh varies according to varieties, but is usually of a bright orange color, soft, rich, and sweet, with an apricot flavor; when soft the pulp should be eaten with a spoon. Some varieties have reddish-brown flesh and are usually edible when quite solid. A peculiarity of these consists in both red, or half red and half brown, fleshed specimens produced on the same tree. This is frequently the case when several varieties are grown near each other, possibly showing the effect of cross pollination."

As to marketing the fruit, Mr. G. L. Taber says in the "Cyclopedia of American Horticulture": "The market value of the fruit is at present more or less erratic. A large proportion of the fruit-eating people of the North do not yet know what a fine fruit the Japanese persimmon is. The fruits have to be shipped while hard and allowed to ripen after they reach their destination. Commission men are likely to sell them, and the public attempt to eat them, a week or two ahead of the proper stage of ripeness; hence the Japan persinmon in its best condition is comparatively little known."

Like all new fruits the public must be educated to their use. The Japan persimmon has the one peculiarity that it can be shipped when hard and taken home for family use when hard. But like some of our best pears the people should be taught to ripen it in the house. To aid in this work a circular of instruction should at first be furnished the dealer, and to each purchaser for home use.

218. The Native Persimmons. - The native species (Diospyros Virginiana) is indigenous to all parts of the 
Southern States known to the writer, and along the streams it, in some cases, extends north to the 40th parallel. The fruit of the best varieties is small as com? pared with the Japan varieties, which often weigh half a pound, and large specimens often weigh from ten to twelve ounces. The largest of the native varieties tested by the writer has been less than two inches in diameter and well loaded with seeds. Yet prior to the advent of the Japan varieties some of the best native sorts were locally prized in the South and propagated by nurserymen.

No horticultural work would prove more interesting and possibly valuable than crossing the seedless varieties of the South, with fruit one inch in diameter, with the seedless Japan (Tanenashi), with fruit three and one half inches in diameter. Such hybrids would be apt to follow the natives in hardiness, as our native is nearest to Nature (104), and the probable seedless fruit may be of medium size and improved flavor. Such a variety might become specially valuable for drying.

As yet, drying the best ripe Japan persimmons has been experimental, but the decision of experts has been in its favor.

A testing committee in several instances has decided that the dried persimmons were far better in quality and more nutritious and healthful than the best Smyrna figs.

Another line of improvement would be in the way of importing hardier varieties from northern Japan and from central Asia. The writer does not know the extent of persimmon-growing in central Asia, but at the Nishni Novgorod fair we were told that the fruit attained large size and was dried for commerce and home use in great quantity. Regel says: "The date plum in the warmer district of Darvas becomes a large tree." This would indicate it to be a different species from that of the 
varieties we have from Japan. As Darvas is on the 40th parallel and far into the interior of the continent, we may safely believe that their cultivated varieties would prove much hardier than those from the Japan island in the Gulf stream on about the same latitude. It would now be easy to secure the varieties grown in central Asia and it would prove interesting if not profitable to cross them with the Japan varieties.

219. Propagation and Management.-The native persimmon is easily propagated for stocks from the seeds planted early in the South or later, if the seeds are stratified. Select native varieties and the Japan sorts are collar-grafted upon the seedlings. But it is best to transplant the seedlings to nursery rows before collar-grafting is done, as it gives a better root system. Budding is also practised, but this should be on transplanted stocks. If budded or grafted where the tap-roots went down from the seed they are difficult to transplant successfully.

Top-working the native species as it stands in orchard, or growing wild, is often practised profitably. Even in the pine barrens of Florida the top-grafted Japan varieties have formed fine heads and borne heavy crops.

The native varieties are usually diœcious (34); but the best Japan sorts are monœcious, or at least most varieties have enough staminate flowers for pollination. Yet it has been proven that the best crops are obtained by intermingling varieties, with the result of varying the fruit to some extent by cross pollination. That is, the varieties with red flesh are often half red and half brown, or some other shade, on the same tree.

The continued heary crops after the trees come into bearing dwarfs the trees so that they make small annual growth. Hence the usual distance apart is about the same as for dwarf pears, from twelve to fifteen feet each way. 
Yet isolated trees first planted in the Southern States we have seen from thirty-five to forty feet in height, with spread of branches like a Southern pear-tree of the Japan type. The fruit is borne on the new growth mainly, hence the pruning is in the way of taking out the dead wood and thinning the inner branches.

220. The Guava.-This is often called the apple of tropical climates. The fruits of the best tropical varieties are often as large as a good-sized apple or pear. It is an immense bearer. The fruit ripens from August to October in southern Florida. If all that start at one time ripened together the load could not be supported and the fruit. would be small. In Cuba it is quite a pest, as it springs up in every unoccupied spot as dropped by the birds. It seems that no special efforts have been made to secure the best varieties, as the large white-fleshed varieties brought from the East Indies to England we have not seen equalled in Cuba or extreme south California. The greater part of the commercial guava jelly comes from the West Indies. The fruit of this species is pear-shaped and is known as Psidium pyriferum by botanists. This as seen in Cuba is small, smooth, with yellow color of skin and flesh, and when fully ripe it is aromatic, mildly acid, and really good in flavor. In south California the strawberry guava is mainly grown. This also is small, claret colored, with pulpy purplish flesh, white at centre. It has a mingling of sweet and sour, and a distinct strawberry flavor. The yellow variety is also prized for jelly-making and for making tarts and marmalade. In Florida what are known as the Japan and yellow strawberry types are grown mainly with foliage looking much like that of the camelia. These will endure about as much frost as the orange, and if frozen down they come into bearing from the seed in two years. At this time some Florida parties have com- 
bined to grow pineapples and tropical guavas in western Cuba. They will propagate the varieties of best grade by grafting and growing from large cuttings. If systematically managed guava jelly and marmalade will be found as a trade product wherever oranges are sold. Planting the seeds where the trees are to stand and top-grafting or crown-grafting them has given the best results in starting plantations in Cuba by American growers. If the Indian varieties are introduced the fruits also can be shipped from Cuba as safely as the orange and at comparatively low rates, as it is an enormous bearer.

221. The Tomato.-This South American fruit has in recent years been developed in size and quality of fruit to an extent that can never be equalled with the tree fruits. Bailey says: "There is every reason to believe that the tomato originally had a two celled fruit, but in the course of amelioration it has multiplied the locules or cells; it has also modified the foliage and stature of the plant."

Dúring the past fifty years the large-fruited varieties have been developed by crossing, selection, and culture, and it has become a commercial fruit in canned form that reaches about every part of Christendom. Over a large part of west Europe it is grown under glass, but in climates where the dent corns ripen it matures in the open air. A large part of the immense ontput of canned tomatoes is put up by canneries in the prairie States, and of late in the Southern States and western New York. In tropical climates it is a perennial, and we have seen it in Cuba with stem six inches in diameter, from which fruit was picked from the roof of two-story buildings. In west Europe, where quite acid fruits are prized, it is used in ripe state by many for eating and preferred to apples; but it is mainly used everywhere for stewing or for table use in fully ripened condition with cream and sugar. 
222. The Melons.-The history of the muskmelon and watermelon is obscure. It is probable that De Candolle is right in his conclusion that they were originally native to Africa, both north and south of the equator. But in prehistoric times they spread into central Asia and were developed to fully their present perfection ages before America was discovered.

In 1882 the writer was astonished by the size and quality of these fruits brought up the Volga on barges from the Caspian, but grown in part on the lower Volga, but largely in Persia and Turkestan. In 1898 Professor N. E. Hansen was still more surprised by the size and perfection of melons of Russian Turkestan. Of muskmelons he says: "Upon reaching Transcaucasia, north of Armenia, between the Black and Caspian seas, extra large muskmelons were observed, especially in the region near Mount Ararat. But it was not until the cotton-growing sections east of the Caspian Sea, in Turcomania, Bokhara, Amu Daria, Samarkand, and Tashkend, all in Russian 'Turkestan, just north of Persia and Afghanistan and west of China, were reached that the climax in size of muskmelons was observed. Ordinary specimens of many varieties weighed fully thirty pounds, as purchased in the bazars, and government officials informed me that select specimens often weighed over one Russian pood (equals thirty-six pounds avoirdupois) each.

"Some varieties do not ripen on the vines, but are hung up in slings in the houses close to the ceiling and ripen through the winter and spring."

The watermelons of the far East are equally variable in size and season. As to season they include the earliest known, and they also include varieties with a thin, hard shell that keep well through winter. 
In a melon test at Brookings, South Dakota, in 1898, thirty-five American and fifty-six Oriental varieties were tested. Of this test Professor Hansen reports: “The five best varieties in order of earliness were United States Department of Agriculture Nos. 23, 32, 16, 19, 79. United States Department No. 23 ripened perfectly and was a red-fleshed melon of excellent quality."

All these early varieties were Oriental. As an example of late-maturing varieties the writer planted in 1883 a quarter of an acre of a late Russian variety beside a public road on the grounds of the Agricultural College at Ames, Iowa. They made a fine, even growth, and ripened in September-a heavy crop of melons with such a hard shell that students supposed them to be squashes, and not a single one was tested until they were gathered. When tested in September the quality was not surpassed by any variety of the vicinity, yet they kept in the cellar as well as Hubbard squasbes. At the winter meeting of the Iowa State'Horticultural Society the third Tuesday in January, they were tested, and the decision was reached that "no superior in quality was known, but watermelons in January were out of season."

We now have melons of high quality adapted to all parts of the country where the summers are hot enough to ripen the earliest-maturing varieties of corn. But the commercial centres of melon culture and distribution are usually in sections where simmer droughts are not usual, where irrigation water is arailable, or on land where the melon roots can reach permanent water, as on Muscatine Island in Iowa.

The main essentials to profitable melon-growing are a warm, sandy loam soil, good culture, moist but not wet soil at the roots, and not least, purity of the seed. Melon- 
SOME OTHER TROPICAL AND SUBTROPICAL FRUITS. 22\%

growers with some experience save their own seed from selected specimens grown where they could not mix with other varieties. As early ripening is desirable North and South, it is usual to plant the seeds on sods under glass for setting out as soon as the weather favors for early local use and shipping. 


\section{. CHAPTER XVII.}

\section{THE AMERICAN GRAPES.}

\section{Grape History and Development. - Except on}

favored soils on the west coast our grapes may be said to be truly American. In some cases the varieties grown east of the Rocky Mountains are hybrids produced by crossing with the European species; yet, as Professor Bailey says, " the grape of Europe and of history has always led a precarious existence when introduced into our Eastern States, and it is now wholly supplanted by the ameliorated offspring of the native species."

No part of the earth is richer in native species of the grape, and their development in a comparatively brief period by seedling production, selection, and crossing has no parallel case in modern horticultural history.

At this time the dessert use of the grape in the States and Territories of the Union is not equalled in any part of -Europe. Grapes are grown in private gardens in all parts, and commercial growing of the fruit has developed to such extent that good dessert grapes in baskets are now supplied to every grocery, lumber camp, and mining district from gathering time in autumn to past mid-winter. The period of grape-eating has been extended until it about equals that of the apple, pear, and orange. The work of improving the dessert quality of the grape is still going on, and some of our young people will live to enjoy 
the period in the near future when grapes as high in quality as the best known in Europe or Asia will become commercial over the Union. So far we have been working to secure desirable dessert varieties, while in Europe the leading effort has been in the direction of perfecting the wine grapes.

On the Pacific slope the European varieties have been grown successfully since the first Spanish settlement, and its seeds have been scattered by birds and animals until it is now common as a wild vine in the hills. At Fresno, California, in the Salt River valley of Arizona, and at other points in the arid sections, the raisin varieties reach a perfection rarely attained in their natal home on the Mediterranean hills. The commercial growing of the best raisin grapes not only requires the soil and air suited to their perfect development, but the hot, dry air needed. for their drying must be continuous. In our broad domain, therefore, we not only grow the best wine and table grapes of Europe, and the best raisin grapes of the Orient, but are blessed with a new race, home developed, adapted to the wants of less equable sections east of the mountains. The native species from which the best of our northern varieties have been developed by selection and crossing is the Vitis labrusca of the Eastern States. This is known as the fox grape in the Eastern States, Canada, and south to the Gulf. Such varieties as the Concord, Worden, Moore's Early, Cottage, and indeed about all of our best northern grapes, sprang from seeds of this species.

The summer grape (Vitis cestivalis) of the South and Southwestern States has given us some good varieties for wine-making, and some for dessert use. Norton's Virginia, Herbemont, Cynthiana, Hermann, and other varieties are of this class.

The river-bank wild grape of the West and Southwest 
(Vitis riparia) has given us such pure-flavored varieties as Elvira, Transparent, Faith, Montefiore, and others.

What are known as the Post-oak rarieties are improred types of the Turkey grape of the Southwest, which is only a stocky variation of Vitis astivalis. This has given such excellent pure-flavored Southern varieties as Carman, Beacon, and Bailey.

The Muscadine grape of the South (Vitis rotundifolia) has given such pure-flavored rarieties as Eden, Flowers, James, and the Scuppernong.

It is also true that some of our desirable varieties, such as Delaware, Isabella, and Purity, are such wide departures from primitive types that it is not easy to classify them. In many cases it is known that favorite varieties are crosses with the foreign species, and it is more than probable that others will show traces of foreign parentage when grown from seed.

224. Grape-propagation. - The grape is propagated easily from seeds, layers, cuttings of the new wood, and by grafting. It is only grown from seeds where attempts are made to develop new varieties by crossing or selection (110). The different modes of layering are outlined in sections (52) and (53) and growing by cuttings in section $(60)$.

In growing vines from cuttings commercially, specially favorable soils are selected. As an instance, in Iowa they succeed best on the loess soils of the Missouri slope, as this soil is very. fine in texture of its particles and favorable for drainage in wet periods and for the ascent of moisture from below in dry ones. In New York for the same reasons grape-rines are grown commercially on the finely comminuted and well-drained soils on the east shores of Lake Erie. While it is true that grapes can be grown from cuttings on almost any soil, it is yet true that only 
special soils and subsoils will develop strong one-year-old vines with long and strong roots.

225. Growing Vines from Single Buds.-The growing of vines from single buds is mainly practised with new varieties where rapid propagation is desired with a limited stock of new wood. It is also practised with such varieties as Delaware, that do not readily root from dormant cuttings planted in the open air. The buds are cut from thoroughly ripened wood late in autumn and kept in moist cellar, where they will not get dry. In February or March at the North the wood is divided into cuttings, as shown in Fig. 64. The cuttings are stuck in shallow boxes filled

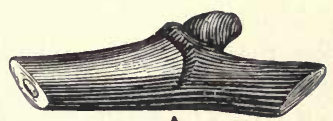

A

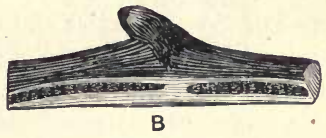

B

Fra. 64.-Single-eye cuttings. $A$, usual plan of cutting; $B$, some grooves shaved off the lower side.

with pure sand, inserting at an angle so the bud will be upward and not more than half an inch below the sand. The filled boxes are placed in a propagating house with gentle bottom heat.

The best temperature of the air is about fifty degrees and that of the sand about forty degrees. When the leaves begin to expand the heat can be increased, both of air and sand. The sand is kept uniformly moist, but not wet. When the cuttings have made a growth of two or three inches they are potted in two- or three-inch pots. The pots are placed where the air is confined and quite moist for a few days, when they can be gradually exposed to the outer air when spring is sufficiently advanced. With some care in ventilation the boxes of cuttings can be placed in a hot-bed for rooting. Grape-cuttings are often made from unripe 
wood. These root more rapidly from single-eye cuttings than those from ripe wood, but they rarely make healthy, strong plants. Some really valuable new grapes have made a bad reputation by being propagated at first from green wood cuttings.

226. Grafting the Grape.-Grafting the grape is mainly confined during recent years to the parts of Europe and California where the varieties of the European species (Vitis vinifera) are grown. The destruction of vineyards by the phylloxera became a national calamity in France, and soon extended to Germany and the Pacific slope of the United States. After testing hundreds of plans for the destruction of this tiny insect, it was found that grafting the European varieties and their hybrids on stocks of our wild species (Vitis riparia) gave the best success, as this stock is less injured by this destructive louse. In the States east of the mountains it is also found beneficial to graft such hybrid varieties as Brighton, Salem, Lindley, and Wilder on phylloxera-resisting stocks. In some sections the Delaware also succeeds far better worked on Vitis riparia stocks.

227. Some Modes of Grafting the Grape.-Where young seedling stocks are used of our wild species, one of the surest and easiest methods is shown at Fig. 65. The earth is scraped away from the crown of the stock and the top of the cut-off crown is sloped upward as in whip-grafting (84). In this slope a gash is cut as in whip-grafting, taking care not to split the stock. The scion has a wedge tongue, as shown in Fig. 65, with a part of the lower end stuck in the soil. No waxing is needed, but the soil is banked up to the top bud of the scion. This grafting is done before the sap starts in the spring.

As the lower end of the scion takes root it must be cut 
off, after the union has taken place, where the native root is desired.

In grafting above the ground on wild vines we have found the plan shown in Fig. 66 very successful. After

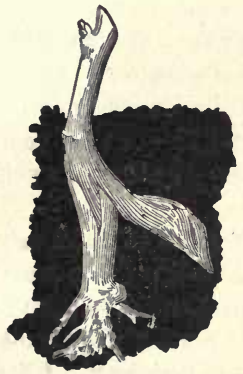

FiG. 65.-Grape-grafting. (After Bailey.)

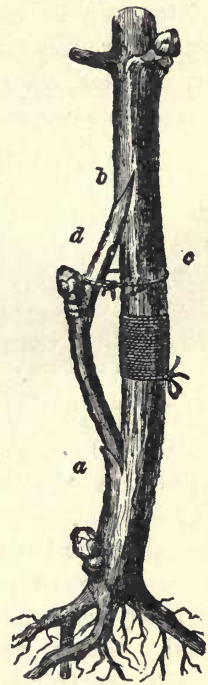

Fig. 66. - Top-grafting the grape. (After Hussman.)

the leaves are well started in the spring, wrap wire around the vine as shown between the nodes. Below and above gash the vine for the insertion of a scion wedged at both ends. After springing in the scion, secure it by tying as shown and wax the wounds made at points of insertion. The bud on the scion will soon start growth, and during the season the writer has had a growth of six or more feet 
from the scion bud without removing the top of the stock. Indeed, we have had the best success where the top has not been cut away until the next season, when the growth of scion is able to use all the sap flow. Roses, shrubs, and other vines can be safely grafted in this way early in the spring and the top eut away when growth begins.

The common commercial plan used in California on a large scale is quite as successful in the States east of the

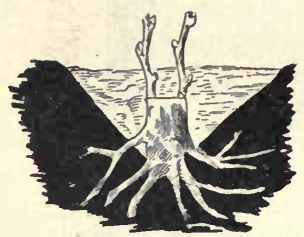

FiG. 67.-Grape grafted low down with long scions. (After Bailey.) mountains. By this plan the ordinary cleft grafting $(90)$ is practised, using scions fourteen inches long. If the established stock is not more than half to three fourths of an inch in diameter at the crown only one scion is inserted. But if an inch in diameter two scions are put in -one on each side, with the bark of stock and scion together, as shown in Fig. $6 \%$.

The use of the long scion or scions is to make use of the sap pressure from the established stocks. The long scions are tied to a small stake for support and are banked to the top bud. Long grafts thus inserted with fruit-buds, often, if permitted, ripen fruit the first year. I have had the best success with the long-scion system when dormant scions were inserted after the leares of the stock had begun to expand and the first heavy sap pressure was over.

The inarching (54) method practised for instruction in German school gardens is also worthy the attention of amateurs. Cuttings or plants are started around a cultivated vine trained on a stake. As the stocks grow upward on small stakes, a branch or shoot of the cultivated variety is inarched on the top shoot of the stock. This union is 
accomplished during the season of most active growth and new wood cell formation. When united the shcot of the cultivated variety is severed just below the point of union and the top of the stock just above it, giving a top-worked vine for planting where wanted.

228. Best Soil and Location for Vineyard.-Much has been written on this topic that after experience has shown had little foundation. About three leading facts deserve the attention of commercial planters:

(1) Air-drainage (97) is essential for protection from early spring or early autumn frosts at the North.

(2) The porous subsoil is required that will give drainage in a wet time and permit moisture to ascend to the upper soil in a dry period.

(3) Dark-colored soil with an abundant supply of humus and nitrogen is not desirable for profit, as it develops long-jointed wood and rampant growth not favorable for early, well ripened, or good crops of fruit. Rather thin land for a good corn crop gives the best fruit in quality, and freedom from rot of fruit or disease of vine. But such land may need barnyard manure, potash, and phosphoric acid as the vines get age. Even in the South and California the best grapes in quality, and for shipping or wine-making, are grown on lands not rich enough for the best crops of corn. Yet it is true that good grapes can be grown for home use and local market on any dry land over a large part of the Union by selecting the varieties adapted to the varied condition of soil, latitude, and longtitude.

229. Varieties for Varied Sections.-It is not easy to sclect any one variety adapted to all parts of the Union. Such dessert varieties as Concord, Worden, Moore's Early, and Cottage as yet are the cosmopolitan varieties starred or double starred by the American Horticultural Society 
in uearly all the States of the Union. But different parts of the United States present such varied soil and air conditions that about all the highest developed varieties of the world find with us congenial conditions. In California such exquisite table grapes as the Flame, Tokay, Emperor, Black Hamburg, Chasselas, Verdal, and Thompson's seedling are grown to perfection, and in the hot, dry valley at Fresno, and in the Salt River valley of Arizona, such raisin grapes as. White Muscat, Sultana, Thompson's seedling and other choice varieties are grown in immense quantity. The importance of the raisin interests can be estimated by the fact that $103,000,000$ pounds of raisins were produced in 1894. It is also suggestive that one thousand car-loads of table grapes have reached the Eastern States from the west coast in a single year. The wine-grape interest has also been dereloped on the west coast to an extent not reached at any other point in America. In the South the highly developed varieties of the vinifera type grown on the west coast are not a success, and the development of the native species by Munson and others is in the experimental stage. As yet the varieties grown for the Northern market for dessert use are such as Concord, Worden, Moore's Early, Ives, Moore's Diamond, Delaware, Niagara, Lindley, and a few others. The dessert variety that finds most favor in the North as put up by Southern growers is the Delaware.

But farther south a new era is dawning in dessert-grape culture. Some of the hybrids produced by crossing the best European varieties with the best Southern native species have been tested, such as Brilliant, Gold Coin, Muench, Superb, and Eden. When some of the best of these recently developed varieties become commercial, they will be favorites in the Northern markets, as they have the tender, juicy, sprightly texture peculiar to the Delaware, 
qualities rarely found in the vinifera varieties of the west coast.

In the North it may be said that any neighborhood where dent, or even the eight-rowed flint, corn can be ripened, will permit the ripening of some of our American grapes. As yet commercial grape growing is confined to the near vicinity of our lakes and the bluff soils of our large rivers. East of Lake Erie, in New York, over 25,000 acres are now planted in what is known as the Chautauqua belt. In this belt, and in Ohio, Concord, Worden, Moore's Early, Niagara, and Catawba are mainly grown and shipped in baskets over a large part of the Northern States east of the Rocky Mountains. Other grape-growing centres are south of Lake Erie, in Ohio, at Ontario, Michigan, and on the Mississippi bluffs in Missonri. In these centres the recent tendency has been in the direction of growing improved varieties of better quality than Concord. In the newer plantations on Lake Erie, and south, Catawba, Moore's Early, Moore's Diamond, Brighton, Worden, Cottage, and Niagara are now planted mingled with the Roger hybrids.

Dealers and consumers are now demanding varieties comparing favorably in quality with Brighton, Isabella, and Delaware. The wine interests on the Missouri bluffs and in the Lake Erie region are also seeking for better varieties for pressing.

The newer plantings at this time are largely of such varieties as Delaware, Norton's Virginia, and Cynthiana, for wine-making and the bottling of the unfermented juice.

230. Distance Apart and Planting.-It is not easy to formulate rules in regard to distance apart of vines in plantation. Those familiar with our native varieties know that the Delaware with its relatively short growth will not 
require as much room as Moore's Early, which has longer internodes and requires longer pruning than most varieties. As a rule, the strong-growing Labrusea varieties should be planted ten feet apart in the rows and the rows should be ten feet apart. In the South such strong-growing varieties as Herbemont, and the Estivalis hybrids are planted twelve to fourteen feet apart in the rows and the rows nine feet apart.

In California, with the very short system of pruning on low stumps, the rows are planted eight feet apart each way.

With increased experience, the tendency of recent plantings has been to plant far enough apart to give room for root-expansion and to give air movement and circulation both ways between the rows.

In planting, first-class one-year-old vines grown on selected soil (60) give the best results. As to depth of planting, the usual direction has been to plant about as deep as they stood in nursery. But increased experience now favors deeper planting. In the prairie States, and over the North, where root-killing of young vines is common, it is customary now to plant vines fully eighteen inches deep on dry soil. When planted, only about the usual covering is pressed down on the roots. As the season advances the holes are gradually filled in connection with the culture. With this deep planting, if the upper nitrogen-feeding roots are killed, the deeper waterfeeding roots will sustain the plants until new surface roots are developed. This deep setting is now also gaining ground in California and the South. Where vineyards are started in the raisin-producing sections of California and Arizona, the cuttings are stuck two feet deep, and Mr. Gustaf Eisen of Fresno states: “For trial I planted some cuttings of raisin grapes five feet deep, and they were at one year old several times larger than those set two feet 
deep, and bore fruit the first summer." In this deep setting of cuttings or vines the lower part sends out rootlets which extend growth still deeper in soil not too wet. But the surface roots are sent out in proper position. The gain is merely in the first year's growth, as when set in the ordinary way the deep roots will be extended in due time.

231. Varied Modes of Training.-Under natural conditions the wild vine climbs to the top of forest-trees and spreads out laterally in the tops, where it bears fruit exposed to the sun and air. While the vine is climbing upward it rarely if ever shows fruit until a branch assumes an approach to the horizontal position. Under cultivation practically the same plen is followed except in the way of shortening the stem and controlling the amount of fruit produced by cutting back the new growth, which alome produces the flowers and fruit. In Nature, the tree or rocks to which it clings gives stability and relative freedom from damage from winds, while under culture this is given in California by adopting the dwarf-tree form and in other sections by training on stakes or a wire trellis. Many plans of training on wire trellis have been practised in this country and Europe, but in this connection only those generally practised in this country will be considered.

232. Training for Laying Down at the North.-In the North, especially in the prairie States, vines are pruned late in autumn and the canes laid down for winter covering. To avoid much bending in laying down, the main cane is trained on the lower wire, as in Fig. 68.

The first year it is usual to allow the vines to grow on the ground without care. They are not much in the way in cultivation, and they make about as much root growth and ripen their wood quite as well as when tied up. In the fall the growth is cut back to a stub which is covered 
with a mound of earth, and in the far North a covering of coarse manure is applied over the mound, as young vines are liable to be root-killed the first season after setting out.

The next spring the trellis should be made. For this system four wires are used, the lower one eighteen inches from the ground and the others about ten inches apart.

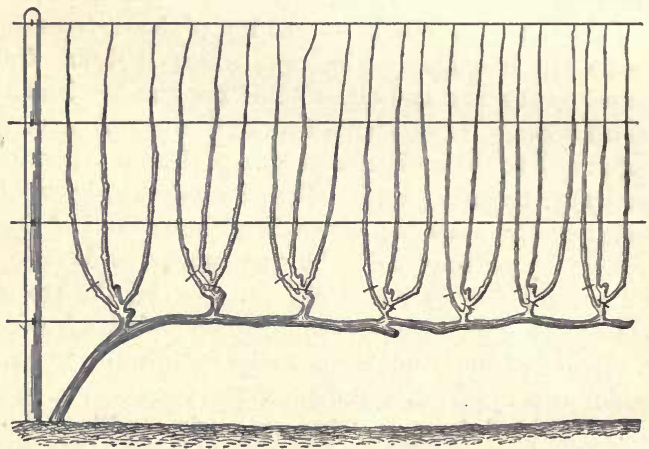

Fig. 68.-Completed vine. The lines at base show where to prune.

No. 12 galvanized wire is usually selected. The supporting posts are set from twelve to fourteen feet apart, with the end posts well braced to prevent being drawn inward, when the rines are loaded with foliage and fruit.

The second spring after building the trellis, carefully uncover the stubs and permit only one bud to grow, rubbing off the others as they start. Train the vine perpendicularly, and when it reaches the top wire pinch off the terminal point to develop laterals and growth below. In the fall cut off the laterals or side branches close to the main cane and cut the main cane back to well-ripened 
wood. In laying the cane down for covering, some earth is removed from the crown, as an aid to the careful bend-, ing of the cane, as low down as possible.

The third season, about the time the buds begin to start, take up the cane and tie to the lower wire, as shown in Fig. 69.

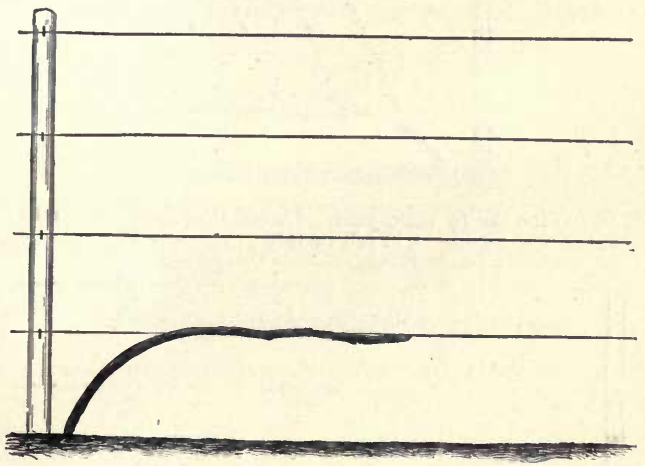

Fra. 69.-Vine in spring of third season.

During the third summer laterals are started upward, as shown in Fig. 70, which is effected by some pinching of surplus shoots. When the latcrals reach the top wire they are pinched back. This pinching of the terminals favors the formation of fruit-buds near the main cane. In the fall of the third year cut back the upright shoots, as shown by the dotted lines in Fig. 70 . The terminal cane is not dotted for cutting, as it is left entire for the extension of the cane on the lower wire, as shown in Fig. 71 , when tied up the fourth spring. Usually with this system the vines give some fruit the third season.

The fourth spring shoots spring up from the spurs, 
shown in Fig. 71 , and are pinched at the top wire and the main laterals are pinched to give shorter and firmer growth. In the fall the canes are wain cut back at the

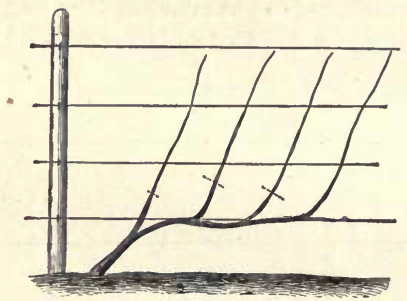

FIG. 70.-Vine fall of third year. Dotted line shows where to cut in fall pruning.

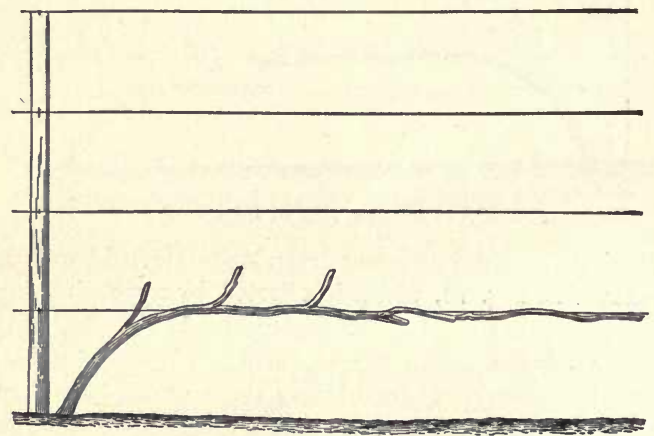

Fia. 71.-Vine in snring of fourth year.

dotted lines in Fig. 72, leaving from three to six buds, depending on the perfection of the canes.

The fifth season the vine is completed at the close of the season, as shown in Fig. 68. The gain in this system is 
in the ease of laying down for winter protection and the even distribution of the bearing wood. In the prairie States it is also a gain to keep the fruit near the ground, with a leaf canopy above, but a circulation of air beneath. But the permanent success of the plan depends on summer pinching of the up-growing shoots and laterals. This summer pinching, if started early, develops fruit-buds low down on the laterals. If not pinched, the buds will

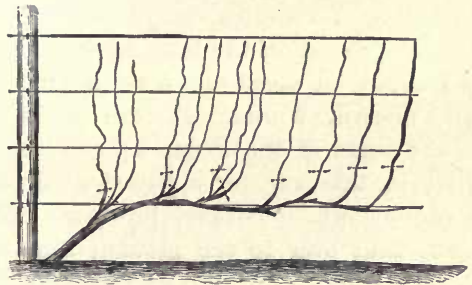

FIG. 72.-Vine in autumn of fourth year. Dotted lines show where to prune.

develop higher up, requiring longer spurs. We have kept a vine on this plan for twelve years without undue increase in length of spurs. If any of them get too long a new shoot can usually be started upward from the lower part of the spur.

233. Diagonal Training Plan.-In the prairie States, and in other extended areas, a simple renewal system is practised that is only a variation of the system generally practised in the Chautauqua district of New York. The first year the vines remain on the ground. In the fall they are cut back to a stub with two or three buds and mounded. The four-wire trellis is built the second spring and two canes are started from the stub which are trained perpendicularly and pinched when they reach the top wire, 
In the fall the strongest laterals are pruned to spurs with two or three eyes and the main cane is cut back to a length of about three feet. The third spring the two canes are both trained, in the same direction, diagonally on the wires.

The after pruning is on the same plan except that the main canes are longer and some of the strongest laterals of some varieties can be pruned to longer spurs.

The gain in training all canes in one direction is that it favors the bending over and covering the bearing wood in winter. On the grounds of the Iowa Agricultural College at Ames, a vineyard of about one acre planted with such varieties as Concord, Worden, Moore's Early, Cottage, Telegraph, and some of the Roger hybrids was managed by the writer in this way for a period of fifteen years. The canes were not wholly covered in winter. The bearing wood was bent over to the ground, some prunings placed over the spurs, with enough earth to hold them down. Some earth was also thrown around the crown, leaving the stiff part of the stems exposed to the air. Bending down and covering the bearing wood, with its knife wounds on the spurs, materially lessens winter evaporation and increases the yield and quality of the fruit, even in parts of the West where the exposed tops are not liable to be injured by winter's cold. During a period of eighteen years this vineyard produced heavy and regular crops without renewal of the canes, except in the way of starting new shoots from near the crown and cutting out the old canes when the new ones were old enough for bearing.

234. The High Renewal System.-In relatively mild climates where winter protection is not essential, snch as western New York, the river bluffs of Missouri, and in sections of the South, a modified system of high renewal 
training is practised in large vineyards. Three wires are used for the trellis, with the lower wire usually twenty inches above the ground. The renewal head is started on a tree-like stem at or near the lower wire, as shown in Fig. 73. It will be noticed that $d d$ in the illustration are wood of the preceding year's growth which may be called long spurs of bearing wood of the prectding year's growth. It will also be observed that spurs for fruitbearing are left on the short arms $g$ and $b$. After growth

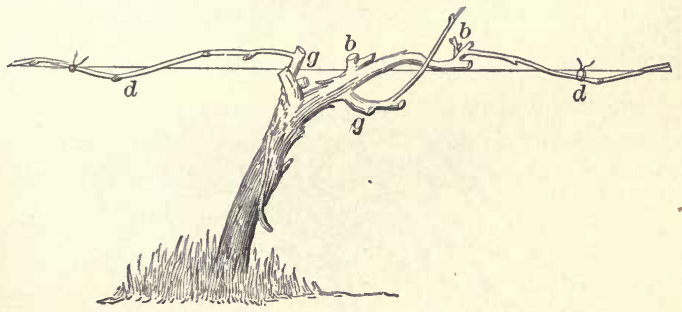

Fig. 73.-High renewal plan, vine pruned.

starts the fruit will form on the young shoots on the lower wire and between the lower and second wire. As growth extends from $d d$ and the arms, it is tied to the upper wires.

At the next pruning the long spurs $d d$ are eut away and their places are taken by other long shoots that have grown up from the arms.

Those who have some experience will realize at once that with this high renewal system no two vines will permit the formation of arms or stubs in the same position. The main essentials are the retaining of arms or stubs capable of starting new growth, and the annual renewal of the long spurs $d d$. 
In starting young plantations on this plan, the cane is trained upright on a small stake, the second year to the lower wire, where it is caused to divide by pinching.

When the vines are fully established the arms or stubs are renewed or shortened every two or three years by starting new shoots direct from the old head. If this is not done the arms or stubs would soon get too long.

235. The Pacific Slope System.-Fifteen years ago,when the writer made his first study of the fruits of the west coast, nearly all the vineyards of the raisin, wine, and table grapes of the vinifera class were grown on the selfsupporting dwarf-tree, like form shown in Fig. 74. At

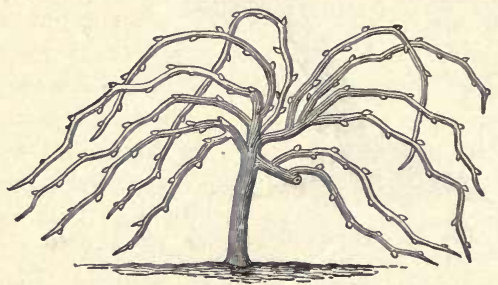

FIG. 74.-Self-supporting vine.

that time the writer expressed the opinion that the system was faulty, for the reasons that it exposed much of the fruit to the hot sun and that the sap pressure early in the season was too great for the few growing points and that sooner or later it would result in diseased conditions. Visits to the west coast since that time have not changed this opinion. Disease has ruined hundreds of vineyards with this system of short pruning, while those who have practised longer pruning, with wire or stake support, have, so far as known to the writer, grown more perfect fruit, have had less rot, and the vines have retained health and 
escaped the fungons discase that baffled the scientists as to its identity. In the few cases where grape-growers have adopted the high-arm system of the Chantanqua belt (Fig. 73), the stem and arms have with the vinifera varieties grown large, but the surface for starting new growth is much larger and the side growth on the lower wire has relieved the sap pressure and given more fruit less subject to rot and sun scalding than with the old short-spur stub system.

236. Other Systems of Pruning.--The fan renewal system adopted in parts of the Union is much like the diagonal-training plan of the prairie States, except that in this system the canes are trained in both directions on the wire, as shown in Fig. 75. What is known as the Thomery system is shown at Fig. 76. This is not as com-

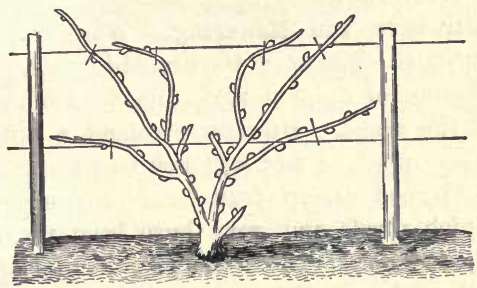

Fia. 75.-Two-year-old vine pruned on the fan system.

plicated in practice as it appears. It is useful in home grounds where space is limited, where a single row can be started in a sunny situation. It is really the laying-down plan (232) two stories in height. The vines are planted eight feet apart and every alternate one is run up to the top wires, while the intermediate vines fruit on the lower trellis. In this double-decked plan the spurs will soon get too high if every shoot that starts from the lower side of 
the spur is not saved or at least enough are saved to keep up a renewal of the spurs at least once in three years. With this care we have made a Thomery row in the garden very profitable and satisfactory for many years,

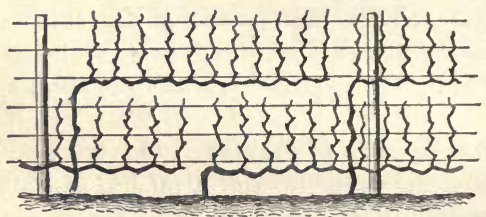

Fig. 76.-Thomery training.

giving five or six varieties, ripening at different times on the same garden row.

237. Cultivation and Manuring.- Whatever may be said of continued culture of the orchard fruits, there can be no difference of opinion as to the need of continued culture of the grape. Howerer excellent a variety may be, the experienced grower will not believe that perfect bunches and good dessert fruit can be picked from vine rows in which weeds and grass have been permitted to grow. The usual plan of vineyard culture is to use a small turning plow in the spring, after the vines are tied to the wires, turning the furrows toward the rows. As the weeds start in the line of the rows they are taken out with the hoe in connection with some of the earth thrown inward by the plow, working on both sides of the row. The after culture is with the cultivator and harrow, keeping the top soil mellow and level. After midsnmmer the culture should not be deeper than three inches, as deep culture at this period interferes with the root-hairs needed for fruit development. Experience and observation also 
have impressed the belief that the spring plowing between the rows of bearing vines should not be deeper than four inches. Many grape-growers in the prairie States use the plow before pruning and laying down the vines in the fall, turning the furrows toward the rows as a help in protecting the roots over winter. This also favors the work of laying down the canes and banking the crowns (233).

With the fall plowing the culture in the spring is deferred until the vines are tied up and the weeds start in the rows. The hoe is then used and the after culture is wholly with the cultivator and harrow.

238. Need of Humus in Cultivated Soils.-In speaking of soil selection (228) the need of fertilizing soils after several crops have been gathered was indicated. In this connection the absolute need of hunus in the soil continually cultivated must be considered more in detail. Even on good corn soils continued culture soon uses up or "burns out" the fresh vegetable humus that has much to do with the physical texture of the soil. An experiment conducted by the writer illustrated this fact forcibly. For a period of five years crops were grown on half an acre of quite rich prairie soil that could be taken away, including the roots, such as beans, currant cuttings, and apple and plum seedlings. The sixth year the plot including the adjacent field with the same soil was sown to barley. The crop made fine growth on the untreated ground, but did not get high enough on the experimental plot to be reached by the cutting sections of the reaper. In this case the beans gave nitrogen to the soil, but nothing was left to give the needed humus. In the orchard the use of cover-crops (126) give nitrogen and a plentiful supply of humus to the soil. In the vineyard the cover-crop cannot be used and we must rely on barnyard manure with possible use of 
nitrate of soda, potash, and phosphoric acid as the vineyard attains age.

239. Shading Vineyard Soils.-It is stated above that cover-crops cannot be used in vineyards. This is true in practice, as the shading of the soil by growing crops is in the way of needed summer care and it favors rot and other fungoid diseases. It is also true that the general belief in all parts of the Union is, and has been, that the bare, well-tilled soil is needed by the heat-loving grape-rine. But facts do not warrant the latter belief. In Nature the American wild species grow to greater perfection where the roots are shaded by tree- and plant-growth and by the leaves and leaf-mould. That at least some of our best varieties need shade of roots from the sun in the heated period is shown by the fact that the Delaware, with bare surface culture, is a failure in Iowa. But when the space between the rows is quite deeply covered with sorghum bagasse or prairie hay, it shows healthy foliage and bears full crops of as perfect fruit as is grown, where it is a favorite commercial variety. In the perhaps distant future it no doubt will be found advantageous to cultivate early in the season, and when the time for mildew and black rot comes have the bare soil covered with some lowgrowing leguminous growth, such as burr clover or our small-growing vetches. 


\section{CHAPTER XVIII.}

\section{THE RASPBERRY AND BLACKBERRY.}

240. The Raspberry: Origin of American Varieties.The raspberry has been cultivated as a fruit over Europe and Asia during the historic period and even back to the fourth century. The best European varieties were introduced quite as early as the apple, pear, and grape. But like the European grape it was soon found to be unreliable, except in a few favored localities. Indeed, it may be said. that the imported varieties of raspberry were more general failures than the grape, as the latter does well in California, while the European raspberries, with the exception of the Antwerp and Fontenay, are not a commercial success anywhere on our continent. Gradually by selection and hybridizing we have developed a number of red, black, and yellow varieties that compare favorably with the best of the Old World. It is now a popular commercial fruit in all parts of the Union and quite a favorite with amateurs, as a well-managed plantation lasts for many years without renewal.

241. Cultivated Species.-Attempts have been made within the past five years to classify our cultivated varieties and determine the species to which they belong. But it, is not wholly satisfactory, as it is evident that we have many hybrids difficult to place botanically. Even our list of European varieties mostly shows traces of crossing with 
our American red species and the purple-cane class. For horticultural purposes it is best to divide the varieties into the following classes:

(1) The black-cap varieties.

(2) Purple-cane varieties.

(3) The American red varieties.

(4) The European red varieties.

242. The Black-cap Family (Rubus occidentalis).-A distinguishing characteristic of this class is that it does not sprout from the roots, but is propagated from the tips of the young canes. As found native in nearly all parts of the Union it is excecdingly variable in habit and fruit. Nearly all cultivated varieties are selections from the local types, as distributed by the birds in corners and waste places. The fruit is not always black. In many localities varieties are found with yellow fruit, and such red or scarlet varieties as Ellisdale and Shaffer, that only root from the tips of growth, are usually classed by growers with the black caps, but botanically they are classed with the purple-cane species (Rubus neglectus).

243. Propagation and Transplanting.-The canes of the varieties that root from the tip are strong and stocky at the base, but slender at the tops, which droop over to the earth in late summer. If the ground is mellow, and the canes are not swayed by the wind, they will root without aid. But where plants are desired it is far more certain to peg down the points when they enlarge and change color and cover with some earth pressed down quite firmly. If covered without pegging the winds often sway and draw them from the covering. It is customary to leave the rooted tips undisturbed until wanted for spring planting. If taken up the fibrous mass of roots, shown in Fig. .\%, are not easy to care for unless at once planted where they 
are to stand for fruiting. Fall planting succeeds well even in the prairie States, if a mound of earth is thrown over

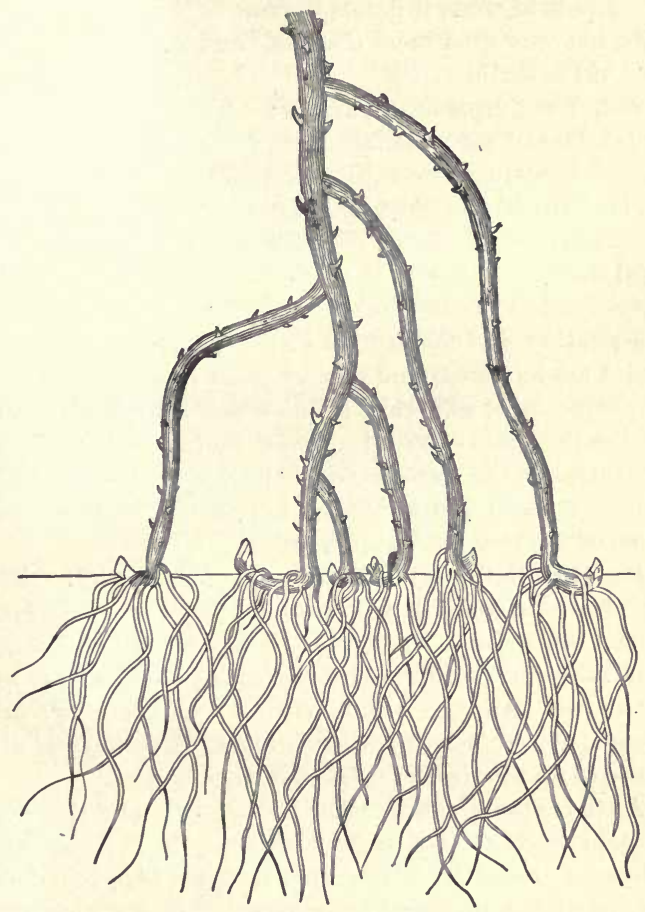

Fig. 77.-Divided cane of black raspberry taking root in the soil. (After Fuller.)

the plants to be removed in early spring. In planting these rooted tips it must be kept in mind that growth does 
not start from the attached stem but from the erown. The section of stem is upside down and its mission is accomplished when it develops roots at the point. Plant with the crown not more than half an inch below the surface of the earth.

244. The Purple-cane Varieties.-This is an interesting and valuable assemblance of varieties which has been elassed as a true species, Rubus neglectus. It appears to be intermediate in eharacter between the black eaps and the American red species. Fuller says of it: "The principal difference between the varieties of the black caps and purple cane is in the fruit. The first, as is well known, has a rather dry, tough fruit with a peculiar flavor. Its grains are numerous and very irregular in size. The fruit of purple eane, as a rule, is rather soft, juicy, often very brittle, the grains separating very readily; color varying from light red to dark brownish purple, but never black; the flavor mild and agreeable, but entirely distinct from those of the true black-cap raspberry."

Professor Bailey says of the purple-cane family: "The type has no characters which are not found in one or both of the other two. Neither has it any normal or continuous range, but occurs where the black and red species are associated. All this points strongly to hybridity; and there is now sufficient accumulation of experimental evidence to prove a hybrid origin for these berries."

As the botanic elassification is uncertain, and the close relation to the black caps is evident, it is usual with growers to elass the purple-cane varieties that root from the tip of the canes and never sprout from the roots with the black caps (242). This leaves a small but excellent class which, like the Philadelphia, are not easy to root from the tips of growth and not sprouting as freely as the red varieties. 
245. American Red Varieties (Rubus strigosus).-The wild red raspberry of the United States is widely distributed and its fruit, as found wild, often approaches closely in quality the European red species (Rubus idlous). As it seems to have naturally crossed with the black-cap species, and crosses readily with the European red varieties, it is singular that as yet no attempt has been made to improve this valuable species except by selection and cultivation, and we have no evidence of its crossing with other species, except naturally with the black caps. Yet it is quite possible from what we know of their history that such choice varieties as Cuthbert and Turner are hybrids, with the added quality and size of the European varieties.

246. Propagation and Transplanting.-The American red varieties and the sprouting purple canes are propagated by sprouts and root-cuttings. Nearly all the varieties sprout so freely that a resort to other methods is not needed. But the Philadelphia and some other sorts sprout more sparingly and are often grown from rootcuttings (50). In some cases also propagators thrust a spade down in a circle around the plant about eight inches from the centre, which increases the sprouting very materially. Transplanting, in rows for fruiting the suckers of the reds and sprouting purple canes, can be done easily and rapidly, as they start from the cut-back top like a small shrub. Plant firmly at the depth they stood before taking up and cut back the tops to near the ground surface of the hills or stools. The first cultivation of spring may be with a small turning-plow, but all after culture should be with the eultivator, taking care to keep the general surface about level. The hoe must also be used between the stools. 
247. Pruning the Raspberry. - The first year after planting not more than two shoots should be allowed to grow, and for field culture without stakes these should be pinched back when one foot in height to start lateral branches and to give a stocky habit. The second season the sprouting varieties will throw up suckers. From four to six of the strongest ones should be left and the others cut away. The black caps will also throw up sprouts from the crown, which may also need thinning. In both cases the plants should again be pinched back when one foot in height. The after pruning may be summed up as follows: (1) Regulating in spring the number of new shoots that should grow in each stool.

(2) Pinching back the shoots to one foot in height and later shortening the laterals. (3) In the fall, or early the next spring, cut out all the wood that has borne fruit the previous season. (4) Catting back the laterals of the black cap and long-caned purplecane varieties to from ten to fifteen inches. In the prairie States it is usual to defer cutting out the old bearing wood until spring when the plants are not laid down for winter protection. The old canes help to hold the young ones from breaking down and also help to hold the snow in winter.

248. Mulching and Manuring.-In the prairie States the successful growers for market cultivate well as closely to the plants as possible until the fruit is about half grown. The rows are then mulched with straw or coarse manure, a distance of two feet each side of the rows. Some of the large growers grow green clover for this use. It is cut when in blossom and used as a mulch. The growers at Sparta, Wisconsin, and at other points report the largest yields of the most perfect fruit where the cloyer was used for ten years in succession and worked into the soil. In all parts where dry weather is apt to shrivel the fruit this 
mulching is imperatively needed. After mulching, the narrow space between the covering is cultivated to conserve moisture and keep the soil mellow. If this system" of mulching is kept up and worked into the soil no other fertilizing will be needed. But if not mulched, and clean culture is given, barnyard manure must be applied as with the grape.

249. Winter Protection.-The usual way given in our American fruit-books to lay down the raspberry and blackberry, is to commence at one end of the row and lay down the canes all in one direction in the line of the row. But where laying down is necessary a much better plan is now practised. The rows are laid out east and west and the plants are turned to the north. A deep furrow is turned away from the row on the north side, running the plow as close to the stools as possible. The assistant prepares a cavity in the furrow and the operator crowds over the tops, while with his foot he crowds the crowns toward the open furrow to lessen the bend as the tops are crowded north into the opened cavity, where they are covered with the earth taken out for the reception of the next lot of canes. With some practice in using the fork and pressing with the foot, few canes are broken and the work progresses rapidly. The assistant who covers, soon finds that some straw or litter over the canes, before the earth is thrown on, helps in holding down the canes. In the spring the vines are raised with a round-tined fork. When raised, it will be found that they will not regain the upright position. Some of them partly broken will remain nearly horizontal and in the way of cultivation. This is provided for by a wire resting on open iron hooks driven in small low posts close to the row on the north side. In the fall, prior to covering, the wire is dropped down and the vines rest on it. In the spring, as the canes are taken up, the 
wire is raised, lifting them up to an angle of about 45 degrees. If any of the eanes are too upright they are tied to the wire or pressed under it. In this position the fruitbuds develop more evenly and the fruit grows larger and better on account of leaning away from the sun and the shading by the young eanes growing upright south of them for next year's fruiting. In practice this plan gives less work and trouble in laying down, inereases the quantity and quality of the fruit, and separates the bearing from the new wood, which is a gain in picking the fruit and a gain in summer pinching of the new eanes and in eutting out the old canes after bearing. In parts of the country where these fruits are not laid down, the plan of stretehing a wire on low stakes north of the rows will answer the purpose of staking. The bearing eanes are bent north and tied to the wire and the new eanes growing upright are not in the way of fruit-picking, shade to some extent the fruit, and as our summer storms are mainly from the south they are not as liable to be broken down, as they will rest against the bearing eanes and wire.

250. Staking Raspberries and Distance Apart.-On rich ground the black caps and purple-eane varieties, and also the reds grown, as they should be, in stools, should be staked or supported on both sides by wires on low stakes. Stakes, if kept in the dry when not in use, are durable and the expense of staking is not as great as is usually suspected. Fuller says: "The cost of stakes is less than two cents each, and I cannot afford to grow raspberries without staking, because every stake will save on an arerage ten cents' worth of fruit, and in many instances three times that amount." In the East, ehestnut stakes are mostly used, and in the West, cedar stakes sawed out for this use in Temnessee are not much more expensive than pine, and 
the same is true of nursery and fruit-tree label stakes from Tennessee.

In Europe the plan of staking is shown in Fig. 78, with bearing wood tied to the stakes and the new canes growing up between the stakes.

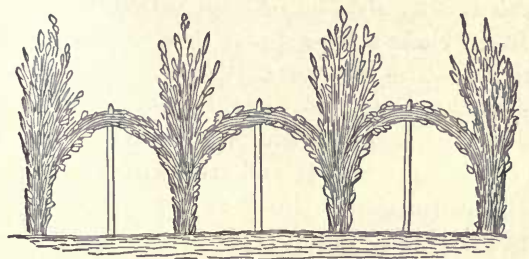

FiG. 78. - European plan of staking the raspberry.

The culture is usually only one way. The rows are about six feet apart and the bearing stools should be from two to four feet apart, depending on the variety as to vigor of growth.

The sprouting kinds are planted about two feet apart in the rows and the sprouts that come up are treated as weeds. But some care is needed from year to year in the way of taking out the suckers from the stools where they are too thick and preserving them where too thin. In practice the stools are not permanent in position, as the strong suckers will not always be found on both sides alike, so the stools change position about every year.

The black-cap varieties, and such purple canes as Shaffer and Ellisdale, are more permanent in position and make a broader extension of stool. Hence the rows should be at least two feet further apart than the sprouting varieties.

251. The American Blackberries.-It is beyond doubt true that we have in the United States the largest and best 
native wild blackberries of the north temperate zone and probably of the world. The cultivated varieties are all selections of best varieties found in a state of nature, and, so far as known to the writer, the blackberry is not grown commercially in any part of the world except the United States and Russia, and the Russian varieties grown on the Volga River bluffs are not equal in size or quality to our best varieties. The varieties cultivated belong, in different sections of the States, to several quite distinct types or species. But the horticulturists describe the habit of growth and style of cluster and fruit without much regard to botanic distinctions. Four main types are recognized by close-observing growers: (1) The high bush of clearings and fence rows of the Northern States with long clusters, such as those of the Ancient Briton. (2) The type with lower growth and short clusters, such as those of the Snyder and Kittatinny. (3) The hybrid cls s between the blackberry and dewberry, represented by Wilson and Rathbun. (4) The trailing dewberries, such as Lucretia, Mayes, and Windom.

The readiness of all these classes to cross naturally when adjoining shows that they are very nearly allied. In the prairie States, even, all the types of the dewberry and blackberry will, when adjoining, cross naturally and almost invariably, as shown, when the grower or birds have planted the seeds, which is not usual with distinct and well-defined species.

When the dewberry and blackberry are crossed the resulting seedlings bear perfect seeds, which is another indication that they are nearly allied.

252. Propagation and Management.-The blackberry and raspberry are nearly allied botanically and require about the same treatment and the same methods of propagation as the red raspberry. At the North it requires 
laying down for winter protection of canes and fruit-buds (249).

Neat and methodic amateurs grow the plants in stools, as with the red raspberries, but eommercial growers by pinching (24\%) develop stocky plants which are grown in narrow matted rows. With this plant care is needed in the spring to destroy the weaker shoots and only to permit the strongest to form canes for the next year's fruiting.

In the spring-pruning the work is deferred until the blossom-buds begin to appear, as these buds are often near the ends of the young eanes. Some seasons eutting back the tops will destroy all the fruit-buds nearly. But taking out of the old wood must be done in the fall, where laying down is practised. In taking out the canes that have fruited, an implement is used with a handle five feet long, as shown in Fig. 79.

253. The Dewberry.-This vine-like species naturally trails on the ground. Some of the modern varieties, such as Lueretia and Windom, bear large fruit, softer in texture than most blackberries, and they are now found in all our fruit markets. All the eultivated dewberries are propagated by covering the tips of growth, as with the black-cap raspberry. The best suecess in growing the dewberry has been by training the vines diagonally on wires, as practised with the grape (233). In the fall the vines are cut back, according to their growth and ripening, to from twelve to thirty 
inches when they are laid down and covered at the North and West. Some growers keep the plants from the ground with brush or straw under the rines, but this interferes with cultivation and the two-wire low trellis gives much better satisfaction. The Logan berry is a stronggrowing vine of the dewberry type and is considered to be a cross between the wild blackberry of California and some raspberry, supposed to be the old Red Antwerp. It has the habit of the dewberry and roots from the tips, but its flavor suggests the raspberry. It is not as hardy as our dewberries, but can be grown by winter covering. 


\section{CIIAPTER XIX.}

\section{THE STRAWBERRY AND ITS CULTURE.}

254. Some Historical Notes.-Without much doubt the first settlers on the Atlantic coast found larger and better wild strawberries than were at that time under cultivation in Europe. Mr. G. E. Stone, in "Garden and Forest," gives many facts from early New England history to sustain this statement. He quotes from Dr. Dwight this statement, written in 181\%: "The meadow strawberry of this country is the best fruit of the kind which I have seen. I have seen several that were four and a half inches in circumference, many which were four, and bushels which were between three and four." Professor Bailey also quotes Roger Williams in 1843 as follows: "This berry is the wonder of all the fruits growing naturally in these parts. It is of itself excellent, so that one of the chiefest doctors of England was wont to say that God could have made, but never did, a better berry. In some parts where the natives have planted I have many times seen as many as would fill a good ship within a few miles' compass."

The best varieties of the New England and Virginia species were taken to west Europe early in the seventeenth century. Their larger size and superior quality led to the neglect of the native wood varieties (Fragaria vesca), and it was soon found that what was known as the Virginia strawberries gave new and improved varieties from the 
seed which took rank for a number of years as the largest and best varieties known.

But later the advent of the Chilian species into west Europe marked a new era in the development of the strawberry. The Chilian species (Fragaria Chiliensis) was introduced into France in 1712 and at once became popular. In England the original varieties did not prove hardy enough for outdoor growing. But soon seedlings and hybrids were produced that displaced all previonsly known varieties. The Wilmot Superb, British Queen, and other Chilian seedlings and crosses were soon grown commercially. In $185 \%$, five hundred acres of the two varieties named above were grown near Brest, which is still a strawberry-growing centre. In this country the varieties originating in Europe were grown with varying success for a number of years, but the cosmopolitan varieties of our present list may be said to have sprung from the pioneer work of a few men who crossed the South American species with those native to our soil. As instances, C. M. Hovey, of Boston, gave us the first very large strawberry by crossing, which is known as Hovey's seedling. J. S. Downer, of Kentucky, in the same way produced the Charles Downing, Green Prolific, and Kentucky. James Wilson, of New York, produced the Wilson's Albany, and William Parmalee, of Connecticut, produced the Crescent seedling. These are noted, as they were the pioneers in the great work of developing our present remarkable list of American strawberries, not excelled, if cqualled, in the world.

Professor Bailey says: "The advent of the Chilian strawberry in European and American gardens, and its phenomenally rapid amelioration, obscured the native species, however, and the latter are now practically out of cultivation. Now and then some evidence of native blood 
can be seen in an early variety, but the influence of our own field strawberry in the improvement of the garden varieties has evidently been very small."

From a botanical standpoint this is wholly true, but from the horticultural point of view the exact adaptation of varieties to our varied climates and soils has largely come from our native species. As an instance, we know that the Charles Downing sprang from a seed of the western wild species (Fragaria Illinocnsis) pollinated by a Chilian variety, and we also know that in habit of growth and runners, and in choice aromatic flavor, it follows the native, while the Chilian pollen has given size of fruit and decidedly modified the foliage. Our native species has also transmitted the required hardiness.

255. Staminate and Pistillate Varieties.-All botanists have described the strawberry as perfect in flower or bi-sexual. But our cultivated varieties are now classed as staminate and pistillate or pistillate and perfect. Without doubt this change has come from two main causes: (1) The cultivated plants often assume forms and show changes quite different from the natural type. (2) Hybridizing often brings about sterility in various forms. In the case of the Green Prolific, Horey seedling, and other sorts, it is known that they were the product of a cross of two bi-sexual varieties, yet they lave no perfect stamens. In such cases we know that the change was made by hybridizing, Fig. 80 at $A$ shows the pistillate flower. If planted apart from perfect varieties no fruit will develop unless partially or wholly pollinated by bees or other insects. Fig. $80 \mathrm{~B}$ shows the flower of a perfect variety, with the stamens in a circle around the mass of pistils in the centre.

In planting, some growers plant one row of a perfect variety alternated with two rows of a pistillate variety. 
Others alternate the rows, planting as many rows of perfect as of pistillate varieties. In private gardens the perfect and imperfect varieties are often alternated in the rows. This plan mixes the varieties in a way not desirable

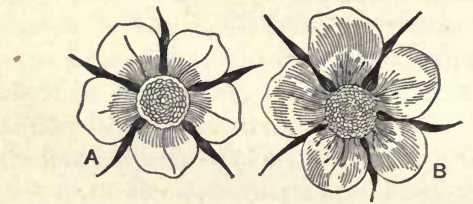

Fig. 80.-A, Imperfect strawberry flower ; $B$, perfect flower, showing the stamens.

for furnishing plants, but favorahle for perfect pollination and large and perfect berries.

We now have many varieties of fine size and excellent quality with perfect flowers, but experienced growers prefer to alternate the perfect and imperfect varieties, as it is found in practice that the pistillate varieties will escape injury of the ovaries by frost when those of the staminate sorts are killed. It is also found that a frost that will blacken the ovaries of the staminate varieties will not injure the stamens. The development of pollen is an exhaustive process, hence the ovaries of the perfect varieties are not as well stored with starch, and as perfectly matured, as those of varieties that have no stamens or pollen.

Fuller says: “Strawberry culture would probably have been just as far advanced if we had never had a pistillate varicty in cultivation, and much confusion would have been avoided. Had not Mr. Hovey produced so good a pistillate variety as he did, it is very likely that such kinds would never have been tolerated by fruit-growers anywhere." This may be true in some parts of the Union, 
but is not true in the prairie States, for the reason above given, which is well established by long experience.

256. Setting Out and Care of the Plants.-In the Northern States fall-plowing best fits the soil for spring-planting. The soil is fined by the winter frosts and the chance of injury of the plants by cut-worms is much lessened. In the spring the soil is fitted for planting by merely harrowing the surface. For what is known as the matted. row system set the plants eighteen inches apart in the rows and make the rows four feet apart. In setting, reject all plants with dark-colored roots. The new plants of the previous year's growth should alone be planted, and they always have light-colored roots. The usual directions for planting are to prune the roots and spread them out in natural position as in planting a tree. In practice this is not found to be necessary or profitable. Planting with a narrow spade really gives better results. If the soil is in moist but not wet condition the spade is thrust down by a man walking backward. He draws the handle towards him until there is room to drop in the plant with roots spread out in fan shape. The assistant holds the plant in place while the spade is withdrawn and then presses the dirt firmly in the cavity and levels the surface so that the lower leaves are not buried. If the soil is a little sticky the man places the spade with its back away from him and presses it down six inches, moves it from him and then withdraws it. The assistant follows and places a plant with roots spread out laterally in the cavity, and it is firmed by another movement of the spade downward and toward the plant, when the boy again firms and levels the surface with his hands. This plan does not place the roots in natural position, but it gets them down to moisture, and when the plant begins to grow a new set of roots will start in natural position. Those with most experience 
favor planting the roots wet so that the fine earth will adhere to them, which is accomplished by keeping the plants in a pail with about two inches of water in the bottom. As the assistant picks up a plant for planting the dead leaves and surplus live ones are picked off.

From the start the soil should be kept mellow around the plants.with a pronged hoe and the cultivator should be started soon after planting. The first runners are trained out in the line of the rows to fill up the vacancies and to be out of the way of close culture. As the season advances the rows are allowed to spread out as they fill up in the centre, and before culture ceases they should form matted rows from twelve to fourteen inches wide. Late in the fall, after the ground freezes the matted rows should be lightly covered with marsh hay if obtainable. If not, straw will answer the purpose, or any litter that does not lie in lumps and is fairly free from weed-seeds. The covering is not thick enough to exclude frost, but it prevents the alternate freezing and thawing of the winter period and lessens evaporation. If left on quite late in the spring, it also retards the period of blossoming, which is an advantage in some localities. Sometimes at the West, when a late frost is apprehended, the covering raked between the rows is returned as a protection. It is best to leave the raked-off covering between the rows until after the crop is picked. The coarsest of the straw is then taken out and the tramped-up particles are cultivated into the soil.

257. The Two-year System of Cropping.-We have much talk in books and papers about the best methods of renewing old plantations. But the experience of growers each year strengthens the belief that more than two crops from the same plantation should not be attempted. The first and second crops are in all respects satisfactory with ordinary care, and grass and weeds can be kept out with 
comparative ease. On the other hand, if the third and fourth crops are gathered, it is with added expense and much reduced yield of less perfect frnit for home use or market. It is much less expense and tronble to set out a new plantation than to clean out an old one, and at best we cannot get the yield of the matted rows secured the first two years.

Plowing under the plants after the second crop is picked adds much humus and plant-food to the soil, which will give quick growth to a crop of cow-peas to be plowed under late in the fall. If necessary on account of restricted space, the ground can again be planted with strawberries the next spring. But repeated crops on the same ground should not be attempted for the third time without giving a period of at least two years to the growing of other crops.

258. The One-year System.-In about all the States small fruit-growers and gardeners combined practice the system of turning under the plants after picking one crop. The plants are set in rows only three feet apart, and matted rows established the first season about one foot wide. The next spring the crop is picked and the plants turned under for a crop of late vegetables the same season.

With this plan the ground is kept rich and weed-growth is kept down with comparatively small expense. Those with little experience would decide that this pian is not a wise one, as the second crop is usually as good as the first. But the gardener is pleased with it, as weeds have no chance to get established and insects and fungi do more damage the second year than'the first. Again: the gardener knows that the expense of setting out a new plantation on clean mellow ground is a small item when compared with fighting weeds and grass in a two-year-old plantation.

259. The Hill System of Growing.-The hill system of growing is practised with such large fruiting varieties of 
the Chilian elass as Brandywine, Cumberland, Jesse, and Sharpless, that form large compact plants with comparatively few runners. They are planted three feet apart with plants one foot apart in the rows. All runners are cut as they appear and cultivation is kept up regularly. In autumn the whole surface is mulched lightly. In the spring this is left around the plants to keep the fruit clean. After the second year new plants are allowed to root between the old ones, which are taken out when the new ones become strong. With this plan the rows are often kept up for several years. The plan is found profitable for the fancy market. - As Fuller says: "One strong stool with plenty of room for its roots will give more and larger fruit than twenty plants that are crowded."

Where the one-year system is carried on commercially, with ligh culture and manuring, it largely takes the place of the hill system, with large varieties grown for those who are willing to pay an extra price for a fine article.

260. The Strawberry Under Glass.-Those who have had experience know that no cultivated fruit will grow under glass with as little care and expense, and fruit as bountifully, as some varieties of the strawberry. The low structure with the vines only two or three feet from the glass gives the best results. $\Lambda$ few years ago the system of growing bright-colored and good berries in this way for winter marketing at fancy prices became quite a large business. But the extensive growing of the strawberry on the Gulf coast and delivering them North at moderate prices has about confined the work to amateur growers, who derive satisfaction and pleasure, if not profit, in watching the development of strawberries in winter.

The main essentials to suceess are: $(a)$ The selection of perfect-flowering varieties, as the pistillate ones will need hand pollination in the still air of the plant-room. 
(b) The plants should be rooted in three-inch pots the previous summer, by sinking the pots and rooting the plants starting on the runners in the pots. When well established, and the pots full of roots, keep them in an airy place until cold weather, with occasional watering. When placed under glass shift to four-inch pots. (c) A temperature of 60 to 75 degrees in the day and 50 to 60 at night is favorable, and indeed any care farorable for such hardy plants as the geranium will suit the strawberry. (d) When the fruit is developing, water can be applied more liberally, and application of liquid manure at this time will give increased vigor to the plants and an increased crop of fruit.

261. Shelter from Drying Winds.-Over a large part of the United States and Canada the strawberry is lessened in yield of perfect fruit and health and thrift of vine by direct exposure to prevailing drying winds. This is specially true in the arid States and over those west of the great inland lakes. Experiments made by Professor Green, of Minnesota, and others in the prairie States, have demonstrated that beds sheltered from dry winds, and protected from the direct rays of the sun by lath frames-as practised by pineapple growers in Florida-liave given a still greater increase in size and perfection of fruit and health of foliage. In practice the lath-shading would not prove profitable, but it pays well where possible to select positions for planting sheltered by tree growth, or in other ways, from prevailing dry winds in the growing season. The same is true of the raspberry and blackberry. In nature they are found usually in sheltered and even shaded positions, and direct exposure in the interior states to raking winds not only lessens the fruit yield, but favors the development of the small fruit fungi referred to in the chapter on spraying. 


\section{CHAPTER XX.}

\section{THE CURRANT AND GOOSEBERRY.}

262. The Red and White Currants.-Although we have many varieties of the cultivated currants in Europe and America, all except what are known as black eurrants belong to one species (Ribes rubrum). With the red and white currants there has been no intermingling of speeies, and when we grow our garden varieties from seed they vary but little. If we plant the seed of such old varieties as Red and White Dutch and Victoria, we have a very near reproduction of the parents, except that the color may vary. Those who have planted the seeds of the Fay report that nearly half of the seedlings bear white or yellow fruit. Professor Card says: "Perhaps through its long sojourn in the low countries the currant has inherited something of the staid Dutch qualities of the inhabitants, and does not readily depart from long-established eustoms." But no cultivated fruit responds more promptly to good treatment in the way of culture, manure, and proper pruning. In the same vicinity we find the old varieties differing so much in size and quality as to lead to belief that they were distinet varieties.

Botanists say that the wild red currants of this continent belong to the species found over Europe. But as yet we have no cultivated native variety of value. All our varieties have been imported from Europe or grown from seed of the foreign varieties.

The fruit is each year becoming more general in demand 
in our markets and its commercial growing is being extended. In the home gardens, with common care, it bears good fruit when thirty or more years old. As a dessert fruit it is not equal to the strawberry, but it comes at a different season, and such varieties as the White Grape require no more sugar to make them palatable than the strawberry. The currant jelly is also a home delicacy that is refreshing and wholesome thronghout the year.

263. Propagation.-The currant is not grown from seed except when new varieties are wanted. But it is interesting to plant the seed in a small way to watch the varied shades of coloring of the fruit of the seedlings. The stratified (5) seeds grow readily if planted very early in the spring. If buried outside, the soil is usually in condition to plant by the time the buried seeds can be taken up. We have planted currant- and gooseberry-seed in March when not more than two inches of the surface soil was thawed. If not planted early the seed sprouts in the sand with which it is mixed.

The almost invariable method of propagation is from cuttings of the young wood planted in the fall (58). Cuttings made and set in August, or as soon as the leaves are ripe, will root during the fall, as shown in Fig. 81. In the figure the cutting is shown in erect position, but it is best to plant all cuttings as shown by figure in section (58).

Layers put down in spring will also

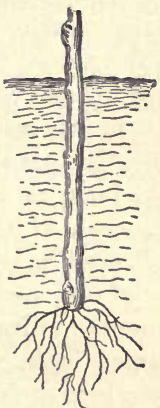

FIG. 81. - Currant cutting planted in August and rooting the same season. be well rooted in the fall, if the shoots are twisted at the point where buried (52). 
The currant is usually grown in bush form. In this stool form they throw up shoots from the crown which can easily be shaped by pruning. But along walks and in well-kept places the tree form is often adopted. This is effected by cutting off all the buds of the cuttings except at the top, and when the top bud starts rub off all shoots but one and train that upward, as noted in section (265).

264. Manuring and Mulching.-The currant will grow and bear under neglect on almost any soil, but to bring the fruit to perfection it must hare culture and a rich soil. It is a heavy feeder and its greatest perfection is reached on heavily manured soil. It will even do without culture if the soil is made very rich and the whole surface between the rows is mulched. It is a cold-blooded plant and will thrive and bear perfect fruit when heavily mulched with sorghum bagasse, straw, or even coal ashes. Some growers mulch heavily near the plants and cultivate in the centre of the rows. Sawdust kept on the surface is often used near to and between the plants in the line of the rows. But in this case the old, partially rotted sawdust is used. The Fay currant is specially benefited by the sawdust mulching, as much of the fruit hangs down on pendent branches, which the mulching keeps clean.

It must be kept in mind that with currants the feedingroots run very near the surface. Hence commercial growers cultivate with a narrow harrow, with the teeth slanted back, while the plants are young, and then mulch the whole surface. But others continue the shallow cultivation, with frequent manuring.

265. Pruning and Training.-In field culture the principle of renewal is practised. The best fruit grows on two-year-old wood, and many growers of fancy fruit prune out all wood older than two years, and have young wood coming forward to fill its place. But the usual rule is 
to cut out all canes older than three years. This annual cutting out of old eanes favors the starting of many new shoots. The superfluous ones must be eut out. But those coming from the older wood are not cut back closely. Spurs are left which load with fine fruit the next season.

In garden culture it is best to follow this renewal plan, as where the old wood is left the fruit soon becomes small and the currant-borer will rapidly increase in number and injury to the canes.

Some summer pinching should also be practised on the points of growth of the most vigorous shoots. This gives better form to the bush and also favors the development of fruit-spurs at the base of the shoots.

When the tree form is desired in private yards or gardens, a single shoot is started from the single bud left at the top of the cutting. The second spring cut the cane back to a height of from twelve to eighteen inches and allow four or five shoots to branch at the top. The third spring shorten the branches and allow ten to twelve shoots to grow. The after-pruning is a repetition of cutting back in such way as to secure new growth in symmetric form. But those who attempt this plan of training must keep in mind the necessity of short pruning. The spurs are eut to within an inch of the old wood early each spring.

266. The Black Currant.-The black currant (Ribes nigrum) has long been a favorite culinary fruit in most parts of Europe, but as yet it is not much grown in the United States. But in many neighborhoods, settled by Europeans mainly, it is found in most gardens and its fruit is much esteemed, especially when stewed or canned for winter use. The well-grown fruit is nearly as large as the Morello cherries, and when canned the color is almost 
identical with that of stewed cranberries. The fruit has a peculiar odor in the skin that many dislike. This is easily removed by immersing the fruit, in a wire basket, for a few moments in boiling-hot water prior to stewing or canning.

There is nothing essentially different in its management from that of the red currant, except in pruning. The best fruit grows on wood of the preceding year's growth, while the red varieties bear the best fruit on two-year-old wood. Where grown commercially in Europe, the young growth is headed back fully one half each year. This favors the starting of new shoots for the next year's fruiting and the cutting back tends to give larger fruit, as with the grape. But this plan requires a system of periodic heading back, quite severely in the dormant period, to secure a renewal of new wood over the whole exterior. But a more primitive system is adopted by amateurs who follow the European home plan. The bearing branches are cut when the fruit is ripe and carried to a bench in the shade, where the fruit is picked at leisure. This annual cutting back gives strong bearing shoots for the next crop.

In Europe, in the summer of 1882, the writer heard the story repeated, from England east to the Volga River, that the jam and jelly of the black currant was the general remedy for all throat affections, and that the jelly mingled with water was a sure cure for bowel disorders and summer troubles of the stomach.

267. Golden Currant.-This native fruit (Ribes aureum) of the West has been too much neglected. As found in its native haunts it varies in size of fruit, and quality and habits of regular bearing, as widely as our native plums. The few attempts at selection and culture have been 
mainly by seedling production. As a marked instance, the Crandall as sent out seems to have been propagated from seeds, with the result that no two bushes were alike in fruit or habits of bearing. The true Crandall, as propagated from cuttings, is as large as the Black Naples currant of England and wholly free from the peculiar odor of that variety. It is also a remarkable bearer without much attention to pruning. But like all currants the size of the fruit is inereased by keeping a supply of young wood for bearing. Another merit of this species is that it will thrive and bear in the South and Southwest, where the summers are too hot for the successful growing of the red and English black varieties. By selection and culture we could soon develop varieties of great value for cultivation over a large part of the Union.

268. The Gooseberry.-In all parts of western and eastern Europe a number of varieties are cultivated, larger in size but not better in quality than our selected American varieties As yet the eastern European varieties have not been tested in this country. The varieties introduced from England and west Europe have not failed as generally as the foreign grapes. In some sections east of the lakes two or three English varieties are grown commercially, and a number of seedlings with a possible admixture with the native species are grown across the continent. This is specially true of such fine American seedlings as Industry, Triumph, and Chautauqua.

The American varieties now widely grown, such as Champion, Downing, Houghton, Pale Red, Pearl, and Smith, have been produced by seleetion and seedling production, like our American plums, raspberries, and blackberries. In quality they are superior to the European varieties, but as yet they do not equal them in size. As 
a fruit for dessert and eulinary use the gooseberry has not as yet come into such general use as in England, but its use is gradually increasing. It is now found in nost home gardens and is grown commercially near our larger cities. With the increased use of the fruit the European distinction between dessert and culinary varieties will be recognized and increased interest taken in the development of new and improved varieties by hybridizing, seedling production, and selection.

269. Propagation and Culture.-The gooseberry is closely related to the currant, and is propagated in nearly the same way. The wood does not ripen as early as that of the currant, and there is less gain in the fall planting of the cuttings. The most successful mode yet tested is to tie the cuttings with willow bands in small bundles and bury on dry ground for early spring planting. For home use, or even more extended propagation for sale, layering is practised (53). The young wood bent down and covered in the spring will make strong plants for planting the next spring. Some varieties, like the Champion, will emit roots from near the points of growth without aid where they reach the earth in moist seasons.

Growing from seed is only practised by those who wish to secure new varieties by selecting the best of the seedlings. The surest method with small lots of seed is to mash the berries in sand in jar or box and bury outside for winter freezing, or in warmer climates they may be kept anywhere where the sand can be kept moist. In the spring plant sand and seed together in shallow box or boxes, to be kept in. the shade until perfect leaves are dereloped on the seedlings. If not sown too thickly the plants are exposed to the sun late in the season and not planted in rows for trial until the next spring. 
270. Pruning and Training.--Like the red currant, the gooseberry bears the best fruit on two-year-old wood. Hence the main pruning consists in removing canes older than three years. Grown in the ordinary bush form, little pruning is needed the first two or three years after planting. If on rich soil and good culture is given, some clipping back in early spring of the strongest shoots is beneficial, as it favors the development of fruit-spurs below. If not clipped back during the first year, the canes will get long and the fruiting-spurs will be at the top on canes so long that the fruit will bend it to the ground. With the American varieties no attempt should be made to keep an open top. The fruit should be well shaded, especially in the Western States, from the direct rays of the sun.

The gooseberry has a habit of growth favorable for training in many ways. In England the writer has seen gooseberry plants said to be thirty and even forty years old trained on walls and buildings of such size and spread of wood that the single plant gave each year over one bushel of fruit. Our American varieties in like manner can be made to cover a low arbor. Indeed, as Fuller says, "It may be trained as espaliers, or in almost any manner that one's fancy may suggest."

271. Culture and Manuring.-The gooseberry is peculiarily a northern plant. In hot climates it fails altogether or loses its leaves too early and the fruit is small and poor. Like the currant it loves a rich soil, continued early shallow culture, and mulching, when the fruit is half grown, like the raspberry, to give best returns in field culture. In home gardens, such American varieties as the Champion can be grown on the north side of a fence where no other fruit will grow, or between tree rows, where the plants can only be warmed by the sun at certain hours of the day. 
To show its nature in our climate more fully, it is well to state that mulching the whole spaces between the plants with ten inches of hard coal ashes and cinders for a period of twelve years in Iowa gave continued crops of large fruit without a trace of mildew, and this experiment included varieties subject to mildew with common culture, such as Industry and Triumph. 


\section{CHAPTER XXI.}

\section{PROMISING WILD FRUITS WORTHY OF SOME ATTENTION.}

272. The Dwarf Juneberry.-The dwarf Juneberry, shadbush, or service-berry (Amelanchier alnifolia), has become quite popular where locally grown. In some cases in Iowa it has been grown and marketed as high-bush huckleberry. Indeed, Professor Bailey says, "They closely resemble large huckleberries." The Success variety has become commercial and has been referred to another species (A. botryatum), but grown side by side with selected native varieties from Colorado, South Dakota, and other parts of the arid States, the decision must be that they all belong to the same species. It is really a neglected native fruit of considerable value. Professor Card says of the fruit of Amelanchier alnifolia: "Dark purple or blue, with bloom, large, sweet, juicy. A valuable species for fruit or ornament."

With several years' experience in growing the fruit, it has been found that with proper pruning and culture the size and quality are as much improved, as are the currant and gooseberry, by good treatment. The best varieties are very heavy annual bearers, and the only drawbacks at present are that the fruit ripens unevenly and the birds, if permitted, will take it as fast as ripened where grown in 
a small way. But in the few cases at the West where it has been grown by the acre for market, the berries taken by the birds have not been missed, as the fruit-eating birds at that season seem local in their habits. Where grown in a small way for home use, the low bushes are easy to cover during the brief ripening season. In the near future, when more general attention is given to this fruit, varieties will be secured by seedling production, selection, and crossing, that will be much larger in size, of better quality, and that will ripen more evenly. Bird-netting will also, in the near future, be obtainable, as in Europe, at prices within the profitable reach of growers of Juneberries, cherries, and the Japan persimmons, which also are ruined often by the picking of birds.

In a few cases "it has been grown by the acre in Iowa and sold in the groceries as high-bush huckleberry. As the huckleberry does not grow on the limestone soils of the prairie States, such deception is easily practised, and indeed some varieties now grown are not a bad substitute, as they are larger in size, quite as juicy, and as pleasant in flavor as the commersial huckleberries.

273. Propagation and Pruning.-The dwarf varieties are usually propagated from the sprouts that start from the lower part of the crown like those of the flowering almond. These when taken off have not much show of roots, but the bark is softened and will emit stronger roots in time to support growth if planted early in spring. It will also grow from cuttings of the young wood made in the fall and placed in solar hot-bed, as practised with the cuttings of the grape (60). The cuttings can also be started by grafting on short pieces of apple-root and set down in nursery to the top bud. The cuttings soon root above the apple-wood, and I have not known the plan to change or modify the growth of the bush. Spring layers 
twisted where covered with earth (53) will also make strong plants before fall.

The first three years after planting there is little need of pruning. But later the renewal plan gives best results. The suckers coming up from the crown are mainly permitted to grow and the old canes that have borne fruit two or three years in succession are cut out, as with the currant and gooscberry. As it bears on wood and spurs of the preceding year's growth the cutting out takes much bearing wood, but enough is left for a full crop and the new growth at once takes the place of that cut out. The renewal plan soon makes a stool two or more feet in diameter by the extension of the crown sprouts. Hence it is best to plant eight feet apart each way and cultivate in both directions. When the stools are as large as needed, the extension is easily arrested by taking up the sprouts for propagation, or if not needed throw them in the brush pile.

274. The Buffalo-berry.-As a combined ornamental and fruit-bearing shrub, the buffalo-berry (Shepherdia argentea) deserves more attention than it has yet received. It is native to the bluffs of the upper Missouri and extends north to the Black Hills. It also extends westward to the Sierra Nevada Mountains and southward. As found in different localities, often not widely separated, it varies in size of bush, size of its silvery leaves, and in the size and color of its fruit. In the Black Hills the writer has met with bushes bearing red and yellow berries within ten feet of each other. This natural tendency to variation leads to the belief that by cultivation, seedling production, and selection, varieties could soon be developed bearing fruit as large as the red Duteh currant and ultimately as large as the Cherry or Fay. The plant is diøcious (34), but seems peculiarly a favorite of the bees and insects, as I 
have known isolated pistillate bushes to load with fruit when no pistillate plant was found in the near vicinity. As yet the plant is mainly used in the East and West for ornamental groups on the lawn or for ornamental hedges. The leaves are silvery on both sides, and when loaded with bright-scarlet fruit, the contrast with the silvery foliage and young branches is very pleasing and attractive. But the most pleasing effect of such plantings is realized when the staminate and pistillate plants are intermingled in groups or hedges. In the dormant period, the sexes can readily be separated, as the fruit-buds differ materially. The pistillate plants hare smaller, more slender buds, which are arranged in less compact clusters. The staminate plants show relatively large clusters of buds which are decidedly larger in size and more rounded than the pistillate buds. Five minutes given to a study of the buds will enable the novice to separate the seedlings without making a mistake. When grown from seed in nursery row the plants should stand one foot apart and not be used until three years old, when buds will appear and the sex of each plant can be determined.

The pruning should be confined to pinching or clipping the point of growth extending beyond the line of symmetry, and to taking out dead wood as it may appear. In the prairie States, an isolated plant with exposed stem always sunburns on the south side. Hence the need of growing in groups or hedges for mutual shelter, and where isolated plants are grown they must be kept in bush form by heading back and allowing suckers to start from the crown. As to the uses of the fruit it is fully equal, if not superior, to the red currant for jelly and marmalade, but it is not equal to the best currants for dessert use, canning, or stewing. But it will thrive and bear loads of fruit in 
dry elimates where the currant fails, and, as stated, it is ormamental as well as useful for its fruit.

275. The Barberry.-Several of the species and varieties of the barberry have long been used in Europe, Asia, and to some extent in America for combined use for ornamental planting, hedges, and varied uses of the fruit. The jelly and marmalade made from the heavy crops of fruit are preferred in Europe and Asia for dessert use to that of the currant, and they are extensively used in siek-rooms and hospitals as a cooling anti-febrile food for patients. A seedless variety is also used in Europe for stewing, which is preferred by many to the currant, and it is claimed that its acid is very similar to the lemon in its physiological effects on the system. For combined use, as a hedgeplant or screen and for jelly-making and marmalade, the Amur species (Berberis Amurensis) is best for the Northwest and over a large part of the country. So far as observed, this species is free from the attacks of the cluster-cup fungus. This species also seems to reproduce itself from the seed, which is not true of many recognized species, which we have found to give many extreme variations of the seedlings. In Southern climates the largeleaved species from Japan, known as Berberis Bealii, will prove valuable for ornament and fruit. This is classed with-the Mahonias, but its seedlings seem to class it as a hybrid. For low ornamental hedges requiring little pruning, and as single specimens on the lawn, Berberis Thunbergia has no superior, but its brilliant red fruits have not enough acid for jelly or marmalade.

It is propagated usually from suckers that spring up around the crown for neighborbood use. If the shoots are well twisted (53) it ean also be propagated by spring layering. But the Amurensis and Thunbergia species will vary little when grown from seed, which germinates readily 
if stratified-for spring planting. But special varieties, such as the seedless, must be propagated by suckers, layers, or cuttings of the young wood, like the hardy hydrangia (62).

276. Goumi (Eleagnus longipes). - This quite-near rela-. tive of our buffalo-berry was introduced from Japan. It is a bush in habit with reddish-brown branches and handsome foliage with peculiar star-like centres above and brown scales below. The fruit is oval, and dark green until of full size, when it suddenly changes to a beautiful crimson, dotted with golden spots. When fully ripe the fruit is of the size of small cherries, with a spicy flavor that most persons like. It makes an excellent sance and a jelly that has an agreeable aromatic flavor. In mild climates where the Japan plums are fully hardy, it is a very heavy bearer and an ornamental shrub on the lawn. As with the Juneberry, the birds are peculiarly fond of the fruit. If grown commercially, however, the quantity the birds take would not be missed.

It is propagated by cuttings of the young wood planted in autumn (58). But it is more frequently propagated by half-dormant cuttings in June and July under glass. We have secured additional hardiness of plant by budding and grafting it on seedlings of Elcagnus angustifolia, which also increases the vigor and size of the bush.

277. The Huckleberry.-The huckleberry is the most widely distributed wild fruit of the Northern and Southern States. In nearly all parts of the Union it is gathered for local use and sent to distant markets. In its season the receipts of the fruit exceeds 2000 bushels per day, and as far west as Wisconsin, an annual crop of 20,000 bushels is gathered and shipped to Chicago, Milwaukee, and as far west as Des Moines and Omaha. Aside from the wild cranberry it is the leading commercial wild fruit of this country. But as yet it is not cultivated anywhere, except 
in a small way by amateurs and for trial at some of the experiment stations. In Wisconsin the area in which the wild plant thrives is gradually growing less, mainly by the extension of stock-growing with its tramping and pasturing, and the same is true at the East to greater or less extent. The time has come when special efforts should be made to bring it under cultivation and improve it by culture, selection, and possibly by crossing. As yet so little has been done that we have no reliable printed instruction relative to its propagation, culture, selection of soils, or management. So far the experience at the West and the East seems to favor the belief that the highbush varieties are most valuable for cultivation. The lowbushed species, such as Vaccinium Canadense, V. Pennsylvanicum, and V. vacillans, grow on sandy soil and do not seem to thrive or bear well on common cultivated land.

The species that are grown on low rich land, and even in swamps, so far seem to best adapt themselves to new conditions under culture. The Vaccinium Canadense is a Northern species and exceedingly variable, as it is found in the Eastern, Central, and Northwestern States. As obtained from the eastern slopes of the Rocky Mountains it has thriven better in Iowa under culture with some mulching than other species tested at that time.

The high-bush blueberry (Vaccinium corymbosum) grows naturally on good soil and is exceedingly variable in bush and fruit. These two species are probably the best for improvemesi' and culture. Without doubt, seedling production and selection will give the most speedy results in adapting varieties to special soils and to improve the fruit in size and quality.

Jaekson Dawson has been widely quoted as saying: “The growing of huckleberries ànd blueberries from seed 
requires close attention and can hardly be carried on successfully without a greenhonse or frame."

The writer's observation and experience has been quite different. If the berries are rubbed apart in sand soon after they are gathered and stratified (5) in box buried outside to retain moisture, they grow as readily as seeds of the currant, grape, or strawberry. Plant in boxes of sandy earth on the surface, pressing them down with a piece of board and cover with heary paper like verbena seed (11). Remove the paper when growth starts, but keep in the shade and out of the wind, and mulch between the rows with fine moss. When the plants have formed true leaves the plants should be potted in thumb pots in sandy earth and later as they make growth in four-inch pots. With Iowa-grown seed of the $V$. Canadense stratified and frozen we have had no more trouble than with strawberry-seed, but the huckleberry-seed is a month slower in germination. The selected varieties may be propagated by cuttings of the subterranean stems (49) or by layering by twisting the shoots (53).

A. S. Fuller says: "The huckleberry is one of those fruits which have been always neglected. Why this neglect I am at a loss to understand, for it possesses naturally better qualities than the currant or gooseberry. All the Northern species are hardy, producing no thorns, and the berries are more firm than the raspberry, blackberry, or strawberry; consequently they will bear carriage well and are suitable for market. Thousands of bushels are annually gathered from the woods and fields, but these sources of supply will not always be available; besides, we should not be content with depending wholly upon nature for either the necessaries or the luxuries of life while a helping hand would not only increase the quantity but improve the quality." 
At this time some of the experiment stations are taking up this desirable work of adapting varieties to soil variations and the size and quality by seedling production, and in the near future it is hoped valuable results will be published.

278. The Sand Cherry.-During the past fifteen years the writer has given considerable attention to the sand cherry, as growing wild in the Black Hills, Wyoming, eastern Colorado, northern Nebraska, and in various places in the Dakotas. The conclusion reached from observation and testing hundreds of seedlings on the experimentstation grounds at Ames, is that it is a promising fruit for development by selection and probable erossing with the cultivated cherries and plums. In Colorado we have tested varieties fully as large as the English Morello cherry and about as free from astringency. Discredit was thrown on this variety by growing and distributing its seedlings. If this variety and others we have tested had been grown by budding and grafting, or from root-cuttings, they would have become valuable, especially at the North, where cultivated cherries are not easily grown.

In connection with its seedling production and selection, with a view to improvement, it will prove valuable as a stock for dwarfing the cherry and plum (186). All varieties of the plum worked upon it have made good union and have been dwarfed to some extent in size of tree and have borne fruit earlier and more eontinuously than when on plum-roots. So far, our suceess in using it as a stork for the eherry has not been as favorable, as only a small per cent of the buds inserted lived. But the few that succeeded seemed to make a good union and have made durable dwarfed trees. Perhaps we have yet to learn the proper season for performing the work. 
279. The Tree Cranberry.-Under this name the highbush cranberry (Viburnum opulus) is propagated as a combined ornamental and fruit-bearing shrub. It is in no sense a cranberry, but is nearly allied to the cultivated snowball. The large bush is hardy everywhere nearly in Europe or America. It is pleasing in habit and foliage and the fruit is very showy well into winter. Professor Card says of the fruit and shrub: "The plant deserves all the praise it is likely to receive as an ornamental, but as a fruit-producing plant it is of doubtful value. The fruit is said to be very sour, but more agreeable than the true cranberry."

In the prairie States this species is decidedly variable in habit, size, and leaf. Its fruits are also variable in size and quality. The sauce and jelly of the best varieties are prized by the few who have tested them. But not the least interest possessed by this handsome shrub is the great possibility of improvement in size and quality of its cranberry-like fruits by cultivation and selection of the best seediings. It is propagated readily from stratified seeds planted shallow early in spring. It also is propagated readily by layering and from dormant cuttings planted in autumn (58).

280. The Cranberry.- Although this widely known American fruit has long been commercial and found in the market of about every city, village, and mining and lumber camp of the Union, it may be said that it is a wild fruit. While it is true that selected varieties have been propagated, it cannot be said that they are larger or better than were found in the cranberry marshes when the first settlements were made at Cape Cod or in Wisconsin. In the early days of our history, the home supply and the relatively small quantity marketed was picked from the primitive marshes. The first systematic planting and 
management of the plants began on the Atlantic coast from 1835 to 1840 . Since that time tens of thousands of acres of land, almost or wholly worthless for other uses, have been planted. In many cases low boggy tracts on the Atlantic coast and in Wisconsin, that bred miasmatic diseases, have been changed into handsome fruit gardens that are not only profitable but inviting and healthful. In some respects the systematic growing of the cranberry is like growing the rice-plant for crops, as it involves both flooding and arrangements for partial drying of the land at stated periods. At Cape Cod, in New Jersey, and in Wisconsin, the preparation of the land and the management of the plants and crops are about the same. The first work is usually clearing away the sod and moss and levelling. But if very wet the ditches are first excavated around blocks of the marsh, all leading to an outlet on a lower level. Where possible, this main outlet of the ditches is provided with a dam with gates to flood the whole plantation when needed. In many cases a brook is diverted from its course to flow through the ditches. In other cases a reservoir is constructed on a higher level from which water can be supplied as needed. In Wisconsin the plantations are quite usually started near a stream from which water can be drawn into a reservoir. This is preferred, as the stream water is often too cold. Usually the land has enough sand. But if not four inches of sand is spread over the surface, after turfing and clearing, in which the plants are set. The best method of planting observed by the writer is to set out the plants one foot apart, cover the roots lightly, and then firm the earth by stepping over the roots. The plants should be kept moist. But often enttings are used six to eight inches long with leaves on, which are stuck at an angle in the moist sand with an inch or two of the cutting exposed to the air. $\Lambda$ 
full crop is obtained in three or four years. The cultivation is mainly in the way of pulling the weeds by hand. The plant roots so readily that the runners cut up in a straw cutter are often sown orer the field, followed by rolling to press them down. But it pays to plant rooted cuttings, as a rule, as a full stand of plants soon gives returns for the added expense.

To start the plants the ditches are kept about half full of water, which keeps the surface sand moist by capillary attraction. As the plants are set early, late frosts at the North often work damage to the growing points. Hence flooding at night, when frost is suspected, is practised, drawing it off the next morning. In the fall the plants are more mature and are not easily injured by frosts. Early in November the plantation is flooded and the water remains until spring frosts are over. Sometimes late frosts come when the fruit has set in Wisconsin. If this is threatened the beds are again flooded, letting it off the next morning to prevent scalding the berries. Floods from rains or melted snow sometimes give trouble in winter by lifting the ice and the plants with it where the water is shallow. To prevent this the surplus water is drawn off at the gates.

Indeed, it is an unusual crop to cultivate, and its profitable management, including the picking and sale of the fruit, only gives large profits to those who study the habits of the plant and the evolution of its culture as practised by successful growers. The large cranberry (Vaccinium macrocarpon) is now the main species grown. This is a North American species, and as yet it is not cultivated in other countries.

In granitic soils, free from lime mainly, the Bell cranberry is often grown on sandy or sandy-loam soil, with a coating of swamp mud or peat mixed in. Culture is given 
WILD FRUITS WORTHY OF SOME ATTENTION. 293

early in the season, followed by a mulching of sawdust. But this is only in an amateur way; yet recent experiments show that seedling production and selection may give varieties that will grow on moist sandy land wherever the blueberry will thrive and bear fruit under cultivation. The seeds should be treated the same as those of its near relative, the huckleberry ( $27 \%)$. 


\section{CHAPTER XXII.}

\section{SOME LEADING NUT TREES.}

281. Advance of Nut-growing. - In Europe and Asia nut culture is nearly as ancient as the cultivation of the edible fruits, and by selection and culture the native varieties, usually much inferior to our native species, have been improved in size and quality to such extent that many of them are grown commercially and shipped to every eivilized part of the world. In China and Japan, also, nut improvement has been going on for centuries by selection and propagation of the best varieties, and indeed it may be said that the recent introduction of the Japan chestnuts has given an impetus to American nut-growing in the States east of the lakes and in the South. With the exception of commercial almond-and walnut-growing in California, it may be said that in the States we have not had, until recently, a nut plantation in the States, except in the way of retaining forest-grown trees of chestnut, hickory, walnut, and other species in land-clearing.

Attention has recently been drawn to select varieties of our native nuts, and amateurs and the experiment stations have recently begun the important work of propagating and planting the largest and best varieties. Present indications favor the belief that during the next decade nut culture will be extended in a way that will materially lessen the importation of nuts into this eountry. 
282. The Almond.-This near relative of the peach has handsome peach-like blossoms, and the nut is botanically the pit of the fruit. But the thin, hard, fleshy part is not edible and splits open at maturity, releasing the nut or pit. De Candolle says: "There are many localities in the region extending from Mesopotamia and Turkestan to Algeria where excellent botanists have found the almond wild." He also says: "I remark finally that the difference between the bitter and sweet almonds was known to the Greeks and even to the Hebrews."

Whatever might have been its origin it was early distributed over the warm temperate parts of Europe and Asia. As introduced into California the varieties came largely from Spain and south France, but the imported varieties have now been mainly discarded in favor of locally grown seedlings. Professor Wickson says truthfully: "Thus far the almond has yielded more firewood. than any other single fruit tree which has been largely planted in California." But he continues: "In spite of these facts the almond will remain an important California product through the satisfactory performance of trees enjoying favorable environment."

The trees are about as hardy as the peach, but they blossom early and the erop is liable to be cut off by frosts. Henee the trees in frosty loealities have been taken out and the industry is now mainly confined to the nearly frostless loealities. The varieties differ materially in season of flowering, and at this time the latest ones to bloom are being planted. But all bloom too early, and recent attention has been given to the varieties of Turkestan. As to the quality of the Turkestan varieties, the writer tested them at the Oriental fairs. They were smooth, symmetrieal, plump, with thin shell, and gray in color-without the use of sulphur we were told. They came from the 
valıey of Zarafslian, of which Dr. Schuyler says: "The gardens constitute the beanty of this land. The long rows of poplar-and elm-trees, the vineyards, the dark foliage of the pomegranate over the walls, transport one to the plains of south France and Lombardy. In early spring the outskirts of the city, and indeed the whole valley, are one mass of pink and white with the bloom of almond, peach, cherry, apple, apricot, and plum, which perfume the air for miles around. Nowhere are fruits more abundant, and of some varieties it can be said that nowhere are they better."

As this valley is on the 40th parallel, in the heart of Asia, we may safely conclude that the varieties of the almond will flower later than those of Spanish extraction, and that the petals and all parts of the flower are less delicate. It is also probable that the Asiatic varieties have a better supply of pollen than those of moister climates. It is naturally and originally a dry-climate tree, and long growing in the moister air of sonth France and Spain seems to have rendered most varieties incapable of selfpollination, and they require intermingling to secure full crops of fruit.

The almond is grown to some extent in Florida and on the Gulf coast, but not commercially. The tree is about as hardy as the peach, and it sometimes bears full crops where varieties are mingled or when mixed with peachtrees.

It is propagated by budding on bitter-almond seedlings usually, but, like the peach, it can be grown on chicasaplum stocks.

It may be possible to develop hardier varieties by crossing. The Siberian almond is hardy even in South Dakota and Minnesota. Botanically it is a true almond and bears regular crops of true almonds scarcely edible. By crossing 
with the paper-shell varieties we may secure hardy varieties with good quality of nut.

283. The English or Persian Walnut.-In Europe the commereial varieties of Asiatic walnut (Juglans regia) are referred to simply as walnuts. But in the United States they are ealled English walnuts or Madeira nuts. The varieties from west Europe do not prove hardy in tree, except at a few points in the Middle States, and in many places where the tree is hardy they fail to bear nuts profitably. Near the seacoast, from New Jersey southward to Georgia, the nut has been profitably cultivated for home use and market for many years. In Florida and the Gulf States it has not been favorably reported, mainly on aecount of the root-knot. On the Pacifie slope the tree is hardy in north California, but as yet varieties have not been found that have borne nuts in a regular and profitable way. In south California, in fertile valleys where water is permanent by seepage from higher irrigated levels, within ten feet of the surface, in Santa Barbara, Los Angeles, and Ventura counties, walnut orchards are proving profitable and the acreage is rapidly increasing. With increased experienee, commereial growers now intermingle varieties in orchard planting, even including trees of the native black walnut, to supply pollen. It may prove that lack of pollination is a main cause of failure to perfect fruit in many places where the trees are hardy enough to be used for shade. Luther Burbank, of Santa Rosa, California, is a close observer. He says: "Walnut-trees thrive and grow in Sonoma County, but fail to produce nuts, except a tree here and there. I discovered the reason in 1890 and fully confirmed it in 1891. Most of the trees in this section are pistillate, and, with one or two exceptions, they are strietly so. Another reason with some nut trees is that staminate flowers appear too early, or too late to bo of 
service to the pistillate flowers. This is a very important matter in nut culture."

Where walnut-growing is now systematized by commercial planting, alternating varieties is practised. It may prove that in many places where the trees prove hardy but unfruitful, that as yet no attention has been given to the important question of pollination.

284. Walnut Propagation.-The belief has been quite general in this country that budding or grafting the nut trees has proven more uncertain and difficult than the grafting of the stone fruits. But where thrifty young stocks are used in European nurseries a better stand of nut trees is usually secured by grafting than with the plums and cherries.

The most perfect success known to the writer has been reached by using young thrifty stocks and inserting the grafts under the bark (94) as soon as the bark can be raised, when the buds are well started. The scions used are also started and are cut as used. The wounds are waxed, as is also the end of the scion. A paper sack is then tied tightly over the stock and scion to lessen evaporation. If left without tying, the paper sack in high winds is apt to break or loosen the scion. This is the favorite method of grafting the oaks and all tree-growing species of the nut family in west and east Europe. The plan known as ring or flute budding (7\%) has also given good results in west Europe and in California.

On thrifty young stocks California propagators have had success also with the walnut by summer budding (72), nsing the smaller buds at the base of the young wood scions. But in Europe and on the west coast the stocks in which the summer buds are inserted are not cut back until the next spring, and then are cut with a high stub, to which the growing shoot is attached by tying. 
285. Possible Increase of Hardiness.-The varieties of English walnut so far cultivated in this country have come to us from the equable and rather moist climate of west Europe. At Ames, Iowa, they have proven far more tender than peach-trees. But a variety grown from nuts gathered at Saratov in south Russia has proven far hardier than the peach and perfectly hardy in Missouri. As noted on former pages of the orchard fruits, we now have access commercially to central Asia. In this dry interior climate, walnuts with thin shells are grown extensively, and beyond doubt they will prove worthy of trial in our interior States.

286. Black Walnut.-The native black walnut (Juglans nigra) has a wide distribution in the Northern States. It is one of our largest trees and its lumber is so valuable for gun-stocks, furniture, and other uses, that trees of large size are becoming scarce in every locality. Along streams in the prairie States it was a common tree in the early days of prairie settlement, but most all the trees have been cut latterly for export of the logs to Europe.

The nuts of our native walnut are beyond doubt the largest and best wild ones of the earth, but as yet no move has been made for their improvement. In Europe and Asia the wild walnuts of Armenia, north India, Burmah, Japan, and central Asia are vastly inferior to our best native types. But they have been improved by selection and culture until we have the modern walnuts of commerce.

As found in the prairie States the nuts are more variable than in other parts of the Union observed by the writer. In a few cases varieties are found with relatively thin shell that splits readily and the meat parts from the shell divisions freely. But as yet they all have the peculiar flavor that many like and a few dislike. Burbank, of California, 
has proven that the Persian walnut will cross with Juglans nigra and also with the J. Californica of the west coast. In the near future we will probably have crosses with the best European varieties that will combine the good qualities of the two species.

287. Propagation and Planting. - The black walnut grows readily from the nuts if managed properly. In the fall, spread out the nuts without removing the shucks under trees and cover with four inches of leaves. Early in spring plant very shallow, firming the earth by stepping on each covered nut. If to be used for stocks for budding or grafting, the nuts easiest to secure will answer the purpose. But if planted for nut-growing, care should be taken to hunt for the trees bearing the largest and best nuts. In the prairie States groups or local areas of walnut were found in the early days, with relatively thin shell, that have been reproduced by many by planting the nuts. But if scions of select varieties are procurable, it is not difficult to insert them under the bark of thrifty young stocks, as noted in section (284).

It has also been found that scions of Juglans regia will unite well with the wood of young thrifty stocks of our native black waluut, and it increases the hardiness of the former when grown in more trying climates remote from the ocean.

288. The Butternut.-The American butternut (Juglans cinerea) is also a valuable lumber tree. The wood has been used for palace-car finishing and other work requiring a high polish, and the large trees are becoming scarce. The nuts are variable in size, thickness of shell, and size and ease of extraction of the meats. The quality of the select varieties is preferred by many to that of the Persian walnut, as it is tender, crisp, oily, and pleasantly flavored. The drawback is that the rough, hard shells do not fit it 
as well for use in sitting-room or parlor as the nuts that can be crushed by the nut-cracker. As yet we have no named varieties, and we know of no attempt to improve it by the propagation of select varieties found in all localities where it grows naturally. In its native ranges, apparent hybrids are found with the black walnut. In confirmation of this fact Juglans regia and $J$. cinerea have been crossed in Europe and also in California. Indeed it seems that all species of the walnut family cross naturally as well as by hand pollination. M. Andre of France reports that his opinions as to the limits of species have undergone change since he saw in the nurseries of the Paris museum seedlings of Juglans regia almost identical with the black walnut. Select varieties of the butternut can be budded or grafted on thrifty young seedlings of the same species, as noted in section (284) and probably also on black-walnut stocks.

289. The Hickory-nut.-Of the native species of the hickory found in the United States, the pecan (Hicorin pecan) stands first at present in conmercial value; the little shellbark $(H$. ovata $)$ stands second; and the big shellbark (H. laciniosa) stands third in order of value. The two last named are Northern and will be first considered. The $H$. ovata has a broad distribution from Quebec to Iowa and south to the Southern States. The nut is white, often oblong but varied in shape, and it is always four-angled, with a sweet and pleasant kernel. In size it is variable and also in thickness of shell. The selected varieties are thin-shelled, with a large kernel easily separated from the shell divisions. The trees of this species are quite ornamental and grow on relatively high land and on rather dry bottom lands. The big shellbark species grows best on rich bottom land and under cultivation succeeds best on rich, rather moist soil. A large part 
of the varieties propagated and named by propagators belong to the little shellbark or shagbark species.

The peean seems to be confined to the bottom lands of the Western States in the valley of the Mississippi and its tributaries. Although generally found on bottom lands subject to overflow of streams, yet it often is found in Missouri, Arkansas, Kentucky, and other Southwestern States, on upland where moistened by springs or percolation from higher levels. Under cultivation it is found to do as well on upland as the big shellbark of the South. As gathered from the stream-bottoms and from planted orchards, the annual output is very large. The large thin-shelled varieties have retailed at the North at higher prices than has been obtained for other nuts home-grown or imported. The smaller sizes with thicker shells have been mainly used in candy-making. A single firm, we are told by Mr. William A. Taylor, in New York "has prepared and marketed 100,000 pounds of these in a year."

As yet the home demand is not supplied. As to foreign demand Mr. Taylor says: "From the favor which exhibits of this nut in the American station were received, it seems probable that a considerable export trade can be developed whenever the supply of choice nuts exceeds the demand for home consumption."

The present outlook favors the belief that the propagation and planting of the finest dessert varieties now obtainable on a largo seale on suitable land from Kentucky and Missouri south to southern Texas would prove far more profitable than orange-growing in California.

290. Pecan Propagation.-This valuable nut has been thus far mainly grown from the nuts. But it has been found that the nuts from a given tree bearing nuts that will bring forty cents per pound will not reprodnce the variety. The experience in budding and grafting has as 
yet been limited and the results have not been favorable as a rule. But some nurserymen have had equal success in grafting the pecan and shellbark hickories by using thrifty young stocks standing in nursery row. The stocks are cut two inches below the earth surface and a scion is inserted by side-grafting (86), winding with waxed cotton cloth for holding the parts together, and mounding to the top bud of the scion. The pecan and shellbarks can also be safely grafted in early June, or earlier South, by slipping the scion under the bark (284) and mounding to the top bud.

291. The Chestnut.-Select varieties of the American sweet chestnut (Castanea Americana) are the best in quality that the writer has tested in Europe, Asia, or America, but the varieties of Japan are much larger and some of the west European sorts are superior in size to any we have yet produced, with the exception of some hybrids, which so far have lost in quality what they have gained in size.

Many things are in favor of rapid advances in chestnutgrowing. It is far easier to propagate than the walnuts or hickory-nuts, it comes into bearing earlier, and it seems to find a ready market at paying prices. The chestnut has been one of the leading nuts for home use and marketing for centuries in western Asia, Europe, Japan, and north Africa, and indeed a staple article of food when partially dried. It is also used for boiling, and its meal has varied uses in the culinary department.

The largest chestnuts, approaching in quality our best native varieties, came from Sardis in Asia Minor to the Oriental fairs we visited. But as yet these have not been tested in the United States.

The Japan chestnuts make a much smaller and more compact tree than those of Europe, Asia, or the United 
States. The leaves are also smaller. The burs are smaller, but the nuts are larger than any varieties yet introduced. Some of the best varieties of all classes are described in Part II of this book.

The tree and bush species, known as "chinquapins" in the South, bear smaller nuts than the chestnuts and usually grow in bush form not more than three to five feet in height. But the tree species (Castanea pumila) on rich soils, in Arkansas and east Texas, we have known to grow thirty or more feet in height. But on thin land both species are shrubs that throw up numerous suckers or stolons. The dwarf species have been used to some extent as stocks for the Japan and other good varieties. But the habit of suckering is specially objectionable.

292. Propagation and Planting. - All varieties and species grow readily from the nuts kept moist by stratification. But the nuts must be planted as early as the condition of soil will permit, or they will sprout in the box (5). If grown from seed, the tap-roots should be cut by running a sharp spade under them or they should be transplanted when one year old, to give a good root system. In grafting we have found the side-graft (85) most successful, doing the work in the open air when the buds begin to expand. At the West, if the scions are inserted early they are apt to dry up before active sap-circulation begins. We have had the best success when they were covered with paper sacks (284).

As yet, in the eastern States, grafting has been mainly confined to inserting scions in sprouts on mountain land, where the chestnut or chinquapin are indigenous. Where the Japan varieties have been inserted in this way, they have proven profitable in some cases. But the weeds, sprouts, and danger of fire have proven drawbacks to this system, and systematic orchards are now being started. 
The usual plan has been to set out two-year-old seedlings once transplanted and graft them the next spring after they have become well established. By culture early in the season and the use of cover-crops of the legumes later, the grafted varieties soon come into bearing. Clean culture through the season has not given good results, as the exposed earth during the hot period gets too warm for the health of the trees and roots (126).

It is best to plant the native and European varieties in rows thirty feet apart, running north and south. To give an approach to forestry conditions, they may be planted only eighteen feet apart in the rows. The smaller-growing Japan varieties should also have ample space between the rows, not less than twenty-fire feet, and may be planted fifteen feet apart in the rows running north and south.

In all parts the chestnut is a dry-land or hill tree. In the West, on high, dry ridges, it is grown up to the 44th parallel, but on rich drift-soil, where corn thrives best, the trees are short-lived and unfruitful. The tree does not seem capable of self-pollination. In no case has the writer known a tree in isolated position to bea: nuts. Yet blocks planted with a single variety bear well. Where varieties of different species are intermingled in Europe, the crosspollination gives hybrids when the nuts are planted. This seems true also in this country, as we now have natural hybrids between the chestnut and chinquapin in the South.

A main trouble in the commercial growing of the chestnut is the attack of the weevil. Growers in Europe and America pour boiling-hot water over the freshly gathered nuts. The covered chestnuts are then stirred to prevent cooking them. Those not perfect, on account of weevil perforation, will float on the top. Treated in this way the nuts are not further troubled with weevil, and keep better 
when fully dried, and the nuts are more palatable and not so hard and horny as when dried without the scalding.

293. The Filbert.-The filbert is grown commercially over a large part of Europe and Asia, and the nuts are found for sale in about every grocery and fruit-store. Tons of the nuts are annually shipped to the United States. The varieties from west Europe have not succeeded well in any part of the Union. Over abont the whole country, our summers are too hot or the winters too cold. The flower catkins develop in autumn. In the North they are apt to be killed by the cold, and in the South and in California the warm spells of early winter expand the flowers, to be caught usually by winter frosts, and in nearly frostless regions in California the summers are so hot that fungus diseases are developed. Yet we have some seedlings from imported varieties - mostly hybrids it is suspected-which are grown in a small way in the Eastern States and California.

The propagation of special varieties is usually by cuttings of new wood planted in the fall or during winter in mild climates. In Europe, the trees are shaped in nursery prior to selling or planting, with a stem three to four feet high, with an open top and a head with not less than six branches.

The pruning is never neglected by professional growers. The thin, unfruitful twigs are cut out, and the new growth in the dormant period is shortened back nearly to the female bnds. But in this cutting, care is taken to leave enough of the male catkins for an ample supply of pollen. The male catkins and female buds are shown in Fig. 82.

294. The Hazel-nut.-This is found native in about all parts of the Union, in timber openings and borders where the soil is shaded and where the leaf-mould deposits of years have not been disturbed. Some of the varieties as found 
wild bear nuts nearly as large as the ordinary filbert and better in quality. In the prairie States the select varieties have been cultivated in a small way, planted in rows only two feet apart with five-foot spaces between the rows. Growth is started by cultivation in the early part of the
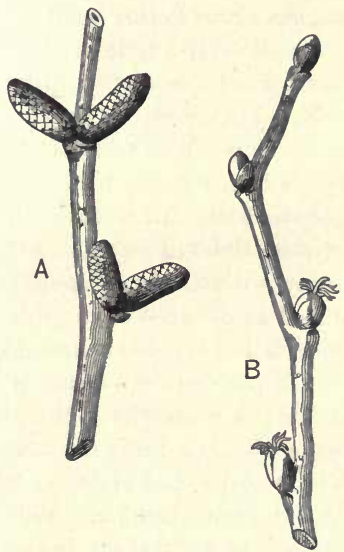

Fra. 82.-A, Male catkins of filbert; $B$, female flowers of filbert. (After Bailey.)

season, followed by mulching with leaves after the first of July, which is cultivated in the soil the next spring. After the plants attain bearing size, the mulching is continuous winter and summer, clipping the weeds that come through the mulch. With this treatment and proper pruning good crops, as large nearly as filberts, have been harvested. Beyond all doubt a few years of culture and selection will give native varieties as large as the best 
filberts and better in quality, but in our climate it will be necessary to follow nature's methods by shading the soil between the rows and providing an ample stock of fresh humus in the soil. At the West, with this system, no diseases or insects have as yet troubled the plant, except the weevil.

295. Propagation and Pruning.-In starting from select varieties it will not be best to grow seedlings, as they vary exceedingly. But seedlings may be grown and budded or grafted. No plant yet tested has proven easier to bud or graft than the hazel or filbert. But, like the rose, the sprouts from the wild stock are apt to spring up and give trouble. Hence the best plan is to grow the plants from cuttings put out in the fall as soon as the leaves drop. The cuttings root with about as much certainty as the currant if mulched as directed in (58).

When the plantation is established, partially or wholly rooted suckers will be freely produced, with the mulching system, for sale or the extension of the plantation.

The pruning of the hazel-nut is identical with that of the filbert. The catkins that appear on the new wood in pairs only bear staminate flowers. The pistillate flowers come from rounded buds, also on the new wood, but not on the same shoot usually (Fig. 82). The pruning consists in shortening the wood of the preceding year's growth in the spring when the pistillate flowers appear. Strong shoots are headed back to favor the starting of laterals for next year's bearing, and the old wood that has borne nuts should be cut out. This must be repeated each spring.

296. Cocoanut.-The cocoanut palm is one of the most peculiar economic trees of the earth. Floating in ocean water for months does not impair the vitality of the nut, 
and if it lands on a tropical or subtropical shore, it takes root in the sand and will bear nuts where the ocean waves wash over its roots. In the United States it is alone grown in southern Florida, and on its southern keys near the shore-line. In Cuba the statement of De Candolle, that it only grows on the seacoast, does not seem to hold good, as I have seen the palms loaded with nuts on quite high land several miles in the interior. The tree grows on the beach sands, but it does not reach the size or load of nuts observed on higher and richer land. Maturin M. Ballou spent much time in Cuba looking up its resources in 1890 . He says of the cocoanut as grown in the interior, on the west part of the island: "The cocoanut-tree grows to a height of fifty feet and more, differing from the royal palm by its drooping nature. At its summit is a waving tuft of dark-green glossy pinnate leaves from ten to fifteen feet in length, like mammoth plumes, immediately under which are suspended the nuts in heavy bunches, often weighing three hundred pounds." But these apparently interior trees on richer soil have the breath of the warm Gulf stream from the varied directions except east, and are situated where they get permanent moisture at the roots. But the truth is correctly stated by De Candolle, who says: "Unfortunately this tree requires a warm, damp climate such as exists only in the tropics or in exceptionable localities just without them. Nor does it thrive at a distance from the sea." On thinner soil near the beach at Biscayne Bay, and at other points south of Lake Worth in Florida, the trees make less growth and lean from the course of the prevailing winds. At Lake Worth tourists often see nuts hanging within two feet of the ground, while in Cuba, on richer land, we have seen the nuts hanging down thirty feet from the ground. 
297. Propagation and Varieties.-In all ages the cocoanut has been propagated almost exclusively by planting the large nuts. To gire anchorage to the trees, the nuts are planted two feet deep, and as the plant grows the earth or sand is filled in gradually, as in deep planting of the grape. But the nuts are usually sprouted before planting by burying in the earth deep enongh to secure the needed moisture. The germination of the nuts is interesting to watch. The three prominent eyes of the nuts indicate the location of the ovules. With needed heat and moisture, the finger-like ovule imbedded in the rich creamy substance of the large end begins to extend growth. Soon it appears through the largest eye and begins the work of rending the outer coat of the fibrous covering. Little fibrous roots also extend into the flesh of the nut for support. As growth progresses the hard shell is parted and the roots extend into the earth. From the start, as the leaves grow upward, they begin to assume the typical form of the species. The roots are numerous, but nerer attain large size. In improving in the suburbs of Havana, the writer watched the digging ont of large cocoanut palms in bearing. In no case was a root observed more than three fourths of an inch in diameter. Yet when loaded with the heavy clusters of nuts weighing three hundred pounds, and the great leares expanded like sails, we were told that storms rarely blew down a tree of this species. The writer saw trees in exposed positions in Cuba, said to be seventy-five years old, still bearing large clusters of nuts.

As grown in different tropical coast climates the cocoanut differs in size, color, and texture and flavor of the flesh, and even trees grown from nuts of the same tree differ in size and quality of the nut. 
It is probable that the systematic owners of plantations from the United States now settling in Cuba, Porto Rico, and the Philippines will soon learn to propagate from the best trees of the best varieties, as even now they are propagated from cuttings of the head of young trees, and even from those of old trees, where broken down by the tropical storms of south Florida and its keys.

298. Brazil-nut.-This tropical nut is also included, as it thrives well in Porto Rico, the Philippines, and Cuba. It is not hardy anywhere in the United States, and the commercial supply comes mainly from Brazil and other parts of tropical South America, and is grown on native wild trees. It is one of the largest trees of the tropical forests. The nuts-from eighteen to twenty-five in number-are enclosed in a hard shell. The great balls of fruit are five to eight inches in diameter, and fall heavily to the earth when the nuts are ripe. So far as known to the writer, it has never been cultivated, yet it is one of the leading commercial nuts of the world, under the name of cream-nut, nigger-toe, or Brazil-nut.

Although in its native tropical forests it reaches a height of one hundred and thirty feet, the isolated trees grown from the nut by amateurs in Cuba spread out, making handsome round-topped trees that bear bountiful crops quite as young as do our nut trees of the North. If the great supply of forest nuts from Brazil is cut short by forest clearing, or in other way, the cultivation of this valuable nut in Cuba, Porto Rico, and the Philippines may become profitable. This is the more probable, as the use of its oil is on the increase. It has long been the oil used by watch-makers and repairers, and for all delicate machinery, and its use by artists and in high-grade cookery is rapidly increasing. The latest publications do not speak of improved varieties of cream- or Brazil-nut, but in 1901, 
for the first time, a variety of the nut appears in American groceries that is a decided improvement. The shell is soft, wrinkled, and the undulations extend to the nut. The grocers report this soft-shelled'variety perfect in nearly all cases, while a large per cent of the common cream-nuts are abortive. 


\section{CHAPTER XXIII.}

PLANNING AND PLANTING THE HOME GROUNDS.

\section{American Rural and Suburban Homes.-Among} the nations of the world the United States is alone in its system of rural and suburban homes. The farmer, as soon as means permits, fits up a comfortable, and often beautiful home on his own land, and the business man and retired farmer plans a suburban home, often a palatial one, on his own land, with its well-kept lawn, trees, shrubs, and flowers. Even the thousands who flock to our shores from the Old World, as soon as able begin the work of home-making on their own land, and in no case attempt to revive the commune system of the old country.

But it cannot yet be said that the fitting-up of American homes is always in accordance with the principles of landscape gardening. As yet, a large proportion of our rural homes and suburban places show mistakes in planning and planting. In the selection of varieties and species, mistakes are too often made. The pictures and extravagant praise of new varieties of trees, shrubs, and flowers, by nurserymen in distant localities or States, often lead to the planting in prominent places of varieties and species wholly unsuited to the soil and climate. In the prairie States even, landscape gardeners often assu me that varieties hardy at the East, or near the inland lakes, will do as well on prairie soil and in prairie climate. Another leading 
mistake is made by beginners in the way of planting evergreens, shade trees, and shrubs on the front lawn, which in a few years develop into a thicket. Even in south California, a few years ago, the plan of quite thick planting in front of the house soon dereloped thickets that gave trouble and expense, when observation led to the adoption of a more natural and beantiful system. As yet even the village and city parks and school grounds are often planted with straight rows and without a settled plan.

But near our larger cities the influence of example and the guidance of the landscape gardener have led to a more methodic system in the way of planting in such manner that the after-growth will form a picture in connection with the well-kept grass that is the canras on which the picture is outlined.

300. Starting a New Home.-If the purchase and fittingup of a new place is contemplated, many things should be considered in advance. Other things being equal, the home site should have air-drainage and water-drainage $(97)$. This is desirable for health of family as well as the health of fruits and ornamentals. In a level region, such as is common in the prairie States, an elevation of only a few feet above the general level is desirable. The nearness to desirable neighbors, church, schoolhouse, and other social advantages should also be regarded where means permit. The quality of the water, nature of the soil and subsoil, and general outlook upon desirable views should also hare consideration. In the prairie States, and over the Northern States, a south or east frontage is more desirable than a north or west one. When the site is selected, set the house back, if possible, far enough to give a desirable lawn in front. 
301. Grading and Enriching the Lawn.-After the building is completed and the first rough shaping of the grounds is finished, care should be taken in the final smoothing of the front lawn to enrich the soil with fine, well-rotted manure. While grass will grow on thin soil, the carpet of grass that makes a picture, when it has a frame of green foliage in the background angles and corners, can only be secured on a rich soil, with an abundant supply of fresh vegetable humus. The ordinary subsoil from cellar and well with only a thin covering of black soil will not give the needed thick carpet of grass. Before sowing the grass-seed, the trees and shrubs shonld be planted and the flower-beds made ready for planting. This gives a regular and.smooth surface on which to start the grass. Prior to sowing the seed, it is also desirable to border the walks, tree groups, and shrub groups with a belting of sod pressed down low in the soft soil. This defines the borders, and grass-seed should not be sown inside the space allotted to groups or over the surface of flower-beds. In practice these ontlining strips of sod are useful in fixing boundaries and in the way of securing established grass for clipping along roads and borders from the start. Until the sod is strong enough to support the mower in turning, the clipping shonld be done with the scythe.

302. Where to Plant Trees and Shrubs.-The location of tree and shrub groups depends largely upon the shape of the grounds, and no two places may be exactly the same in expression when the work is finished. As stated, the first essential is a spacious lawn. Keep the centre of the place open, planting only the borders. This principle applies to the front lawn on all places, large and small. On small places, the simple plan shown at Fig. 83 will illustrate some of the general principles suitable for those 
who wish pleasant surroundings, but who have not the time or means to care for more extended grounds more elaborately laid out and planted. The simple plan given may be suitable for one or four acres, and includes lawn with shrub gromps (6), shade-trees (2), evergreen-trees (3) for a background, vegetable and small fruit garden (10), and an orchard (9) without shelter on the north, but fairly

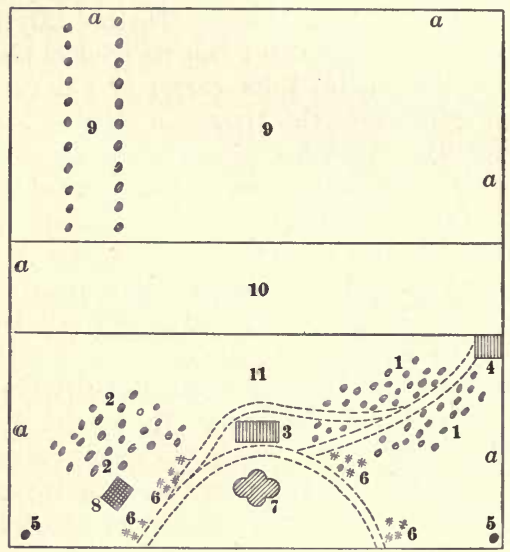

Fig. 83.-Suburban or Farm Home.

$a$, Amur barberry hedge: 1, deciduous shade trees: 2, evergreen trees; 3 , house ; 4 . barn ; 5 , dwarf pines ; 6 , shrubs ; 7, flowerbed; 8 , perennial bed ; 9 , orchard ; 10, garden; 11, back yard.

well sheltered on the south, as advised in section (99). The plan shows the orchard rows planted closest in north and south rows, with wider spaces between (112). The back yard (11) should be in grass, well kept, for air-circulation, drying clothes, lawn-tennis, and play-ground. The vegetable and small fruit garden (10) is north of the 
house and sheltered on the north by the orchard, which is a special advantage in the prairie States and over a large part of the Union.

Fig. 84 gives a simple plan for planting, with street on

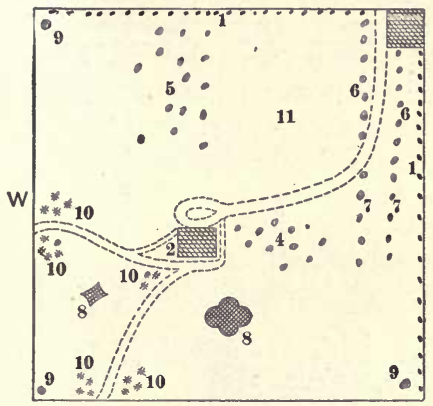

Fig. 84.-Subtrban or Fakm Home.

1, Deciduous shade trees; 2, evergreen trees; 3 , hou e; 4, barn ; 5 , dwarf pines; 6 , shrubs; 7 , flower-beds ; 8 , perennial beds ; 9 , orchard; 10, vegetable garden; 11, back yard.

the south and west of two corner suburban lots. The view over the lawn is open on the south and west with group of shade trees (4) and of evergreens at (5). The figure is self-explanatory, except the planting of two rows of cherryand plum-trees down to the lawn on the south, with the round-topped morello cherries as a background of the lawn. Some of the round-headed varieties, such as Spate morello, English morello, Shadow morello, and Early morello, are ornamental during summer and in autumn they hold their foliage as late, or later, than the cut-leaved birch.

To still further illustrate the simple laying out of small places, Fig. 85 gives a plan for laying out and planting 
two inside lots. The house is placed a few feet east of the centre to give room for a group of shade trees on the west. East of the house is a handsome group of conifers with cherry-and plum-trees back of them, screening the barn

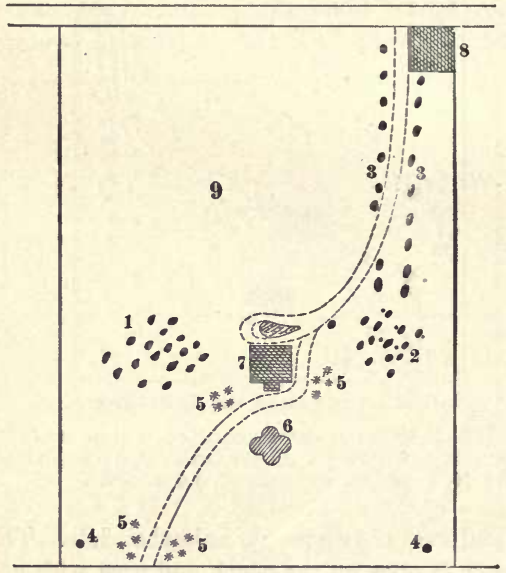

INSIDE CITY LOT

FIG. 85.-1, Shade trees; 2 , evergreens; 3 , plum and cherry ; 4, dwarf pine; 5 , shrubs; 6 , flower-beds ; 7 , house ; 8 , barn ; 9 , garden.

from the front view. In the corners dwarf pines are shown, but a small, well-kept group of shrubs would often be preferred. The wagon-road for the delivery of wood, coal, or provisions comes through the fruit trees from the alley. The shrub groups in all plans must be kept pruned as noted in (152). 


\section{Planning and Planting More Extended Grounds. -}

In improving larger park-like grounds with varied hill and valley, and possibilities in the way of natural or artificial water views, it is always advisable to employ an experienced landscape gardener. He alone will be able to give each varied view its peculiar individual expression, and yet combine the whole so that a walk or drive over the place will present a pleasing and yet united succession of views. But the open space in front of the residence, more or less modified by undulations of the surface, was urged as an essential element of taste by A. J. Downing and others in Europe and America fifty years ago. As an example, Downing gives the home seat of the Van Rensselaer family, Fig. 86 , and that of the Livingstons, Fig. $8 \%$.

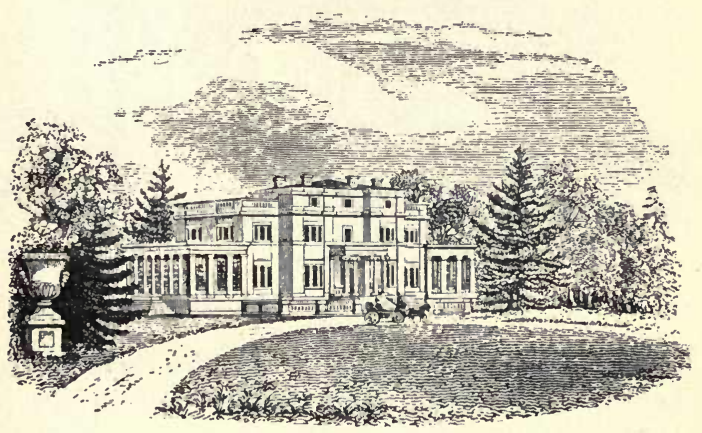

Fig. 86.-Beaverwyck, the seat of Wm. P. Van Rensselaer, Esq.

In Fig. 86 the planting is all back of the lawn, but in Fig. 87 a single old tree is retained in the front with a high stem, showing it to be a relic of the primitive forest. In laying out a large place, the expert will prove an 
essential helper, but the owner must decide, as a rule, on the healthfulness of the location, its accessibility, its capacity for improvement at a given cost, the fitness of the soil for tree-, shrub-, and grass-growing, the character of the water, and the social and other advantages. The preliminary chapters of this book will give hints on transplanting, pruning, and even the propagating, pruning, and management of shrubs, small fruits, and orchard

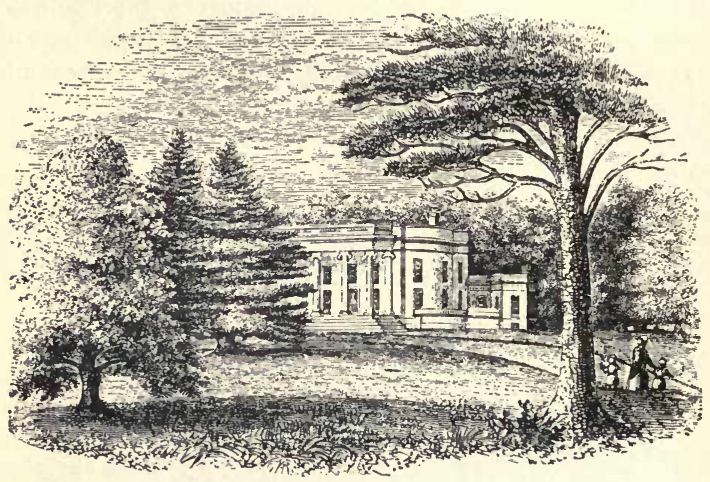

FIG. 87.-The Manor of Livingston.

fruits. Aid will also be given by consulting books devoted to landscape gardening, such as those of Maynard, Kemp, Long, Bailey, and others.

A few general principles cover the leading essentials in such improvements, aside from the artistic blending of the landscape gardener. His services are often needed in the varied grouping adapted to varied elevations and slopes, the locating of the grass-plots, the preservation of vistas or outlooks in the direction of inviting views, the 
planning of roads and walks, securing natural effects at group borders by under growth, hiding undesirable views, and above all, giving his aid in selecting species that will give needed size and effects in all leading positions and prove absolutely hardy in the given climate. In this work of deciding on exact adaptation, a study of the oldest plantings in the near vicinity will often prove valuable in the selection of varieties and species.

304. Improving 0ld Places. - It often happens that large and small places have trees, shrubs, and hedges when purchased, or when the decision is reached to attempt a

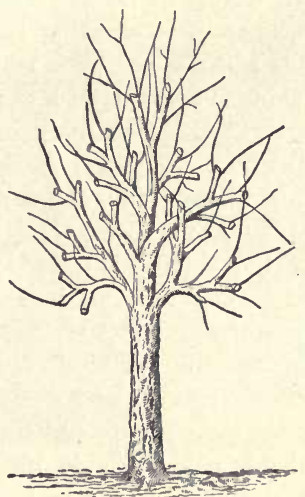

FrG. 88. - An old tree headed back. (After Maynard.)

change for the better. In planning for a change in the landscape expression, it usually happens that many of the old plantings ean be utilized. With systematic cutting back and shaping they can be changed into shapely trees and shrubs $(14 \%, 152)$. If the cutting back is done in the 
dormant season, unshapely trees will soon develop fine tops, if headed back as shown in Fig. 88.

In some cases a single tree of a large-growing species may be made the centre of a tree group by planting rapidgrowing species around it, with undergrowth at the boundaries. In other cases where a shade is needed, a single tree may be given room to shade a corner of the grassy lawn. The single spreading white elm or other fine shade tree may also have place in a grassy dell, or hollow of the grounds, where it has ample room to spread in natural form.

Second-growth timber of varied species is often found on suburban tracts and lots standing too thick for forest or park. On lots some of the trees may be permitted to stand properly thinned and cut back at proper places, but not to interfere with the open lawn or the garden and small fruits in the rear.

In larger places, where groups are wanted, better effects can often be produced for a few years by permitting the greater part of the thriftiest trees to stand thinning gradually as the tops begin to crowd, or as the primal plan of the grounds require.

In starting groups the selection of species should be given attention. Evergreens and deciduous trees should not be mixed in the same group, and such trees as cottonwood and Lombardy poplar should not be mingled with hard maple and hackberry. The trees and shrub groups should have a harmonious expression. Where not guided by an experienced gardener, the beginner in such work will form tree clumps rather than artistic groups. Many years ago Price wrote: “Natural groups are full of openings and hollows, of trees advancing before or retiring behind each other, all productive of intricacy, of variety, of deep shadows, and brilliant lights. In walking about 
them the form changes at every step, new combinations, new lights and shades, new inlets present themselves in succession. But clumps of trees, like compact bodies of soldiers, resist attacks from all sides. Examine them in every point of view, walk around them-no openings, no vacancy, no stragglers."

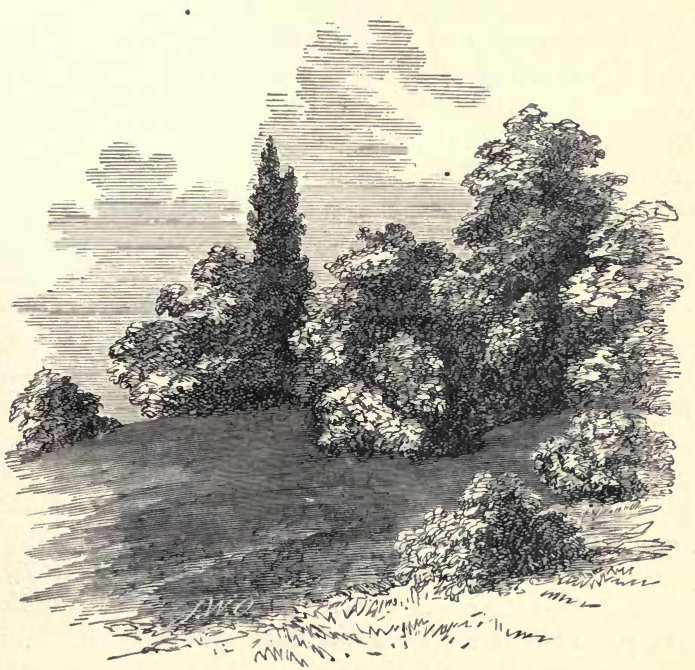

Fig. 89.-Large-growing trees arranged in centre of groups. (After Maynard.)

Where trees of the same species are planted in a group, or species similar in size and form, the expression when grown is that of a clump. To avoid this, the skilled planter sets the taller species at a group corner or in the centre, with the smaller and handsomer trees and even 
large shrubs at the outer irregular edges. Fig. 89, from Maynard's excellent work, gives an idea of this irregular yet natural system of grouping.

305. Transplanting Trees and Shrubs.-Chapter IX of this volume gives some of the essentials of transplanting of fruits and ornamentals in connection with nursery-grown trees. It also discusses the relative success of fall and spring planting (11\%). In lawn and park planting, as well as in planting street trees for shade, it is quite general in most localities to procure them from the timber. Nursery-grown ornamental and shade trees are given a better root system by transplanting in nursery when young or by cutting the tap-roots with a spade or tree-digger, run under them. The young forest trees have deep, extending roots, with relatively few fibrous surface roots that are obtainable in digging. But with needed care in digging, with proper depth and spread of roots, trees of medium size can be safely planted in the spring when the buds are bèginning to swell.

If larger trees are wanted for certain positions it will prove most profitable to move them in the winter. A trench not less than three feet deep is dug around the trees, extending under at the base and including a ball of earth not less than three feet in diameter, late in the fall. Before the ground freezes the holes are also dug for the reception of the trees and filled with straw or coarse manure. When the balls in which the roots are encased are frozen hard, the use of a lever loosens them, when they are lifted with block and tackle on trucks or sleds and drawn to their new position.

The usual belief seems to be that the transplanting of trees with stems two to three inches in diameter is very expensive work. But the digging is not skilled labor, and an improvised derrick, block and tackle, and a sliding 
platform to run on snow were all the appliances used three years ago in moving about one hundred trees, deciduous and evergreen, on a part of the Iowa Agricultural College campus, that had been for years in vineyard. In planting, moist dirt from ground covered with strawy manure was used for filling tightly around the frozen ball, and the tops were prevented from swaying in the wind by wires attached to stakes driven in the ground. No pruning of the tops was done, except on the large pines, which were cut back quite severely at the points of growth (153). Only two trees were lost out of near one hundred planted.

306. The Need of Hardy Trees and Shrubs. - The main purpose of these brief notes on home surroundings has been to gire some practical hints on the location of trees and shrubs on the home grounds of the farmer and suburban residents of moderate means. The large places and parks are usually cared for by those who make it a business. The importance of impressing the need of planting the hardiest known shrubs and trees, on home grounds, school grounds, and cemeteries specially, cannot be overrated. Even as far south as Atlanta, Georgia, Jacksonville, Florida, and Hot Springs, Arkansas, the visitor in the summer of 1895 saw more crippled or dead fruit trees, ornamental trees, and shrubs than ever has been seen in the Northern States. The cemeteries over the whole South showed a few perfect varieties and species that seemed to be more beautiful than ever standing amid the desolation wrought by the cold on the more tender species of the south and west Europe. After what are known as the "test winters," this loss of trees on private gromnds and in cemeteries and parks is found not only in the prairie States, but east of the lakes and in the South. IIence the writer's respect for such trees and shrubs as Cut-leaved birch, Silver spruce (Picea pungens), Duchess 
apple, Concord grape, Spirca Van Houttei, and Rosa rugosa, that are safe to plant on varied soils in nearly all parts of the Union.

In the succeeding chapter some of the ornamental and shade trees and shrubs are noted in connection with their relative hardiness, as observed during the past forty years by the_writer. 


\section{CHAPTER XXIV.}

SOME OF THE LEADING SHADE, LAWN, AND PARK TREES.

307. Adapting Trees to Soil and Climate.-The nursery catalognes of the Eastern, Southern, and West coast States give lists of the leading trees, shrubs, and flowers, with brief descriptions, but the planter is given no instruction, as a rule, in the important work of adapting varieties and species to a given soil and climate. To a great extent this is true also of our works on landscape gardening. Planters in the prairie States have had no guide except in the horticultural reports and the fugitive notes in the agricultural press.

In this chapter only the leading varieties and species will be noted that do well over large areas of the country and on varied soils, adding a few specially desirable ones that are less cosmopolitan.

In many cases the same species differs in hardiness as obtained in different parts of the Union. As well-known examples, Picea pungens from the western slopes of the Rocky Mountains will not survive the climate found east of that range; the box elder and sugar maple of the Eastern States will not live long west of the Great Lakes. Indeed this varied hardiness of given species applies so 
generally, that it is always safest to plant local types of all species, or those from similar climates.

308. Sugar or Rock Maple.-This is a popular shade, park, and lawn tree over a large part of the Union, with proper selection of varieties. The sugar maple (Acer saccharinum, Weugh; A. saccharum, Marsh) does well east of the lakes and over a large part of the Southeastern States, with some local variety variations in the South. In the prairie States the trees from Eastern and Southern nurseries do not thrive. On the other hand, the native type known as Acer nigrum thrives on varied soil over a large part of the West. But as grown from Missouri seed the trees do not prove hardy in north Iowa and Minnesota. Hence in improving home places, the trees should be grown from locally grown seed or be obtained from as nearly local timber growth as possible.

309. Norway Maple (Acer platanoides). - This, as represented by its many varicties, is also variable in hardiness and adaptation to our varied soils and climates. The nursery varieties are all desirable for ornament in the East and Southeast, and the typical species is fully as hardy in the prairie States as the native sugar maple. This is also true of its handsome variety, Acer Schwedleri.

310. The Dwarf Oriental Maples.-The Japan maples (Acer palmatum) listed in catalogues are peculiarly beautiful as represented by a dozen or more varieties grown in Eastern nurseries. They do well in deep, warm soil, sheltered from drying winds, in the Eastern and Southern States. But all of them fail in the prairie States. But their near relatives of the Oriental type, Acer Tataricum and Acer ginnala, are graceful, small trees, with handsome foliage, coloring finely in autumn, and are hardy in all parts of the West and the cold North. 
311. Box Elder (Acer negundo).-This tree is discarded by Maynard, who says: "It soon takes an irregular form, is easily broken by wind and ice, and is rather short-lived." As found native in the Northwest this is not correct. If properly grown in nursery with straight stem, it makes a handsome round-topped tree, is not as liable to injury from wind or ice as most other trees, and has proven a long-lived species. No shade tree yet planted in the prairie States makes a denser shade.

312. The Silver and Red Maples.-The soft or silver maple (Acer dasycarpum, Erhr; A. saccharinum, Linn) is much used in the East and Southeast. The Western type is a clean, thrifty tree when planted, but has lost in popular favor, as it is liable to be broken by storms and sleet. But this can be avoided by giving the upright form shown in Fig. 90. It runs into varying varieties as grown from seed. Among those propagated, Wier's cutleaved is most valuable perhaps for giving variety to group-planting.

313. The Red Maple (Acer rubrum) is used to some extent at the East and Southeast for ornamental planting, on account of its bright-red flowers and fruit and its varied-colored leaves in autumn. As found native in Wis-

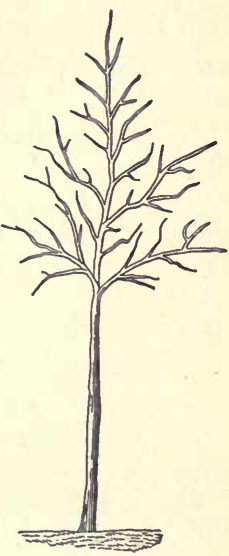
consin, the species varies in form, Fia. 90.-Properly becoming more compact and more shaped shade tree. closely resembling the native sugar maple.

314. The Elms.-The white elm (Ulmus Americana) is one of the grandest trees of the temperate zones for street and avenue planting, and it should have a place in parks 
and on large lawns. Like all our widely distributed native trees the species varies in hardiness and even in habit as grown in widely separated loealities. Varieties from the South or East will not thrive on the prairie, but our native variety makes as fine trees as can be found in New England. Some specimens that have had plenty of room, planted in open prairie exposure forty years ago, have now a spread of top of ninety feet or more.

Ulmus effusa, from east Europe, is also a grand tree for ornamental planting or shade over the prairie States, but as yet it has not been propagated to any great extent.

The cork-barked white elm (Ulmus racemosa) has been thus far a neglected tree. It has not been propagated or recommended for ornamental planting. But as found native in north Iowa, it is one of the most desirable of the elms, where rather compact, round-topped trees are desirable.

The red elm (Ulmus fulva) is used to some extent in ornamental planting at the East and Southeast. At the West the native trees make a fine appearance in groups, but isolated trees in open exposure are liable to fungus growths on the branches and leaves.

The European elm (Ulmus campestris) is more upright and compact than our white elm and is used to some extent in Eastern planting, but it is not hardy in the prairie States.

315. The Hackberry (Celtis occidentalis). - This also has been a negleeted tree by propagators and planters. As found native in the prairie States, it forms a round-topped tree of rapid growth, with exceedingly varied shade of foliage on different trees. In fact by propagating special variations in one lot of seedlings we may have a large number of distinct varieties. It is easily propagated from the crushed berries stratified for spring planting. 
316. The Plane-tree (Platanus occidentalis).-This has for many years been a popular shade and park tree over the north temperate zone of both eontinents. As an avenue tree in large parks and private places, it has been used with happy effect in giving variety of expression. Downing says truly: "For the purposes of shade and shelter the Ameriean species is the finest, as its foliage is longest and broadest."

In the Eastern States a fungus trouble of the leaves canses the foliage often to drop, followed by a new erop later in the season. This weakens the tree, and it is less planted than formerly. With the native species of the West this leaf disease has not appeared.

317. The Basswood or Linden.-Over west and east Europe the linden (Tilia Europea) is a favorite tree for avenues, streets, shade, and in park grouping But this European species in the States has been troubled witl borers, leaf-blight, and other diseases. But the American species (Tilia Americana) is a elean, healthy tree much used for avenue and street trees and also for park groups. Downing says of it: "One of the most beautiful trees. Its head forms a fine pyramid of verdure."

In the park system of Minneapolis, Minnesota, it has been much used for avenues, streets, and in park groups. When transplanted with high stem the south side is apt to be sun-scalded before the spreading of the top ean shade it. Hence it is usually wrapped with gunny sacking or hay ropes when set out to protect the stem.

In western New York several varieties of the European linden are used in ornamental planting with good effect, such as the white-leaved, weeping, golden-barked, and cut-leaved, but they only succeed locally and are not hardy in the West. 
318. The Honey Locust.-As a park tree this is gaining ground rapidly. The native species (Gleditschia triacanthos) was a favorite with A. J. Downing, who says of it: «There is a peculiar elegance about its light-green and beautiful foliage which wafts so gracefully in the summer breeze, and folds up on the slightest shower, that it stands far above the common locust for the embellishment of scenery."

It does not sprout like the black locust, and is more like the acacias of California. It grows rapidly from the seeds after scalding (6).

319. The Birches. - The most valuable of all the birches for ornamental planting is the cut-leaved weeping variety, classed by Bailey as a variety of Betula alba. If all the varieties with pendent habit should be included as variations of Betula alba this would be correct. But for two main reasons the writer is impressed with the belief that it belongs to a distinct species. When at the Agricultural College, near Moscow, Russia, in 1882, Professor Williams, Professor Shroeder, and Dr. Arnold pointed out the original tree of the cut-leaved weeping.birch, and stated that it was a sport found among several hundred seedlings of Betula Amurensis. A number of the seedlings were found on the grounds, all with pendent habit, which we were told was a peculiarity of the Amur species. But the only one with deeply cut leaves was the sport pointed out. The second reason for believing it a distinct species from the Amur valley is that it is hardy in all parts of the West and Northwest, while the other pendent varieties grown in Eastern nurseries do not endure our summer heat or winter's cold. Indeed, it is a thriftier, longer-lived tree on the prairies than it is near the lakes or east of them. In addition to all this, its seedlings up to the present, so far as observed, are hardy, thrifty, and 
pendent in habit, but they have entire, or nearly entire, leaves. The typical form and leaf of this handsome variety are shown in Fig. 91.

East of the lakes the canoe-birch (Betula papyracea),

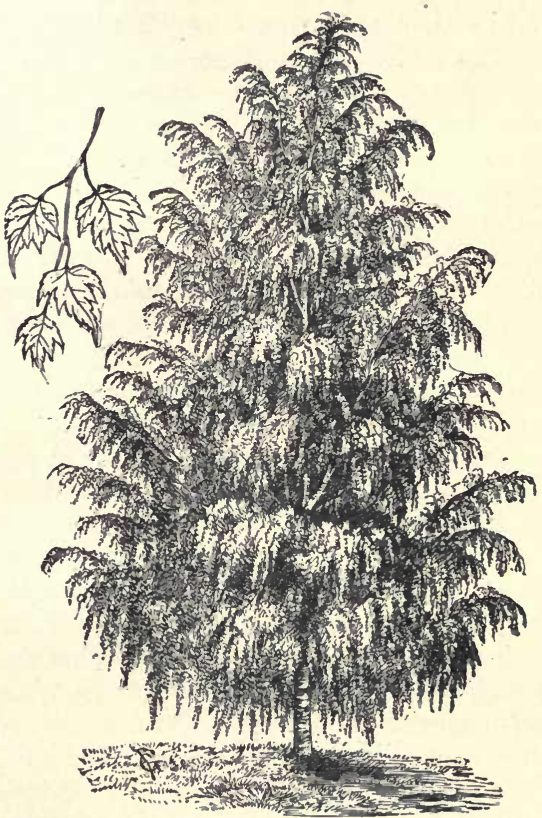

Fig. 91.-Cut-leaved weeping-birch. (After Maynard.)

the European birch ( $B$. albc $t$ ), and the sweet birch (B. lenta) are planted to some extent on lawns and in parks, but since the advent of the beantiful cut-leaved 
weeping variety they are less used. Int none of them, except the latter, has proven long-lived west of the lakes. Even the native birches that grow along the streams of eastern Iowa are not durable trees on prairie places or parks.

All of the birches imported by the writer from the steppes of east Europe have proven defiant to heat, drought, and cold on the eollege grounds at Ames, and where tested at the West. They were imported under the names of Betula carpinifolia, B. Siberica, B. urticifolia, and B. Maximowiczii. The latter is now mentioned by Alfred Rehder as "probably the most beantiful of all birches, perfectly hardy at the North, and of rapid growth." This species is credited to Japan, but as it is hardy at St. Petersburg and Moscow, and also in the northwest prairie States, it is probable that its home is the Amur valley, from whence Dr. Maximowiez brought the seeds to St. Petersburg and Moscow.

320. The 0aks. - In our relatively new country the oak has not been planted as freely as its merits demand. The impression has been too common that it was a tree of the centuries and that it was too slow in growth to use in the development of an American home. But of late the large nurseries of the Eastern States have propagated it freely, and people are learning that it grows in quite rich soils about as rapidly as the sugar maple. The planting of the best native species in Fairmount Park, Philadelphia, in large number after the exposition in 1876 has done much to encourage the planting of the oak.

Trees twenty years old are now about as large as the elms, sycamores, and sugar maples planted at the same time. On the campus of the Agricultural College at Ames, Iowa, the growth of oaks in twenty-five years has about equalled that of the red elm, sugar maple, hackberry, 
and other popular trees. About all the oaks offered by the New York nurseries do well east of the lakes. But at the West it is best to plant the native species, such as the white, bur, chestnut, and pin oaks. Where not obtainable in nurseries, it is far better to plant the acorns in mellow soil than to transplant young trees from their native localities. In practice it has been found that the seedling that throws its tap-root down where the tree is to stand will, in fifteen years, far excel in size and thrift even the nursery-grown tree set at same time four to five years old.

The most rapid-growing, handsome oak with deeply cut leaves known to the writer is the type of Quercus pedunculata, grown on the bluffs of the Volga in Russia. Trees grown from acorns of this species twenty years ago are now fine trees, bearing annual crops of long, slim acorns that sway in the wind on stems four inches long. But the Western chestnut oak (Quercus prinus) on rich soil is about equal to it in growth, but not in ornamental foliage. Red oak (Quercus rubra) also makes rapid growth on rich soil, and its foliage is handsome and richly colored in autumn.

321. The Oleasters.-What is known at the West as wild olive or oleaster (Elceagnus angustifolia) is hardy from the lakes west to Colorado and northwest to Manitoba. This species or variety differs materially from the $E$. hortensis of Eastern nurseries, which is not hardy at the West. In the prairie States the E. angustifolia makes a round-topped tree twenty-five feet in height and its dense crop of silverycolored leaves make a good shade. But the hortensis is much smaller in growth, with less dense habit and less fragrant flowers. The angustifolia can be used to advantage in grouping and also in places as a single specimen. Its roots dêvelop nitrogen in the soil, like the legumes, 
and grass will grow under its shade quite as well as in open exposure, and all crops will grow well close to it.

The buffalo-berry ( $E$. argentea) has been mentioned iin the list of native wild fruits (274). It is also valuable in small groups on lawns and in parks. It is a large bush or small tree with silvery foliage, contrasting finely with its dark-red fruit in late summer and autumn. This is diøecious (34). Hence it must be in groups to give crops of fruit.

322. Ornamental Species of Prunus.-In relatively mild climates of the Eastern and Southern States the Japan weeping ard double-flowering cherries noted in catalogues, as single specimens or on certain group borders are unique and handsome. Of the plum farnily the variegated-leaved varieties of the domestica species, the double-flowered varieties of the myrobalan, the aucuba-leaved bird cherry. double-flowering sloe, and still others, can be used to adrantage in planting.

In the West one of the most valuable of the family for shade and ornament is Prunus Maackii. This makes a medium-sized tree with spreading top and large leaves, making a dense shade. Its flowers are pure white in long racemes, fragrant, and retain their freshness in the parlor vase for several days.

The Prunus padus of east Europe is also hardy in the West and makes a beautiful small tree. Sovth of the $42 \mathrm{~d}$ parallel in the prairie States Prunus aucubifolia, $P$. triloba, and $P$. virgata are also hardy if top-worked on our native plum and grown as small trees.

Some of the handsome round-topped morello and griotte cherry-trees, such as Wragg, Spate morelio, Shadow morello, and Cerise de otheism, may also have a place in the grouping of large lawns and private places. Without pruning they assume regular forms and their dark-green 
foliage lasts late in autumn. The heavy loads of fruit are also ornamental as well as useful.

323. Mountain-ash Family.-The European mountainash (Sorbus aucuparia) is a desirable tree for giving variety of expression on the outer edge of groups, and the same is true of the American species (Sorbus Americana). The latter, as obtained from the upper lake region, is a roundtopped handsome small tree that loads with bright-colored fruits, even more freely than the European. It is also much hardier than the foreign species in the Northwest.

The oak-leaved mountain-ash (Sorỏus quercifolia), Fig. 92 , is more regular in form and for certain positions is more

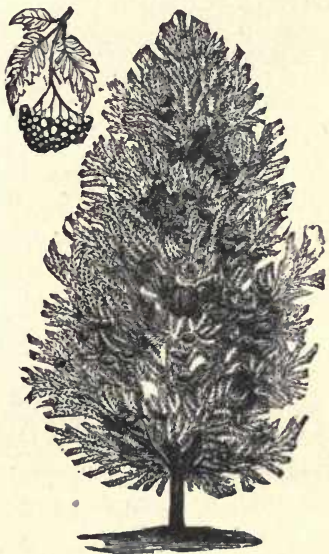

Fig. 92.-Oak-leaved mountain-ash (Pyrus aucuparia quercifolia). (After Maynard.)

ornamental than either of the above, but is not so hardy as the American species. The white beam tree (Pyrus aria) of west and east Europe is closely related to the mountain-ash 
and crosses readily with it. Its foliage is broad and distinct, and some of its varieties are hardy in all parts of the Union. The varieties argentea and alpestris, from east Europe and central Asia, are hardy far north, and will, when better known, be much used in ornamental planting.

324. The Apple Family. - The wild crab-apple (Pyrus coronaria), especially the Western form of the Soulard type, has value for ornamental planting. Nursery grown, it is as easy to transplant as other apple-trees, and makes fully as rapid growth. It is handsome in form, foliage, flowers, and even fruit.

Bechtel's double-flowering crab seems to indicate a remarkable tendency to variation in our native crab. As stated in catalogues its flowers are like perfectly double small roses and its fragrance is equal to the best of the roses. This seems to be hardy East and West.

Parkman's double-flowering and the Chinese doubleflowering are prized in milder climates, but are not hardy at the West except south of the 40th parallel.

It is the same with the double-flowering hawthorns of west Europe, none of which prove hardy west of the Great Lakes, but they are valuable in milder climates. But the large-growing native hawthorns of the States east of the Rocky Mountains have more value in landscape work than is usually suspected, especially in the more rugged portions of the grounds. Of its proper position Downing has said: "It is most agreeable to the eye in composition when it forms the undergrowth or thicket, peeping out in all its freshness of gay blossoms or bright fruit from beneath and between groups and masses of trees."

It is the same with the double-flowering hawthorns of west Europe, none of which prove hardy west of the great lakes, yet they are valuable in milder climates. But the large-growing native hawthorns of the States east of the 
Rocky Mountains have more value in landscape work than is usually suspected, especially in the more rugged portions of the grounds. Of its proper position Downing has said: "It is most agreeable to the eye in composition when it forms the undergrowth or thicket, peeping out in all its freshness of gay blossoms or bright fruit from beneath and between groups and masses of trees."

Pyrus ringo of east Europe also has thick dark-green leaves that are not killed by the first frosts. They often remain green and seemingly unfrozen until December in Iowa. It is a handsome round-topped tree bearing large pure white flowers and full crops of ornamental crab-apples. This is hardy in all parts of the Union.

324. Poplars and Willows.-These rapid-growing trees have value in certain places in parks and on large places. The true white poplar of east Europe makes a large tree with silvery foliage. It does not sprout as much as the gray poplar or abele of west Europe. In the centre of a large group, or at an angle or corner, it gives variety of expression in contrast, as Downing says, with darker-foliaged species. If the sprouts are pulled up as they appear the tendency to sprout does not last long. But if cut off they grow stronger than before.

The variety Bolleana also sprouts but little. This is upright in habit and is only admissible where trees with silvery foliage and upright habit are wanted to fix attention to a particular point in the landscape.

Populus certinensis of east Europe has a fine pyramidal habit, with large heart-shaped dark-green leaves with wavy or folded edges. It can be used everywhere to give variety to groups of quick-growing trees.

The willows also have certain uses. In large cemeteries and near water such weeping varieties as Babylonica, Kil- 
marnock, Thurlows, Purpurea, and Napoleonis of the catalogues are useful and give much variety to scenery.

At the West the Napoleonis top-worked on Salix aurea is most valuable together with the Wisconsin weeping, as the others named above are not hardy North of the 42d parallel.

For holding the banks of ponds and streams the smallleaved brook willows are often useful and ornamental, and can be started by sticking cuttings into the banks.

Among ornamental willows with rounded tops and handsome foliage the two best are Salix aurea and Salix laurifolia.

The Salix aurea as received from Russia is far better than the common golden willow, as its leaves are shining and its growth in winter has a much brighter golden color that can be seen from afar. Salix laurifolia from European Russia has been most used at the West, but its value in giving variety of expression to round-topped groups is now being generally recognized.

As a shrub willow for group undergrowth and stream borders, the valne of Salix rosemarinifolia is not as yet fully recognized. Its narrow rosemary-like leaves are quite showy. The east European variety is hardy on upland in the West.

325. The Magnolias. - The beautiful evergreen species of this country and Japan are mainly valuable in the South and on the west coast. Of the deciduous species the cucumber-tree (Magnolia acuminata) is the hardiest, as it makes a large tree in southern Iowa and north Missouri. In the Eastern States some of the deciduons Oriental species, such as Magnolia stellata and M. Kobus, do well in sheltered positions as far north as northern New York. In the North, where hardy, M. acuminata makes a grand 
avenue tree, and the same is true of $M$. grandiflora in the South.

326. The Larches.-The common European and American larehes are peculiar in their adaptation to varied soils and elimates. The American species grows naturally in swamps and the European in moist climates as compared to ours. Yet they both make rapid growth on almost any soil from the Atlantic to the Missouri. They are valuable in giving an expression of boldness which, as Downing says, " seems to have been caught from the wild, rugged chasms, rocks, and preeipices of its native mountains." But he adds: "It should be introdueed sparingly and always for some special purpose."

But at this time we have in the nurseries a weeping variety ( pendula), a Japan species ( $L$. Kaempferi) with lightgreen foliage, changing gradually to yellow in autumr, and Larix Sibirica, with rounded head in open exposure and much denser foliage than other varieties and species. 'The latter appears to stand drought in the West as well as any of our native trees.

327. Some 0ther Desirable Trees.--The maiden-hair tree (Salisburia adiantifolia) is a specially desirable tree from Japan and central Asia that does well over a large part of the Union. Even in southern Iowa it seems to thrive as well as in Georgia. The fern-like, half-tropical foliage is charming, as shown by a single specimen on the lawn.

The yellow-wood (Chionanthus Virginica) is another peculiar ornamental tree in its adaptation to varied soils and elimates. It seems perfeetly hardy on the prairies, yet it is not found native in severe elimates in this country or Asia. It makes a handsome small tree with dark-green foliage and very showy white flowers.

Phellodendron Amurense also has a wide range of adaptation. It is a success east and west of the lakes. Its 
thick, corky bark and elegant pinnate foliage three or four feet long gives variety to a tree group.

The horse-chestnut family is exceedingly varied, and

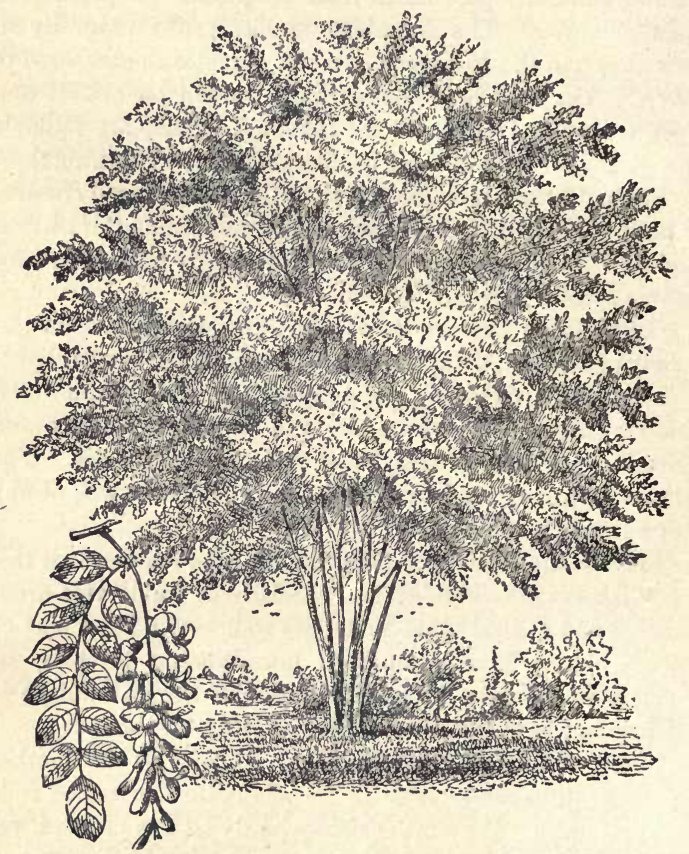

FIG. 93.-Yellow-wood (Cladastris tinctoria).

some of its members are hardy over nearly the whole Union. In the East and Southwest the Esculus hippocastanum, or white-flowered horse-chestnut, is extensively planted for street, avenue, and park trees. The double-flowered vari- 
eties are also much planted, also the red-flowered and other fine varieties and species. In the Weat the native type of LEsculus glabra is mainly planted, except south of the 40th parallel, where most of the European and native species and their varieties are hardy.

The beautiful nursery varieties and species of the beech can only be grown on granitic soils relatively free from lime as a rule. Where the blueberries, huckleberries, and cranberries succeed, the beeches can safely be planted. On the drift soils of the West they fail to thrive.

\section{Some of the Desirable Evergreens.}

At the North the word evergreen is applied to the conebearing trees with persistent foliage. The broad-leaved evergreens are mainly confined to the South.

328. The Spruces.-The Norway spruce has been propaguted more extensively as yet than any other species, and has been widely planted in the Eastern and prairie States. But it is now losing its popularity. As the trees attain the age of thirty years at the East they become relatively thin, and in the West they begin to fail in twenty years. At this time the first-planted trees west of Chicago are dead or in a low state of vitality. This is equally true of its nursery varieties. Yet the Norway is rapid in growth, and for a number of years it shows thrift and beauty as lawn specimens or as shelters and wind-breaks. The White spruce is a Northern species, and varies in hardiness and longevity. As obtained from the Black Hills in South Dakota, it is a beautiful and long-lived tree over the prairie States, and will probably sustain its record east to the Atlantic. But. it seems to be a long-lived tree as obtained nearer the lakes. At Wankegan, Illinois, trees planted over fifty years ago are still dense in habit, regular in form, and are well branched 
to the ground. These trees are still making an annual growth. As obtained near Chippewa Falls, Wisconsin, a large per cent of the plants have the blue tinge of color of Picea pungens.

The silver spruce (Picea pungens) comes to us from the eastern slopes of the Rokcky Mountains. We also have some old trees of this beantiful species, brought to the prairies during the Pike's Peak gold excitement many years ago. These old trees seem to show added beauty each year. Those that had little show of color when young now are nearly as silvery as those that were the favorites when

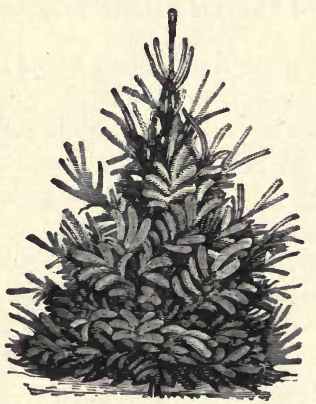

Fig. 94. -Colorado silver spruce (Picea pungens). (After Maynard.)

small. This grand species also seems to do well nearly across the continent. The common name "blue spruce" is not expressive, and properly belongs to the cærulea variety of the white spruce grown in French nurseries. Silver spruce is far better, as the finest specimens have a silvery-blue expression, especially as grown in the dry air of the West. (Fig. 94.)

The Engelmann spruce (Picea Engelmanni) is another noble species of eastern Colorado. It is a slower grower 
than pungens, but it has finer foliage and is more compact in habit. Its ability to stand the dry air of the prairies seems to depend on the locality whence the plants come. Plants from the Clear Creek Valley of Colorado have stood in Iowa as well as the Black Hills spruce. This species is often mixed with Picea pungens in gathering seed in Colorado, and also in digging young plants; but in reality it more nearly resembles the white than it does the silver spruce.

In Eastern and Southern nurseries are to be found several varieties and species of the spruce of local value, such as the Alcock from Japan, the Smith from the Himalayan Mountains, the Oriental from Asia and east Europe, and numerous varieties of the Norway that will give variety of expression.

329. The Firs.-Several of the firs are short-lived when planted in open exposure. The present limits will only permit the mention of those that have done well over large areas of the country.

Abies concolor stands well at the head in withstanding heat, cold, and drought. It is popular over the Eastern States, and is hardy and specially beautiful in the West. As its name indicates, it is even-colored through the year and a thing of beauty at all times. It should be more extensively grown and planted.

The red fir (Pseudotsuga Douglasii) is quite variable as found in different parts of the Rocky Mountains and the Black Hills. As received from the Black Hills it is the most rapid grower yet tested among the conifers, and the most defiant to extremes of heat, drought, and cold. The leaves are also longer, broader, and thicker than on trees from Colorado, and the whole habit is denser and more compact.

As found in Colorado it also runs into variations, some 
of which have been propagated under special names, such as compacta, fastigiata, glauca, and pendula. It is peculiarly a valuable tree for oruamental planting in the West and East. Horticulturally it is classed with the firs, but botanically it is placed between the spruce and hemlock.

East of the lakes the balsam fir (Abies balsamea) and sueh foreign species as $A$. Nordmanniana and A. Pichta are favorites in park and lawn planting, but they are shortlived at the West.

330. Some of the Pines.-The pine family has many species in about all parts of the earth. In this connection only a few of the hardiest and handsomest ean be referred to. The white pine (Pinus strobus) of Iowa and western Wisconsin is adapted to prairie planting, and it has better form and a denser habit for Eastern planting. As obtained from any point east of the lakes, it fails to endure the dry hot air of the corn-growing belt.

The red pine (Pinus resinosa) is a favorite for Northern and Western planting. Its form of top and thick clusters of slender, soft, dark-green and long leaves fit it specially for ornamental planting East or West. But the Eastern type is not hardy on the prairies.

The yellow or bull pine (Pinus ponderosa) as obtained in the Black Hills of South Dakota stands every exposure at the North and West, is quite rapid in growth, with rounded conical top and a bold expression that fits it specially for picturesque parts of the grounds. As obtained from Colorado the tree is more open, and as it attains age it loses its regularity of outline.

Of the foreign species, Pinus laricio is extremely variable in hardiness as obtained from different parts of Europe. Even the variety known as Austriaca or Austrian pine is variable, as grown from seed, in habit of growth, color of foliage, and hardiness as grown in the West. Its harsh 
leaves are not suitable for small places. But it is one of the best for parks and large places. The stone pine (Pinus cembra) from the plains of east Europe is hardy anywhere in the East or West. It is much like our white pine in shade of color of foliage, but it is far more compact in form and is pyramidal in habit. $\Lambda$ s obtained from west Europe it is not hardy at the West.

The type of Scotch pine ( $P$. sylvestris) from east Europe known as Riga pine is hardy at the West, and is more ornamental east of the lakes than the trees grown from seed gathered on the sandy tracts of Alsace, France. Its bluish shade of color of foliage fits it for planting at points to which attention is to be directed.

The Swiss mountain pine (Pinus montana) is extremely variable in habit. The most valuable type at the West is P. pumilio. It is a handsome low-spreading shrub, with dark-green foliage that varies little in color in the drought of summer or the cold of winter. It is specially valuable for corners and angles of lawns, walks, and drives. Several other varieties of varying heights and habits of growth are valuable east of the lakes.

330a. The Hemlock.-The hemlock (Tsuga Canadensis) is also variable in its adaptation to varied climates and soils. As obtained in northwestern Wisconsin it has proven hardy and very beautiful in the prairie States in situations where sheltered from the westerly winds, while plants from western New York have been withered during the first year of growth. The Northwest type also endures drought on high ground, while the Eastern type only succeeds on moist ground. The hardy type is admirably suited for ornamental screens, and can also be used to advantage as single specimens.

330b. Arbor Vitæ.-The American arbor vitæ (Thuya occidentalis) is admired in landscape work when young, 
but as it attains some age it changes the character of its leaves, becomes irregular in habit, and loses its lower branches.

The Eastern nurseries describe several beautiful varieties which do well at the East, but they are not favorites at the West. The best varieties for Eastern use are Siberica, pyramidal, globosa, and the golden.

The most popular use of these varieties is for ornamental screens or hedges east of the Great Lakes, but they all have the fault pointed out by Downing, of taking on a "dingy green hue of foliage in winter," while the hemlock, white spruce, pinus pumilio, and other conifers will retain their characteristic colors in winter. 


\section{CHAPTER XXV.}

\section{SOME OF THE ORNAMENTAL SHRUBS AND VINES.}

331. Some of the Uses of Shrubs.-The flowering and colored foliaged shrubs are used effectively on the borders of tree groups and in groups in the angles, curves, and corners of walks and roads, as shown in Figs. 83 and 84 .

Large shrubs are often used to give irregularity to tree groups, as shown in Fig. 89.

In some cases where a view is not desirable a belt of shrubs may be planted on the inside edge of tree groups, and on many fine places well-kept shrubs are found along walks and drives. Downing's plan is often followed in well-kept places. He says: "Where the character of the scene is that of polished beanty the belts of shrubs may be arranged similar to herbaceous flowering plants, in arabesque beds along the walks. In this case shrubs alone, arranged in relation to their height, may occupy the beds; or, if preferred, shrubs and flowers may be intermingled."

In some cases herbaceous perennials are planted near the walk or road, with low shrubs next, which are succeeded by taller shrub species reaching to a background of trees of small size.

Well-kept shrubs (152) do not obstruct views like tree groups, and they can often be grouped so as to give an apparent reason for road and walk curves, and even to conceal a portion of the walk in advance. 
At this time the purpose is only to give notes on the most desirable shrubs that succeed well over large areas of the United States.

332. The Spiræas.-Spircea Van Houtteii stands well at the head of the list in beauty of form, flower, and ability to thrive in nearly all climates. Its pendulous branches are loaded with pure-white flowers, and through the season its bright-green leaves and graceful habit gives it interest. A single plant with ample room for perfect development often gives a striking expression in a porch corner or angle of the walk. (Fig. 95.)

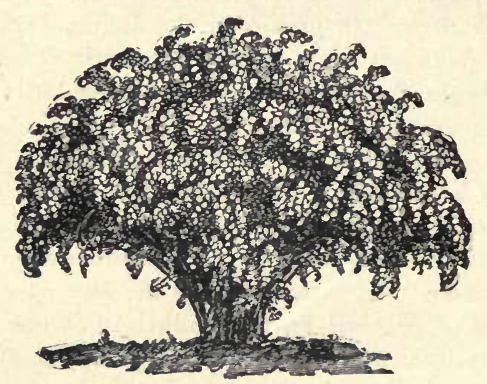

Fig. 95.-Van Houtt's Spiræa (Spiraea Van Houtteii). (After Maynard.)

Spircea prunifolia gives its annual tribute of pure white double flowers. Its habit of growth best fits it for a group. If the strongest canes are cut back after blooming, the number of bearing branches will be much increased (152). (Fig. 96.)

Spircea Thunbergii.-This Oriental species has fine fernlike foliage that in autumn assumes a golden shade. It is useful as a group border, especially near the house.

Spircea trilobata is a dwarf compact grower, with masses 
of white flowers, very useful for border in banking inside a taller growth.

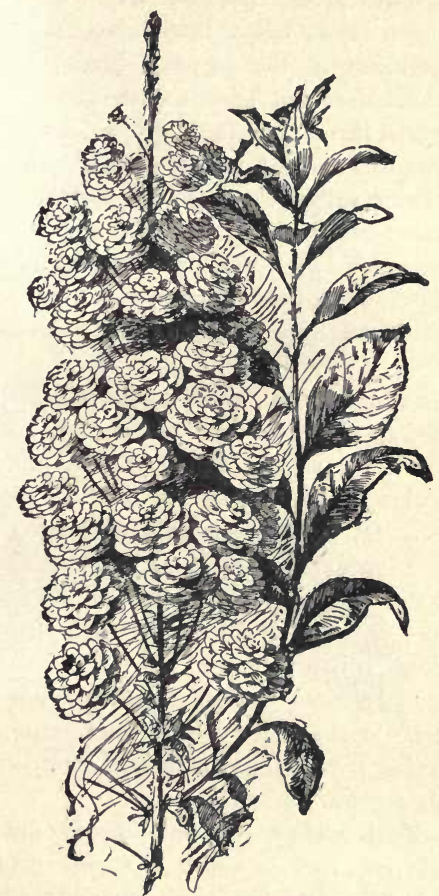

FiG. 96.-Bridal-wreath (Spircea prunifolia).

Spircea callosa alba is also useful as a group or bank border if the old wood is cut back as practised with the roses, as it only bears on wood of the same season's growth. 
333. The Lilacs.-Possibly the most useful of the lilacs in landscape work is the tree lilac, known commercially as Syringa Japonica. As introluced from Japan it has not proven hardy in Iowa; but as introduced from east Europe it is quite as hardy as the common lilac. This makes a small tree that does not sprout from the crown. It has large dark-green leaves, and its large panicles of pure white flowers appear in June. A variety of this sproutless species from the Amur valley was received by the writer from Moscow, Russia, under the name of Syringa Amurensis. Its leaves are much larger than the typical species, and it flowers at the height of only four or five feet. The flowers are pure white, and appear on upright panicles above the large leaves.

The Josikea lilac, from Transylvania, also seems to be a elosely related species. It does not sprout, and its leaves are large, dark green, free from mildew, and it is very hardy everywhere. Its flowers are delicate pink and appear in June. Of the smaller-growing bush species such varieties as Charles $\mathrm{X}$, Marie Legraye, and Lemoine's double-flowered are more desirable than the old-fashioned red and white, as their foliage is better and also the flowers. They also flower when younger.

The Persian species (Syringa Persica) is not as stiff and formal in habit as the other species, and some of the improved varieties, such as the alba and laciniata, are valuable in landscape horticulture.

334. The Mock-oranges.-This numerous family of ornamental shrubs is popularly known as syringa in Europe and America. As this is the botauical name of the lilac family, it seems to be a survival of the old times when the mockorange, lilac, and jasmine were classed together.

In lawn and park planting there is little gain in planting more than four or five of the best varieties that vary in size 
of plant and some in season. Of the larger-growing species Philadelphus coronarius, P. grandiflorus (Fig. 9テ), and $P$. Gordonianus are most valuable for the prairie States, and probably for a large part of the Union. 'The smallergrowing type is best represented by such varieties as $P$.

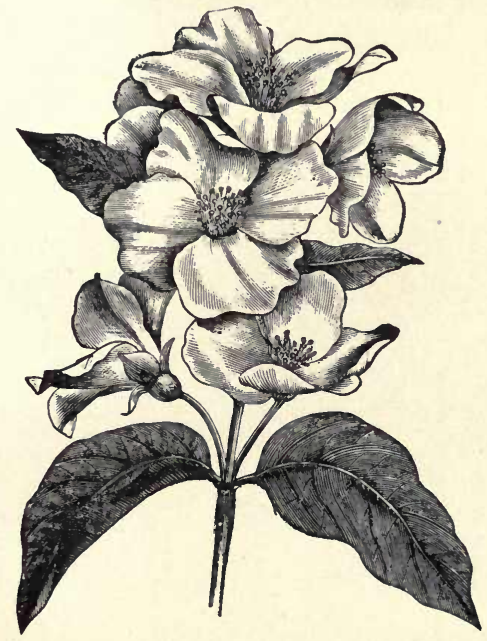

Fig. 97.-Mock-orange, large-flowered (Philadelphus grandiflorus). (After Maynard.)

zeyleri, as their flowers are large, pure white, and very fragrant.

The beauty of bush and profuse flowering of the mockorange species depends largely on slight annual pruning (152)

335. The Barberry.-This is also a numerous family, nearly all of which are liardy in the North and in the 
prairie States. The Amur barberry (Berberis Amurensis) is specially useful in lawn and park work. It grows rapidly into a defensive hedge or sereen, and planted singly in certain positions it assumes a broad, spreading habit of growth, handsome in foliage; and when loaded with its scarlet fruit in autumn it is specially attractive. Fig. 98

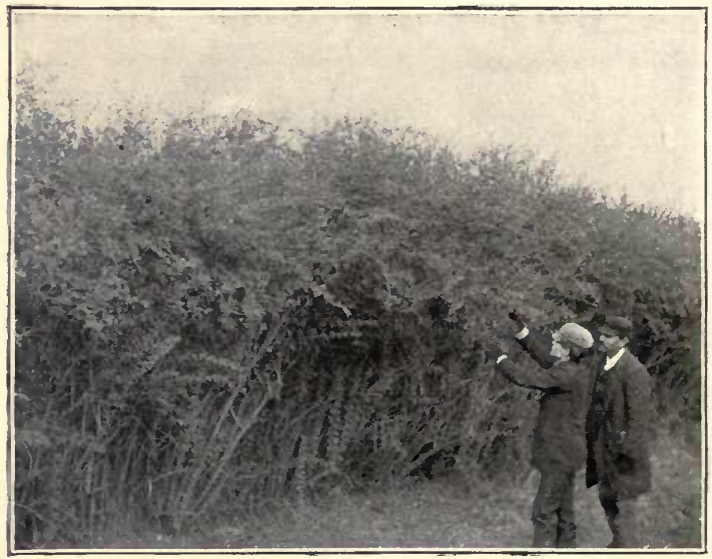

FiG. 98.-Amur barberry screen as grown in north Iowa. (After Gardner.)

shows its habit of growth. Berberis Thunbergii comes next in ornamental value for planting in near proximity to house, walks, and drives. It is not more than four feet in height, with regular compact form without pruning. Its leaves are small, nunerous, and assume gorgeous colors in autumn. All the types are hardy, but the variety from the Amur valley in Asia, known as Maximoviczi, is the hardiest for the far North. 
The purple-leaved variety of the common barberry $(B$. vulgaris) comes third in value to give variety to groups and borders. It retains the purple color of leaves through the season. It contrasts finely with golden-leaved or lighter green leaves of trees or shrubs. To keep this fine variety in compact, bushy form it needs heading-in, while young, in the dormant season.

In the West the common barberry and the purple-leaved are troubled with the cluster-cup fungus on their foliage. But the first two named, and indeed all the Oriental species we have tested, are free from fungus disease of the leaves.

336. The Snowball Family. - The tree or shrub cranberry (Viburnum opulus) is native to the Northern and Western States, and it thrives under nearly all conditions. It is an interesting large shrub for background positions. Its cymes have sterile and fertile flowers, followed by scarlet fruit that hangs on late in autumn and is often used for jelly and marmalade.

The common snowball with sterile flowers is an old-time shrub in all parts of the Northern States. During recent years its foliage has been so weakened by the green apbis that it is less prized for ornamental planting. But careful spraying (159) with kerosene emulsion, turning the nozzle upward, will give thrifty bushes, as we enjoyed in the West thirty years ago without treatment.

The Chinese species (Viburnum plicutum) is now planted almost exclusively at the East and South, but in the prairie States it has not proven able to endure our test winters. Where it thrives it is superior in beauty of its sterile flowers and in its plaited or plicated bright-green leaves to the common species.

337. The Bush Honeysuckles. - Lonicera splendens stands well at the head of the group for varied use on 
home grounds or in parks. It is usually classed as a variety of $L$. Tatarica, and its seedlings follow very closely its habit of growth and leafage, but a part bear yellow and a part red berries. It is much handsomer in flower, leaves, and habit of growth than the old Tatarica. If in early spring some of the upright shoots are cut back the bush assumes a symmetric rounded form of top. Lonicera xylosteum comes next in value for general planting. It is bolder in habit and should be used where the scenery is more rugged. The berries are dark red and shiny. With some needed pruning it is a handsome shrub for any position.

$L$. alba grandiflora of Regel is a marked variety of $L$. Tatarica, with large white flowers, and the bush is easily kept in desirable form.

Lonicera Alberti of Regel, as imported by the writer from Russia, is a low-growing pendulous species with narrow, fern-like leaves, handsome pink flowers, and red fruits in autumn. It is specially useful near roads and walks and in prominent positions where a low, pendulous growth is desirable. Bailey follows Jaquin in referring to this as a variety of Lonicera spinosa. But as grown in the West its slender branches are soft and smooth, with no suggestion of rigidity or thorny growth.

All the species mentioned are hardy over the Northern States.

338. The Hardy Roses.-The queen of flowers can boast of a greater number of fine varieties than any ornamental shrub of the earth. In past as well as present ages it has been the favorite shrub-flower of Asia, Europe, the islands of the ocean, and the western continent.

The finest commercial varieties hare been developed in relatively mild climates of the two continents. Hence of the old favorites we have few varieties that eudure the 
Northern winters without autumn pruning and covering. East of the lakes such bedding varieties as La France, Meteor, Madame Plantier, and Bride are regarded hardy. Also such hybrid perpetuals as General Jacqueminot, Anna de Diesbach, Marshall P. Wilder, and Mabel Morrison are hardy enough, and the same is true of such climbers as Baltimore Belle, Prairie Queen, and Crimson Rambler. West of the lakes all these and others are grown but in autumn all except the climbers are eut back (152) and covered with leaves, sods, or earth. In the South and in California nearly all roses are hardy, and it is only a matter of local selection of varieties, as it is in all parts of the States east of the mountains.

West of the lakes and north of the 41st parallel the truly hardy roses are such as Rosa rugosa and its hybrids, Madame Plantier and Harrison's Yellow. Among the hybrids of Rosa rugosa are now found some desirable double varieties of value even where the old varieties do dwell. This is specially true of Ames, Hansen, Charles Frederick Worth, and Madame George Bruant.

It is often truly said that failure in rose-growing most frequently arises from not making the soil rich enough. Like the currant, the rose will bear heavy manuring, preferably with cow manure; and where coarse manure is used for covering the cut-back bushes in the fall, this covering is spread and used for mulching and final spading into the soil.

339. Evergreen Shrubs.-East of the Great Lakes and over a large part of the South the boxwood (Buxus sempervirens), mountain laurel (Kalmia latifolia), American holly (Ilex opaca), great laurel (Rhododendron maxima), and the beautiful mountain laurel (Rhododendron catuwbiense) can be used to great advantage in shady positions and as undergrowth on the borders of tree groups. But 
in the dry air of the prairie States, planted in limestone drift soils, they are all failures except in parts of Wisconsin, where the granitic soil permits the thrifty growth of the mosses and the cranberry and huckleberry (2\%\% and 280). The holly-leaved Mahonia (Mahonia aquifolium) as found native in the Black Hills and in the Lake Superior region does well in half shaded and sheltered positions in the prairie States and well across the continent. Its handsome glossy foliage, neat habit, and bluish berries render it popular where the other broad-leaved evergreens fail. The Savin, prostrate juniper, Pinus pumilio, and Pinus mugho also are used at the West for covering rockwork, giving variety to tree groups, and sometimes as single specimens.

340. The Hydrangeas. - The only truly hardy species of this quite extended family is known as Hydrangea paniculata grandiflora. (Fig. 99.) It is hardy even in Minnesota, but it does not endure protracted drought as well -as most other shrubs. Its great panicles of remarkably durable flowers show to best advantage whon planted quite thickly in front of banks of shrubbery. It is also useful for groups in certain positions and as single specimens.

With some protection in winter, or as grown in large pots sunk in the lawn in summer and kept indoors in winter, such varieties of the Japan hydrangeas as Hortensia and Thomas Hogg are much used for lawn decoration. In the South these fine varieties are hardy without winter protection.

341. The Tamarix.-The hardiest and most beautiful species is Tamarix Amurensis. In the West this will thrive on dry knolls where no other graceful shrub will live. Its foliage has some resemblance to that of the heath. The pink flowers are in lateral spikes, and the Amur species fiowers often three or four times during the summer. If kept in 
SOME OF THE ORNAMENTAL SHRUBS AND VINES. 359

shape, and a full crop of flowers are produced annually, the new growth must be cut back fully two thirds each season in the dormant period. Tamsrix Gallica is nearly as hardy and desirable and is most generally planted east

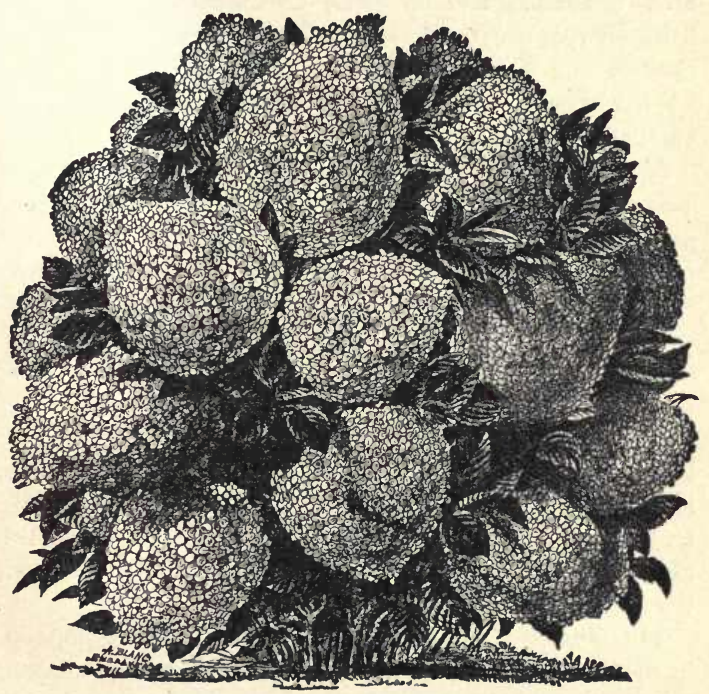

FIG. 99.-Hardy hydrangea (Hydrangea paniculata grandiflora). (After Maynard.)

of the lakes, and in the South Tamarix Africana is mainly used.

342. The Buffalo-berry. - This has been noted as a fruitbearing shrub (2r4). When grown in groups the silvery foliage attracts attention from afar, and when the loads of scarlet fruit appear the contrast with the silvery foliage is still more striking. In groups it is hardy everywhere, but 
isolated specimens with stems trimmed up are apt to sun scald on the south side.

The goumi (Eloeagnus longipes) has also been noted as a fruit $(2 ; 6)$; but its flowers are fragrant, and its reddishbrown branchlets and its silvery-brown foliage with starry hairs above give it interest and value as a shrub in the Eastern and Southern States. West of the lakes it is not hardy enough to endure the winters north of the 40 th parallel.

343. Japan Quizce (Cydonia Japonica). - This is much used for ornamental planting East and South; but it is not hardy enough for the prairie States north of the 40 th parallel. The flowers are mostly scarlet, but varieties have varied shades of red and some are pure white. As they expand before the leaves appear it gives a striking expression from a near or distant view. This is specially true of the vividly scarlet variety.

344. White Fringe (Chionanthus Virginicus).-This is a special favorite. It has heavy dark-green foliage which is ornamental through the season and when loaded with its lace-like peculiar white flowers it attracts much attention. (Fig. 100.) It is quite hardy in sheltered positions at the North.

345. Purple Fringe (Rhus cotinus).-This is popular in the Eastern States under the name of Venetian sumach or smoke-tree. It is a crooked, straggling grower, but its large leaves are handsome and the flowers are in large panicles, at first green, changing to a reddish-brown, and later to a smoke color. 'The seeds or their appendages are in light, airy masses, giving the idea of puffs of smoke issuing from the handsome leaves. If grown slowly on the grassy lawn it is hardy over most of the States.

346. Cut-leaved Sumach.-The beantiful cut leaves of this variety of Rhus glabra give a fern-like expression to 
the foliage, and in autumn it colors up as gorgeously as the oaks. It is gaining in favor each year East and West.

347. Golden Elder.-This is one of our brightest goldencolored shrubs, and the leaves hold the golden hue well through the season. If the old canes are cut out once in two years the beauty of the group will be maintained.

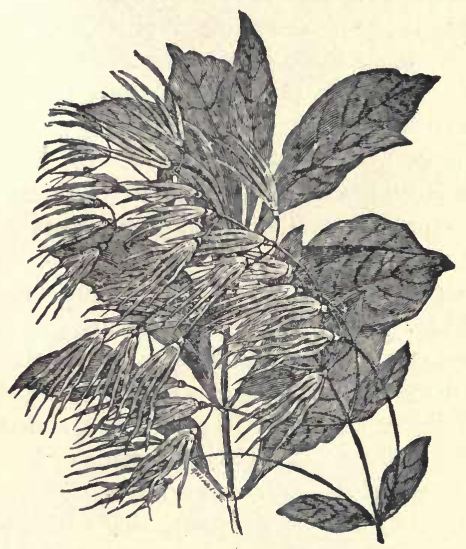

FIG. 100. -White Fringe (Chionanthus Virginicus).

348. The Snowberry.-It is quite usual to plant the snowberry (Symphoricarpus racemosus) and the red Indian currant (S. vulgaris) together in the same group or in banking against a taller group. The snowberry and the low-growing barberries also make a fine contrast.

349. Golden Bell.-The golden bell (Forsythia vividissima) displays its bright-yellow flowers from bottorn to top of the young growth very early in spring - even earlier 
than the Juneberry. Where a drooping or pendent growth is desirable Forsythia suspensa is planted. It is equally hardy and free in flowering. Indeed, in the West its flowerbuds are hardier than those of $F$. viridissima.

350. Pearl Bush.-This common name is given to Exochorda grandiflora and also to $E$. Alberti, which are closely related species. 'The latter species from Turkestan thrives best in the prairie States, and in all parts, so far as known to the writer, the Alberti is most vigorous in growth, has darker foliage, and its pure white flowers show on longer spikes than those of the grandiflora. By pruning it can be kept in good shape, but it has most value when massed with other shrubs, where its irregular habit adds to the variety of expression. The grandiflora as yet is the common variety of the nurseries.

351. Weigela Rosea. (Fig. 101.) - This is the old garden name of Diervilla, of which we now have many varieties. Diervilla rosea is quite as valuable as any in the list. Its fine rose-colored flowers hang in graceful clusters from the áxils of the leaves and end of the branches, and the foliage is better than with most varieties if some of the old wood is cut out at the close of the flowering period each season. This keeps a supply of young grow th that will flower freely. If a white-flowered variety is wanted the Nivea is the best we have tested.

352. Red Dogwood (Cornus sanguinea). - This is a handsome hardy shrub specially valuable for its winter expression when placed in contrast with low-trained Salix aurea or a group of dwarf growing evergreens.

The variegated leaved dogwood (Cornus Sibirica) also has red-colored branches, and its leaves are finely variegated with yellow, white, and green. It contrasts pleasingly with dark-green- or purple-leaved shrubs. 
SOME OF THE ORNAMENTAL SHRCBS AND VINES. 363

\section{Ornamental Climbing Vines.}

In the South and the dent-corn area of the West handsome vines to cover verandas, porticos, porches, arbors, and

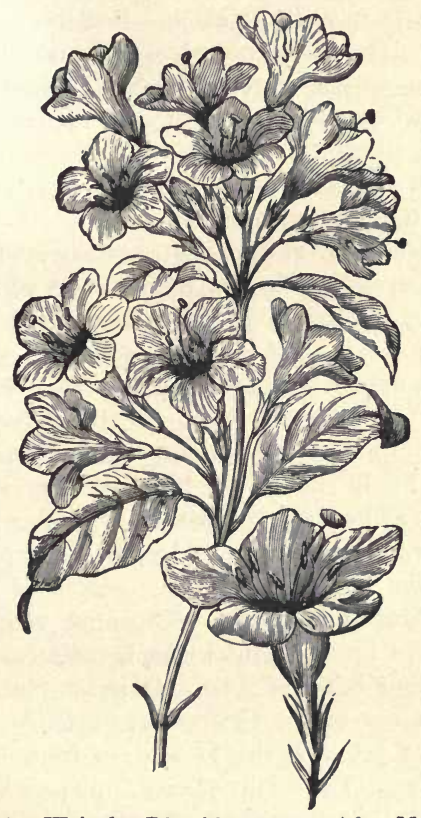

Fig. 101. -Weigela (Diervilla rosea). (After Maynard.)

unsightly walls and fences are far more general in city and country than in cooler and moister climates. During recent years as far south as Atlanta, Georgia, so many of the 
climbing vines generally planted have been killed or crippled by severe winters that at this time only truly hardy species will be noted, except three or four desirable ones for the South, as specially stated.

353. The Climbing Honeysuckle.-Lonicera media of east Europe is specially valuable. It is hardy far North, and does well, so far as tested, South and East. It is handsome in foliage, flower, and fruit. For some reason the bright-red berries are not eaten by the birds and show from afar in midwinter.

Lonicera sempervirens is a native species that is nearly as hardy as the above-naned species. The foliage of this species is evergreen at the South usually. The flowers are trumpet-shaped with rich scarlet color without and a tinge of orange on the inside. It blooms, when not too dry, through the season. Of the Japan species, Lonicera Halleana is the most valuable where it proves hardy. The mature flowers are pure white, peculiarly fragrant, and are quite continuous through the season. At the West this is not hardy enough for porches, but is grown by cutting back and covering in winter.

All the climbing honeysuckles must have trellis or woven wire for support.

354. Climbing Bittersweet.-The most valuable ornamental species tested by the writer is Celastrus punctata, from the Amur valley in Asia. It is far more rapid in growth than our native bittersweet, its foliage is darker green, and as yet it seems to be free from insects and attacks of fungi. The bright-colored fruit popularly known as "wax-work" hangs on late into winter.

The native species, Celastrus scandens, is also valuable for porches if given woven-wire trellis to encourage upward growth. It is also specially valuable for covering arbors, rock-work, wire fences, etc. 
355. Virginia Creeper.-The Ampelopsis quinquefolia, often called the American woodbine, but more properly Virginia creeper, is peculiarly variable as found in different parts of the Union. As found in the Black Hills its leaves have a silvery appearance, and as found clustering over the rocks at the Devil's Backbone in Delaware County, Iowa, it differs materially from the commercial type. The most valuable variety generally propagated is known as $A$. Engelmanni. This has smaller and denser foliage than the usual type, and is known in Chicago as American ivy. The Japan species, $A$. tricuspidata, known commercially as $A$. Veitchi, and as Boston ivy, has lobed leaves that are glabrous and shiny on both sides. This is popular in the East and South, and does well on the east, west, and north exposures, but its foliage burns on a sontherly exposure on porches or walls in Iowa and Minnesota.

356. Chinese Wistaria.-This is a rapid-growing vine that will twine to advantage around porch columns, arbors, and fences. Its large panicles of blue flowers are produced in great profusion.

357. Jackman's Clematis.-This is a showy climber when supported on woven wire. Its intensely violet blue flowers are very large and attractive. At the West the weak canes are cut back and the crown is covered over with leaves or other protective material.

358. Actinidia arguta. - This is a peculiarly rampantgrowing vine from Japan, with a tropical expression of foliage. Where hardy east of the lakes and in the South, it will cover a fence, arbor, or trellis in less time than any vine known to the writer. In the West, north of the 42d parallel, it is not hardy enough for a permanent covering of arbor or porch; but in less important positions, if cut back severely when injured, it soon regains what it has lost, with added beauty of the new growth. 


\section{CHAPTER XXVI.}

\section{PERENNIALS AND BULBS.}

359. The Perennial Beds. - The bed for perennials may be located in front, as shown in Fig. 83, and on quite large front lawns room can also be given for the bulb-bed for early spring effect, to be followed later in the season by canna or German aster.

The flower-lover will also have a perennial bed in the background, where tall, coarse growers, such as golden glow, perennial phlox, and even hollyhock, can be planted in the rear, with lower growers in front. Only a few of the most desirable perennials and bulbous-rooted will be noted in this connection.

360. The Herbaceous Peonia.-The select modern varieties of the Albiflora type stand well at the head of the perennial list in beauty of foliage and flower, bardiness and freedom from insects and fungous diseases. They also thrive on varied soils and in nearly every part of the Union.

For massing, some of the best Chinese varieties are very showy for a long period.

The tree peonia has a woody stem with delicately shaded flowers more or less doubled. Its final height is from three to four feet, and it is much used on shrubby borders. It is popular in the East and South, but does not prove hardy west of the lakes. 
361. Perennial Phlox.-In a rich, well-kept perennial bed this is one of the grandest late summer and autumn flowers. It follows the roses and gives a succession of bloom until late in autumn. It is now obtainable in almost every shade of color. After flowering two or three years the stools should be divided.

362. The Double Hollyhock.-This showy plant may often be used for a background of a bed or against a background of shrubs or dwarf evergreens. It ordinarily flowers the second year and then dies. But if the fleshy roots are divided after flowering and replanted they will flower again the next season. By annual division it practically becomes a perennial.

363. Gas-plant (Dictamnus fraxinella).-A very hardy perennial with large terminal racemes of either pink or white flowers. It has tropical-looking foliage, and is a handsome plant when not in bloom. The slight explosion on warm evenings when a lighted match is held close to the flowers gives rise to the name of "gas-plant."

364. The Hardy Lilies. - These should have a place in every well-kept home place. They do best in a dry soil, naturally underdrained or tiled. The bulbs should be planted four inches deep as early in the fall as they can be obtained. Where the bulbs are at hand they should be divided or separated as soon as the flower-stalks are withered, about once in three years. The best hardy varieties are the Gold-banded ( $L$. auratum), the Lance-leaved ( $L$. speciosum), Garden Easter lily (L. candidum), 'Turk's-cap lily (L. superbum), and the Bateman lily (L. Batemannia). At the West the most valuable are the varieties of Lilium speciosum, on account of their superior hardiness of bulb. For lily propagation by division see section (68).

365. Golden Glow (Rudbeckia laciniata $f$. pl.). -This is not an ornamental plant, but the double yellow flowers 
are developed profusely during late summer and autumn. It makes the finest show when it has a background of taller shrubs or elimbing vines.

366. Japan Iris. - This species of iris has very large flowers that range from pure white through all the shades of pink, red, and purple, with many combinations. It thrives best on rich soil with summer mulching to conserve moisture. The German iris is also desirable, and it thrives on soils too dry for the Japan species.

367. Oriental Poppy.-All the varieties of the perennial poppy (Papaver orientale) are hardy and very showy when in bloom, as the flowers are very large and brilliant scarlet in color.

368. Japan Spiræa (Astilbe Japonica).-A hardy perennial, producing fine feathery panicles of pure white flowers in June. It needs dividing and replanting once in three or four years.

369. Hardy Feverfew (Pyrethrum). - We now have many beautiful varieties of Feverfew with double flowers and a wide range of colors. They flower in June, but if the old flowering stems are cut away they usually flower again in autumn. The roots at the West must have root protection in winter.

370. Moss Pink (Phlox subulata).-This blooms very early and so abundantly that its pink-and-white flowers can be scen near the ground from afar. In the prairie States it succeeds in half-shady spots better than any showy plant tested by the writer.

371. Plume Poppy (Bocconia cordata). - This vigorous, hardy Oriental plant has large tropical-looking leaves, and the flowers are borne in large feathery panicles raised above the fine foliage. It is most too tall for a small lawn, and it is too vigorous and obtrusive to go in a pereunial bed collection. Its place is where bold effects are 
desirable, to be viewed from a distance. As a background for borders it is also an acquisition. It spreads some by suckering. But if the superfluous suckers are taken out each spring there is no extension until towards autumn. It is hardy, but its fleshy roots are killed in nearly snowless winters at the West if not protected by leaf or other mulching.

372. Lily-of-the-Valley.-This beautiful little flowering plant will ever be popular and pleasing. In all parts of our country, with its bright summer sun, it loves the shade. A bed of it where it only gets the morning and evening sun will soon extend its borders. It needs occasional thinning and a dressing of fine manure each fall.

373. Care of the Perennial Beds.-It pays to cover all perenuial beds with forest leaves or coarse manure in autumn, after clearing off the tops and litter. Even if some plants are hardy enough to winter safely without cover, they do better with it. The writer's experience favors the use of forest-tree leaves. They are nature's covering, and it is not well to rake them all off in spring. If a part of them are worked into the soil each spring, it will prove a benefit to the plants by adding humus to the soil. In addition, the application on the surface of a good coating of barnyard manure, well rotted, at least once in two years, will prove beneficial.

374. The Tulip Bed.-The grand modern tulips may also be classed with the hardy outdoor plants, as with slight leafy protection the bulbs live over winter in our most trying climates. In starting a bed order all early or all late flowering varieties. In $n 0$ case mix the early and late sorts in the same bed. Plant at the North in October, abont three inches deep and eight inches apart in all directions, but not in rows. Prior to severe freezing cover the bed with four inches of leaves, to be raked off in early spring. 
When the bed is through blooming and the stems begin to wither, take up and dry the bulbs under cover. When dry cut off the stems, and keep under cover dry until time for replanting in the fall. After the bed is cleared it is planted with canna or German aster for late summer and autumn blooming.

375. Less Hardy Holland Bulbs.-The hyacinth, narcissus, and crocus bulbs are also planted in the fall in beds in the States east of the lakes and in the South. In the Western States, on dry soil and with leaf protection in winter, they are also grown, but not with the simple care required by the tulip, especially after the first crop of bloom from the imported bulbs. Indeed, in the South the best results seem to come from the best grades of imported bulbs. But when the bulbs are selected and, after drying, are rolled up in p:pər, or mingled with dry sand and kept in a dry place, they do fairly well for replanting in the fall. The hyacinth and narcissus are planted some deeper than the tulip, but the crocus is not planted more than one inch deep after firming the soil.

376. The Canna.-By crossing and selection the florists have made remarkable advances with the canna within recent years, in shortening the growth and improving the flowers in size and beauty. Some of the French, Italian, and Crozy varieties of the present are a wonderful advance on the "Indian shot" of a few years ago. Like the tulip, after a start of the best varieties has been secured, they may be retained with moderate care for many years. On large lawns quite extended circular beds, with castor-bean plants in the centre and an edging of upright vinca, give a fine effect. Against a backgromnd of green the richly colored flowers show well. They are also used for centrepieces for flower-beds, and also in snall groups on borders and in shrubbery group borders. As the flowers begin to 
fade they should be clipped, to prevent the development of seed, which is not favorable for continued blooming. In the fall, when the tops are withered by the first frosts, but prior to a freeze that will kill the crowns of the root-stalks, dig the roots and dry them partially, when they can be kept on a shelf in a furnace-heated cellar, not too close to the heater. We have kept the root-stalks in entire hills on the cellar-bottom in a furnace-dried cellar-room, but they are apt to start growth in such position if not divided and potted by the first of February. 'The dividing is very easy, as the root-stalks are separated almost as distinctly as the tubers of the common potato. (See Fig. 32.)

377. The Gladiolus.-Among the summer-flowering bulbs the most showy and popular are the modern varieties of the gladiolus, and they are about as easy to grow and manage as the potato or onion. The bulbs can be kept dry in a box as easily as onions. For continuous effect the bulbs should be planted from early in spring to the first of June. The gorgeous flowers are hardly equalled for the parlor rase and are peculiarly durable. If not in a sheltered position, the flower-stems need supporting by small stakes.

378. The Dahlia.-This is another modern derelopment from a single-flowered Mexican species. Indeed, the development of the new decorative types has come about in our day. The newer types are less rounded than the old forms, and show the loose, free, chrysanthemum style of flower. In the dry, warm, summer air of the prairie States these newer forms are at home, and, indeed, they do well over a large part of the Union. In rich, warm soil in a sheltered position the dahlia gives little trouble, and does not need staking. In autumn at the West the first freeze not only kills the top, but often the buds at the crowns of the tubers. To prevent this it is best to mulch the surface of the bed late in the season. The tubers can be stored dry 
in a closet of the house where sweet potatoes can be kept. They can also be kept well in a furnace-heated cellar on shelves, singly, as when closely packed they are liable to mould. If they dry too much they should be removed to a more distant part of the cellar, keeping in mind the fact that it freezes when a potato would not be harmed, and that the dampness of a common cellar is almost certain to start monld and rotting.

379. Elephant's Ear (Caladium Esculentum). - This tropical plant with immense leaves is often used with canna in tropical beds with good effect. It is really not a Caladium, but the Colocasia, from which the " poi" is made, so much esteemed in Hawaii. The immense fleshy roots are also used for food preparations in Japan and the Pacific tropics quite generally. The great tubers are planted whole usually, and in the warm, dry air of the prairie States they seem to thrire as well as in their Pacific home. But when started early in pots the large tubers are divided into a number of sections, each of which makes a strong plant by the time it will do to plant outside, about the first of June at the North.

380. Sweet Pea.-This beautiful and fragrant flower is too well known for description. Its chief value is for cut flowers, as the plant and its supports are by no means ornamental. Its place is in the regetable garden where it can receive horse culture in rows the same as the garden peas. Planted the usual depth of garden peas, and supported by woven wire four feet in width on stakes, it gives a profusion of flowers for the living-room vases well through the season until after very severe frosts.

381. The Castor-bean.--In about all parts of the Union the castor-bean (Ricinus communis) is used in parks and in tropical beds on lawus. Its broad-lobed leaves, showy panicles of flowers, and its after-fruit pods are especially 
pleasing, particularly so when planted in connection with canna and caladium. In our climate it is an annual, ripening its seeds where the early varieties of corn will mature. Yet if seeds grown with us are planted in subtropical regions it makes a tree thirty to forty feet high, and in Cuba the writer has seen trees two feet in diameter of stem. 


\section{CHAPTER XXVII.}

THE VEGETABLE AND SMALL-FRUIT GARDEN.

382. Its Location, Shape, and Shelter.-The site chosen for the house and its surroundings largely determines the position of the regetable and small-fruit garden. In Fig. 83 the garden is north of the house, but this may vary with the frontage to the road and the character of the land and its slope. The garden soil should not be stiff clay, nor with too great a per cent of sand. But where possible soil that will work well should be selected, with porous subsoil that will permit the ascent of moisture from below (96). But if Nature has not provided the desired soil conditions it may often be improved by tiling and manuring. When possible, the slope should be to the south or southeast. On even a slight southerly slope, with shelter at the north, the soil can be worked earlier in the spring, and the growth will be more rapid than on even a very slight northern inclination. If the soil is a trifle sandy, is well manured, and has the needed slope and shelter on the north, the conditions will favor early crops of vegetables, including such subtropical ones as tomatoes, egg-plant, beans, corn, and melons. If in addition an irrigating reservoir (401) is made on the north side to provide water in time of need, the late crops will be farored, and sometimes, in the humid States, the early ones. A retentive clay loam will not prove so easy to work as the sandy loam, 
but it will stand drought better, and will soon be much improved by repeated application of well composted manure. The form of an oblong paralielogram is adopted for the ordinary farm or suburban garden to permit longer rows for horse enlture. Even in ordinary village lots, where a family horse is kept, it pays richly to use the onehorse cultivator in the garden.

In Fig. 83 the shelter on the north is given by the orehard. Where this is not possible a near-by shelter can be provided to protect from low wind-sweep. Market-gardeners often erect tight board fences to take the place of evergreens or trees until the latter can be grown. Garden vegetables, strawberries, and raspberries protected from the northerly winds of the early part of the season will not only make quicker and healthier growth on account of lessened evaporation and more heat, but they will be less troubled by mildew and other fungous troubles.

It must be kept in mind in home development that the properly managed kitchen-garden is t'le most profitable part of the farm or the suburban-residence lots. It will soon show the superiority of home-grown vegetables and small fruits over the stale products of the market, and that the free use of garden products will do more towards preserving the health of the family than the specifics of the drug-store or the visits of the doctor.

383. Rotation of Crops. - The most satisfactory and profitable gardening on a small or large scale requires rotation of crops. The strawberry rows should be moved at the end of two years (258) to fresh soil; the rows in sweet peas, garden peas, and beans should b3 aunually rotated with the sweet coru and potatoes; and indeed all crops should be put ou fresh soil each year, except asparagus and small fruits.

There are other reasons than mere vigor of growth for a 
succession of garden crops. As instances, onions and turnips if grown two years or more on the same soil are subject to insect injury, and the potato, beet, onion, melon, and sweet corn are more liable to scab, rust, smut, and other fungous troubles than they are when systematically rotated-annually.

Some of our methodic farmers include a crop of cow-peas, field peas, or other legumes in the system of rotation as a part of the garden management to give fresh soil well stocked with humus and nitrogen for melons, squashes, and potatoes. With this plan and the growing of garden peas, sweet peas, and beans the whole surface can be rotated with nitrogenproducing crops at least once in three years.

384. Fall Plowing. - There are many advantages in clearing off and plowing the vegetable-garden in autumn in all parts of the Union, but specially in the prairie States. The fining of the soil by winter frosts is a great gain in the North, and the action of the frost seems to be fatal to the destructive cutworms when rolled by the plow from their winter quarters. In the prairie States the different cutworms are often so unmerous on ground not plowed in the fall that it is difficult to save a tomato, strawberry, or other plant set out in the spring. But on fall plowing we rarely find traces of their mischief.

With a light surface cultivation prior to planting the moisture is retained below while the surface is mellow and in fine condition for seed covering or transplanting. Even where the soil is quite heary and inclined to be lumpy when spring plowed, the exposure of fall plowing to the frosts, rains, and snow melting of winter fines it for spring culture, and the particles are ready to deliver up their plantfood for the use of growing plants. If not fall plowed, the spring plowing shonld not be as deep and it shonld be performed as early as possible. Deep spring plowing leaves 
too great a depth with air-spaces not favorable for capillary attraction or presenting a proper seed-bed, nor for root extension. On rather heavy soil, with slope favorable for washing, subsoiling garden-ground is a decided gain in several ways. The pressure of the plow and the tread of the animal below the furrow so impacts the soil at the bottom of the usual plowing that in a few years the water from heavy rains cannot quickly penetrate it, giving rise to gullying and washing away of the finer particles of soil to lower levels. It not only holds the rainfall, and largely prevents washing, but it gives a depth of soil that favors carrying plants through our summer periods of drought. Subsoiling also gives best rosults if done in autumn. If done in spring, it leaves the soil loose and porous to too great a depth. Hence plents will suffer in a dry time far more than on ordinary plowing.

The deep extension of roots also favors the growth of plants in a dry time in the subsoiled garden. Subsoiling and deep plowing in the fall also benefit crops by letting air into the soil that tends to set free the food for plants by chemical action and fermentation.

385. Garden Culture.-Too many seem to conclude that the main purpose of cultivation is the destruction of weeds. But the fact must be recognized that the dust-blanket between rows, frequently stirred by hand or horse cultivator, conserves the soil moisture in the early part of the season and the precipitation of summer showers later in the season. In connection with deep fall plowing and subsoiling the surface culture not only conserves moisture, but it admits atmospheric air and warmth. In other words, it favors what King calls soil ventilation, and in addition it furnishes the needed conditions favorable for surface root action in taking up nitrates and liquid plantfood. 
THE VEGETABLE AND SMALL-FRTIT GARJEX. 379

these interstices next the atmosphere, we shall prevent the water passing off by evaporation."

When the plants are young, hand and horse cultivators are used that throw very little dirt sidewise. These, such as the Planet Junior, can be run very close to the plants (Fig. 102). The different classes of horse hoes are mainly for use later in the season, in corn, potatoes, and other coarser crops in rows wide enough apart for horse culture.

The hand cultivators-of which there are many good patterns-are mainly used in commercial gardens between rows of beets, lettuce, onions, bush-beans, and other small growers planted only sixteen to eighteen inches apart, as illustrated in Fig. 103, which shows the use of attach-

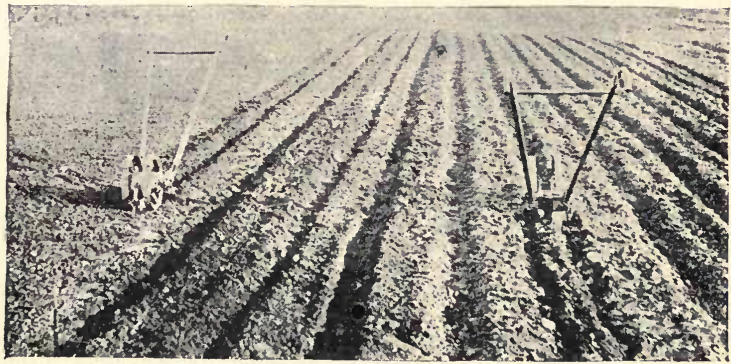

FIG. 103.-Hand cultivators with shovels to open and close furrows. (After Green.)

ment shovels for both opening a furrow between narrow rows and then, by going a second time over the rows, closing and leveling the furrow.

The hand cultivators are also used to great advantage in small gardens in city lots, where a horse cannot be used to advantage. But in farm and suburban-lot gardens, where horse culture can be used, they do not pay. 
Small-growing plants, such as beets, parsnips, onions, lettuce, and radish, are planted in double rows about sixteen inches apart. The horse cultivator is run outside of rows on each side, and between the rows the hand hoe is used, or a hand cultivator if one is owned. But the quantity of such vegetables grown for ordinary family use is too limited to justify its use, as the culture on one side of each row will give the needed conditions for growth if the soil is kept in gardening condition.

It is also usual to plant garden peas and sweet peas in double rows about the same distance apart, using the horse cultivator only on oxe side of each row, and using the hoe between.

386. Procuring Good Seed.-Good pure seed that has been properly grown and gathered from selected plants is specially needed by every one who owns a home or commercial garden. The only safe plan is not to buy of the groceries and dry-goods stores, but order from dealers who have a reputation to sustain. The writer for many years has purchased seeds for home use and for the college vegetable-garden from the old-established seed firms of the Eastern and Middle States, without in any case getting poor seed, low in vitality. As a rule, in gardens it does not pay to gather home seed, not even of tomatoes, beans, or corn, if different varieties are grown in the same garden or in the near vicinity. Commercial garden-seed of established dealers is grown where each variety or species develops the most perfect seed, by those who are comparatively isolated and who grow only one kind of tomato, cucumber, melon, or other garden crop of the same species or, in some cases, oi nearly related species. Every precaution is taken to keep commercial garden- and flowerseeds pure by the well-established houses (3). 
387. Plant Propagation and Transplanting.-The hotbed $(65)$ is a desirable accompaniment of every family garden except in small city places. Well-arranged permanent homesteads often have what is known as a permanent hot-bec. This has a sunken path in the centre with hotbeds on each side, about four feet above the path bottom. Sometimes the heat is given by extension of hot-water- or steam-pipes from the house. Some also use small hotwater heaters, such as are used in bath-rooms of private

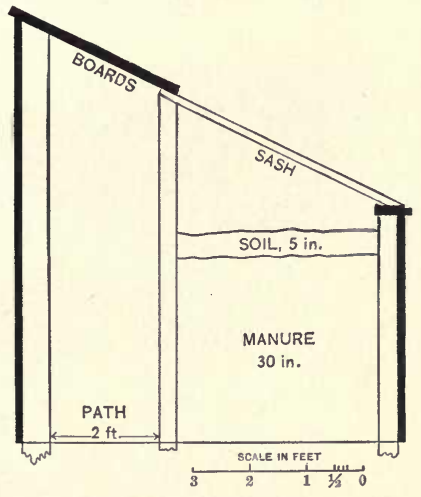

FIG. 104.-Permanent, lean-to hot-bed. (After Green.)

houses. Still others use manure, as in the common hot-bed (65). 'The advantage of such a structure is that the person in charge can go inside to do all the work of watering and caring for the plants and attending to ventilation.

Quite frequently the permanent hot-bed for home use is made as a lean-to on the south side of a building, as shown in Fig. 104. With steps leading down to the path and door opening inward, a bed twelve feet long, using four 
ordinary hot-bed sash, gives a handy, permanent, yet very cheap structure that will prove very useful for the starting of the tender vegetables and flowers. The hot-bed represented has the space below the soil filled with manure. The only change needed for hot-water or steam heating is putting in boards or slate to support the soil, which in the figure rests on the manure. The management is given in section (65) with manure heating.

In growing tomato, egg-plant, or other plants in hotbeds they should be transplanted in "flats," Fig. 105, or,

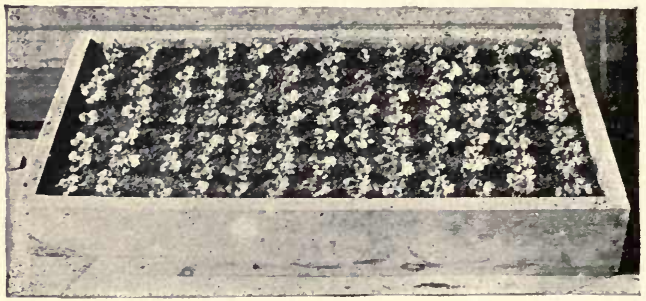

Fia. 105.-A "flat" planted with lettuce to be held in the coldframe for early family use. (After Green.)

better yet, in pots. A main element of success is a supply of stocky, well-rooted plants, and a potted plant with roots encased in a ball of earth can be transplanted safely at any time. But the most favorable time for all vegetable or flower transplanting is on cloudy days, or after four o'clock P.y. in clear weather, as after that time the air is not so dry and the plants have the benefit of the cool night to beconie established. The novice usually fails in properly firming the soil about the roots and crown so well that the plant cannot readily be pulled. The drier the soil the more firmly plants should be set. 
After planting the soil should be at once stirred on the surface, drawing some loose earth around the plant to lessen evaporation from the firmed soil below.

Where pots are not at hand, many amateur gardeners use fruit-cans, unsoldered and without bottoms, in their place. The tins are held together by a wire around them. In planting they are carried to the field in boxes, taking care to keep the dirt from falling out, and in setting the ball of earth is loosened by taking off the wire. With the wire replaced the tins are set around the plants to protect them from sun and wind.

A cold-frame, in addition to the hot-bed is a great convenience. In the cold-frame the plants set out in "flats" and in pots ean be kept to better advantage for hardening off, and the cold-frame is essential for such cold-blooded plants as cabbage, cauliflower, and lettuce until it will do to set them out in open air. In the South the cold-frame is used for starting all plants, as the heat from the sun passing through the glass warms the soil to such extent that ventilation is necessary. The cold-frame is also the proper place to hold flats of transplanted lettuce, as shown in Fig. 105. The cold-frame is identical with the hot-bed frame (65), with the exception of a pit beneath for the heating manure.

388. Manuring the Garden.-Few owners of private gardens have any conception of the large quantity of manure used to produce the great crops in the marketgardens. Henderson says: "It is a grave blunder to attempt to grow vegetable crops without the use of manures of the various kinds. I never yet saw soil of any kind that had borne a crop of vegetables that would produce as good a crop the next season without the use of manure, no matter how 'rich' the soil might be." Horsemanure is best for garden use, and it should be prepared 
at least six months in advance by turning and breaking up to prevent heating. Hogs will do this work if given an opportunity. The manure-pile with a continued supply of well-rotted manure is an essential part of satisfactory gardening. The pile may be made a kind of compost-heap where sods, rotten vegetables, and fruits, weeds, soapsuds, and even water are thrown; watering at times of turning the pile if the top appears to be dry.

The commercial manures extensively applied east of the Lakes and on the Western coast are not much used in the prairie States.

Aside from the application of well-rotted manure, the use of wood-ashes or one of the potash combinations of the trade seems to give the best results with a system of rotation (383) in which a clover or other legume sod is turned under once in two or three years to give the needed supply of nitrogen and the bacterial action that seems to enliven the soil in a way not fully understood. Slaughterhouse tankage is also useful in the prairie States, as it is rich in nitrogen and phosphoric acid, which are in available form to be taken up by plant-roots. In the West it is the cheapest form in which nitrogen and phosphoric acid can be obtained.

In private gardens, however, in all parts of the Union, stable manure properly composted, with occasional rotation of clover or cow-peas, will give the most satisfactory results on a small scale. But in addition, in the humid belt, it is always in order to use wood-ashes, kainite, or other form of potash, not too expensive, at least once in three years.

389. Preservation of Vegetables. - It is usual with most home owners to store vegetables in the cellar under the house. This plan has many objections, not the least of which are the smells, the possible effect on health from 
decay, and the well-established fact that the cellar air is not favorable for keeping any kind of vegetables in good condition. For amateur use no plan is superior to the dirt-covered cave for this purpose. In section 85 this is recommended for storing orchard-fruit root-grafts, and in section $13 \%$ the dirt-covered cave is recommended for keeping early and late winter apples. For the same reasons potatoes, turnips, beets, earrots, parsnips, salsify, and indeed about all vegetables except sweet potatoes will keep without wilting or spronting in the dirt-covered cave, kept cool by occasional brief opening when the air outside is colder than that in the cave.

Vegetables will keep as well in pits, but for home use it is not as easy at the North to get to them for family use as when in the cave. Cabbage is best kept outside for late use. The heads are set together on level soil with the root sticking up in a shallow trench, and then lightly covered with earth until the cold is severe at the North, when the earth is increased in depth to eight inches, and still later mulch is covered over the pit to prevent hard freezing. But if frozen and left until they thaw out under cover, they will rarely be injured. But for early winter use some heads can be kept in the cave by burying the roots in a box of sand.

390. Garden Insects. - With a methodic system of rotation of crops, fall plowing, and a general cleaning up prior to the plowing, but little trouble with garden insects will be experienced. In many cases insect-eggs are carried over on the stalks of plants. As instances, the cabbagelouse lays eggs on old cabbage-leaves and stalks left in the garden, and it is about the same with the cucumber-beetle, leaf-louse, parsley-worm, and squash-bug. The fall plowing also mainly destroys the cutworms in winter quarters, the root maggots, and wire-worms. 
391. Spraying Garden Plants.-The leaf-eating insects are mostly confined to the fruit-trees, small fruits, and shrubs. Hence in the garden the arsenical sprays (156) are mostly used for the destruction of the Colorado potatobeetle, the eabbage flea-beetle, and the striped cucumberbeetle. The kerosene emulsion (158) is used in the garden for the leaf-lice mainly. In lessening the work of the cabbage-louse, and indeed all the aphides, the cleaning up of the garden is a great help, as the eggs live over winter attached to the old leaves and stems if left on the ground. Chinch bugs, when not too numerous, can be headed off in the garden by spraying with kerosene emulsion applied to corn and crops they aitack. Keeping the headlands, corners, and fence sides clean is also a great help.

392. Miscellaneous Garden Insects. - The cabbage-worm can readily be eradicated by using the arsenical poisons (156), and extensive growers of cabbage use them without hesitation before the plants begin to head. But amateurs usually prefer to use less dangerous remedies. The most desirable and successful plan adopted by the writer has been to sprinkle the plants before heading with water that has stood over gas-tar in open exposure to the sun. This seems to act as a repellent, as the butterflies very rarely deposit eggs on the leaves scented with tar. If the worms are found in the heads, they can be killed by dusting with flour just at nightfall. This kills by closing the pores of the slimy worms.

The cabbage-plusia also develops worms from eggs deposited by a winged moth. The tar-water is a repellent also of this moth, and the flour mixed with one sixth its weight of pyrethrum powder will kill the worms if any are hatched from deposited eggs.

As stated, the cutworm is mostly destroyed by fall plowing. Yet enough may be left to cut off valuable 
transplanted plants. The writer's plan has been to wrap the crown of every plaut set out with horse-radish leaves. If a plant is eut above the leaf, it is readily observed and a hunt is made for the culprit. In most eases the plant will start from the wrapped portion when eut so high.

These brief notes on the common insects of the garden are only suggestive. The amateur desiring minute insect descriptions and habits of inseets of the garden should consult some one of the works on economic entomology.

393. Some Neglected Garden Crops.-Most all Ameriean landholders who attempt gardening for home use are aequainted with such common vegetables as sweet corn, potato, pea, cabbage, radish, lettuce, beans, etc., and know something about their planting and care. With the bints given in this chapter a detailed deseription of each, with modes and methods of planting and managing, would be superfluous in most eases, and the few who need such instruction can look it up in special works on gardening for profit. At this time mention will only be made of some vegetables which as yet are too rarely found in private gardens.

394. Asparagus.-This earliest, most healthful, and delicions regetable is rarely found in home gardens in well-kept rows, as grown by market-gardeners. Almost invariably the asparagus-patch is found in a sod-bound corner, where the crop is neither plentiful nor palatable.

No plant responds so promptly to manuring and such eulture in rows as is given to corn and potatoes. $\Lambda$ main essential, in addition to heavy manuring and early spring eulture, is to expose the rows to the open sunshine. In the shade, during the middle of the day, its growth with the best of care is by no means satisfactory. It likewise 
fails to do well on wet land, and on clay it is not as early as on sandy loam soils.

In starting rows it is usually best for the amateur to purchase one-year-old plants of nurserymen or dealers in seeds. Plant in spring, when the soil works well, in rows four feet apart, with the plants three feet apart in the rows. It is best to plant with the crowns of the roots two or three inches below the surface, but it is not best to fill up the channels until after the plants start. Where the plants are not readily obtainable, rows are often started by taking up the seedling plants that spring up in old beds. In July these are about six inches high and transplant about as safely as weeds. These will be well rooted by autumn and come forward about as rapidly as when one-yearsold plants are set in early spring.

In new sections, if plants are not available, they are easily grown from seed. The berries are crushed and mixed with sand (5) and buried outside for spring planting, or they can be planted in the fall half an inch deep in drills with a ridge of earth two inches deep drawn over the rows. In the spring the ridge is raked off, leaving a mellow seed-bed in which the plants will make rapid growth. If desirable they can be transplanted in July in the permanent rows, or they can be left for planting the next spring in a dormant condition.

As to after-care when the plants are dead in the fall, they may be mowed off and burned, and the surface should be treated with a coat of well-rotted manure. In the spring eultivate well the surface, without regard to the position of the plants, prior to the starting of the succulent shoots. It is also best, when the season of picking closes, to cultivate the whole surface. Some cutting can be done in private gardens the second year, but it is preferable to wait until the third season. 
In gathering the shoots for home use it is best to cut them at the surface of the ground. Market-gardeners usually cut the shoots with at least two inches of the white part that grew below the surface. But this lower part is usually tough and slightly bitter, hence for home use it is discarded. If manure is put on in the fall, it must be cultivated in before the shoots start in spring, or it will delay the starting of the shoots often for a period of ten days. Some prefer manuring at the close of the picking season, cultivating in at once.

The writer has not found any great difference in varieties. More depends on culture and mannring. Yet Conover's Colossal, Moore's, and Palmetto are slightly larger than the common variety that has become a weed in some sections.

395. Celery Growing. - This delicious and healthful vegetable is not grown in private gardens to any great extent. Many seem to entertain the opinion that it is a special crop that can only be raised on special soils, such as drained swamps by trenching. But it can be grown in any good garden soil with level culture. Henderson truly says: "Almost all private cultivators still think it necessary to dig out trenches from six to twelve inches deep, involving great labor and expense, and giving a very inferior crop to that planted on the level surface, in the manner practised by market-gardeners."

Celery is an autumn crop, and in our dry summer climate it is fortunate that the main demand is in late autumn and winter. It loves the cooler and moister air of the autumn months, and is usually planted as a second crop, following peas, early corn, and other early crops. The seed is sown in the open ground in early May on rich mellow ground, rather thinly, in rows eight to ten inches apart. At the West the seeds are merely pressed into the 
soil and the bed is covered with a mulching of prairie ha'y until they begin to germinate, when it is removed and the soil between the rows is raked and weeds kept down.

In cooler climates, like that of Long Island, the seeds will germinate when planted an inch deep without mulching, but eren there the soil is usually corered with burlap while the seed is sprouting, to conserve moisture and to keep the soil cooler. As growth progresses the tops are clipped or pinched back to develop stocky plants, and when small they are thinned so as not to crowd each other. Usually the plants are set out for cropping at the West about the middle of July for late fall and winter use, in moist soil six inches apart in the rows, which are usually laid out about four feet apart, where the crop is bleached in the field. But the dwarf kinds, merely bleached by slight mounding, are planted in rows three feet apart.

The first growth is inclined to spread out over the ground. To correct this habit, what is known as " handling" is practised. This is merely drawing up earth with the hands under the drooping stalks and pressing it firmly to them as a support. In after-hoeing, earth is drawn up until they are banked so as to hold the stalks upright. This handling and banking is all the bleaching given to the dwarf self-bleaching varieties, such as the White Plume.

For family use there is not much gain in planting the large-growing varieties that require bleaching by high banking with earth or boards. Such varieties as White Plume and Golden Dwarf give the least trouble and are not excelled in quality.

In storing for late use the plants can be packed close together in boxes, with the lower part of the stems and roots covered with moist sand. These boxes are best kept in a root-cave, but will do nearly as well in a cold, moist 
cellar. The temperature should be kept low, and for late use it should be left out as late as possible. The plants are not injured by ordinary antumn frosts, and with some straw covering they can usually be left out until the last of November in the prairie States.

396. Egg-plant.-This is supposed to be a native of South America, but its origin seems uncertain. It is used as a vegetable in all the tropical and subtropical regions of the world, and is grown in all climates where dent corn will ripen, and the New York Purple is grown in the North where the eight-rowed early corns do not always mature. But to reach proper size of fruit at the North it must be started early in hot-bed, and by potting the plants should nearly reach the stage of blossoming prior to

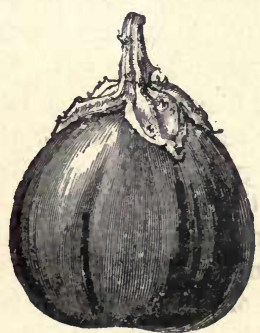

Fra. 106.-New York improved egg-plant.

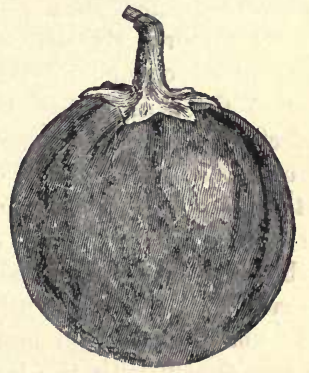

Fra. 107. - Black Pekin eggplant.

setting out the first of June, when the ground becomes warm. The writer has set out plants in six-inch pots on which fruit had already set.' In private gardens for home use it may be set in a warm corner in beds rather than rows at the North.

The plants in rich soil may be planted two feet each 
way. The gain in bedding is that the cross-fertilization of the flowers favors the setting of the fruits and increases the size. If set in single rows, it often happens that the blossoms are not properly pollinated, and it seems incapable of self-pollination. If not pollinated, the fruits will develop partially, but never attain proper size, and very many of the blossoms will not develop fruits.

When of full size the fruits are as large as small squashes (Figs. 106 and 107), but they can be used to about as good advantage when half grown. It is a standard vegetable over a large portion of Europe and Asia and in the South, and as shipped in over the Northern States. But outside of cities it is not as yet commonly grown in gardens.

397. The Lima Bean. - The Lima, pole, and dwarf beans have properly been called the king of the table beans in all countries. But over the Northern States, even at the West, where the Lima beans succeed most perfectly, the dried commercial Limas grown at Santa - Barbara, California, and at other points, are mainly used. But those who enjoy the home-grown beans fresh from the garden will fully agree with the writer that it is one of the most delicious vegetables of the garden and one of the most healthful of the nitrogenous foods.

As not a very large number of hills will supply an average family with the large Lima variety, it pays to plant the beans in pieces of sods with the eye downward, starting them in the hot-bed quite late. By transplanting the sods with beans attached when the ground gets warm, the crop will be advanced fully two weeks. In place of poles we have used woven wire five feet wide, supported by stakes along the line of row. The beans spread out on this support, and if the wire is grounded at the ends it appears to increase the thrift and yield of the plants. At 
the close of the season the wire is rolled up and kept under cover until wanted the next season. There is much modern support to the belief that grounding wire trellis at the ends benefits vines of all kinds by supplying an electrical current.

The bush Lima varieties are smaller in size, but such varieties as Henderson's Dwarf and Burpee's Dwarf are nearly as good in quality as the large white Lima, and they do not require poling.

398. The Melons.-These are included among desirable fruits (222), and are here noted as a rare crop in home gardens. If started on sods in the hot-bed, the crop will be advanced fully two weeks. A main drawback to growing them in the home garden, especially in the suburbs of our cities, is the pilfering by melon-loving boys. But where the surroundings are favorable the home-grown melons are specially desirable, as when brought from a distance they are usually picked when not fully ripe. 


\section{CHAPTER XXVIII.}

\section{IRRIGATION.}

399. Irrigation in the Humid States.-In the truly arid States the work of irrigating crops and fruits is imperatively required. Hence the land brought under cultivation depends on the amount of water arailable from streams, wells, reservoirs, and other possible sources, and crops often suffer in the critical period when the usnal supply falls short. In such extended districts the need of water is fully understood, and there is little need of arguments in faror of irrigation.

The present purpose is to urge the great promise of utilizing, at least in part, the immense volume of water that runs to the sea in the so-called humid States, where the midsummer rainfall is too often scanty for full crops of regetables, farm crops, and fruits.

In the arid or nearly arid States and Territories a vast amount of water is required to carry crops through the season, as the period is long, the evaporation excessive on account of the dry air, the loss by seepage in open ditch is great, and quite generally the subsoil is sandy, involving great loss of water in running it across the orchard, small fruit plantation, or field. But in the humid States the rainfall of spring and early summer is usually abundant and only a brief period of watering is required as a rule. 
400. Watering the Orchard Fruits.-A large part of the watering in the arid States is from mountain streams or from reservoirs filled from such streams or from melted snows. But in the States east of the mountains the streams usually run in deep channels and orchards are usually on much higher land. In the prairie States they could rarely be used for direct irrigation, as the channels are low and they usually run dry except in wet seasons in August, when most needed. But in the more uneven or hilly sections of the States east of the lakes a combination of neighbors will often permit taking the water from some point higher up on the stream into irrigating channels for watering fruits on a lower level. But the rule that water must be pumped from streams, stream-beds, or wells on lower levels to reservoirs on the highest side of the orchard or small fruit plantation has few exceptions.

Perhaps no plan for general uses is more practical and profitable than the one extensively used in east Europe and over a large part of central Asia, where they usually have rains in the early part of the season. During the spring months water is pumped by windmills from a lower level to reservoirs on the highest side of the fruit plantations. These reservoirs are excavated in the soil and the bottom and sides are puddled with clay as now practised in Kansas and Nebraska. When made an iron pipe is laid from the bottom to a distributing pipe across the high side of the plantations, with a hydrant for every two rows of trees or for a space of about forty feet for small fruits and gardens. The water is led by a hose to wooden troughs made $\mathrm{V}$-shaped for running it over the ground. In orchard-watering some work is done in advance. The earth is drawn away to a depth of four or five inches around the crown of every tree, forming a basin six to eight feet in diameter, with the loose dirt compacted at 
the edges. About four inches of sand is covered over the bottom of the carity to prevent baking when water is applied and to lessen the evaporation. The V-shaped troughs are made long enough to reach from one tree to another and are set one at a time on small iron supports made for the purpose. The water runs into a cavity until it is filled, when another is added to reach the next tree. Enough of the troughs are needed for one row. In watering the next row the troughs are brought over one at a time as wanted. In the East the spaces between the excavations are covered with some leguminous cover-crop, usually the sandy vetch. In a very dry time the water is permitted to run after the excavations are filled for a few minutes at each tree. After the inexpensive plant is established, the cost of watering each tree twice during the season-when the fruit is less than half grown and again when two thirds grown-was estimated by a number of orchardists at eight cents. In the arid States this kind of watering would do little good. But to bridge over a dry period in the humid States, it secures a good crop of perfect fruit, when the unwatered trees prove nearly a failure. Even in Florida, with an average rainfall of over sixty inches, irrigation has been largely practised in orange orchards, to bridge over the dry periods and also to save the garden crops and tobacco. In this case the water is pumped from wells by gasoline pumps into large cypress tanks, from which it is distributed over the comparatively level surface by iron pipes to which hose is attached.

In Illinois, Wisconsin, Iowa, and other drift-soil States of the West, the subsoil favors the economical use of water with after culture to prevent the soil from baking.

Another consideration in the prairie States, and indeed east to the Atlantic and south to the Gulf, is that no dis- 
puted rights are to be considered or feared, such as continually harass users of water in the arid States.

As an illustration of the possibilities of reservoir irrigation, the plant of Mueller Brothers, near St. Joseph, Missouri, may be mentioned. The water is pumped from a well on a lower level by a gasoline-engine to a large reservoir on the bluff, nearly one hundred feet above the land to be irrigated. This gives a force to the water convenient for washing vegetables, and certain home uses at the house and barn, whence it is carried to quite an extensive vegetable garden and small fruit plantations. During the dry season of 1901 grocers and hotel-keepers sought the Mueller vegetables and fruits at advanced prices.

The cost of running the pump at this quite extensive plant averages about thirty-five cents per day, but the water is elevated to an unusual height. An elevation of the bottom of the reservoir of ten feet above the land to be irrigated answers the purpose about as well, as the water will run freely to all parts below that level. In the arid States the surfaces to be watered are levelled often at great expense, but this is usually quite impracticable in the prairie States or east or south of the lakes, and it is not needed, as the water is taken from point to point in wooden troughs or in iron pipes and is distributed by hose.

401. Reservoirs with Puddled Bottoms.-Many conclude that wooden or iron reservoirs, or those that are walled and cemented, can alone be depended upon. But over the world the fact has been long known that on quite firm soil the banks and bottom, if well puddled, will hold water quite as well as the cemented reservoirs and give less trouble, as the frosts of winter do not injure the earth banks, but often do much damage to cement-work. In Kansas and Nebraska they have had the most favorable 
experience with reservoirs excavated even in rather light soils.

Mr. A. S. Perry, of Frisco, Oklahoma, after long experience says: "These ponds are made to hold like jugsexcept from evaporation-by puddling one hour a day for two weeks. This is done by using a drag to stir the mud made by some water pumped in. Stirring the mud keeps it muddy and the sediment stops the pores of the soil, which soon becomes impervious to water and seepage. This will work on any clay soil or on a clay loam with some sand."

402. Artesian-well Irrigation.-In South Dakota, parts of Iowa, and in many other parts of the humid States, artesian wells lifting water to the surface in great volume are quite common. They are utilized for irrigation of fruits and crops, but the gain is not as great as is usually suspected. It is not often that the position of the well is favorable for irrigating as large an area as the volume of water would indicate. If water is raised a few feet to a reservoir on the highest ground in the near vicinity it can be utilized at time of greatest need over a large area by troughs or pipes. But it seldom happens that an artesian well can be made to run the water into large reservoirs high enough to be used over as much surface as the water will cover in a humid State. But in the relatively few localities where artesian wells can be obtained at the highest points they will prove very valuable if the surplus water can be stored in late winter and spring for use in the dry season.

In relatively flat countries with some undulation artesian water is distributed to good advantage when the pressure of water will lift it to a height of fifteen feet or more. In the Libyan desert of north Africa are now found hundreds of such wells furnishing water for im- 
mense plantations of date-palms and other tropical fruits. But where water eomes within twenty feet of the surface and the supply is plentiful, the modern gasoline pumps raise and earry the water to elevated reservoirs at a cost so moderate that it is trifling when compared with the usual cost of water in the arid districts. Indeed, the reservoir system has been the main one used in ancient and modern times. In the arid regions the water of the wet season is stored in immense ponds or lakes for use in the dry period, usually in mountains, or by damming mountain streams. In the dry season this stored water is used on large tracts during a long period. In the humid States the dry period is short. Hence our friends from the arid States need not make sport of the smaller ponds filled by pumping from stream-beds or wells.

403. Sub-irrigation.-The best practical illustration of what is known as sub-irrigation is found in the raisinproducing district near Fresno, California. No water is applied to the surface. Six feet below the surface is found a nearly water-tight clay deposit with a porous soil above. The water runs in ditehes down to the clay and seeps under the vineyard, rising to the roots by capillary attraetion.

Another kind of sub-irrigation is found in California, on the bottom lands, on which sugar-beets are grown, in China, and at other points. These lands are in the stream valleys and are sub-irrigated by the seepage water from orange and other irrigation on the higher elevations. The Chinese gardeners also seek such land for vegetablegrowing in California, near Phœnix, Arizona, in Colorado, and at other points where the seepage water from higher land sub-irrigates lower-lying land without making swamps or ponds, which often happens.

In Wiseonsin, near Sparta, and at other points, sandy 
lands with clay subsoil are sub-irrigated for cranberrygrowing. Ditches surround the planted tracts, in which water is introduced from running streams or from reservoirs.

Close observation will disclose hundreds and even thousands of these naturally sub-irrigated tracts in about every State of the Union which have not as yet been utilized for gardening or fruit-growing.

404. Green-house Sub-irrigation.-This lias become far more general than outdoor sub-irrigation. The trenches are made water-tight by spreading cement over the slate bottoms and sides. In the bottom drain-tile are laid in which water circulates and slowly escapes at the joints and through the pores of the tiles. Some lay the tiles two feet apart and others much prefer laying them quite close together. Where the tiles do not fit well some cement is used to tighten the joints to prevent too much water escaping at one point. The water is raised by capillary attraction through the soil covering over the tiles. The benefits of the system arise from the regularity of moisture supply, and the surface does not harden or bake as in surfacewatering.

Practical growers often start plants in shallow boxes and secure irrigation from below by setting the boxes in a shallow pan or vat with water in the bottom until moisture appears on the surface.

405. Surface Culture Needed.-In all kinds of watering, whether on the surface or from below, the surface must be stirred soon after the wetting to prevent baking and to conserve the moisture. If this is neglected with surfacewatering the outcome will prove doubtful as to benefit.

Thorongh culture and the exclusion of weeds tends to hold the moisture in the soil. All systematic gardeners cultivate soon after rains, but the need of it after surface 
irrigation is much greater, as artificial watering seems to harden the surface soil and the process is local, with dry air around it, favoring rapid evaporation from impacted soils.

With sub-irrigation the need of culture or stirring the surface soil is quite as essential, as it favors the ascent of moisture from below and the admission of air from above, both in outdoor and indoor work.

406. Remarkable Results of Irrigation.-The story of the transformation of desert land into producing fields giving several crops of alfalfa in a season, and other crops in proportion, is often told by visitors to the arid States. But as yet little has been said or written about the increased yield of fruits and crops, as the result of watering in the humid States, mainly for the reason that little has yet been done. But at St. Joseph, Missouri (400), at the insane asylum, Joliet, Illinois, and here and there in sevcral States, the increased crops as a result of watering have more than equalled the results in the arid States and at much less labor and cost, as the period when water is needed is short. In Wisconsin, Professor King, after trial and much observation, has stated: "The value of a crop, such as the strawberry, in a season when crops generally are injured by drought, may pay all the expenses of the original cost of the irrigation plant."

Even in New Jersey, with moister air and more rainfall than in the States west of the lakes, the experiment station reports for 1898 and 1899 an average gain of $163 \%$ quarts per acre on the irrigated plots of blackberries over those that are not watered, and the size and selling value was much increased. The Bulletin record reads:

"Plot No. 1, 1898.-Farly Harvest, 1001; J. Wilson, Jr., 2256; Erie, 39; Agawam, 1280; Taylor, 29\%0; Eldorado, 3395. 
“Plot No. 2, 1898. - Early Harvest, 295; Wilson, Jr., 1618; Erie, 2164; Agawam, 318; Taylor, 2535; Elaorado, 2330.

"Plot No. 1, 1899.—Early Harvest, 913; Wilson, Jr., 1875; Erie, 809; Agawam, 2106; Taylor, 1092; Eldorado, 2408.

"Plot No. 2, 1899. -Early Harvest, 1833; Wilson, Jr., 1735 ; Erie, 2535; Agawam, 1618; Taylor, 1209; Eldorado, 4109."

The above figures represent the gain in quarts per acre of the plots irrigated over those watered by nature. In Plot No. 1 it will be noted that the gain of the Eldorado in 1898 was 3395 and in Plot No. 2 it reached 2330. In 1899 the gain on Plot No. 1 of the Eldorado was 2408 and on Plot No. 2 it reached the surprising gain of 4109 quarts over and above the Eldorado plot without irrigation. 


\section{INDEX.}

PAGE

Actinidia arguta for porches......................... 365

Air-drainage in fruit-growing..................... $37-94$

Almond-its history and culture.................... 295

hardy varieties of the $\ldots \ldots \ldots \ldots \ldots \ldots \ldots \ldots \ldots . \ldots 296$

Apple-root-grafting the......................... 78

top-grafting........................... 85

distance apart in planting ..................... 107

marketing summer ...................... 122

autumn and winter varieties.................... 123

storage of winter.......................... 124

origin of the cultivated....................... 159

the native crab............................ 162

dwarf trees of the............................ 164

propagation of the.......................78-164

varied season of given varieties.................. 165

ornamental species......................... 338

Apricot-its pruning............................ 134

history of the............................ 184

Arsenate of lime for spraying....................... 146

Arbor-vitæ.................................. 347

Asparagus in vegetable garden...................... 387

Banana-its history............................... 213

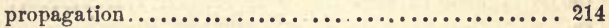

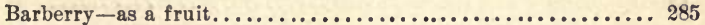

as an ornamental bush...................... 353

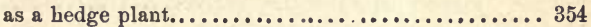


Bark-grafting................................ 91

Birch for ornamental planting....................... 332

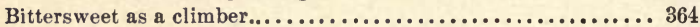

Black walnut................................. 299

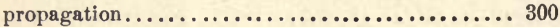

Blackberry-American species...................... 259

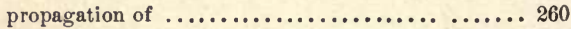

Bordeaux mixture for spraying..................... 153

Bottom heat for seeds and cuttings.................. 59,60

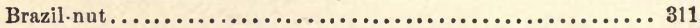

Budding-purposes of........................... 66

some native stocks used................... 67

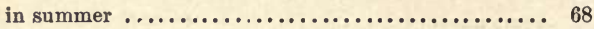

how the work is done...................... 70

the season the seeds are planted................ 71

in June............................... 72

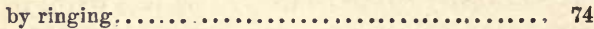

Buds-leaf and fruit............................. 24

adventitious and lateral........................ 27

need of, in plant division...................... 62

essential in some tubers....................... 63

how to cut and insert $\ldots \ldots \ldots \ldots \ldots \ldots \ldots \ldots \ldots \ldots, 70$

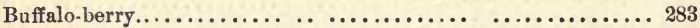

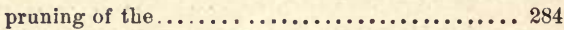

as an ornamental bush................... 357

Bulbs for bedding............................ 370

Bush honeysuckle... ........................... 355

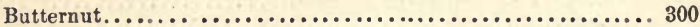

Caladium esculentum. ......................... 372

Canna for bedding ................................ 370

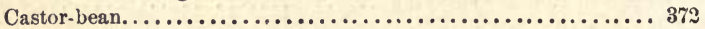

Caterpillars in orchard.......................... 121

Cave-dirt-covered, for storing grafts................ 79

for storing fruits........................... 124

Celery in home gardens........................... 389

Cherry-history and classes of the................... 175 modes of propagation ...................... 178 market supply of the....................... 178 distance apart for planting.................... 108 
PAGE

Cherry-stocks for............................ 88

top-grafting the....................... 86

Chestnut..................................... 303

propagation of the....................... 304

Cleft-grafting............................. 84

imperfect union of $\ldots \ldots \ldots \ldots \ldots \ldots \ldots \ldots \ldots . \ldots \ldots$

Clematis-Jackman's ............................ 365

Cocoanut.................................. 308

varieties and propagation.................. 310

Controlling heat and moisture...................... 58

Cordon-training of fruit trees ....................... 131

Cover-crops-for orchards........................ 116

for arresting blight................... 118

do they dry the soil ?.................... 119

Cranberry, growing of the........................ 291

the tree............................ 290

Crossing-of fruit blossoms........................ 36-100

advance planning of the work............... 100

the parents should be nearly allied.............. 101

effects of violent....................... 102

gathering pollen for ..................... 103

when to apply pollen ..................... 104

speedy testing of the seedlings............... 105

Crown-grafting............................... 80

Cultivation after planting trees .................... 116

Curculio-spraying for the....................... 147

Currant-propagation of the ..................... 273

manuring and mulching.................. 274

pruning and training....................... 274

the black species of....................... 275

the golden $\ldots \ldots \ldots \ldots \ldots \ldots \ldots \ldots \ldots \ldots \ldots \ldots \ldots \ldots \ldots 276$

Cuttings - of the roots........................... 44

ripe wood............................ 53

how to prepare. . . .................. 53

fall planting of. $\ldots \ldots \ldots \ldots \ldots \ldots \ldots \ldots \ldots \ldots \ldots \ldots \ldots, 55$

spring planting..................... 56

those kept in the cellar.................... 57

immature growth....................... 57

need of bottom heat.................... 59

green wond .......................... 61 
Dahlia........................................ 371

Date-history of the ............................ 210 propagation and management................... 212

possible improvement ........................ 213

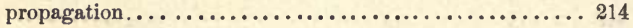

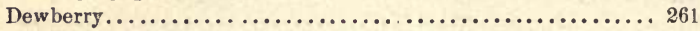

Diervilla rosea for ornamental use................... 351

Division of perennials and tubers $\ldots \ldots \ldots \ldots \ldots \ldots \ldots \ldots \ldots, 63$

of root-stalks............................ 63

of bulbs............................... 65

Dogwood-the red-twigged........................ 362

Dwarf apple- and pear-trees........................ 131

Egg-plant in home garden......................... 391

Elderberry, the golden ............................. 361

Elephant's ear.................................. 379

Elm-white................................... 329

effusa................................. 330

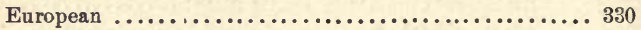

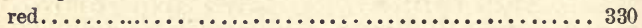

English walnut................................ 297

propagation of the................... 298

hardy varieties..................... 299

Evergreens-transplanting of .. ................... 115 for ornamental planting.................. 343

spruce ..................................... 343

firs............................. 345

pines............................... 346

hemlock........................... 347

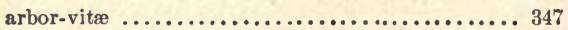

broad-leaved species.................... 357

Feverfew................................... 368

Fig-history of the.., .......................... 207

its possible improvement..................... 208

growing at the North...................... 209

propagation of the........................... 210

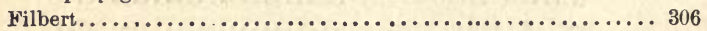

pruning of the... .............................. 307 
PAGE

Firs for ornamental planting......................... 345

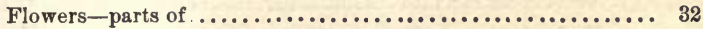

inferior and superior....................... 33

perfect and imperfect...................... 35

cross-pollination of ...................... 35

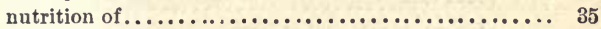

monœcious and diœcious................... 34

possible outcome of ....................... 36

retarding development of.................... 96

Forcing-pits................................. 59,60

Fruit buds and spurs.............................24

Fruits-maturation of ......................... 37

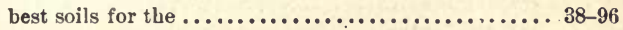

as modified by climate....................... 38-99

as affected by air-drainage.................... 37

on own roots............................. 41

on north and south slopes.................... 94

needed shelter belts for...................... 95

retarding the flowering period of $\ldots \ldots \ldots \ldots \ldots \ldots \ldots, 96$

crossing of the........................... 100

marketing summer... .................... 122

picking winter varieties....................... 124

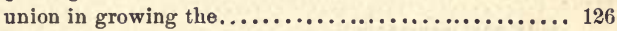

thinning the.............................. 191

Gas-plant.................................... 367

Germination of seeds ............................. 13

Girdled trees-how to save......................... 89

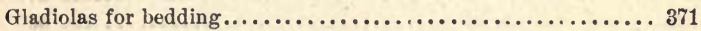

Glass-to control heat and moisture.................. 58

for hot-beds............................. 59

Golden bell for bedding............................ 361

Gooseberry................................. 277

propagation and culture.................. 278

pruning and training...................... 279

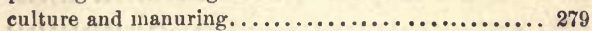

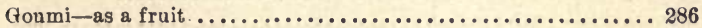

as an ornamental bush....................... 360

Graft-planting-trenching for..................... 82

Grafting-limits of $\ldots, \ldots, \ldots, \ldots \ldots \ldots, \ldots \ldots \ldots, \ldots, 74,75$ 
PAGE

Grafting - saving scions for........................ 75

short roots for........................ 76

wax for............................. 77

crown................................ 80

side.............................. 81

piece root. .......................... 78

of pear, plum, and cherry................. 80

top and bark...........................84-91

soft-tissue........................... 91

to test the value of hybrids ................. 105

Grape-history and development...................... 228

propagation by cuttings ...................230, 231

grafting the............................. 232

best soil for the.......................... 235

varieties of, for varied sections................ 235

distance apart and planting vines............... 237

varied systems of training. . . . . . . . . . . . . . . 239

plan for laying down........................ 239

diagonal training. ....................... 243

high renewal system of training............... 244

Pacific slope plan of training .................. 246

need of humus in vineyard................... 249

Guava....................................... 223

jelly now commercial....................... 224

Hackberry................................... 330

Hazel-nut-propagation and pruning.................306-308

Hedges and screens-care of....................... 139

Hemlock. . . . . . . . . . . . . . . . . ............... 347

Hickory-nut-culture of . . . . . . . . . . . . . . . . . . . . 301

Hollyhock-double............................. 367

Homes-American, rural, and suburban................ 314

starting new............................ 314

lawns for the................................... 315

its trees and shrubs.......................... 316

need of hardy trees and shrubs................ 325

Honey locust.................................. 332

Honeysuckle-bush species.......................... 355

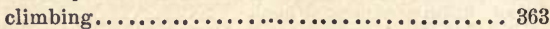

Horse-chestnut.................................. 342

Hydrangea - hardy species of the................... 358 
Inarching.................................. 50

long-scion. .............................. 52

Iris-Japan species of............................. 368

Irrigation-in the humid States...................... 394

of fruit orchards....................... 395

reservoirs for........................ 397

artesian wells for...................... 398

beneath the surface........................ 399

in the greenhouse.......................4 400

remarkable results of....................4 401

Juneberry -the dwarf........................... 281

propagation and pruning.................. 282

Kerosene emulsion for spraying...................... 149

Kumquat as a fruit............................... 303

as an ornamental plant............... 303

Landscape horticulture............................ 313

laying out home place.............. 314

where to plant trees................. 315

laying out large grounds............. 319

improving old places............... 321

planting trees and shrubs............ 324

need of hardy trees and shrubs......... 325

Larch for ornameutal planting....................... 341

Lawn-grading and manuring....................... 315

where to plant trees and shrubs..................315, 316

Layering-summer..........................46, 47

spring............................... 48

Leaf and fruit buds................................ 24

Leaf-period of ripening........................... 28

climatic variation of the....................... 28

Lemon-history of the.......................... 200

propagation and pruning..................... 201

Lilac........................................ 352

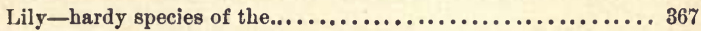

-of-the-valley............................... 369

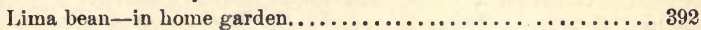

Lime - its uses and propagation..................... 203 
PAGE

Linden or basswood................................ 331

London purple as an insecticide..................... 142

Loquat -its uses and propagation.................217, 218

Magnolias for ornamental planting...................... 340

Maiden-hair or Salisburia........................... 341

Mandarin orange ................................ 204

Maples for ornamental planting.......................... 329

Melons-history and uses.......................... 226

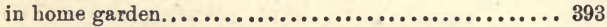

Mice and rabbits in orchard........................ 119

Mock-orange for ornamental use..................... 352

Moss pink.................................. 368

Mounding-for propagation....................... 45

to protect from mice..................... 119

Mountain ash. ................................. 337

Nectarine-its history....... ..................... 187

propagation and protection ................ 187, 188

Nursery-pruning.................................. 127

Nut-trees...................................... 294

almond.................................. 295

walnut ............................... 297

black walnut............................... 299

butternut............................... 300

hickory-nut.............................. 301

pecan.................................. 302

chestnut............................... 303

filbert.............................. 306

cocoanut............................. 308

B̧razil-nut............................. 311

Oaks for lawns and parks. ......................... 334

Old trees-top-working the....................... 87

Oleaster or wild olive. ........................... 335

Olive-its history and uses......................... 205

propagation.... ........................ 206

its commercial products.....................206

Orange-pruning the............................ 137

history of the.......................... 193 
Orange-propagation........................... 196

top-working............................ 198

culture ................................ 198

Orchard - of the larger fruits...................... 93

protection of, from winds................95-122

soil and subsoil for. $\ldots \ldots \ldots \ldots \ldots \ldots \ldots \ldots \ldots \ldots . \ldots . \ldots 9 . \ldots \ldots$

air-drainage.......................... 97

north and south slope of the................. 94

washing of soil......................... 97

double planting of the.................... 107

distance apart of trees........................ 108

securing trees for the.................... 111

proper depth of planting trees................ 112

alternating varieties in the.................. 113

how to plant the trees ....................... 114

cover-crops for the....................... 116

protection of, from rodents.................. 119

stem-borers and caterpillars in..............120, 121

manuring the.......................... 121

tile-draining of the...................... 125

managing stone fruit.................... 190

Pæonia -herbaceous and tree....................... 356

Pea-sweet, for garden planting..................... 372

Peach-orchard culture of.......................... 108

distance apart of trees....................... 108

pruning the............................... 134

history of the............................. 185

propagation of the....................... 186

laying down for protection..................... 188

Pear-distance apart in planting.................... 107

origin of the cultivated varieties................. 167

dwarf trees of the........................ 170

propagation of the....................... 171

best soils for the ........................ 171

care of its fruit. ......................... 172

Pearl bush.................................... 362

Pecan-its value and management................... 302

Perennials for home planting...................... 366

Persimmon-the Japan............................. 219 
Persimmon-native species.......................... 220

propagation of the.................... 222

Phellodendron for ornamental use..................... 341

Phlox - perennial, for bedding ...................... 367

Pineapple-its history and uses ..................... 214

increased uses of the $\ldots \ldots \ldots \ldots \ldots \ldots \ldots \ldots \ldots . \ldots 216$

Pines for ornamental planting......................... 346

Plane or buttonwood tree .......................... 331

Plants-division of................................ 63

Plum-top-working the........................... 86

crown-grafting........................... 81

stocks for................................ 88

distance apart in planting.................... 108

pruning................................ 135

history and classes of $\ldots \ldots \ldots \ldots \ldots \ldots \ldots \ldots \ldots \ldots \ldots . \ldots \ldots$

propagation of the........................... 186

ornamental species of....................... 336

Pollen -how gathered for crossing...................... 103

when and how used......................... 104

Pomegranate.................................... 218

Pomelo or grape-fruit............................. 202

propagation of the....................... 203

Poplar-best species of, for parks...................... 339

Poppy-oriental ............................... 368

Propagation -in Europe............................. 41

from seeds. ........................... 43

by root-cuttings....................... 44

by mounding ........................ 45

summer layering ....................... 46

spring layering ........................ 48

inarching. ........................ 50

long-scion inarching.................... 52

ripe wood cuttings. .................. $53-56$

green wood cuttings.................... 61

by division $\ldots \ldots \ldots \ldots \ldots \ldots \ldots \ldots \ldots \ldots \ldots \ldots \ldots . \ldots . \ldots . \ldots$

budding and grafting..................66-74

top-grafting........................ 84

bark-grafting........................ 91

grafting the apple.................... 78-164

quince.................... 173 
Propagation-grafting the pear $\ldots \ldots \ldots \ldots \ldots \ldots \ldots \ldots \ldots \ldots \ldots \ldots \ldots \ldots \ldots$

cherry..................... 178

peach, plum, and apricot......... 186

orange.................... 192

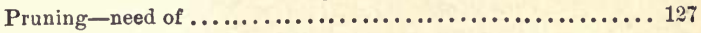

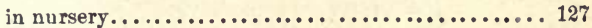

proper time for......................... 128

in young orchards...................... 129

for cordon-training $\ldots \ldots \ldots \ldots \ldots \ldots \ldots \ldots \ldots \ldots \ldots \ldots \ldots \ldots$

to shape trees............................ 133

of the cherry, plum, peach, and apricot.........133, 134

the orange............................... 137

the quince.............................. 137

shrubs................................. 138

evergreens.............................. 139

ornamental hedges........................ 139

Purple fringe................................... 360

Quince-pruning the............................ 137

origin and races of the. .................... 173

propagation and care of ................... 174

Japan species of ......................... 360

Raspberry-origin of American varieties................ 251

cultivated species of the...................251

black-cap family....................... 252

" “ propagation.....................252

purple-cane race ......................... 254

American red variety..................... 255

pruning the........................... 256

mulching and manuring.................... 256

winter protection of plants ................. 257

distance apart and staking.................. 258

Retarding fruit blossoms........................ 96

Roses-hardy varieties of the $\ldots \ldots \ldots \ldots \ldots \ldots \ldots \ldots \ldots \ldots \ldots . \ldots \ldots$

Root-how it grows.............................14, 15

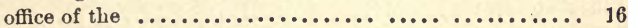

protection of the $\ldots \ldots \ldots \ldots \ldots \ldots \ldots \ldots \ldots \ldots \ldots \ldots \ldots, 16$

division of $\ldots \ldots \ldots \ldots \ldots \ldots \ldots \ldots \ldots \ldots \ldots \ldots \ldots \ldots, 17$

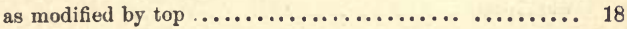


PAGE

Root-how used for propagation....................... 44

winter killing of the........................ 43

use of, in grafting. ........................ 79

Root-grafting-how regarded in Europe................. 40

of the apple....................... 78

how grafts are kept................... 79

Sand cherry-its uses............................ 289

Sap-its movements.............................28-30

Saving girdled trees.............................. 89

Scions-imperfect union of $\ldots \ldots \ldots \ldots \ldots \ldots \ldots \ldots \ldots \ldots \ldots, 30$

cutting and saving...................... 75

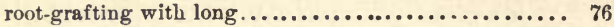

Seeds - variation of seedlings from ..................... 1

variation of plants from seeds of cultivated varieties.... 2

saving of............................... 3

stratification of ............................. 4

soaking and scalding $\ldots \ldots \ldots \ldots \ldots \ldots \ldots \ldots \ldots \ldots \ldots, \quad 5$

fall planting of............................ 6

testing.................................. 7

depth of planting......................... 8

proper time to plant........................ 9

beds shaded for planting........................ 11

in shallow boxes or flats........................ 10

in hot-beds ............................. 10

retained vitality of........................... 12

germination of $\ldots \ldots \ldots \ldots \ldots \ldots \ldots \ldots \ldots \ldots \ldots \ldots, 13$

propagation from........................... 43

Selection of soils and subsoils......................... 93

Shading of soils in orchards........................ 116

Shelter belts for orchards.......................... 45

Shrubs-for ornamental planting ....................... 349

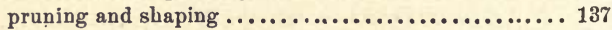

where to plant.............................. 315

Side-grafting of stone fruits and pear. .................79-81

Snowball for lawn planting........................ 355

Snowberry................................... 361

Soft-tissue grafting............................. 91

Soils - most favorable for fruits ..................... 38,98 washing of........................... 97 
PAGE

Soilss hading orchard............................ 116

Spraying-for insects and fungi..................... 141

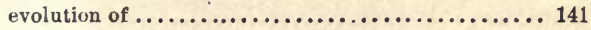

for codling-moth...................... 145

curculio................................ 147

bark and leaf aphis.................... 149, 150

cabbage worm ......................... 152

currant worm........................ 152

strawberry worm......................... 153

apple and pear scab ...................... 154

brown rot of stone fruits.................. 155

fungi of grape and small fruits............... 156

Spiræa - for lawn planting......................... 350

herbaceous species .......................... 368

Spruces for ornamental planting ..................... 343

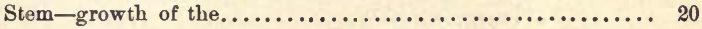

classes of ............................... 21

heart- and sap-wood of $\ldots \ldots \ldots \ldots \ldots \ldots \ldots \ldots \ldots \ldots, 22$

proper height of $\ldots \ldots \ldots \ldots \ldots \ldots \ldots \ldots \ldots \ldots \ldots \ldots, 23$

protection of the $\ldots \ldots \ldots \ldots \ldots \ldots \ldots \ldots \ldots \ldots \ldots \ldots, 23$

girdled by wire............................ 29

borer in the............................. 120

Stocks-commercial............................. 42

uucongenial ......................... 67

native for budding.......................... 67

taking up and packing...................... 76

hardy, for cherry and plum................... 88

best for the orange.......................... 196

best for the apple......................... 78-164

Strawberry-insects of the........................ 153

history of the. ....................... 263

staminate and pistillate.................... 265

planting and trainiug..................... 267

two-year plan of growing. ................. 268

one-year system ...................... 269

hill system of cropping................. 270

growing under glass.................... 2;0

shelter for the.......................... 271

Suckers-propagation from.......................... 43 
Tamarix as a lawn shrub........................... 358

Testing of seeds............................... 7

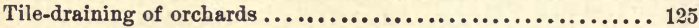

Top-grafting-the apple........................... 84

the cherry and plum................... 86

in the cellar ......................... 89

Transplanting-fruit and ornamental trees.............. 106

distance apart of trees................... 107

planning and staking $\ldots \ldots \ldots \ldots \ldots \ldots \ldots \ldots . \ldots 109$

fall or spring........................ 110

young trees safest to plant................ 110

taking up and caring for trees.............. 111

proper depth to plant................... 112

pruning tops and roots................. 112

alternating varieties..................... 113

of evergreens........................ 114

cultivation after ....................... 116

Tree cranberry for fruit and ornament................... 290

Trees must be adapted to climate and soil................. 327

Trenching-for graft-planting....................... 82

tool for............................... 83

Tubers-dividing and planting of .................. 63

Tulip for lawn planting........................... 369

Union in fruit-growing $\ldots \ldots \ldots \ldots \ldots \ldots \ldots \ldots \ldots \ldots \ldots \ldots \ldots \ldots$

Variation-of seedling............................. 1

of cultivated trees and plants................. 2

$\nabla$ egetable garden-location, shape, and shelter considered...... 374 rotation of crops.. .................. 375

fall plowing of the $\ldots \ldots \ldots \ldots \ldots \ldots \ldots . . . . .376$

culture of an............................ 377

need of good and pure seed ............. 378

propagating plants for................ 381

manuring the...................... 383

preservation of vegetables............... 384

spraying of plants................... 386

neglected crops of the................ 387

Wax-grafting, for varied uses.................. 77

Washing of orchard soils ..................... 97 
PAGE

Weigela rosea................................... 362

Whip-grafting of the apple......................... 79

White fringe..................................... 360

Willows for lawn and park planting.................... 340

Wistaria-Chinese as a clincher....................... 365

Yellow-wood as a lawn tree................................. 341 





\section{SHORT-TITLE CATALOGUE \\ OE THE PUBLICATIONS}

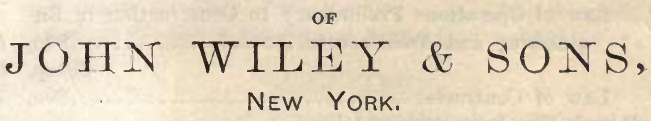

LONDON: CHAPMAN \& HALL, LIMITED.

ARRANGED UNDER SUBJECTS.

Descriptive circulars sent on applieation.

Books marked with an asterisk are sold at net prices only.

All books are bound in cloth unless otherwise stated.

\section{AGRICULTURE.}

Armsby's Manual of Cattle-feeding................. $12 \mathrm{mo}$, 75 Downing's Fruits and Fruit-trees of America.......... 8vo, 500 Grotenfelt's Principles of Modern Dairy Practice. (Woll.) .. 12mo, 200 Kemp's Landscape Gardening.................... 2 mo, 20 Maynard's Landscape Gardening as Applied to Home Decora-

tion ..................................... 150

Stockbridge's Rocks and Soils.................. 8vo, 250 Woll's Handbook for Farmers and Dairymen..........16mo, 150

\section{ARCHITECTURE.}

Baldwin's Steam Heating for Buildings.............. $12 \mathrm{mo}, 250$ Berg's Buildings and Structures of American Railroads....4to, 500 Birkmire's Planning and Construction of American Theatres.8vo, 300

" Architectural Iron and Steel.............. 8vo, 350

" Compound Riveted Girders as Applied in Build-

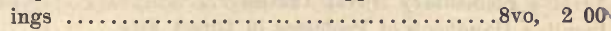

“ Planning and Construction of High Office Buildings $\ldots \ldots \ldots \ldots \ldots \ldots \ldots \ldots \ldots \ldots \ldots \ldots \ldots \ldots . \ldots \ldots$ vo, 350.

" Skeleton Construction in Buildings.......... 8 vo, 300 Briggs's Modern American School Buildings........... 8 vo, 400 . Carpenter's Heating and Ventilating of Buildings.......8vo, 300 Freitag's Architectural Engineering................. 3 vo, 50

“ Fireproofing of Steel Buildings.............. $8 \mathrm{vo}, 250$

Gerhard's Guide to Sanitary House-inspection..........16mo, 100

“ Theatre Fires and Panics.................... 150

Hatfield's American House Carpenter............... 8 vo, 500 Holly's Carpenters' and Joiners' Handbook..........18mo, 75 Kidder's Architect's and Builder's Pocket-book..16mo, morocco, 400 Merrill's Stones for Building and Decoration........... 8vo, 500 . 
Monckton's Stair-building......................4to, 400

Patton's Practical Treatise on Foundations............8vo, 500

Siebert and Biggin's Modern Stone-cutting and Masonry..8vo, 150

Wait's Engineering and Architectural Jurisprudence....8vo, 600

Sheep, 650

“ Law of Operations Preliminary to Construction in Engineering and Architecture.................8vo, 500

Sheep, 550

" Law of Contracts........................8vo, 300

Woodbury's Fire Protection of Mills................ 250

Worcester and Atkinson's Small Hospitals, Establishment and

Maintenance, and Suggestions for Hospital Architecture,

with Plans for a Small Hospital............... 125

The World's Columbian Exposition of $1893 . . .$. ... Large 4to, I 00

\section{ARMY AND NAVY.}

Bernadou's Smokeless Powder, Nitro-cellulose, and the Theory

of the Cellulose Molecule...................

- Bruff's Text-book of Ordnance and Gunnery...........8vo, 600

Chase's Screw Propellers and Marine Propulsion.........8vo, 300

Craig's Azimuth............................. 350

Crehore and Squire's Polarizing Photo-chronograph.....8vo, 300

Cronkhite's Gunnery for Non-commissioned Officers..24mo, mor., 200

- Davis's Elements of Law....................... 8vo, 250

- "Treatise on the Military Law of United States...8vo, 700

$\begin{array}{r}\text { - Sheep, } 750 \\ \hline\end{array}$

De Brack's Cavalry Outpost Duties. (Carr.)....24mo, morocco, 200 Dietz's Soldier's First Aid Handbook.........16mo, morocco, 125

* Dredge's Modern French Artillery.........4to, half morocco, 1500

Durand's Resistance and Propulsion of Ships.......... 8vo, 500

- Dyer's Handbook of Light Artillery...............12mo, 300

Eissler's Modern High Explosives................. 8vo, 400

- Fiebeger's Text-book on Field Fortification......... Small 8vo, 200

- Hoff's Elementary Naval Tactics..................8vo, 150

Ingalls's Handbook of Problems in Direct Fire......... 8vo, 400

- " Ballistic Tables........................8vo, 150

Lyons's Treatise on Electromagnetic Phenomena.......8vo, 600

- Mahan's Permanent Fortifications. (Mercur's.).8vo, half mor. 750

Manual for Courts-martial.................16mo, morocco, 150

- Mercur's Attack of Fortified Places.................12mo, 200

- "Elements of the Art of War.............. 8vo, 400

Metcalfe's Cost of Manufactures-And the Administration of

Workshops, Public and Private........... 8 vo, 500

" Ordnance and Gunnery..................... 500

Murray's Infantry Drill Regulations............18mo, paper, 10

- Phelps's Practical Marine Surveying................8vo, 250

Powell's Army Officer's Examiner.................12mo, 400 
Sharpe's Art of Subsisting Armies in War......18mo, morocco, 150 Walke's Lectures on Explosives................... 8 vo, 400 *Wheeler's Siege Operations and Military Mining....... 8vo, 200 Winthrop's Abridgment of Military Law..............12mo, 250 Woodhull's Notes on Military Hygiene................ 160 Young's Simple Elements of Navigation........16mo, morocco, 100 Second Edition, Enlarged and Revised.......16mo, mor., 200

\section{ASSAYING.}

Fletcher's Practical Instructions in Quantitative Assaying with

the Blowpipe...................12mo, morocco, 150

Furman's Manual of Practical Assaying............... 300

Miller's Manual of Assaying..................... $12 \mathrm{mo}, 100$

O'Driscoll's Notes on the Treatment of Gold Ores....... 8vo, 200

Ricketts and Miller's Notes on Assaying.............8vo, 300

Wilson's Cyanide Processes......................12mo, 150

" Chlorination Process ......................... 150

\section{ASTRONOMY.}

Craig's Azimuth............................4to, 350

Doolittle's Treatise on Practical Astronomy............8vo, 400

Gore's Elements of Geodesy...................... 8 vo, 250

Hayford's Text-book of Geodetic Astronomy.......... 8vo, 300

Merriman's Elements of Precise Surveying and Geodesy....8vo, 250

- Michie and Harlow's Practical Astronomy............8vo, 300

* White's Elements of Theoretical and Descriptive Astronomy.

$12 \mathrm{mo}, 200$

\section{BOTANY.}

Baldwin's Orchids of New England............. Small 8vo, 150

Davenport's Statistical Methods, with Special Reference to Bio-

logical Variation..................16mo, morocco, 125

Thome and Bennett's Structural and Physiological Botany.

$16 \mathrm{mo}, 225$

Westermaier's Compendium of General Botany. (Schneider.)8vo, 200

\section{CHEMISTRY.}

Adriance's Laboratory Calculations and Specific Gravity Tables,

Allen's Tables for Iron Analysis................... 3 vo, 300 Arnold's Compendium of Chemistry. (Mandel.) (In preparation.) Austen's Notes for Chemical Students................12mo, Bernadou's Smokeless Powder.-Nitro-cellulose, and Theory of

the Cellulose Molecule.....................12mo, 250

Bolton's Quantitative Analysis.................... 8vo, 150

Brush and Penfield's Manual of Determinative Mineralogy..8vo, 400 Classen's Quantitative Chemical Analysis by Electrolysis. (Herrick-Boltwood.) 
Cohn's Indicators and Test-papers................12mo, 200

Craft's Short Course in Qualitative Chemical Analysis. (Schaef-

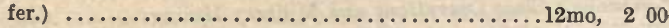

Drechsel's Chemical Reactions. (Merrill.)...........12mo, 125

Eissler's Modern High Explosives................. 8vo, 400 Effront's Enzymes and their Applications. (Prescott.) (In preparation.) Erdmann's Introduction to Chemical Preparations. (Dunlap.)

$12 \mathrm{mo}, 125$

Fletcher's Practical Instructions in Quantitative Assaying with the Blowpipe.................... morocco, 150

Fresenius's Manual of Qualitative Chemical Analysis. (Wells.)

$8 \mathrm{vo}, 500$

" System of Instruction in Quantitative Chemical Analysis. (Allen.) ..................8vo, 600

Fuertes's Water and Public Health.................. 12mo, 150

Furman's Manual of Practical Assaying............... 300

Gill's Gas and Fuel Analysis for Engineers..........12mo, 125 Grotenfelt's Principles of Modern Dairy Practice. (Woll.)..12mo, 200 Hammarsten's Text-book of Physiological Chemistry. (Mandel.)

$8 \mathrm{vo}, 400$

Helm's Principles of Mathematical Chemistry. (Morgan.).12mo, 150 Holleman's Text-book of Inorganic Chemistry. (Cooper.)

(In preparation.)

Hopkins's Oil-chemists' Handbook................. 8vo, 300 Keep's Cast Iron. (In preparation.)

Ladd's Manual of Quantitative Chemical Analysis.......12mo, 100 Landauer's Spectrum Analysis. (Tingle.)............ $8 \mathrm{vo}, 300$ Lassar-Cohn's Practical Urinary Analysis. (Lorenz.) (In preparation.) Löb's Electrolysis and Electrosynthesis of Organic Compounds.

(Lorenz.) ............................... 100

Mandel's Handbook for Bio-chemical Laboratory........12mo, 150 Mason's Water-supply. (Considered Principally from a Sanitary Standpoint.).................... 8 vo, 500

" Examination of Water. (Chemical and Bacteriological.) .......................... 125

Meyer's Determination of Radicles in Carbon Compounds.

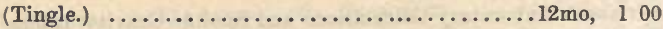

Miller's Manual of Assaying..................... $12 \mathrm{mo}, 100$

Mixter's Elementary Text-book of Chemistry...........12mo, 150

Morgan's Outline of Theory of Solution and its Results...12mo, 100

Elements of Physical Chemistry.............12mo, 200

Nichols's Water-supply. (Considered mainly from a Chemical and Sanitary Standpoint, 1883.)............... 250

O'Brine's Laboratory Guide in Chemical Analysis........8vo, 200 O'Driscoll's Notes on the Treatment of Gold Ores.........8vo, 200

Ost and Kolbeck's Text-book of Chemical Technology. (Lorenz--Bozart.) (In preparation.) 
* Penfield's Notes on Determinative Mineralogy and Record of

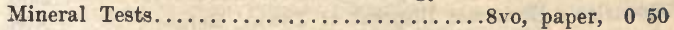

Pinner's Introduction to Organic Chemistry. (Austen.)...12mo, 150

Poole's Calorific Power of Fuels..................... 8vo, 300

* Reisig's Guide to Piece-dyeing.................... 8vo, 2500

Richards and Woodman's Air, Water, and Food from a Sanitary

Standpoint . .......................... 200

Richards's Cost of Living as Modified by Sanitary Science.12mo, 100

" Cost of Food, a Study in Dietaries...........12mo, 100

Ricketts and Russell's Skeleton Notes upon Inorganic Chem-

istry. (Part I.-Non-metallic Elements.)..8vo, morocco, 75

Ricketts and Miller's Notes on Assaying............ 8vo, 300

Rideal's Sewage and the Bacterial Purification of Sewage. 8 vo, 350

Ruddiman's Incompatibilities in Prescriptions........... 8vo, 200

Schimpf's Text-book of Volumetric Analysis...........12mo, 250

Spencer's Handbook for Chemists of Beet-sugar Houses.

$16 \mathrm{mo}$, morocco,

" Handbook for Sugar Manufacturers and their Chemists ....................... moroce,

Stockbridge's Rocks and Soils.................. 8 vo, 250

* Tillman's Elementary Lessons in Heat..............8vo, 150

* “ Descriptive General Chemistry............8vo, 300

Turneaure and Russell's Public Water-supplies......... 8vo, 500

Van Deventer's Physical Chemistry for Beginners. (Boltwood.)

$12 \mathrm{mo}, 150$

Walke's Lectures on Explosives.................. 8vo, 400

Wells's Laboratory Guide in Qualitative Chemical Analysis.

“ Short Course in Inorganic Qualitative Chemical Analysis for Engineering Students.............. 12mo, 150

Whipple's Microscopy of Drinking-water............. 3 vo, 30

Wiechmann's Sugar Analysis....................... 8vall 8v, 250

“ Lecture-notes on Theoretical Chemistry....12mo, 300

Wilson's Cyanide Processes............................ 150

" Chlorination Process.................... $12 \mathrm{mo}, \quad 150$

Wulling's Elementary Course in Inorganic Pharmaceutical and

Medical Chemistry....................... 200

\section{CIVIL ENGINEERING.}

BRIDGES AND ROOFS. HYDRAULICS. MATERIALS OF ENGINEERING. RAILWAY ENGINEERING.

Baker's Engineers' Surveying Instruments...........12mo, 300

Bixby's Graphical Computing Table....Paper, $19 \frac{1}{2} \times 24 \frac{1}{4}$ inches. 25

Davis's Elevation and Stadia Tables................. 8 vo, 100

Folwell's Sewerage. (Designing and Maintenance.)......8vo, 300

Freitag's Architectural Engineering............... 8 vo, 350 
Goodhue's Municipal Improvements.................12mo, 175

Goodrich's Economic Disposal of Towns' Refuse........8vo, 350

Gore's Elements of Geodesy...................... 2 vo, 50

Hayford's Text-book of Geodetic Astronomy............8vo, 300

Howe's Retaining-walls for Earth................... 12mo, 125

Johnson's Theory and Practice of Surveying........ Small 8vo, 400

" Stadia and Earth-work Tables...............8vo, 125.

Kiersted's Sewage Disposal.....................12mo, 125

Mahan's Treatise on Civil Engineering. (1873.) (Wood.)..8vo, 500

- Mahan's Descriptive Geometry...................8vo, 150

Merriman's Elements of Precise Surveying and Geodesy... 8vo, 250

Merriman and Brooks's Handbook for Surveyors....16mo, mor., 200 Merriman's Elements of Sanitary Engineering.......... $8 \mathrm{vo}, 200$ Nugent's Plane Surveying. (In preparation.)

Ogden's Sewer Design............................... 200

Patton's Treatise on Civil Engineering......8vo, half leather, 750

Reed's Topographical Drawing and Sketching...........4to, 500

Rideal's Sewage and the Bacterial Purification of Sewage..8vo, 350

Siebert and Biggin's Modern Stone-cutting and Masonry..8vo, 150

Smith's Manual of Topographical Drawing. (McMillan.)..8vo, 250

* Trautwine's Civil Engineer's Pocket-book....16mo, morocco, 500

Wait's Engineering and Architectural Jurisprudence.....8vo, 600

Sheep, 650

“ Law of Operations Preliminary to Construction in Engineering and Architecture............... 500

Sheep, 550

“ Law of Contracts...................... $8 \mathrm{vo}, 300$

Warren's Stereotomy-Problems in Stone-cutting.......8vo, 250

Webb's Problems in the Use and Adjustment of Engineering

Instruments .................... moroce, 125

-Wheeler's Elementary Course of Civil Engineering......88vo, 400

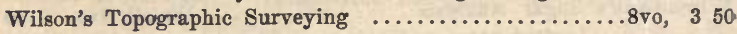

\section{BRIDGES AND ROOFS.}

Boller's Practical Treatise on the Construction of Iron Highway Bridges ............................... 8 vo, 200

- Boller's Thames River Bridge................4to, paper, 500 Burr's Course on the Stresses in Bridges and Roof Trusses,

Arched Ribs, and Suspension Bridges............8vo, 350

Du Bois's Stresses in Framed Structures........... Small 4to, 1000

Foster's Treatise on Wooden Trestle Bridges............4to, 500

Fowler's Coffer-dam Process for Piers............... 8vo, 250

Greene's Roof Trusses..........................8vo, 125

" Bridge Trusses....................... 8vo, 250

" Arches in Wood, Iron, and Stone...........8vo, 250

Howe's Treatise on Arches.................... 8vo, 400 
Johnson, Bryan and Turneaure's Theory and Practice in the Designing of Modern Framed Structures...... Small 4to, 1000 Merriman and Jacoby's Text-book on Roofs and Bridges:

Part I.-Stresses in Simple Trusses................. 8vo, 250

Part II.-Graphic Statics...................... 8vo, 200

Part III.-Bridge Design. Fourth Ed. (In preparation.). .8vo, 250

Part IV.-Higher Structures..................... 8vo, 250

Morison's Memphis Bridge............................. 1000

Waddell's De Pontibus, a Pocket Book for Bridge Engineers.

$16 \mathrm{mo}$, mor., Specifications for Steel Bridges...........12mo,

Wood's Treatise on the Theory of the Construction of Bridges

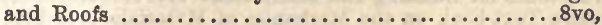

Wright's Designing of Draw-spans:

Part I.-Plate-girder Draws................. 8 vo,

Part II.-Riveted-truss and Pin-connected Long-span Draws.

$8 \mathrm{vo}, 250$

Two parts in one volume.................... 3 vo, 30

\section{HYDRAUIICS.}

Bazin's Experiments upon the Contraction of the Liquid Vein

Issuing from an Orifice. (Trautwine.) ............8vo, Bovey's Treatise on Hydraulics................... 8 vo, Church's Mechanics of Engineering. . . . . Coffin's Graphical Solution of Hydraulic Problems..16mo, mor., Flather's Dynamometers, and the Measurement of Power.12mo, Folwell's Water-supply Engineering. $\ldots \ldots \ldots \ldots \ldots \ldots \ldots . . \times \ldots$ vo, Frizell's Water-power........................ Fuertes's Water and Public Health...............12mo, "Water-filtration Works.................. 12mo, Ganguillet and Kutter's General Formula for the Uniform Flow of Water in Rivers and Other Channels. (Hering and Trautwine.)....................... $8 \mathrm{vo,}$ Hazen's Filtration of Public Water-supply..............8vo, Hazleurst's Towers and Tanks for Water-works.........8vo, Herschel's 115 Experiments on the Carrying Capacity of Large, Riveted, Metal Conduits.................... Mason's Water-supply. (Considered Principally from a Sanitary Standpoint.) ........................ $8 \mathrm{vo}$, Merriman's Treatise on Hydraulics.................. 8 vo, * Michie's Elements of Analytical Mechanics............ 8vo, Schuyler's Reservoirs for Irrigation, Water-power, and Domestic Water-supply............................... 8vo, Turneaure and Russell. Public Water-supplies...........8vo, Wegmann's Design and Construction of Dams.............4to, Water-supply of the City of New York from 1658 to

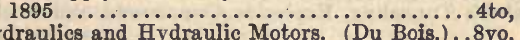

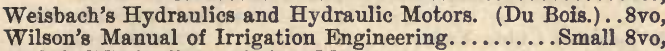
Wolff's Windmill as a Prime Mover................. 8vo, Wood's Turbines............................... * Elements of Analytical Mechanics............. 8vo,

\section{MATERIALS OF ENGINEELING.}

Baker's Treatise on Masonry Construction...........8vo, 500 Black's United States Public Works...................... 4to, 500 Bovey's Strength of Materials and Theory of Structures...8vo, 750 
Burr's Elasticity and Resistance of the Materials of Engineer-

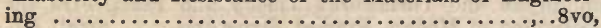

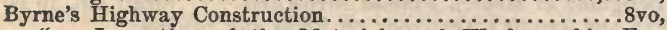

" Inspection of the Materials and Workmanship Employed in Construction..................16mo, Church's Mechanics of Engineering................... Ch John's Materials of Construction Keep's Cast Iron. (In preparation.)

Lanza's Applied Mechanics..................... 8vo, Martens's Handbook on Testing Materials. (Henning.)........

2 vols, 8vo, Merrill's Stones for Building and Decoration...........8vo, Merriman's Text-book on the Mechanics of Materials.... . 8vo, Merriman's Strength of Materials...................12mo, Metealf's Steel. A Manual for Steel-users..............12mo, Patton's Practical Treatise on Foundations............ 8vo, Rockwell's Roads and Pavements in France...........12mo, Smith's Wire: Its Use and Manufacture........... Small 4to, Spalding's Hydraulic Cement.....................12mo, Text-book on Roads and Pavements..........12mo, Thurston's Materials of Engineering............. Parts, 8vo,

Part I.-Non-metallic Materials of Engineering and Metal-

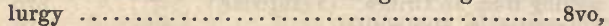

Part II.-Iron and Steel..................... 8vo,

Part III.-A Treatise on Brasses, Bronzes and Other Alloys and Their Constituents.................. Thurston's Text-book of the Materials of Construction..... Tillson's Street Pavements and Paving Materials......... Waddell's De Pontibus. (A Pocket-book for Bridge Engineers.)

“ $16 \mathrm{mo}$, morocco, Wood's Treatise on the Resistance of Materials, and an Appendix on the Preservation of Timber.........8vo,

" Elements of Analytical Mechanics..............

\section{RAILWAY ENGINEERING.}

Berg's Buildings and Structures of American Railroads..4to, Brooks's Handbook of Street Railroad Location.. 16mo, morocco, Butts's Civil Engineer's Field-book..........16mo, morocco, Crandall's Transition Curve................16mo, morocco,

“ Railway and Other Earthwork Tables.......8vo, 150 Dawson's Electric Railways and Tramways. Small 4to, half mor., 1250 " "Engineering" and Electric Traction Pocket-book.

Dredge's History of the Pennsylvania Railroad: (1879.).Paper, 500

- Drinker's Tunneling, Explosive Compounds, and Rock Drills.

Fisher's Table of Cubic Yards..................... Cardboard, Godwin's Railroad Engineers' Field-book and Explorers' Guide.

$16 \mathrm{mo}$, morocco, 2500 25 Hudson's Tables for Caleulating the Cubic Contents of Excavations and Embankments................... 8 vo, Nagle's Field Manual for Railroad Engineers....16mo, morocco, Philbrick's Field Manual for Engineers........16mo, morocco, Pratt and Alden's Street-railway Road-bed............ 8vo, 
Searles's Field Engineering..............16mo, morocco,

Railroad Spiral.................16mo, morocco, 150

Taylor's Prismoidal Formulæ and Earthwork...........8vo, 150

* Trautwine's Method of Calculating the Cubic Contents of Excavations and Embankments by the Aid of Diagrams ............................ The Field Practice of Laying Out Circular Curves for Railroads................12mo, moroceo, Cross-section Sheet...................................

(c

Cross-section Sheet.

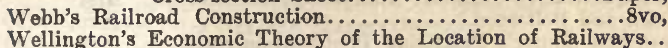
Small 8vo,

\section{DRAWING.}

Barr's Kinematics of Machinery.................... $8 \mathrm{vo}$,

* Bartlett's Mechanical Drawing..................... 8vo, Durley's Elementary Text-book of the Kinematics of Machines. (In preparation.)

Hill's Text-book on Shades and Shadows, and Perspective..8vo, Jones's Machine Design:

Part I.-Kinematics of Machinery............... 8vo,

Part II.-Form, Strength and Proportions of Parts..... .8vo,

MacCord's Elements of Descriptive Geometry...........8vo,

" Kinematics; or, Practical Mechanism.........8vo,

" Mechanical Drawing......................4to,

“ Velocity Diagrams.......................

* Mahan's Descriptive Geometry and Stone-cutting...... 8vo, Mahan's Industrial Drawing. (Thompson.)........... 8vo, Reed's Topographical Drawing and Sketching...........4to, Reid's Course in Mechanical Drawing............... "Text-book of Mechanical Drawing and Elementary Machine Design........................... 8 vo,

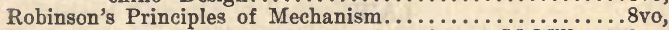
Smith's Manual of Topographical Drawing. (McMillan.).8vo, Warren's Elements of Plane and Solid Free-hand Geometrical Drawing ............................... “ Drafting Instruments and Operations............. 12mo, “ Manual of Elementary Projection Drawing.....12mo, “ Manual of Elementary Problems in the Linear Perspective of Form and Shadow............12mo,

“ Plane Problems in Elementary Geometry.......12mo, " Primary Geometry......................12mo, " Elements of Descriptive Geometry, Shadows, and Perspective ............................

“ General Problems of Shades and Shadows.......8vo,

“ Elements of Machine Construction and Drawing. .8vo, “ Problems, Theorems, and Examples in Descriptive Geometry ......................... Weisbach's Kinematics and the Power of Transmission. (Herrmann and Klein.) ........................ Whelpley's Practical Instruction in the Art of Letter Engraving ................................. Wilson's Topographic Surveying................. Wilson's Free-hand Perspective................. 8vo, Woolf's Elementary Cour'se in Descriptive Geometry. . Large 8vo, 


\section{ELECTRICITY AND PHYSICS.}

Anthony and Brackett's Text-book of Physics. (Magie.)

Anthony's Lecture-notes on the Theory of Electrical Measur-

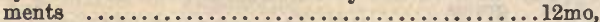

Benjamin's History of Electricity................

Benjamin's Voltaic Cell.......................8vo,

Classen's Qantitative Chemical Analysis by Electrolysis. Her-

rick and Boltwood.) ..................... 8vo,

Crehore and Squier's Polarizing Photo-chronograph......8vo,

Dawson's Electric Railways and Tramways..Small 4to, half mor., 1250

Dawson's “Engineering" and Electric Traction Pocket-book.

$16 \mathrm{mo}$, morocco,

Flather's Dynamometers, and the Measurement of Power..12mo,

Gilbert's De Magnete. (Mottelay.)................8vo,

Holman's Precision of Measurements. ..............8vo,

Telescopic Mirror-scale Method, Adjustments, and

Tests .................................. 8vo,

Landauer's Spectrum Analysis. (Tingle.)............ 8vo,

Le Chatelier's High-temperature Measurements. (Boudouard-

Burgess.) .................................

Lob's Electrolysis and Electrosynthesis of Organic Compounds.

(Lorenz.) . . . . . . . . . .

Lyons's Treatise on Electromagnetic Phenomena........ 8vo,

* Michie. Elements of Wave Motion Relating to Sound and

Light . . . . . . . . . . . . . . . .

Niaudet's Elementary Treatise on Electric Batteries (Fish-

back.) ................................. 250

- Parshall and Hobart's Electric Generators..Small 4to, half mor., 1000 Thurston's Stationary Steam-engines...............8vo, 250

* Tillman. Elementary Lessons in Heat.............8vo, 150

Tory and Pitcher. Manual of Laboratory Physics..Small 8vo, 200

LAW.

"Davis. Elements of Law........................... 250

- "Treatise on the Military Law of United States..8vo, 700

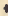

Sheep, 750

Manual for Courts-martial...............mo, morocco, 150

Wait's Engineering and Architectural Jurisprudence.....8vo, 600

Sheep, 650

“ Law of Operations Preliminary to Construction in Engineering and Architecture................8vo,

Sheep,

" Law of Contracts.....................

Winthrop's Abridgment of Military Law...........12mo,

\section{MANUFACTURES.}

Beaumont's Woollen and Worsted Cloth Manufacture....12mo,

Bernadou's Smokeless Powder-Nitro-cellulose and Theory of the Cellulose Molecule...................... r2mo,

Bolland's Iron Founder................... eloth,

" "The Iron Founder" Supplement.............12mo,

“ Encyclopedia of Founding and Dictionary of Foundry

Terms Used in the Practice of Moulding....12mo,

Fissler's Modern High Explosives.................. 8 vo, 400

Effront's Enzymes and their Applications. (Prescott.) (In preparation.)

Fitzgerald's Boston Machinist................... $18 \mathrm{mo}$, 100 
Ford's Boiler Making for Boiler Makers............18mo, 100

Hopkins's Oil-chemists' Handbook.................. 8vo, 300 Keep's Cast Iron. (In preparation.)

Metcalf's Steel. A Manual for Steel-users............12mo, 200

Metcalf's Cost of Manufactures-And the Administration of

Workshops, Public and Private..............8vo, 500

Meyer's Modern Locomotive Construction..............4to, 1000

"Reisig's Guide to Piece-dyeing......................8vo, 2500

Smith's Press-working of Metals................... 8vo, 300

"Wire: Its Use and Manufacture..................... 4to, 300

Spalding's Hydraulic Cement.................... 2 mo, 200

Spencer's Handbook for Chemists of Beet-sugar Houses.

" $\quad 16 \mathrm{mo}$, moroceco, ists.......................16mo, morocco, Thurston's Manual of Steam-boilers, their Designs, Construction and Operation....................... $8 \mathrm{vo}$, Walke's Lectures on Explosives.................. 8vo, West's American Foundry Practice................. 12mo, " Moulder's Text-book.....................12mo, Wiechmann's Sugar Analysis................ Small 8vo, Wolff's Windmill as a Prime Mover.................8vo, Woodbury's Fire Protection of Mills...............

\section{MATHEMATICS.}

Baker's Elliptic Functions....................... 150

* Bass's Elements of Differential Calculus................12mo, 400

Briggs's Elements of Plane Analytic Geometry...........12mo, 100

Chapman's Elementary Course in Theory of Equations....12mo, 150

Compton's Manual of Logarithmic Computations.........12mo, 150

Davis's Introduction to the Logic of Algebra...........8vo, 150

Halsted's Elements of Geometry..................8vo, 175

" Elementary Synthetic Geometry.............8vo, 150

Johnson's Three-place Logarithmic Tables: Vest-pocket size, pap., 15

100 copies for 500

Mounted on heavy cardboard, $8 \times 10$ inches, 25 .

10 copies for 200 .

“ Elementary Treatise on the Integral Calculus. Small 8vo, 150

“ Curve Tracing in Cartesian Co-ordinates.......12mo, 100

"Treatise on Ordinary and Partial Differential Equations .............................. 8 vo, 350 " Theory of Errors and the Method of Least Squares ............................ 150

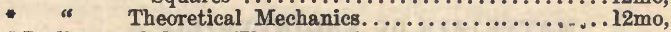

- Ludlow and Bass. Elements of Trigonometry and Logarithmic and Other Tables..................... "Trigonometry. Tables published separately..Each, Merriman and Woodward. Higher Mathematics.........8vo, Merriman's Method of Least Squares............... $8 \mathrm{vo}$, Rice and Johnson's Elementary Treatise on the Differential Calculus ................ Small 8vo, " Differential and Integral Calculus. 2 vols. in one................. Small $8 \mathrm{vo}, 250$ Wood's Flements of Co-ordinate Geometry............... 8 vo, 200 "Trigometry: Analytical, Plane, and Spherical....12mo, 
Baldwin's Steam Heating for Buildings................. 2 mo, 250

Barr's Kinematics of Machinery.................. 8 vo, 250

" Bartlett's Mechanical Drawing................... 8vo, 300

Benjamin's Wrinkles and Recipes....................12mo, 200

Carpenter's Experimental Engineering................ 8 vo, 600

Heating and Ventilating Buildings..........8vo, 300

Clerk's Gas and Oil Engine..................... Small 8vo, 400

Cromwell's Treatise on Toothed Gearing................12mo, 150

"Treatise on Belts and Pulleys.............. $12 \mathrm{mo}, 150$

Durley's Elementary Text-book of the Kinematics of Machines. (In preparation.)

Flather's Dynamometers, and the Measurement of Power ...12mo, Rope Driving.............................

Gill's Gas an Fuel Analysis for Engineers.............. 12mo, Hall's Car Lubrication......................... 12mo, Jones's Machine Design:

Part I.-Kinematics of Machinery.............. $8 \mathrm{vo}$,

Part II.-Form, Strength and Proportions of Parts..... 8vo, Kent's Mechanical Engineers' Pocket-book....16mo, morocco, Kerr's Power and Power Transmission. (In preparation.)

MacCord's Kinematics; or, Practical Mechanism.........8vo, " Mechanical Drawing....................... " Velocity Diagrams..................... 8vo, Mahan's Industrial Drawing. (Thompson.).............. Poole's Calorific Power of Fuels.................. 8 vo, Reid's Course in Mechanical Drawing.............. 8 vo, "Text-book of Mechanical Drawing and Elementary Machine Design......................... Richards's Compressed Air..................... 12mo, Robinson's Principles of Mechanism................ 8 vo, Smith's Press-working of Metals.................. Thurston's Treatise on Friction and Lost Work in Machinery and Mill Work................... " Animal as a Machine and Prime Motor and the Laws of Energeties...................12mo, Warren's Elements of Machine Construction and Drawing. .8vo, Weisbach's Kinematics and the Power of Transmission. (Herrmann-Klein.) ......................... " Machinery of Transmission and Governors. (Herrmann-Klein.) . .....................

" Hydraulies and Hydraulic Motors. (Du Bois.).8vo,

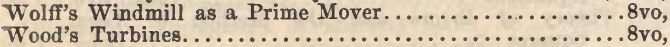

\section{MATERIALS OF ENGINEERING.}

Bovey's Strength of Materials and Theory of Structures. .8vo, Burr's Elasticity and Resistance of the Materials of Engineer-

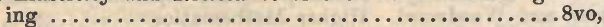
Church's Mechanics of Engineering................. $8 \mathrm{vo}$, Johnson's Materials of Construction............... Large 8vo, Keep's Cast Iron. (In preparation.)

Lanza's Applied Mechanics..................... Martens's Handbook on Testing Materials. (Henning.)....8vo, Merriman's Text-book on the Mechanics of Materials... .8vo, 
Metcalf's Steel. A Manual for Steel-users..............12mo, Smith's Wire: Its Use and Manufacture............ Small 4to, Thurston's Materials of Engineering............. vols., 8vo, Part II.-Iron and Steel....................... 8vo, Part III.-A Treatise on Brasses, Bronzes and Other Alloys and their Constituents.................... Thurston's Text-book of the Materials of Construction....8vo, Wool's Treatise on the Resistance of Materials and an Appendix on the Preservation of Timber.........8vo, "Elements of Analytical Mechanics...............

\section{STEAM ENGINES AND BOILERS.}

Carnot's Reflections on the Motive Power of Heat. (Thurston.)

Dawson's "Engineering" and Electric Traction Pocket-book.

Ford's Boiler Making for Boiler Makers..............18mo, Hemenway's Indicator Practice and Steam-engine Economy.

Hutton's Mechanical Engineering of Power Plants..... 12mo, " Heat and Heat-engines................... 8vo,

Kent's Steam-boiler Economy..................... Kneass's Practice and Theory of the Injector........... 8vo, MacCord's Slide-valves........................ 8vo, Meyer's Modern Locomotive Construction.............4to, Peabody's Manual of the Steam-engine Indicator.........12mo, Tables of the Properties of Saturated Steam and Other Vapors.......................... "Thermodynamics of the Steam-engine and other Heat-engines $\ldots \ldots \ldots \ldots \ldots \ldots \ldots \ldots \ldots \ldots . . . .6$ vo, " Valve-gears for Steam-engines................ Peabody and Miller. Steam-boilers.................. Pray's Twenty Years with the Indicator................... 8vo, Pupin's Thermodynamics of Reversible Cycles in Gases and Saturated Vapors. (Osterberg.)...............12mo, Reagan's Locomotive Mechanism and Engineering........12mo, Rontgen's Principles of Thermodynamics. (Du Bois.)....8vo, Sinclair's Locomotive Engine Running and Management. .12mo, Smart's Handbook of Engineering Laboratory Practice..12mo, Snow's Steam-boiler Practice..................... 8vo, Spangler's Valve-gears.......................... Notes on Thermodynamics................. 12mo, Thurston's Handy Tables....................... 8vo, "Manual of the Steam-engine................... 8 vo, Part I.-History, Structure, and Theory ............ 8vo, Part II.-Design, Construction, and Operation......... 8vo, Thurston's Handbook of Engine and Boiler Trials, and the Use of the Indicator and the Prony Brake........ 8 vo, " Stationary Steam-engines................... “ Steam-boiler Explosions in Theory and in Prac-

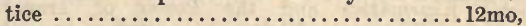
“ Manual of Steam-boilers, Their Designs, Construction, and Operation....................

Weisbach's Heat, Steam, and Steam-engines. (Du Bois.). . . Whitham's Steam-engine Design ................... Wilson's Treatise on Steam-boilers. (Flather.)......... 16mo, Wood's Thermodynamics, Heat Motors, and Refrigerating Machines ............................... 
Barr's Kinematics of Machinery................ Bovey's Strength of Materials and Theory of Structures..8vo, Chordal.-Extracts from Letters...................12mo,

Church's Mechanics of Engineering................ $8 \mathrm{vo}$, Notes and Examples in Mechanics............8vo,

Compton's First Lessons in Metal-working............12mo, Compton and De Groodt. The Speed Lathe............12mo, Cromwell's Treatise on Toothed Gearing.............12mo, Treatise on Belts and Pulleys...............12mo, Dana's Text-book of Elementary Mechanics for the Use of Colleges and Schools..........................mo, Dingey's Machinery Pattern Making................. Dredge's Record of the Transportation Exhibits Building of the

World's Columbian Exposition of 1893 .....4to, half mor., Du Bois's Elementary Principles of Mechanics:

Vol. I.-Kinematics .........................8vo,

Vol. II. - Statics.......................... 8vo,

Vol. III.-Kinetics....................... 8vo, Du Bois's Mechanics of Engineering. Vol. I......... Small 4to, 1000 Durley's Elementary Text-book of the Kinematics of Machines.

(In preparation.)

Fitzgerald's Boston Machinist..................16mo, Flather's Dynamometers, and the Measurement of Power.12mo, Rope Driving......................12mo,

Hall's Car Lubrication............................... Holly's Art of Saw Filing..................... 18mo, * Johnson's Theoretical Mechanics.................12mo, Jones's Machine Design:

Part I.-Kinematics of Machinery............... 8vo,

Part II.-Form, Strength and Proportions of Parts....8vo, Kerr's Power and Power Transmission. (In preparation.)

Lanza's Applied Mechanics.................... 8 vo, MacCord's Kinematics; or, Practical Mechanism........8vo, " Velocity Diagrams..................8vo, Merriman's Text-book on the Mechanics of Materials.....88v, * Michie's Elements of Analytical Mechanics...........8vo, Reagan's Locomotive Mechanism and Engineering.......12mo, Reid's Course in Mechanical Drawing............... 8vo, Text-book of Mechanical Drawing and Elementary Machine Design........................ 8vo,

Richards's Compressed Air.....................12mo, Robinson's Principles of Mechanism................ Sinclair's Locomotive-engine Running and Management. .12mo, Smith's Press-working of Metals.................. Thurston's Treatise on Friction and Lost Work in Machinery and Mill Work.................. 8 vo, * Animal as a Machine and Prime Motor, and the * Animal as a Machine and Prime Motor, and the Warren's Elements of Machine Construction and Drawing. .8vo, Weisbach's Kinematics and the Power of Transmission. (Herrman-Klein.) ................8vo, " Machinery of Transmission and Governors. (Herr(man-Klein.) …................8vo, Wood's Elements of Analytical Mechanics.............8vo, " Principles of Elementary Mechanics.............12mo,

" Turbines ...........................

The World's Columbian Exposition of $1893 . \ldots \ldots \ldots \ldots \ldots$ to, 


\section{METALLURGY.}

Egleston's Metallurgy of Silver, Gold, and Mercury:

Vol. I.-Silver...................................... 750

Vol. II.-Gold and Mercury......................... 750

Keep's Cast Iron. (In preparation.)

Kunhardt's Practice of Ore Dressing in Europe........8vo, 150

Lo Chatelier's High-temperature Measurements. (Boudouard-

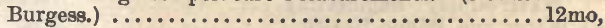

Metcalf's Steel. A Manual for Steel-users..............12mo,

Thurston's Materials of Engineering. In Three Parts..... 8vo,

Part II.-Iron and Steel....................... 8 vo,

Part III.-A Treatise on Brasses, Bronzes and Other Alloys and Their Constituents......................

\section{MINERALOGY.}

Barringer's Description of Minerals of Commercial Value. Oblong, morocco, Boyd's Resources of Southwest Virginia.............. " Map of Southwest Virginia.........Pocket-book form, Brush's Manual of Determinative Mineralogy. (Penfield.).8vo, Chester's Catalogue of Minerals................ 8vo, paper,

“ Diction of the Dana's System of Mineralogy...........Large 8vo, half leather, " First Appendix to Dana's New "System of Mineralogy."

“ Targe 8vo,

c Text-book of Mineralogy ..................

" Minerals and How to Study Them.............. 12mo,

" Catalogue of American Localities of Minerals.Large 8vo,

" Manual of Mineralogy and Petrography..........12mo, Egleston's Catalogue of Minerals and Synonyms..........8vo, Hussak's The Determination of Rock-forming Minerals. (Smith.) ...................................... 8voll * Penfield's Notes on Determinative Mineralogy and Record of Mineral Tests..................... Rosenbusch's Microscopical Physiography of the Rock-making Minerals. (Idding's.)...................... * Tillman's Text-book of Important Minerals and Rocks..8vo, Williams's Manual of Lithology ................... 8 vo,

\section{MINING.}

Beard's Ventilation of Mines..................... $12 \mathrm{mo}, 250$

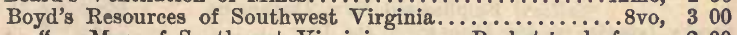

"Drinker's Tunneling, Explosive Compounds, and Rock

Drills.........................4to, half morocco, 2500

Eissler's Modern High Explosives.................... 4 wo, 00

Goodyear's Coal-mines of the Western Coast of the United

States ...............................12mo,

Ihlseng's Manual of Mining.......................

Kunhardt's Practice of Ore Dressing in Europe.......... $8 \mathrm{vo}$,

O'Driscoll's Notes on the Treatment of Gold Ores.........8vo,

Sawyer's Accidents in Mines......................8vo,

Walke's Lectures on Explosives.................... 8vo,

Wilson's Cyanide Processes.......................12mo,

Wilson's Chlorination Process................... 12mo, 
Wilson's Hydraulic and Placer Mining...............

Wilson's Treatise on Practical and Theoretical Mine Ventilation ...............................

\section{SANITARY SCIENCE.}

Folwell's Sewerage. (Designing, Construction and Maintenance.)

"Water-supp,

Fuertes's Water and Public Health....................

"Water-filtration Works...................

Gerhard's Guide to Sanitary House-inspection........... Goodrich's Economical Disposal of Towns' Refuse.... Demy 8vo, Hazen's Filtration of Public Water-supplies............ 8vo, Kiersted's Sewage Disposal....................... 12mo, Mason's Water-supply. (Considered Principally from a Sanitary Standpoint.....................

“ Examination of Water. (Chemical and Bacteriological.) ...........................

Merriman's Elements of Sanitary Engineering............. Nichols's Water-supply. (Considered Mainly from a Chemical and Sanitary Standpoint.) (1883.) ..............8vo,

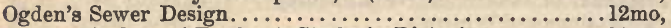
Richards's Cost of Food. A Study in Dietaries...........12mo, Richards and Woodman's Air, Water, and Food from a Sanitary Standpoint......................... Richards's Cost of Living as Modified by Sanitary Science. 12mo, Rideal's Sewage and Bacterial Purification of Sewage.....8vo, Turneaure and Russell's Public Water-supplies.........8vo, Whipple's Microscopy of Drinking-water.............. $8 \mathrm{vo}$, Woodhull's Notes on Military Hygiene............... 16mo,

\section{MISCELLANEOUS.}

Barker's Deep-sea Soundings................... 8 vo, Emmons's Geological Guide-book of the Rocky Mountain Excursion of the International Congress of Geologists. Large 8vo, 150

Ferrel's Popular Treatise on the Winds..............8vo, Haines's American Railway Management............. 12mo, Mott's Composition, Digestibility, and Nutritive Value of Food. Mounted chart,

“ Fallacy of the Present Theory of Sound.........16mo, Ricketts's History of Rensselaer Polytechnic Institute, 1824$1894 \ldots \ldots \ldots \ldots \ldots \ldots \ldots \ldots \ldots \ldots \ldots \ldots \ldots \ldots \ldots \ldots$ Small $8 \mathrm{vo}$, Rotherham's Emphasised New Testament........... Large 8vo, " Critical Emphasised New Testament......12mo, Steel's Treatise on the Diseases of the Dog............. 8vo, Totten's Important Question in Metrology............ 8vo, The World's Columbian Exposition of $1893 \ldots \ldots \ldots \ldots . .4$ to, Worcester and Atkinson. Small Hospitals, Establishment and Maintenance, and Suggestions for Hospital Architecture, with Plans for a Small Hospital. .............. 12mo,

\section{HEBREW AND CHALDEE TEXT-BOOKS.}

Green's Grammar of the Hebrew Language...........8vo, “ Elementary Hebrew Grammar..............12mo,

" Hebrew Chrestomathy..................... 8 vo, Gesenius's Hebrew and Chaldee Lexicon to the Old Testament Scriptures. (Tregelles.)........ Sinall 4to, half moroceo, Letteris's Hebrew Bible....................... 8vo, 





\section{UNIVERSITY OF CALIFORNIA AT LOS ANGELES}

THE UNIVERSITY LIBRARY

This book is DUE on the last date stamped below

Form L.-9-20m-8,'37 



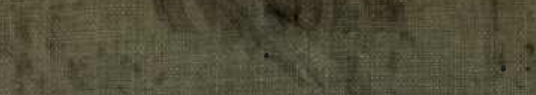

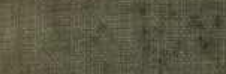

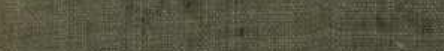

(26)

1. W

13:

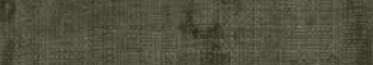

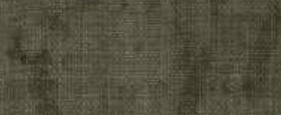

Q

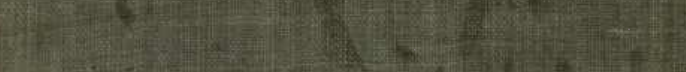

(1)

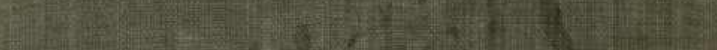

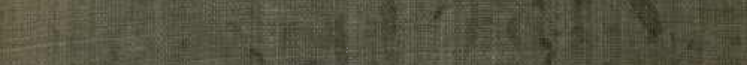

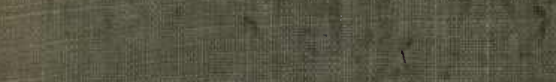

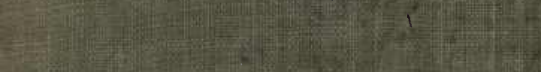

(1)

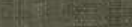

20

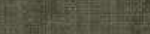

(1)

(2)

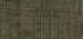

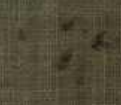

4

3ele

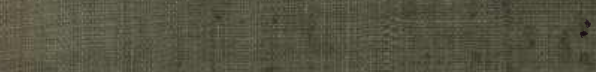

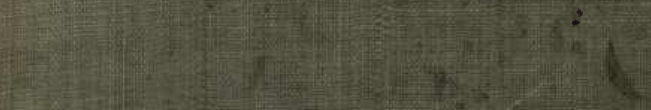

S.

(2)

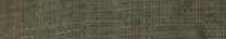

